Matching breeding goals with farming systems to enhance the sustainability of fish farming

Mathieu Besson 


\section{Thesis committee}

\section{Promotors}

Prof. Dr I.J.M. De Boer

Professor of Animal Production Systems

Wageningen University \& Research

Prof. Dr J. Komen

Personal chair at the Animal Breeding and Genomics group

Wageningen University \& Research

\section{Thesis Co-promotor}

Dr M. Vandeputte

Researcher, Animal Breeding and Integrative Biology

French National Institute for Agricultural Research (Inra)

\section{Other members}

Prof. Dr J. Verreth, Wageningen University \& Research

Prof. Dr I. Olesen, Nofima, Norway

Prof. Dr F. Phocas, Inra, France

Prof. Dr J. Potting, PBL Netherlands Environmental Assessment Agency, The Hague

The research presented in this doctoral thesis was conducted under the joint auspices of the Graduate school of Agriculture, Food, Biology, Environment and Health of the Agricultural, Veterinary and Forestry Institute of France and the Graduate School of Wageningen Institute of Animal Sciences of Wageningen University \& Research and is part of the Erasmus Mundus Joint Doctorate Program "EGS-ABG". 


\title{
Matching breeding goals with farming systems to enhance the sustainability of fish farming
}

\author{
Mathieu Besson
}

Thesis

Submitted in fulfillment of the requirements for the joint degree of doctor between

AgroParisTech

by the authority of the General Director, Prof. Dr G. Trystram,

and

Wageningen University

by the authority of the Rector Magnificus, Prof. Dr A.P.J. Mol,

in the presence of the

Thesis Committee appointed by the Academic Board of Wageningen University

and

The Head of The Graduate School Agriculture, Food, Biology, Environment and Health of

the Agricultural, Veterinary and Forestry Institute of France

to be defended in public

on Friday 27 January 2017

at 1.30 p.m. in the Aula of Wageningen University 
Besson, $\mathrm{M}$.

Matching breeding goals with farming systems to enhance the sustainability of fish farming,

201 pages.

Joint PhD thesis, AgroParisTech, Paris, France and

Wageningen University \& Research, Wageningen, the Netherlands (2017)

With references, with summary in English and French

ISBN 978-94-6343-006-7

DOI: http://dx.doi.org/10.18174/395219 


\section{Abstract}

Besson, M. (2017). Matching breeding goals and farming systems to enhance the sustainability of fish farming.

Joint PhD thesis, Wageningen University, Wageningen, the Netherlands and AgroParisTech, Paris, France

Fish farming is the fastest growing animal food-producing sector in the world. The production of cultured fish grew from about 15 to 50 million tons from 1995 to 2014 (FAO, 2016). Fish farming, however, faces challenges regarding its economic viability and its environmental sustainability. One way to enhance the sustainability of fish farming systems is selective breeding. The aim of this thesis was to investigate the opportunity to develop economically and environmentally sustainable breeding programs in fish farming. Thus, we first develop a bioeconomic model combined with a life cycle assessment to compute the economic (EV) and environmental values (ENV) of two important traits: thermal growth coefficient (TGC) and feed conversion ratio (FCR). Then we evaluate the EV and ENV of those two traits in several production systems having different limiting factors. Finally, we investigated how genetic gain, in a breeding program with TGC and FCR in the breeding goal, would differ when using different sets of quotaspecific EVs or ENVs. This thesis shows that the economic and environmental values of traits change with the factor limiting the production of the farm. The differences in EV resulted in different genetic gain, which confirms that breeding programs should be finely tuned according to the limiting factor of the production system to maximize economic return. Furthermore, we found that, depending on the correlation between TGC and FCR, using EV in breeding goals could decrease environmental impacts of fish production. To conclude, this thesis shows there are opportunities for developping breeding programs in fish farming that could balance economic profitability and environmental sustainability. 



\section{Contents}

1. General introduction 9

2. Economic values of growth and feed efficiency for fish farming in 21 recirculating aquaculture system with density and nitrogen output limitations: a case study with African catfish (Clarias gariepinus)

3. Environmental impacts of genetic improvement of growth rate and feed conversion ratio in fish farming under rearing density and nitrogen output limitations

4. Influence of water temperature on the economic value of growth rate in fish farming: the case of sea bass (Dicentrarchus labrax) cage farming in the Mediterranean

5. Effect of production quotas on economic and environmental values of growth rate and feed efficiency in sea cage fish farming

6. Comparing economic and environmental responses of breeding goals for sea bass designed for different production quota

7. General Discussion

References

Summary

Résumé 



\section{1}

General introduction 



\subsection{Sustainability challenges of fish farming}

Fish farming ${ }^{1}$ is undergoing a rapid expansion driven by multiple factors, the most important ones being the increase in demand, due to population growth, urbanization and rising incomes, and the decrease in supplies from capture fisheries. The production of cultured fish grew from about 15 to 50 million tons from 1995 to 2014 (FAO, 2016).

This impressive development of fish farming, however, raises several concerns. From the economic point of view, a strong competition between fish farmers emerged, causing a decline in fish prices (Asche and Bjorndal, 2011). This decline has been observed in European cultured species, like salmon, and was even stronger for species with a smaller market size, such as sea bass and sea bream. Nowadays, fish prices remain stable due to higher demand but still display high volatility (Oglend, 2013). Therefore, it is an important challenge for fish farmers to maintain good profitability by reducing their cost of production or by increasing their added value. Additionally, the intensive culture of fish in high densities is associated with the outbreak of infectious diseases caused by bacteria, viruses (infectious pancreatic necrosis) or parasites. Despite strict sanitary rules and the availability of vaccines against certain pathogens, disease outbreaks still cause high mortalities, challenging not only welfare and ethics (Ashley, 2007) but also economics of fish farms (Asche et al., 2009). Recently, concerns about environmental impacts of fish farming arose (Naylor et al., 1998). The feeds contain a significant amount of fish meal and fish oil (about 20 to $30 \%$ depending on the species) that supply the requirements of carnivorous fish in amino acids and in fatty acids (Tacon and Metian, 2008). Consequently, fish feed is responsible for an intensive use of natural fish resources (Naylor et al., 2000; Boissy et al., 2011), and a limitation of the use of fish meal and oil would reduce the pressure on natural stocks of fish. Another major environmental impact of fish farming is the release of nutrient-based pollutants from wasted feed and from fish excretion. These emissions are potentially harmful to natural ecosystems as they may cause eutrophication (Folke et al., 1994; Mente et al., 2006), especially in open systems (sea cage and flow through), where effluent water is directly released to the environment, with no treatment possible.

All these issues can be viewed as a global sustainability challenge for fish farming. Sustainable production is based on three pillars, economic, environmental and

\footnotetext{
${ }_{1}^{1}$ Fish farming is a branch of aquaculture that refers to the production of finfish in fresh, brackish or sea water.
} 
social sustainability. Economic sustainability implies balancing revenues and costs, so that a farm can sustain its activity and employment (De Boer, 2012). Environmental sustainability implies using natural resources efficiently to ensure their availability in the future and minimizing emissions to air, water and soil (De Boer, 2012). Finally, fish farming should be socially sustainable, or in other words, a system should be embedded in its social and cultural context, respectful towards humans and fish, and should contribute to the equity of management of resources (De Boer, 2012). The sustainability issues can be addressed by changing the performance of the fish through better farming practices or by implementing selective breeding. Selective breeding is particularly interesting because it directly influences the performance of the animals.

\subsection{Selective breeding to address sustainability challenges of livestock}

\section{Economic aspects}

Selective breeding generates permanent and cumulative changes in animal performance, directed towards specific future objectives. In breeding programs, the first general objective is to increase farm profitability. This is done by defining the aggregate genotype $(\mathrm{H})$, which is a linear combination of the different traits one wants to improve, each trait being weighted by its economic value (EV), as follows:

$$
H=E V_{1} \times A_{1}+E V_{2} \times A_{2} \ldots
$$

Where $A_{i}$ is the additive genetic value of trait $i . E V$ expresses the economic gain or loss obtained by changing the level of the trait, while keeping the other traits in the breeding goal constant (Hazel, 1943). The use of EVs optimizes the direction and the magnitude of the change in performances in order to maximize the economic response of a breeding program. Consequently, most emphasis in selection is on traits with the largest (negative or positive) absolute EV. EVs are calculated using simple profit equations or bioeconomic models.

A profit equation is a single equation from which economic values are derived as partial derivatives with respect to trait level (Groen, 1988). Profit equations are often simplistic in terms of relationship between trait level and physical and technical parameters, which results in a linear herd structure (Nielsen et al., 2013). However, production systems are complex and herd structure might change according to trait level. In theory, EVs must be derived from situations where 
management is optimized (Goddard, 1983; Dekkers, 1991). Therefore, bioeconomic models that describe a production system by a set of equations are becoming more popular to derive economic values. These models estimate the economic profit of a farm as function of physical, biological, technical and economic parameters, and their potential relationships. Consequently, bioeconomic models allow for a dynamic overall system including dynamic herd structure. With bioeconomic models, EVs are derived from change in profit due to change in trait level.

In livestock, breeding goals based on estimated economic values were successfully implemented to improve production-related traits and economic efficiency of broiler, dairy cattle and pig production (Havenstein et al., 1994; NRS, 1996; Norsvin, 1996). Thus, selective breeding has directly contributed to the economic sustainability of livestock production by reducing the cost of production and/or by increasing revenues.

\section{Health and welfare aspects}

Breeding for economic efficiency, however, may lead to unexpected negative responses in functional traits (behavior, physiology and immunology) (Rauw et al., 1998). This is due to some unfavorable genetic correlations between production and functional traits. Therefore, the strong selection pressure placed on production trait for economic reason, coupled with the negative genetic response between production and functional traits, caused health and welfare issues. Therefore, after focusing on economic objectives only, breeding goals in livestock started including health and welfare aspects. To do so, Olesen et al. (2000) suggested to combine economic values with non-market values in the aggregate genotype:

$$
H=\left(E V_{1}+N V_{1}\right) \times A_{1}+\left(E V_{2}+N V_{2}\right) \times A_{2} \ldots
$$

The non-market value ( $\mathrm{NVi}$ ) is a value that accounts, for example, the indirect health and welfare benefit from selection for traits in the breeding goal. Few methods have been proposed for deriving NV (Olesen et al., 1999). Among these methods, one is based on consumer's willingness to pay for improved welfare of fish (Olesen et al., 2010). Another method is based on selection index theory where $\mathrm{NV}$ is derived based on how much selection response in production traits farmers or breeders are willing to lose to improve or maintain functional traits (Nielsen et al., 2005; Nielsen et al., 2006). With this method, the accepted loss in response in production traits, and thus NV of non-production traits depends on the choice made by breeders. Still, an advantage is that this method directly integrates health and welfare issue into selective breeding. 


\section{Environmental impacts}

Besides economic and welfare aspects, breeding might also reduce environmental impacts, such as use of water or land, or emission of $\mathrm{CO}_{2}$, methane or ammonia (Wall et al., 2010). Thus, environmental impacts have received increasing attention in the definition of breeding goals. Environmental impacts occur not only at the farm level, but also during the production of farm inputs (upstream processes), such as feed production, or during processing or selling of animal products (downstream processes). A method commonly used to assess the environmental impact of livestock or fish production is life cycle assessment (LCA). LCA is a standardized method that estimates the environmental impacts of a product during the entire life cycle, or in other words, throughout the production chain. LCA links the environmental impacts along the production chain to the main output of that system, i.e. also referred to as the functional unit (Guinée et al., 2002). Functional units in LCAs of food products are, for example, $\mathrm{kg}$ of fat-and-protein-corrected milk, kg of grain or meat produced (de Vries and de Boer, 2010) or ton of fresh fish produced (Henriksson et al., 2012). Two types of environmental impacts are distinguished in a LCA: the use of natural resources (e.g. land, fossil energy, or water) required for the production of a functional unit and the corresponding emission of pollutants (e.g. ammonia, nitrate or methane) from a given production system. Use of resources or emission of pollutants can contribute to different environmental problems (referred to as impact categories), such as fossil energy use, acidification, eutrophication of or climate change (de Vries and de Boer, 2010). For example, to assess the impact of a production system on climate change, emissions of the main greenhouse gases in food production (i.e. carbon dioxide $\left(\mathrm{CO}_{2}\right)$, methane $\left(\mathrm{CH}_{4}\right)$ and nitrous oxide $\left.\left(\mathrm{N}_{2} \mathrm{O}\right)\right)$ are summed along the chain based on their equivalence factor in terms of $\mathrm{CO}_{2}$ equivalent $\left(\mathrm{CO}_{2}\right.$-eq, 100-year time horizon).

Because of its capacity to include environmental impacts at every step of the production system, LCA has started to be used to investigate the environmental effects of genetic improvement in livestock (Wall et al., 2010; Bell et al., 2011; Bell et al., 2013; van Middelaar et al., 2014). van Middelaar et al. (2014) proposed a method combining LCA with a bioeconomic modeling to calculate the environmental values of different traits in dairy cattle. Similar to economic values, environmental values represent the change in environmental impacts (i.e. climate change) after genetic improvement of one trait, while keeping the other traits constant. The purpose of the bioeconomic model developed by van Middelaar et al. (2014) was to estimate the amount of resources used and the pollutants emitted by a farm to produce one ton of milk as a function of animal performances. 
The bioeconomic model was also used to calculate economic values of milk yield and longevity. Then, LCA was used to estimate the emission of greenhouse gases (GHG) generated by the production of one tone of milk from this specific production system. The environmental values of milk yield and longevity were both calculated by comparing GHG emissions before and after genetic change. Using this method, van Middelaar et al. (2014) found that genetic improvement of milk yield and longevity increased economic benefit at the farm level and decreased GHG emissions along the production chain when producing one ton of milk. Therefore, selective breeding has a proven potential for reducing environmental impacts of livestock production and increase economic profit at the same time. These results were supported by other studies such as Wall et al. (2010) who showed that improving longevity (number of lactation) of dairy cows decreased methane emission per kg of milk. However, Bell et al. (2011) showed that improving milk yield would reduce emission per ton of milk produced but would increase emission at herd level. Although Bell et al. (2011) did not optimize management after genetic change, these results show that the choice of functional unit influences environmental values and could influence the direction of genetic change when ENV are used in breeding programs. So far, and to our knowledge, environmental values have not yet been included in breeding programs.

\subsection{Economic and environmental breeding objectives in fish}

Compared to livestock, breeding programs for fish are recent. The first large-scale breeding program was started in the 70s in Norway for Atlantic salmon (Gjedrem, 2010). Nowadays, selective breeding has been applied to other fish species such as rainbow trout, coho salmon, sea bream and sea bass (Yáñez et al., 2014; Chavanne et al., 2016). Initially, as in livestock, fish breeding programs focused on improving growth rate, and this generated high responses to selection (Gjedrem and Rye, 2016). For instance, in Atlantic salmon, the genetic gain for growth rate was $22.6 \%$ per generation (Thodesen et al., 1999), and up to $40 \%$ in sea bass (Vandeputte et al., 2009). This high response is due to the high heritability of growth rate and the high selection intensity that can be applied in fish. Selection for production traits, however, might have side effects on functional traits as observed in livestock. Therefore, fish breeding companies still consider growth rate as a major trait to improve (Chavanne et al., 2016; Janssen et al., 2016). In addition to growth rate, feed conversion ratio (FCR) is considered to be an important trait for fish farmers (Sae-Lim et al., 2012). This because, an improvement of FCR would reduce the use of feed per $\mathrm{kg}$ of fish produced and thus decreases the cost of production. 


\section{Knowledge gaps in economic breeding objectives}

In salmon, selective breeding was shown to be an effective method to increase economic returns. The benefit to cost ratio of the breeding program developed in Norway for salmon during 7-8 generations of selection was estimated to be 8 to 1 (Gjerde et al., 2007 cited in Gjedrem et al., 2012). In Nile tilapia, Ponzoni et al. (2007) estimated that breeding for harvest weight, feed intake, and survival over 10 years could yield an economic return of $\$ 32$ million at the national level in Malaysia. Besides this global economic appraisal of breeding programs, fish breeders mostly use a desired gains approach to set the direction of genetic change. With desired gains, the relative change in breeding values of traits is determined according to farmers' preferences (Sae-Lim et al., 2012). Therefore, the purpose of desired gain is not necessarily to maximize profit but to generate response towards a predefined objective. Conversely, economic values maximize the economic gain of a breeding program (Gibson and Kennedy, 1990). In fish breeding, very few studies focused on estimating economic values using a profit equation (Ponzoni et al., 2007; Ponzoni et al., 2008). However, in many cases, farming systems in general might be too complex to be modeled with a single profit equation.

For instance, recirculating aquaculture systems (RAS) are farming systems where part of the effluent water loaded with nutrients from wasted feed and fish excretion can be re-used in fish tanks after treatment by a bio-filter (Martins et al., 2010; van Rijn, 2013). Therefore, the production of fish in RAS is limited by the treatment capacity of the bio-filter, but may also be limited by the density of fish in the tanks - for which there is generally a limit. Conversely, sea cage systems are open to natural variation of environmental conditions, such as water temperature which influences growth and oxygen availability. The oxygen availability can become limiting when the oxygen supply is lower than the oxygen consumption by the fish. In addition to bio-physical constrains, production systems might be constrained by production quotas that aim at limiting the environmental impacts of a farm. A precise knowledge of what limiting factors are and how they impact the production system is critical to elaborate breeding goals, as it has been shown earlier that the impact of genetic improvement on farm management changes according to the factor limiting production at farm level (Gibson, 1989; Groen, 1989). Therefore, the economic values of traits in fish farming as in livestock are expected to change according to the farming system and to the limiting factor applied. This has not been studied in fish farming so far. Therefore, developing a bioeconomic model for calculating economic values of traits included in breeding 
goals would be an important step towards the development of breeding programs maximizing farm profitability in different production system constrained by different limiting factors.

\section{Knowledge gaps in environmental breeding objectives}

So far, research focused on reducing environmental impacts of fish farming by changing or improving the production system. For instance, fish meals and oils in the feed were partially replaced by vegetal meals and oils to reduce the use of natural fish resources (Tacon and Metian, 2008; Naylor et al., 2009). However, the effect of this replacement is not univocal. LCA studies showed, indeed, that using vegetal ingredients increased global eutrophication by increasing the use of fertilizers in crop production (Papatryphon et al., 2004; Pelletier and Tyedmers, 2007; Boissy et al., 2011). Other research lead to the development of RAS with the objective to release less nutrients into the environment (Martins et al., 2010; van Rijn, 2013). However, using LCA, Aubin et al. (2009) showed that RAS have higher climate change, eutrophication and energy use than flow-through and sea cage systems. Therefore, other approaches should also be investigated to improve environmental sustainability of fish farming. Selective breeding was shown to have potential for decreasing environmental impacts in livestock (Wall et al., 2010; Bell et al., 2011; van Middelaar et al., 2014). For instance, improving growth rate could increase the production of farms. Such an increase would dilute the fixed environmental impacts associated with infrastructures over more fish produced. Additionally, improving the feed efficiency of fish would reduce the consumption of feed per unit of fish produced.

The potential of using LCA to define environmental breeding objectives in fish breeding has never been studied before. Environmental values of TGC and FCR are unknown as well as the relationship between economic and environmental values. Additionally, it is still unknown, even in livestock, whether breeding objectives using economic values would generate similar or different response to selection compared to breeding objectives using environmental values. 


\subsection{Aim of the thesis}

The aim of this thesis was to investigate the opportunity to develop breeding programs to enhance economic and environmental sustainability of fish farming. To reach this aim, we targeted three objectives.

- The first objective was to develop a method that enables computing the economic and environmental values of two important traits in fish farming, thermal growth coefficient (TGC) and feed conversion ratio (FCR).

- The second objective was to evaluate the economic and environmental values of those two traits in several production systems having different limiting factors.

- The last objective was to investigate how economic and environmental values can be used to develop breeding programs that improve profit and decrease environmental impacts in fish farming.

\subsection{Thesis outline}

This thesis is composed of 7 chapters including the present general introduction (chapter 1) and a general discussion (chapter 7).

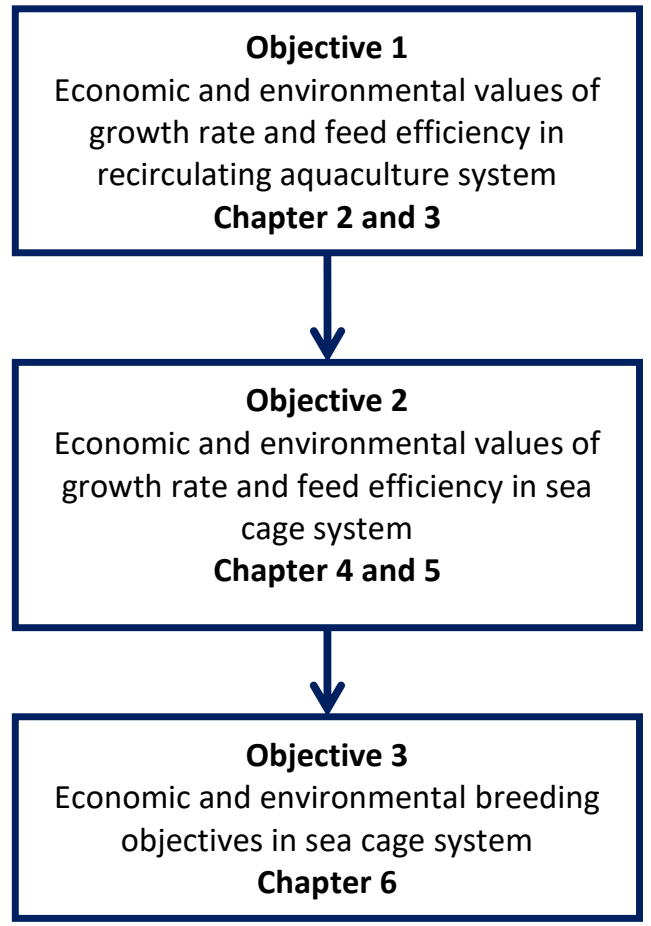


In chapter 2, we develop a bioeconomic model to estimate the profit of a farm depending on the level of TGC and FCR. This model was first applied to a recirculating aquaculture system (RAS) producing catfish and constrained by the rearing density or by the nitrogen treatment capacity of its bio-filter. Using this bioeconomic model, we estimated the economic values TGC and FCR in both limitation situations. Then, in chapter 3, we combined the bioeconomic model with a life cycle assessment (LCA) to estimate the environmental values of TGC and FCR. We investigated the same RAS as in chapter $\mathbf{2}$ with rearing density or treatment capacity as limiting factors. Therefore, we could compare economic and environmental values of TGC and FCR

In chapter 4, we adapted the bioeconomic model to a sea cage system producing sea bass. In sea cages, fish are undergoing natural variations of temperature that will affect their rearing performances and also variations in oxygen supply, which can become limiting when fish densities are too high. Therefore, we estimated the economic value of TGC in different regions of the Mediterranean with different temperature profiles.

In chapter 5, we used the combination of the bioeconomic model and the LCA to estimate the economic and environmental values of TGC and FCR in a sea cage system constrained by four different production quotas.

Finally in chapter 6, we simulate a simple breeding program with TGC and FCR in the breeding goal. First, we compare, for different correlations between TGC and FCR, the total economic gain generated by the breeding goals from the four quotas explored in chapter 5. Second, we investigate, within quota, if economic values alone could be used to decrease environmental impacts or should environmental values be used.

In chapter 7, we discuss the relevance and challenges of using bioeconomic modeling and LCA to estimate EV and ENV of traits. Then, we discuss how fish breeding programs could enhance economic and environmental performances of fish farms. 



\title{
2
}

\section{Economic values of growth and feed efficiency for fish farming in recirculating aquaculture system with density and nitrogen output limitations: a case study with African catfish (Clarias gariepinus)}

\author{
M. Besson ${ }^{1,2,3}$, H. Komen ${ }^{1}$, J. Aubin ${ }^{4}$, I.J.M. de Boer ${ }^{5}$, M. Poelman ${ }^{6}$, E. Quillet ${ }^{3}$, \\ C. Vancoillie ${ }^{7}$, M. Vandeputte ${ }^{3,8}$ and J.A.M. van Arendonk ${ }^{1}$
}

\footnotetext{
1 Animal Breeding and Genomics Centre, Wageningen University, PO Box 338, $6700 \mathrm{AH}$ Wageningen, the Netherlands

2 AgroParisTech, UMR1313 Génétique animale et biologie intégrative, 16 rue Claude Bernard, 75231 Paris 05, France

3 INRA, UMR1313 Génétique animale et biologie intégrative, Allée de Vilvert, 78350 Jouy-en-Josas, France

${ }^{4}$ INRA, Agrocampus Ouest Rennes, UMR1069 Sol Agronomie Spatialisation, 65 rue de Saint Brieuc, 35042 Rennes, France

${ }^{5}$ Animal Production Systems group, Wageningen University, P.O. Box 338, 6700 AH Wageningen, the Netherlands

${ }^{6}$ IMARES, Wageningen UR, Korringaweg 5, 4401 NT Yerseke, the Netherlands

${ }^{7}$ Fishion Breeding, Breedijk 13, 5705 CJ Helmond, the Netherlands

8 IFREMER, Chemin de Maguelone, 34250 Palavas-les-Flots, France
} 



\section{Abstract}

In fish farming, economic values (EV) of breeding goal traits are lacking while they are key parameters to make decisions regarding selection objectives. The aim of this study was to develop a bioeconomic model to estimate EVs of two traits representing production performances in fish farming: thermal growth coefficient (TGC) and feed conversion ratio (FCR). This approach was applied to a farm producing African catfish (Clarias gariepinus) in a recirculating aquaculture system (RAS). In RAS, two factors could limit production level: the nitrogen treatment capacity of the bio-filter, or the fish density in rearing tanks at harvest. Profit calculation includes revenue from fish sales, cost of juveniles, cost of feed, cost of waste water treatment and fixed costs. In the reference scenario, profit was modeled to zero. EVs were calculated as the difference in profit per $\mathrm{kg}$ of fish between the current population mean for both traits $\left(\mu_{t}\right)$ and the next generation of selective breeding $\left(\mu_{t}+\Delta_{t}\right)$ for either TGC and FCR. EVs of TGC and FCR were calculated for three generations of hypothetical selection on either TGC or FCR (respectively $6.8 \%$ and $7.6 \%$ improvement per generation). The results show that changes in TGC and FCR can affect both the number of fish that can be stocked (number of batches per year and number of fish per batch) and the factor limiting production. The EVs of TGC and FCR vary and depend on the limiting factors. When dissolved $\mathrm{NH}_{3}-\mathrm{N}$ is the limiting factor for both $\mu_{\mathrm{t}}$ and $\mu_{\mathrm{t}}+\Delta_{\mathrm{t}}$, increasing TGC decreases the number of fish that can be stocked but increases the number of batches that can be grown. As a result, profit remains constant and EVTGC is zero. Increasing FCR, however, increases the number of fish stocked and the ratio of fish produced per kg of feed consumed ("economic efficiency"). The EVFCR is $0.14 € / \mathrm{kg}$ of fish, and profit per $\mathrm{kg}$ of fish increases by about $10 \%$. When density is the limiting factor for both $\mu_{\mathrm{t}}$ and $\mu_{\mathrm{t}}+\Delta_{\mathrm{t}}$, the number of fish stocked per batch is fixed and therefore, extra profit is obtained by increasing either TGC, which increases the annual number of batches or by decreasing FCR, which decreases annual feed consumption. $E V_{T G C}$ is $0.03 € / \mathrm{kg}$ of fish and $E V_{F C R}$ is $0.05-0.06 € / \mathrm{kg}$ of fish. These results emphasize the importance of calculating economic values in the right context to develop efficient future breeding programs in aquaculture.

Keywords: economic values, feed conversion ratio, fish farming, recirculating aquaculture system, selective breeding, thermal growth coefficient. 


\subsection{Introduction}

At world scale, fish farming production doubled over the last ten years (FAO, 2012) and breeding programs are considered a key step in the development of fish farming (Gjedrem et al., 2012). In most terrestrial livestock breeding programs, genetic improvement is realised through selection on a breeding objective, defined as a linear function of traits to be improved, each trait weighted by its economic value (EV) (Hazel, 1943). EV expresses the economic benefit/loss obtained from genetic improvement of a trait in a production system (Groen, 1988). In Nile tilapia (Oreochromis niloticus), Ponzoni et al. (2007) estimated that breeding for harvest weight, feed intake and survival over ten years can have positive economic returns of US\$32 million at national level. In most farmed fish species, however, EVs of breeding goal traits are lacking and genetic improvements are mostly realised using breeding objectives that describe the desired rate and direction of genetic change for a set of traits in a breeding goal (e.g. Sae-Lim et al., 2012). Groen (1988) suggested to model production at farm level to determine EVs of each trait while considering limitations constraining production. When limitations are applied, EVs of traits may change and breeding goals have to be adapted for such limitations (Gibson, 1989; Groen, 1989).

This study aimed, therefore, to develop a bioeconomic model to calculate EVs for two key traits in fish farming: thermal growth coefficient (TGC) and feed conversion ratio (FCR). We investigated African catfish (Clarias gariepinus) reared in a recirculating aquaculture system (RAS) as a case study for two reasons. (1) RAS is an interesting development model for fish farming, which includes treatment loop for a better water and waste management (Martins et al., 2010; van Rijn, 2013). (2) In RAS, two factors could limit production, the nitrogen treatment capacity of the bio-filter or the fish density in tanks, which suggest changes in EVs of TGC and FCR.

\subsection{Material and methods}

\subsubsection{Farm design}

A typical commercial Dutch RAS farm producing about $500 \mathrm{t}$ of African catfish indoor per year was modeled using $R$ software (R Development Core Team, 2008). RAS parameters were based on information from Fishion Breeding, Viqon Water Solutions and Skretting. In this indoor system, water was thermo-regulated at $27^{\circ} \mathrm{C}$ through regulating the ambient air temperature. The RAS was composed of four main compartments: a series of 20 rearing tanks ( 6 tanks of $6 \mathrm{~m} 3$ for fish from 13 to 
$80 \mathrm{~g}$ and 14 tanks of $50 \mathrm{~m} 3$ for fish from 80 to $1300 \mathrm{~g}$ ), a mechanical filter, which removed solid waste, a bio-filter where nitrifying bacteria broke down ammonia into nitrites and nitrates and a denitrification reactor where denitrifying bacteria processed nitrates into nitrogen. Clean-up water was re-used in rearing tanks and only $30 \mathrm{~m}^{3} /$ day of effluent water was directed to a waste water treatment plant, which corresponds to $96 \%$ of recirculation. The time needed for a fish to grow from 80 to $1300 \mathrm{~g}$ represented one production cycle. During one cycle, fourteen batches of fish were stocked successively in the fourteen tanks. A batch of fish was defined as a group a fish of the same age stocked in the same tank. Consequently, fish biomass reached a peak just before the oldest batch was harvested and the maximum standing stock (MSS) was reached (Figure 2.1).

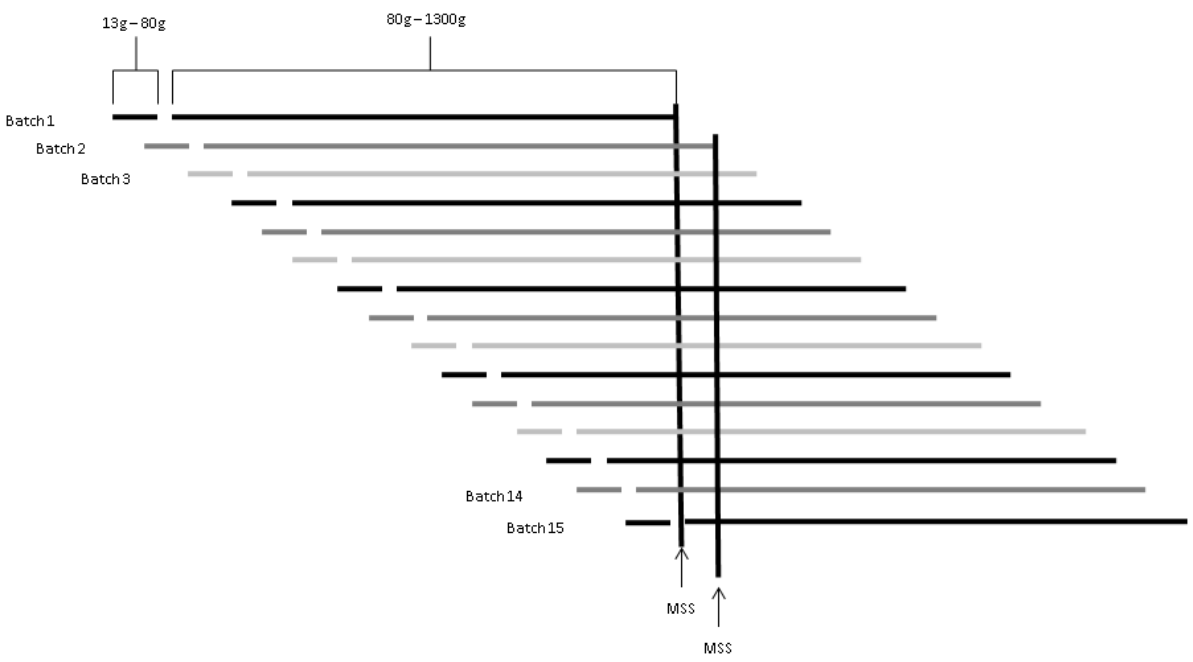

Figure 2.1: Production scheme of a typical African catfish RAS in the Netherlands.

\subsubsection{Individual growth model}

Fish growth was modeled based on the thermal growth coefficient (TGC) from Dumas et al. (2007). The two main model assumptions are that growth rate is allometrically related to body weight ( $\mathrm{W}$ in $\mathrm{g}$ ) and that growth rate is an allometric constant related to mean daily water temperature averaged over the rearing period (Dumas et al., 2007).

$$
\mathrm{TGC}=\frac{\mathrm{W}_{\mathrm{H}}^{1-\mathrm{b}}-\mathrm{W}_{\mathrm{I}}^{1-\mathrm{b}}}{\sum_{\mathrm{i}=1}^{\mathrm{n}} \mathrm{T}}
$$


Where $n$ is the number of days between initial $\left(W_{1}\right)$ and harvest weight $\left(W_{H}\right)$ and $T$ is the mean daily temperature at day $n$ (constant to $27^{\circ} \mathrm{C}$ ). 1-b is a weight exponent specific to species (Dumas et al., 2007). This weight exponent was set at 0.475 in order to fit the growth curve obtain by the TGC equation to the growth curve of African catfish commonly observed in farms ( $13 \mathrm{~g}$ to $1300 \mathrm{~g}$ in 119 days at $27^{\circ} \mathrm{C}$ ). Fish weight at day $n\left(W_{n}\right)$ and daily weight gain at day $n\left(D W G_{n}\right)$ were calculated as:

$$
\begin{gathered}
\mathrm{W}_{\mathrm{n}}=\left[\mathrm{W}_{\mathrm{I}}^{0.475}+\left(\mathrm{TGC} \times \sum_{\mathrm{i}=1}^{\mathrm{n}} \mathrm{Ti}\right)\right]^{1 / 0.475} \\
\mathrm{DWG}_{\mathrm{n}}=\mathrm{W}_{\mathrm{n}}-\mathrm{W}_{\mathrm{n}-1}
\end{gathered}
$$

Feed utilization efficiency was expressed as feed conversion ratio (FCR), defined as a unit of feed consumed divided by a unit of body mass gain. FCR is a parameter depending on the life stage of fish which increases as fish size/age increases (Robinson and $\mathrm{Li}, 2010$ ). FCR was, therefore, modelled as a power function of $\mathrm{W}_{\mathrm{n}}$ $\left(F C R_{w n}\right)$, using data from commercial feed trial, in order to keep the same FCR among different growth rate scenarios:

$$
\mathrm{FCR}_{\mathrm{Wn}}=0.37 \times \mathrm{W}_{\mathrm{n}}^{0.112}
$$

In the present model we assumed that TGC and FCR were not related and that a change in one of these parameters did not modify the other. Using DWGn and FCRwn, individual daily feed intake at day $n\left(D F I_{n}\right)$ was calculated as well as individual daily feed distributed (DFD $)$ assuming $1 \%$ of feed wastage (not consumed by the fish):

$$
\begin{gathered}
\mathrm{DFI}_{\mathrm{n}}=\mathrm{DWG}_{\mathrm{n}} \times \mathrm{FCR}_{\mathrm{Wn}} \\
\mathrm{DFD}_{\mathrm{n}}=\mathrm{DFI}_{\mathrm{n}} \times 1.01
\end{gathered}
$$

\subsubsection{Individual waste excretion model}

The concentration of nitrogen, expressed as ammoniacal nitrogen $\left(\mathrm{NH}_{3}-\mathrm{N}\right)$ and the Chemical Oxygen Demand (COD) in effluent water was calculated using a massbalance approach (Cho and Kaushik, 1990; Cowey and Cho, 1991). Details of the calculations for $\mathrm{NH}_{3}-\mathrm{N}$ emission and $\mathrm{COD}$ are shown in appendix 2.2 and 2.3, respectively. The first step to model $\mathrm{NH}_{3}-\mathrm{N}$ excretion was to calculate the amount 
of nitrogen $(\mathrm{N})$ provided by the feed eaten and wasted at day $\mathrm{n}$ ( $\mathrm{N}$ _feed_intake and $N_{-}$feed_waste ${ }_{n}$ ) and the amount of $N$ fixed by the fish at day $n\left(N_{-}\right.$fish $n$ ) (the composition of the feed is given in appendix 2.1):

$$
\begin{aligned}
\text { N_feed_intake }_{\mathrm{n}} & =72 \times \mathrm{DWG}_{\mathrm{n}} \times \mathrm{FCR}_{\mathrm{Wn}} \\
\text { N_feed_waste }_{\mathrm{n}} & =\text { N_feed_intake }_{\mathrm{n}} \times 0.01 \\
\mathrm{~N}_{-} \text {fish }_{\mathrm{n}} & =24.5 \times \mathrm{DWG}_{\mathrm{n}}
\end{aligned}
$$

Where 72 is the $\mathrm{N}$ content of feed (in $\mathrm{g} / \mathrm{kg}$ of feed) calculated as the protein content of the feed (45\%) divided by 6.25 and 24.5 is the $\mathrm{N}$ content of fish (in $\mathrm{g} / \mathrm{kg}$ of fish) calculated via the $\mathrm{N}$ content of the feed multiplied by the $\mathrm{N}$ retention capacity of African catfish, 34\% (Salhi et al., 2004; van Weerd et al., 1999). The total individual $\mathrm{NH}_{3}-\mathrm{N}$ excretion at day $\mathrm{n}$ ( $\mathrm{N}$ _excretion $\mathrm{n}_{\mathrm{n}}$ ) was given by:

$$
\text { N_excretion }_{\mathrm{n}}=\mathrm{N}_{-} \text {feed_intake }{ }_{\mathrm{n}}-\mathrm{N}_{-} \text {fish }_{\mathrm{n}}
$$

Calculation of the suspended ( $N_{-}$suspended ${ }_{n}$ ) and dissolved ( $N_{-}$dissolved ${ }_{n}$ ) was given by:

$$
\mathrm{N} \_s u s p e n d e d_{\mathrm{n}}=6.732 \times \mathrm{FCR}_{\mathrm{Wn}} \times \mathrm{DWG}_{\mathrm{n}}
$$

N_dissolved $n$ was needed to calculate the MSS and was calculated from equations 2.8, 2.10 and 2.11 as follows:

$$
\mathrm{N}_{-} \text {dissolved } \mathrm{n}=\text { N_excretion } \mathrm{n}+\mathrm{N}_{-} \text {feed_waste }_{\mathrm{n}}-\mathrm{N}_{-} \text {suspended }_{\mathrm{n}}
$$

$$
\mathrm{N}_{-} \text {dissolved }_{\mathrm{n}}=\mathrm{DWG}_{\mathrm{n}}\left(\left(65.988 \times \mathrm{FCR}_{\mathrm{Wn}}\right)-25\right)
$$

The amount of $\mathrm{NH}_{3}-\mathrm{N}$ in effluent water $\left(\mathrm{N} \_\right.$eff $n$ ) was calculated as:

$$
\text { N_eff }{ }_{\mathrm{n}}=0.1 \times \text { N_suspended }{ }_{\mathrm{n}}
$$

To calculate COD in effluent water we first need to calculate the COD of feed wasted at day n (COD_wasten) and the COD of organic excretions of the fish $\left(C O D \_\right.$excretion $\left.n\right)$. COD_wasten was calculated according to protein, crude fat and 
carbohydrate concentration in the feed wasted at day $\mathrm{n}$ (in $\mathrm{kg} / \mathrm{kg}$ of feed) multiplied by the stoichiometric oxygen demand (in $\mathrm{kg}$ of $\mathrm{O}_{2}$ per $\mathrm{kg}$ of feed) of these elements $\left(\mathrm{COD}_{\mathrm{p}}=1.3, \mathrm{COD}_{\mathrm{CF}}=2.9\right.$ and $\left.\mathrm{COD}_{\mathrm{c}}=1.07\right)$ :

$$
\begin{aligned}
& \text { COD_waste }= \\
& \text { (protein } \times 0.013+\text { crude_fat } \times 0.029+\text { carbs } \times 0.0107) \times D F I_{n}
\end{aligned}
$$

COD_excretion $n$ was calculated using feed eaten at day $\mathrm{n}$ and the digestibility of proteins, crude fat and carbohydrates:

$$
\begin{aligned}
& \mathrm{COD}_{\text {excretion }}= \\
& (\text { protein } \times 0.13+\text { crude_fat } \times 0.29 \text { carbohydrates } \times 0.428) \times \mathrm{DFI}_{\mathrm{n}}
\end{aligned}
$$

With COD_waste $e_{n}$ and COD_excretion $n$ we can calculate COD required to oxidize the organic matter remaining in effluent water (COD_eff $)$ :

$$
\begin{aligned}
& \mathrm{COD}_{\text {eff }}= \\
& \quad(\text { protein } \times 0.11+\text { crude_fat } \times 0.24+\text { carbs } \times 0.33) \times \mathrm{DFI}_{\mathrm{n}}
\end{aligned}
$$

\subsubsection{Batch model}

The amount of dissolved $\mathrm{NH}_{3}-\mathrm{N}$ excreted per day per fish was used at batch level to calculate the maximum number of fish that could be stocked per batch ( $\mathrm{Nb}_{-}$fisho). $\mathrm{Nb}$ _fisho was calculated from the maximum treatment capacity of the bio-filter (maximum $\mathrm{NH}_{3}-\mathrm{N}$ load in $\mathrm{kg}$ of $\mathrm{NH}_{3}-\mathrm{N}$ per day) which was fixed and dependent on the size of the bio-filter. Therefore, $\mathrm{Nb}$ _fisho depends on the cumulative individual excretion of $\mathrm{NH}_{3}-\mathrm{N}$ of all fish in all 14 batches ( $\mathrm{j}=1$ to 14 ) at MSS ( $\mathrm{N}_{-}$dissolved $\mathrm{MsS}$ ).

$$
\mathrm{Nb}_{-} \text {fish }_{0}=\frac{\text { maximum N_NH3 load }}{\sum_{\mathrm{i}=1}^{\mathrm{j}}\left(\mathrm{N}_{\text {dissolved }_{\text {MSS }(\mathrm{j})}}\right) \times\left(1-\mathrm{M}_{\mathrm{Wn}(\mathrm{j})}\right)}
$$

N_dissolvedmss(j) was calculated from equation 2.13 for each batch $\mathrm{j}$. $M W_{n}(j)$ was the cumulative mortality at fish weight $W_{n}$ in batch $j$. Cumulative mortality was modelled as a linear function of fish weight:

$$
\mathrm{M}_{\mathrm{Wn}}=0.0001 \times \mathrm{W}_{\mathrm{n}}+0.0113
$$


Where 1- $M_{1300}$ corresponds to a total survival of about $85 \%$ from stocking to harvest size. With $\mathrm{Nb}_{-}$fisho and $\mathrm{M}_{\mathrm{Wn}}$, daily number of fish, daily feed consumption, daily waste excretions and finally, production of fish at batch level were calculated.

\subsubsection{Farm model}

The number of tanks of $50 \mathrm{~m}^{3}$ available was used to calculate the number of batches stocked per year. The number of batches, therefore, depended on the time interval between batches defined by the time needed for a batch to grow from $80 \mathrm{~g}$ to 1300 $\mathrm{g}$ at $27^{\circ} \mathrm{C}$ ( $\mathrm{Nb} \_$days) and by the number of tanks available ( $\mathrm{Nb}$ tanks $=14$ ).

$$
\begin{aligned}
\text { Nb_days } & =\frac{\left(W_{H}^{0.475}-W_{I}^{0.475}\right) \times 27}{\mathrm{TGC}}=\frac{597.30}{\mathrm{TGC}} \\
\mathrm{Nb}_{\text {b batch }} \text { year } & =\frac{365 \times 14}{\text { Nb_days }}=\frac{5510}{\text { Nb_days }}=9.22 \times \mathrm{TGC}
\end{aligned}
$$

Annual fish production, feed consumption and waste excretions at the farm level were calculated from the number of batches per year and total $\mathrm{kg}$ of fish produced per batch, total feed consumption per batch of fish and waste excretions per batch. The average realised FCR over the year was calculated as:

$$
\text { FCR }=\frac{\text { feed distributed per year }}{\text { fish production per year }}
$$

\subsubsection{Limiting factors}

In our production system of catfish in RAS, two factors could limit fish production at farm level. The first one is the rearing density of fish, which was set at $230 \mathrm{~kg} / \mathrm{m}^{3}$, according to best practice recommendations. This maximum density value is chosen such that oxygen concentrations will stay well above $4 \mathrm{ppm}$, resulting in optimized fish growth and fish welfare. The volume of a production tank was $50 \mathrm{~m}^{3}$, therefore, the maximum amount of fish harvested per batch was limited to $11,500 \mathrm{~kg}$ or 8,846 fish of $1.3 \mathrm{~kg}$. The second limiting factor depended on the maximum dissolved $\mathrm{NH}_{3}-\mathrm{N}$ treatment capacity of the bio-filter, or maximum $\mathrm{NH}_{3}-\mathrm{N}$ load, reached at MSS. In our situation, the volume available for bacteria biomass (biomedia) was $150 \mathrm{~m}^{3}$ and the maximum $\mathrm{NH}_{3}-\mathrm{N}$ load was equal to $39 \mathrm{~kg}$ of dissolved $\mathrm{NH}_{3}-\mathrm{N}$ at MSS. There were, therefore, two different and distinct ways to 
calculate $\mathrm{Nb}$ _fisho according to the limiting factor. When density was the limiting factor the number of fish harvested was fixed to 8,846 fish per batch. When dissolved $\mathrm{NH}_{3}-\mathrm{N}$ was the limiting factor, however, $\mathrm{Nb}$ fisho varied depending on N_dissolvedmss per batch (Eq. [2.18]).

\subsubsection{Economic parameters and economic profit}

A summary of fixed and variable costs is given in table 2.1. Fixed costs represented, in total, $164,204 €$ per year for a farm producing $500 \mathrm{t}$ of fish per year.

Table 2.1: Revenue and costs (variable and fixed) of an African catfish RAS in the Netherlands.

\begin{tabular}{|c|c|c|}
\hline Item & Abbreviations & Values \\
\hline \multicolumn{3}{|l|}{ Variable revenue } \\
\hline fish & Rfish & $1.35 € / \mathrm{kg}$ of fish \\
\hline \multicolumn{3}{|l|}{ Variable Costs } \\
\hline feed & Cfeed & $1.10 € / \mathrm{kg}$ of feed \\
\hline juveniles & Cjuveniles & $0.14 € /$ unit \\
\hline discharged water & Cp.u. & $43.2 € /$ p.u. \\
\hline \multicolumn{3}{|l|}{ Fixed costs } \\
\hline insurance & Cins & $5,000 €$. farm $^{-1} \cdot$ year $^{-1}$ \\
\hline administration & Cadm & $5,000 €$. farm $^{-1} \cdot$ year $^{-1}$ \\
\hline work & Cwork & $30,000 €$. farm $^{-1}$.year ${ }^{-1}$ \\
\hline rent & Crent & $70,000 €$. farm $^{-1}$.year ${ }^{-1}$ \\
\hline maintenance & Cmaint & $10,000 €$. farm $^{-1}$.year ${ }^{-1}$ \\
\hline energy & Cenrg & $30,000 €$. farm $^{-1}$.year ${ }^{-1}$ \\
\hline sewer & Csewer & $4,204 €$. farm $^{-1}$.year ${ }^{-1}$ \\
\hline unpredictable & Cunp & $10,000 €$. farm $^{-1}$.year ${ }^{-1}$ \\
\hline
\end{tabular}

The calculation of the Dutch nitrogen taxes was used to calculate the cost of discharged water. This tax was calculated in pollution units (p.u.), which was expressed in quantity of oxygen needed to break down organic pollution produced per person and per year (1 p.u. $=49.6 \mathrm{~kg}$ of oxygen $)$ :

$$
\text { p. u. }=(4.57 \times \text { N_eff }+ \text { COD_eff }) / 49.6
$$


Annual profit per farm (annual_profit) and profit per $\mathrm{kg}$ of fish produced (profit_fish) were given by (see Table 2.1 for abbreviations):

annual $_{\text {profit }}=$

(Number of fish harvested per year $\times$ harvest weight $\times$ Rfish)

- (kg feed distributed per year $\times$ Cfeed)

- (Number of juveniles stocked per year $\times$ Cjuveniles)

- (Nbp.u. $\times$ Cp.u. $)$

- fixed costs

and

$$
\text { profit_fish }=\frac{\text { annual_profit }}{\text { fish production per year }}
$$

\subsubsection{Economic values (EV)}

In selection-index theory, the aggregate genotype or breeding goal is usually defined as a linear function of traits to be improved; each trait multiplied by its economic value (EV). The economic value expresses the value of a unit change in a trait while keeping the other traits in the aggregate genotype constant (Groen, 1988). In our study, the economic value of FCR is positive because it represents a predicted change in profit for a specific level of genetic improvement. However, in an aggregate genotype equation, the sign of the economic value indicates the direction of desired change. Consequently, in an aggregate genotype equation, the economic value of FCR would be negative because selection is for lower FCR values. The bioeconomic model was used to calculate the economic value (in $€ / \mathrm{kg}$ of fish) of FCR and TGC in three steps:

1) The model was run for the current population mean for trait $t\left(\mu_{t}\right)$ to obtain the initial annual profit per farm, which was divided by annual fish production to obtain profit per kg of fish (profit_fish ${ }_{\mu t}$ ).

2) For each trait, the mean was increased, after one generation of selection, by $\Delta_{t}$ to $\mu_{\mathrm{t}}+\Delta_{\mathrm{t}}$ while keeping the mean of the other trait at its current value. Percentage of improvement per generation of trait mean obtained after one generation of phenotypic selection on one trait only can be calculated as $\mathrm{i} \times \mathrm{h}^{2} \times \mathrm{CV}$, where $\mathrm{i}$ is the intensity of selection, $\mathrm{h}^{2}$ is the heritability and CV is the coefficient of phenotypic variation. If selection intensity is fixed to 1 (38\% of 
selected animals), percentage of improvement per generation in TGC and FCR is equal to $h^{2} \times C V$. As there are not yet genetic parameters for African catfish, we used genetic parameters of rainbow trout (Oncorhynchus mykiss) as a proxy. In rainbow trout, the $\mathrm{h}^{2}$ and the CV of TGC was found to be respectively 0.32 and 21.23 (Silverstein et al., 2009) while the $h^{2}$ and the CV of FCR was found to be respectively 0.17 and 45.69 (Kause et al., 2006). The percentage of improvement per generation (with $\mathrm{i}=1$ ) was, therefore, $6.8 \%$ for TGC and $7.6 \%$ for FCR (Sae-Lim et al., 2012). We used these percentages of improvement per generation to define $\Delta_{\mathrm{TGC}}=\mu_{\mathrm{TGC}} \times(1+0.068)$ and $\Delta_{\mathrm{FCR}}=\mu_{\mathrm{FCR}} \times(1-0.076)$. The model was run a second time when the mean of the trait was increased by $\Delta_{\mathrm{t}}$ to calculate the annual profit per farm after genetic improvement. The annual profit per farm was divided by annual fish production before genetic improvement according to Groen (1989) to obtain profit per kg of fish: profit_fish $\mu t+\Delta t$.

3) Finally, the economic value per generation was calculated for both trait as:

$$
\mathrm{EV}_{t}=\text { profit_fish } \mu \mathrm{t}+\Delta \mathrm{t}-\text { profit_fish } \mu \mathrm{t}
$$

Economic values of TGC and FCR were calculated for three generations of selection. Economic values were, therefore, calculated for 16 combinations of TGC and FCR according to four TGC values times four FCR values. These four values of each TGC and FCR were composed of the reference scenario plus 3 generations of selection. In the reference scenario TGC was 8.33 using equation 2.1 and reference data (119 days at $27^{\circ} \mathrm{C}$ to reach $1.3 \mathrm{~kg}$ and using $\left.1-b=0.475\right)$. At farm level, FCR observed is fluctuating between 0.80 and 0.82 . In the reference scenario, therefore, FCR was fixed at 0.81 to balance costs with revenues when TGC $=8.33$. Hence, the four TGC values were 8.33, 8.9, 9.5, 10.15 and the four FCR values were $0.81,0.75,0.69$, 0.64 . The different FCR values were obtained by varying only the weight exponent

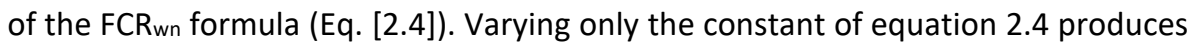
unrealistic values in the lower fish weight range. The practical consequence of varying only the weight exponent of equation 2.4 was that improvement of FCR will mostly be due to better feed conversion in late life. 


\subsection{Results}

\subsubsection{Reference scenario}

Production parameters of the reference scenario show that the two limiting factors are well respected. The density at harvest time is under $230 \mathrm{~kg} / \mathrm{m}^{3}$ and the quantity of dissolved $\mathrm{NH}_{3}-\mathrm{N}$ at MSS equals $39 \mathrm{~kg}$ (Table 2.2). In the reference scenario, dissolved $\mathrm{NH}_{3}-\mathrm{N}$ is, therefore, the limiting factor. Production per year is, moreover, close to what is projected from the design parameters of the farm (500 t of fish per year). Total annual production cost is about $699,036 €$ among of which cost of feed represents $66 \%$ of total costs (variable + fixed) while fixed costs represent $23 \%$. The cost of juveniles and of waste water discharge (p.u) represents $9.3 \%$ and $1.7 \%$ of the total costs, respectively.

Table 2.2: Production parameters for African catfish RAS in the reference scenario, TGC $=8.33$ and FCR $=0.81$.

\begin{tabular}{lc}
\hline Production Parameter & Value \\
\hline Number of fish harvested per batch & 7,667 \\
Stocking density at harvest & $199 \mathrm{~kg} / \mathrm{m}^{3}$ \\
Number of batches per year & 52 \\
Production of fish per year & $518 \mathrm{t}$ \\
Feed consumption per year & $420 \mathrm{t}$ \\
$\mathrm{NH}_{3}-\mathrm{N}$ dissolved at MSS & $39 \mathrm{~kg}$ \\
Profit per farm per year & $0 €$ \\
\hline
\end{tabular}

\subsubsection{Annual profit per farm in tested scenarios}

The two limitations are acting in the system but only one is relevant at any given time depending on the level of TGC and FCR. For the sake of clarity, these two situations were first analyzed separately: 1 ) when only dissolved $\mathrm{NH}_{3}-\mathrm{N}$ discharged was the limiting factor and 2) when only fish density at harvest was the limiting factor. Then, the impact of both limitations combined on profit per year per farm was studied.

\section{Limitation on dissolved $\mathrm{NH}_{3}-\mathrm{N}$ at MSS (Table 2.3)}

When only dissolved $\mathrm{NH}_{3}-\mathrm{N}$ is the limiting factor, the number of fish stocked and harvested per batch varies depending on FCR and TGC values (Table 2.3 and Eq. [2.18]). A decrease in FCR (at the same TGC) increases farm profit per year. Lower FCR results in lower total feed distributed per fish (Eq. [2.5]) and therefore, lower 
dissolved $\mathrm{NH}_{3}-\mathrm{N}$ (Eq. [2.13]). Hence, the number of fish stocked per batch can be increased in order to reach limitation on dissolved $\mathrm{NH}_{3}-\mathrm{N}$, which increases the annual production of fish. The amount of feed distributed per year also increases, but less than the annual production of fish. Consequently, the ratio of fish sales over cost of feed increases, resulting in higher profit.

An increase in TGC (at the same FCR) does not change profit in this particular situation. This can be explained by the fact that faster growing fish have higher daily weight gain, which increases dissolved $\mathrm{NH}_{3}-\mathrm{N}$ per fish (Eq. [2.13]). Fewer fish, therefore, should be stocked to respect the limitations on dissolved $\mathrm{NH}_{3}-\mathrm{N}$, resulting in fewer fish harvested per batch (Eq. [2.18]). This decreasing number of fish is offset by rearing more batches (Eq. [2.21]). Therefore, annual fish production as well as feed consumption does not change and profit stays constant over different TGC values. It can be concluded that when dissolved $\mathrm{NH}_{3}-\mathrm{N}$ alone is the limiting factor, extra profit is obtained only by decreasing FCR, which increases productivity and feed consumption.

\section{Limitation on fish density at harvest time (Table 2.4)}

When only fish density is the limiting factor, the number of fish harvested per batch is constant and equal to 8,846 fish (Table 2.4). A decrease in FCR (at the same TGC) does not have an impact on the annual production of fish. The total feed distributed per fish, however, decreases resulting in lower annual feed consumption. Consequently, profit increases with decreasing FCR.

An increase in TGC (at the same FCR) also increases profit. As the number of fish harvested per batch is constant, the number of batches per year increases linearly with TGC (Eq. [2.21]). Hence, profit increases when TGC increases because the share of fixed costs in total costs decreases. It can be concluded that when density alone is the limiting factor, extra profit is obtained by increasing either TGC which increases production per year or by decreasing FCR which decreases feed consumption per year. 
Table 2.3: Effect of different values of thermal growth coefficient (TGC) and feed conversion ratio (FCR) on fish production parameters when production is only limited by dissolved NH3-N at maximum standing stock (MSS).

\begin{tabular}{|c|c|c|c|c|c|c|c|c|}
\hline \multirow[b]{2}{*}{$\mathrm{TGC}$} & \multirow[b]{2}{*}{ FCR } & \multicolumn{7}{|c|}{ Limiting factor $=$ dissolved $\mathrm{NH}_{3}-\mathrm{N}$ at maximum standing stock $(39 \mathrm{~kg}$ ) } \\
\hline & & $\begin{array}{c}\text { Total feed } \\
\text { distributed per } \\
\text { fish, kg }\end{array}$ & $\begin{array}{c}\text { Number of } \\
\text { fish harvested } \\
\text { per batch }\end{array}$ & $\begin{array}{c}\text { Number of } \\
\text { batches per } \\
\text { year }\end{array}$ & $\begin{array}{l}\text { Annual fish } \\
\text { production, } \mathrm{t}\end{array}$ & $\begin{array}{c}\text { Annual feed } \\
\text { consumption, } \\
\mathrm{t}\end{array}$ & $\begin{array}{c}\text { Annual profit } \\
\text { per farm, } €\end{array}$ & $\begin{array}{c}\text { Profit per kg } \\
\text { of fish, } €\end{array}$ \\
\hline 8.33 & 0.81 & 1.054 & 7,585 & 52 & 518 & 420 & 0 & 0 \\
\hline 8.33 & 0.75 & 0.974 & 9,029 & 52 & 610 & 457 & 71,114 & 0.12 \\
\hline 8.33 & 0.69 & 0.900 & 10,801 & 52 & 729 & 505 & 163,744 & 0.22 \\
\hline 8.33 & 0.64 & 0.832 & 13,185 & 52 & 890 & 570 & 288,468 & 0.32 \\
\hline 8.9 & 0.81 & 1.054 & 7,179 & 55 & 518 & 420 & 0 & 0 \\
\hline 8.9 & 0.75 & 0.974 & 8,454 & 55 & 610 & 457 & 71,114 & 0.12 \\
\hline 8.9 & 0.69 & 0.900 & 10,113 & 55 & 729 & 505 & 163,744 & 0.22 \\
\hline 8.9 & 0.64 & 0.832 & 12,346 & 55 & 890 & 570 & 288,468 & 0.32 \\
\hline 9.5 & 0.81 & 1.054 & 6,722 & 59 & 518 & 420 & 0 & 0 \\
\hline 9.5 & 0.75 & 0.974 & 7,916 & 59 & 610 & 457 & 71,114 & 0.12 \\
\hline 9.5 & 0.69 & 0.900 & 9,469 & 59 & 729 & 505 & 163,744 & 0.22 \\
\hline 9.5 & 0.64 & 0.832 & 11,560 & 59 & 890 & 570 & 288,468 & 0.32 \\
\hline 10.14 & 0.81 & 1.054 & 6,294 & 63 & 518 & 420 & 0 & 0 \\
\hline 10.14 & 0.75 & 0.974 & 7,412 & 63 & 610 & 457 & 71,114 & 0.12 \\
\hline 10.14 & 0.69 & 0.900 & 8,302 & 63 & 729 & 505 & 163,744 & 0.22 \\
\hline 10.14 & 0.64 & 0.832 & 10,134 & 63 & 890 & 570 & 288,468 & 0.32 \\
\hline
\end{tabular}


Table 2.4: Effect of different values of thermal growth coefficient (TGC) and feed conversion ratio (FCR) on fish production parameters when production is only limited by density at harvest.

\begin{tabular}{|c|c|c|c|c|c|c|c|c|}
\hline \multirow[b]{2}{*}{ TGC } & \multirow[b]{2}{*}{ FCR } & \multicolumn{7}{|c|}{ Limiting factor $=$ density at harvest $\left(230 \mathrm{~kg} / \mathrm{m}^{3}\right)$} \\
\hline & & $\begin{array}{l}\text { Total feed } \\
\text { distributed } \\
\text { per fish, kg }\end{array}$ & $\begin{array}{c}\text { Number of fish } \\
\text { harvested per } \\
\text { batch }\end{array}$ & $\begin{array}{c}\text { Number of } \\
\text { batches } \\
\text { per year }\end{array}$ & $\begin{array}{c}\text { Annual fish } \\
\text { production, } \\
\mathrm{t}\end{array}$ & $\begin{array}{c}\text { Annual feed } \\
\text { consumption, } t\end{array}$ & $\begin{array}{l}\text { Annual profit } \\
\text { per farm, } €\end{array}$ & $\begin{array}{l}\text { Profit per } \\
\text { kg of fish, } €\end{array}$ \\
\hline 8.33 & 0.81 & 0.811 & 8,846 & 52 & 597 & 484 & 25,369 & 0.04 \\
\hline 8.33 & 0.75 & 0.749 & 8,846 & 52 & 597 & 448 & 66,344 & 0.11 \\
\hline 8.33 & 0.69 & 0.693 & 8,846 & 52 & 597 & 414 & 104,262 & 0.17 \\
\hline 8.33 & 0.64 & 0.640 & 8,846 & 52 & 597 & 383 & 139,257 & 0.23 \\
\hline 8.9 & 0.81 & 0.811 & 8,846 & 55 & 638 & 517 & 38,310 & 0.06 \\
\hline 8.9 & 0.75 & 0.749 & 8,846 & 55 & 638 & 478 & 82,071 & 0.13 \\
\hline 8.9 & 0.69 & 0.693 & 8,846 & 55 & 638 & 442 & 122,567 & 0.19 \\
\hline 8.9 & 0.64 & 0.640 & 8,846 & 55 & 638 & 409 & 159,942 & 0.25 \\
\hline 9.5 & 0.81 & 0.811 & 8,846 & 59 & 681 & 553 & 52,132 & 0.08 \\
\hline 9.5 & 0.75 & 0.749 & 8,846 & 59 & 681 & 511 & 98,868 & 0.15 \\
\hline 9.5 & 0.69 & 0.693 & 8,846 & 59 & 681 & 472 & 142,118 & 0.21 \\
\hline 9.5 & 0.64 & 0.640 & 8,846 & 59 & 681 & 436 & 182,035 & 0.27 \\
\hline 10.14 & 0.81 & 0.811 & 8,846 & 63 & 728 & 590 & 66,894 & 0.09 \\
\hline 10.14 & 0.75 & 0.749 & 8,846 & 63 & 728 & 545 & 116,808 & 0.16 \\
\hline 10.14 & 0.69 & 0.693 & 8,846 & 63 & 728 & 504 & 162,000 & 0.22 \\
\hline 10.14 & 0.64 & 0.640 & 8,846 & 63 & 728 & 466 & 205,630 & 0.28 \\
\hline
\end{tabular}




\section{Dissolved NH3-N and fish density as concomitant limiting factors}

Figure 2.2 shows the evolution of the annual profit per farm expressed in euro for different combinations of FCR and TGC. To illustrate the full range of situations and their consequences on the system, two extreme values of TGC (7 and 13) are shown also in figure 2.2. As mentioned earlier, decreasing FCR increases profit, independently of TGC. The rate of increase in profit is, however, different according to the factor limiting fish production, i.e. fish density or dissolved $\mathrm{NH}_{3}-\mathrm{N}$. For example, when TGC is 7, the limiting factor is density and the dissolved $\mathrm{NH}_{3}-\mathrm{N}$ limitation is never reached. Profit follows, therefore, a linear function (Figure 2.2). When TGC has increased to 13 , however, the limiting factor has become dissolved $\mathrm{NH}_{3}-\mathrm{N}$ and the maximum density is never reached. Profit follows, therefore, an exponential function of decreasing FCR (Figure 2.2). When TGC progressively increases from 8.33 to 10.15 , the limiting factor of the production system switches from dissolved $\mathrm{NH}_{3}-\mathrm{N}$ to density at harvest. Indeed, when dissolved $\mathrm{NH}_{3}-\mathrm{N}$ is the limiting factor, decreasing FCR increases the number of fish harvested per batch.

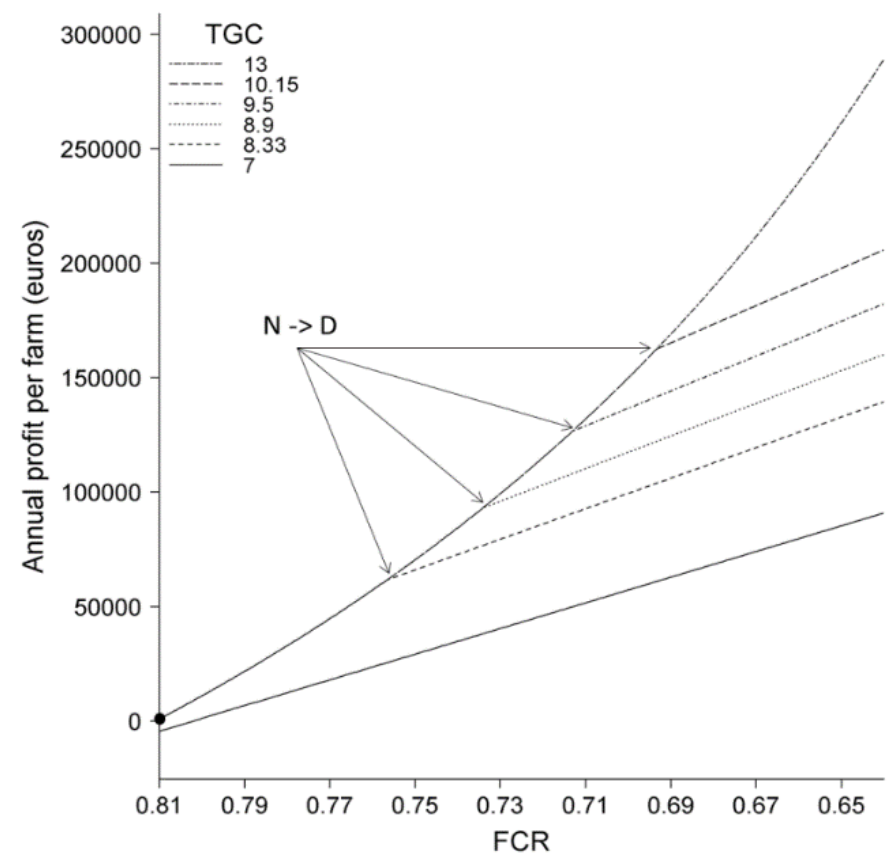

Figure 2.2: Annual profit per farm as a function of thermal growth coefficient (TGC) and feed conversion ratio (FCR). Each line describes the evolution of the profit for a given TGC when FCR decreases as a result of selective breeding. The black spot represents the reference scenario, TGC = 8.33 and FCR $=0.81$. The arrows illustrate the point where the limiting factor switches from rearing density (D) to dissolved $\mathrm{NH}_{3}-\mathrm{N}(\mathrm{N})$. 
There is a point, however, where the maximum density of fish is reached and density becomes the limiting factor. It can be concluded that for TGC values between 7 and 13, profit initially follows an exponential function of decreasing FCR until the point where density becomes the limiting factor. At this point, the relation with profit to FCR becomes linear. The point of switch is determined by the TGC value.

\subsubsection{Economic values of TGC and FCR}

Economic values of TGC and FCR for different combinations of TGC and FCR are given in figure 2.3. For instance, in the reference scenario (FCR $=0.81$ and $T G C=$ 8.33), $\mathrm{EV}_{\mathrm{FCR}}$ is $0.13 € / \mathrm{kg}$ of fish and represents the extra profit obtained by improving FCR by $7.6 \%$ (from FCR $=0.81$ to 0.75 ) with TGC constant at 8.33 (Figure 2.3). In the reference scenario, $E V_{T G C}$ is $0 € / \mathrm{kg}$ of fish and represents the extra profit obtained by improving TGC by $6.8 \%$ (from TGC $=8.33$ to 8.90 ) with FCR constant at 0.81 (Figure 2.3).

As explained before, EVs depend on the limiting factor. In figure 2.3, four different zones can be distinguished depending on the limiting factor of the current population mean $\left(\mu_{\mathrm{TGC}}\right.$ and $\left.\mu_{\mathrm{FCR}}\right)$ and on the limiting factor of one generation of selection in either TGC or FCR.

The most significant results are observed in zones 1 and 4 . When the limiting factor is dissolved $\mathrm{NH}_{3}-\mathrm{N}$ (zone 1), $E V_{\text {TGC }}$ is $0 € / \mathrm{kg}$ of fish because increasing TGC does not bring extra profit. $\mathrm{EV}_{\mathrm{FCR}}$ is, however, equal to $0.14 € / \mathrm{kg}$ of fish. On the other hand, when density is the limiting factor (zone 4), $E V_{T G C}$ becomes equal to $0.03 € / \mathrm{kg}$ of fish and $\mathrm{EV}_{\mathrm{FCR}}$ is 0.05 or $0.06 € / \mathrm{kg}$ of fish.

We can also notice that when dissolved $\mathrm{NH}_{3}-\mathrm{N}$ is the limiting factor, $\mathrm{EV}_{\mathrm{FCR}}$ decreases when one generation of selection in FCR leads to a situation where density is the limiting factor (zone 2). When density is the limiting factor, EV $\mathrm{TGC}_{\mathrm{TGC}}$ decreases when one generation of selection in TGC leads to a situation where dissolved $\mathrm{NH}_{3}-\mathrm{N}$ is the limiting factor (zone 3). 


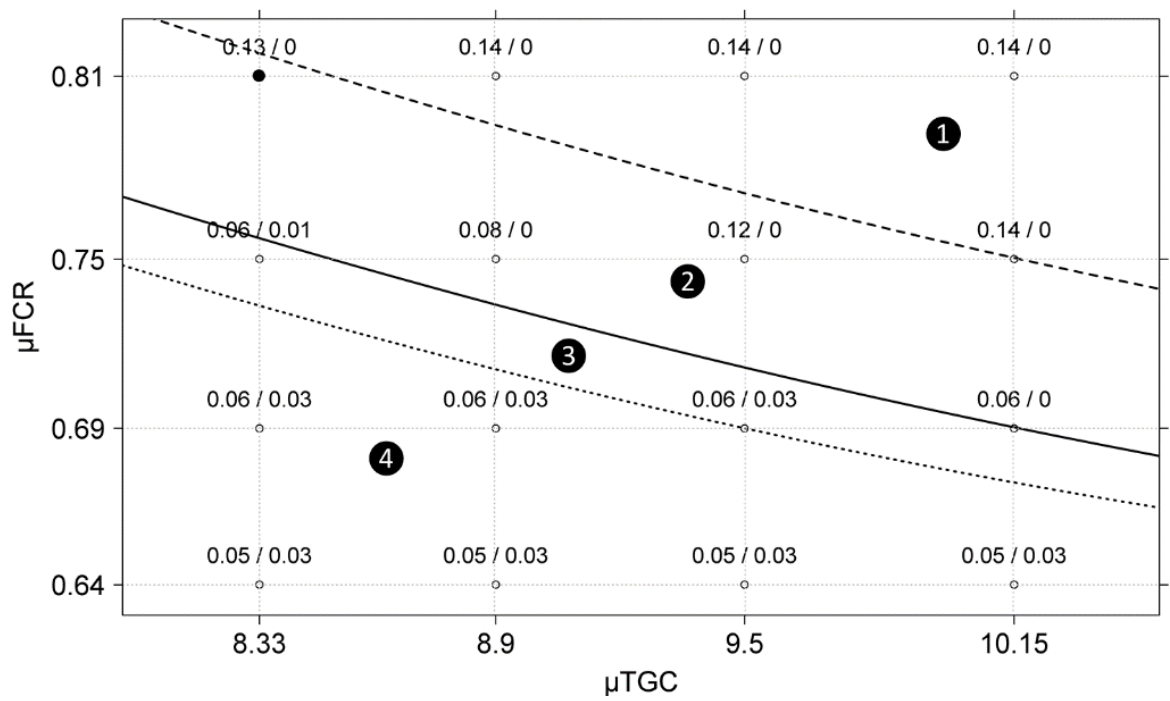

Figure 2.3: Economic values (EV) of feed conversion ratio (FCR) and thermal growth coefficient (TGC) for $\mathbf{1 6}$ combinations of $\mu \mathrm{TGC}$ and $\mu \mathrm{FCR}$ classified in four different zones depending on the limiting factor of the current population mean ( $\mu \mathrm{TGC}$ and $\mu \mathrm{FCR}$ ) and on the limiting factor after one generation of selection. In zone 1, dissolved NH3-N is the limiting factor and one generation of selection in either TGC or FCR does not change this. In zone 2, dissolved NH3-N is the limiting factor and after one generation of selection in FCR density becomes the limiting factor. In zone 3 density is the limiting factor and after one generation of selection in TGC dissolved NH3-N becomes the limiting factor. In zone 4, density is the limiting factor and one generation of selection TGC or FCR does not change this. The black spot represents the reference scenario, $\mathrm{TGC}=8.33$ and $\mathrm{FCR}=0.81$.

\subsection{Discussion}

The bioeconomic model developed in this study was based on farm data and allowed us to investigate the economic impact of improving growth rate (TGC) and feed conversion ratio (FCR) at farm level in a recirculating aquaculture system (RAS). In RAS, two factors could limit the production level: fish density at harvest time or dissolved $\mathrm{NH}_{3}-\mathrm{N}$ at Maximum Standing Stock (MSS). The economic impact was expressed via economic values (EV) calculated as extra profit obtained per $\mathrm{kg}$ of fish produced when improving TGC by $6.8 \%$ or FCR by $7.6 \%$ (simulating one generation of selection). Feed conversion ratio and thermal growth coefficient are the main two traits considered by fish breeders because TGC is expected to increase productivity, while FCR decreases feed cost, which represents about $50 \%$ of annual total cost due to the high amounts of protein and lipids in carnivorous fish diets (CNA, 2011). 
The results of our study confirm the economic potential of decreasing FCR but on the other hand it shows that increasing TGC does not always result in an increase in profitability in RAS. From a theoretical point of view, the calculations of EVs are only relevant in a system with optimized management (Amer et al., 1994; Dekkers, 1991). In our bioeconomic model, the farming system was considered optimized as each of the two limiting factors was respected. When dissolved $\mathrm{NH}_{3}-\mathrm{N}$ is the limiting factor, the number of fish stocked per batch depends on FCR and TGC. In this situation, increasing TGC forces a farmer to decrease the number of fish stocked in order to account for the increase in dissolved $\mathrm{NH}_{3}-\mathrm{N}$ excretion. When dissolved $\mathrm{NH}_{3}-\mathrm{N}$ is the limiting factor, therefore, TGC does not increase productivity. On the other hand, decreasing FCR always decreases feed cost per unit of fish produced with both limiting factors of dissolved $\mathrm{NH}_{3}-\mathrm{N}$ and density.

Calculation of EVs shows that EV factor of the current generation and on the limiting factor operating at the next generation of selection. For TGC, when dissolved $\mathrm{NH}_{3}-\mathrm{N}$ is the limiting factor, $\mathrm{EV}_{\mathrm{TGC}}$ is always zero, meaning that increasing TGC does not have any impact on annual profit per farm. These results can be partly explained by our choices for the modelling of FCR wn (Eq. [2.4]) and FCR (Eq. [2.22]). According to James (1982), EVs of traits included in the breeding goal should be calculated regardless of correlations among those traits. We, therefore, modeled $F C R_{w n}$ as a function of fish weight to make TGC and FCR independent. We also considered, according to farm data, that mortality was independent from TGC. The consequence of these assumptions is that changes in TGC neither affect FCR wn nor FCR.

On the other hand, when the limiting factor is density for both $\mu_{\mathrm{TGC}}$ and $\mu_{\mathrm{TGC}}+\Delta_{\mathrm{TGC}}$, $E V_{T G C}$ is $0.03 € / \mathrm{kg}$ of fish. In most fish species, EVs are lacking and the economic impact of breeding programs is not known. However, a study by Gjerde and Olsen (1990) on Atlantic salmon (Salmo salar) found that the EV of improving growth rate by $10 \%$ in salmon farming was about $0.09 € / \mathrm{kg}$ of fish (Gjedrem et al., 2012). This difference can be due to the low margin between production costs and revenues of African catfish compared to Atlantic salmon.

Economic values of FCR confirm the importance of feed in farm profitability, because FCR always gets a positive EV whatever the limiting factors. EVFCR can reach $0.14 € / \mathrm{kg}$ of fish when $\mathrm{NH}_{3}-\mathrm{N}$ is the limiting factor, which is higher than the maximum value of $0.05-0.06 € / \mathrm{kg}$ of fish when density is the limiting factor. Improving FCR through selective breeding increases, therefore, the annual profit per farm. The percentage of improvement tested in this study (7.6\%) represents, however, the genetic gain of one generation of selection on FCR only and is purely hypothetical. Apart from rainbow trout, there are no genetic parameter estimates 
for FCR in any commercial fish species. Thodesen et al. (1999) found a reduction in FCR of $4 \%$ per generation as a correlated response to selection for growth in Atlantic salmon. In rainbow trout, Kause et al. (2006) predicted that selection for daily gain would only increases daily gain by $17.6 \%$ per generation and simultaneously would increases feed efficiency (1/FCR) by $8.4 \%$. This suggests a positive correlation between feed efficiency and growth rate, which is consistent with results in terrestrial livestock species, such as pig and poultry (Clutter and Brascamp, 1998; Crawford, 1990). Other studies in different fish species show a more complex picture. Thodesen et al. (2001), for instance, found a phenotypic correlation of 0.79 between feed efficiency and growth rate while Silverstein et al. (2005) found a moderate correlation of -0.38 between residual feed intake (RFI) and growth rate. Due to this moderate correlation, Silverstein et al. (2005) suggested that selection on growth rate only will not necessarily improve feed utilization efficiency. In parallel, some other studies in salmonids did not show any correlation between growth rate and feed efficiency and showed that genetic gain in growth was due to higher feed intake, while feed efficiency remained unchanged (Mambrini et al., 2004; Sanchez et al., 2001).

Assumptions on the links between FCR and growth rate can have a high impact on the profitability of fish breeding programs. Ponzoni et al. (2007), for instance, simulated a genetic improvement program in Nile tilapia including harvest weight, survival rate and feed intake in the breeding goal. One of their assumptions was that the genetic and the phenotypic correlation between harvest weight and feed intake was 0.85 . The practical consequence of these correlations is that improving harvest weight will increase feed intake but by a lower rate resulting in a lower FCR. In their study, the estimated benefit over cost ratio of implementing a breeding program ranged from 8.5 to 60 . This high positive economic return was, however, mostly due to a better feed conversion ratio correlated to the genetic improvement of harvest weight.

Gjedrem et al. (2012) suggested to run a simple breeding program including only growth rate in the breeding goal in order to limit the initial investment and, consequently, to incite farmers to use improved stock. Considering no correlation between TGC and FCR, implementing a breeding program for growth rate would be profitable only when density is the limiting factor. Considering a negative correlation between TGC and FCR, however, implementing a breeding program for growth rate would also lead to a small improvement in FCR. Gjedrem et al. (2012) estimated this correlated response to be $2.76 \%$ per generation in Atlantic salmon. Assuming a percentage of improvement of $6.8 \%$ in TGC and $2.76 \%$ in FCR we can estimate the economic benefit of implementing such breeding program in African 
catfish in RAS. In the reference scenario ( $T G C=8.33$ and FCR $=0.81$ ), with dissolved $\mathrm{NH}_{3}-\mathrm{N}$ as limiting factor, the total extra profit obtained from one generation of selection would be $0.05 € / \mathrm{kg}$ of fish ( $\mathrm{EV}_{\mathrm{TGC}}=0 € / \mathrm{kg}$ of fish $+\mathrm{EV}_{\mathrm{FCR}}=0.05 € / \mathrm{kg}$ ). If the production is limited by density (still in the reference scenario), the total benefit obtained from one generation of selection would also be $0.05 € / \mathrm{kg}$ of fish $\left(\mathrm{EV}_{\mathrm{TGC}}=\right.$ $0.02 € / \mathrm{kg}$ of fish $+E V_{F C R}=0.03 € / \mathrm{kg}$ of fish).

Therefore, in this particular situation of African catfish raised in RAS, implementing a breeding program that only aims at improving TGC would always be profitable only in a situation of density limitation, whether or not there is a genetic correlation between TGC and FCR. The implication of this finding is that RAS farms should be designed according to maximum rearing densities, using larger bio-filters than needed in order to remain in the situation of density limitation and to obtain higher profit from improving growth rate only. Using a larger bio-filter would, however, increase the fixed costs of the farm.

Our findings can also be extended to other livestock systems where animal manure can cause greenhouse gas (GHG) emissions and eutrophication. In the UK, the government defined Nitrate Vulnerable Zones (NVZs), which designate agricultural lands draining nitrates to vulnerable or polluted waters. In these areas, farmers must comply with a limitation on the amount of nitrogen from livestock manure applied on their farm whether by grazing animals (cattle, sheep, deer, goats and horses.) or by spreading (Department for Environment Food \& Rural Affairs, 2013). This limitation corresponds to $170 \mathrm{~kg}$ of nitrogen per hectare and per year but extra manure production can be stocked in manure storage facilities. However, storage of manure could be forbidden in the future and farmers could have to deal with a strict limitation. In this case, therefore, faster growing animals (with the same feed efficiency) will have a similar impact as faster growing fish in RAS when dissolved $\mathrm{NH}_{3}-\mathrm{N}$ is the limiting factor. Faster growing animals would increase production rate but farmers would have to rear fewer animals, which will then result in a zero economic value for growth rate.

To conclude, we found that the economic values of TGC and FCR changed depending on the factors limiting fish production in a closed containment system such as a RAS. The economic value of growth rate is zero when dissolved $\mathrm{NH}_{3}-\mathrm{N}$ is the limiting factor. Hence, it is not always economically profitable to breed for faster growing fish. On the other hand, FCR always get a positive economic value in with limitation situation but economic values of FCR are higher when $\mathrm{NH}_{3}-\mathrm{N}$ is the limiting factor. Those results show the importance of modelling the entire farming system to calculate economic values in order to develop efficient breeding program in aquaculture for the future. 


\section{Acknowledgement}

M. Besson benefited from a joint grant from the European Commission and IMARES, within the framework of the Erasmus-Mundus joint doctorate "EGS-ABG". 


\section{Appendices}

Appendix 2.1: Composition of the feed.

\begin{tabular}{ll}
\hline Composition & Quantity, in \% \\
\hline Protein & 45 \\
Crude fat & 12.5 \\
Crude ash & 9 \\
Other Carbohydrates & 22.5 \\
Phosphorus & 1.1 \\
\hline
\end{tabular}

\section{Appendix 2.2:}

Equation 11:

$\mathrm{N} \_$suspended $\mathrm{n}$ is calculated using the digestibility of protein (dig_P $=90 \%$ ) and the solubility of suspended $\mathrm{N}$ (sol_susp $=15 \%)$ :

$N_{-}$suspended $_{n}=\left[\left(N_{-}\right.\right.$feed_intake $n \times\left(1-\right.$ dig_P$\left.\left._{-}\right)\right)+N_{-}$feed_waste $] \times(1-$ sol_susp $)$

$N_{\text {_suspended }}=\left[\left(72 \times \mathrm{DWG}_{\mathrm{n}} \times \mathrm{FCR}_{\mathrm{n}} \times(1\right.\right.$-dig_P $\left.\left.)\right)+\left(0.72 \times \mathrm{DWG}_{\mathrm{n}} \times \mathrm{FCR}_{\mathrm{n}}\right)\right] \times(1-$ sol_susp)

N_suspended $=6.732 \times \mathrm{FCR}_{\mathrm{Wn}} \times \mathrm{DWG}_{\mathrm{n}}$

\section{Equation 13:}

$\mathrm{N} \_$dissolved $\mathrm{n}=\mathrm{N}$ _excretion $\mathrm{n}+\mathrm{N}$ _feed_waste $\mathrm{n}-\mathrm{N} \_$suspended $_{\mathrm{n}}$

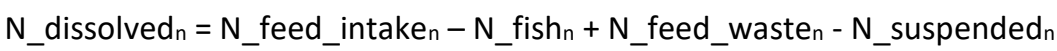

$N_{\text {_dissolved }}=\left(72 \times \mathrm{DWG}_{n} \times \mathrm{FCR}_{n}\right)-\left(25 \times D W G_{n}\right)+\left(0.72 \times \mathrm{DWG}_{n} \times F C R_{n}\right)-(6.732 \times$ $\left.\mathrm{FCR}_{W_{n}} \times \mathrm{DWG}_{\mathrm{n}}\right)$

$N \_$dissolved $=\left(65.988 \times D W G_{n} \times F C R_{n}\right)-\left(25 \times D W G_{n}\right)$

\section{Equation 14:}

Emission of $\mathrm{NH}_{3}-\mathrm{N}$ in effluent water can be calculated using the retention capacity of the mechanic filter (retention_susp $=90 \%$ ) and the percentage of nitrification (perct_nitri $=100 \%)$ :

N_eff $f_{n}=(1-$ retention_susp $) \times N \_$suspended $_{n}+($ 1-perct_nitri $) \times N$ _dissolved N_eff $=0.1 \times N \_$suspended $n$

\section{Appendix 2.3:}

Equation 15:

COD_waste $=($ protein $\times 1.3+$ crude_fat $\times 2.9+$ carbs $\times 1.07) \times\left(D^{2} I_{n} \times 0.01\right)$ COD_waste $=($ protein $\times 0.013+$ crude_fat $\times 0.029+$ carbs $\times 0.0107) \times D F I_{n}$ 
Equation 16:

COD_excretion $n$ is calculated using digestibility of proteins (Dig_P $=90 \%$ ), crude fat (Dig_F $=90 \%$ ) and carbohydrates (Dig_C $=60 \%$ ):

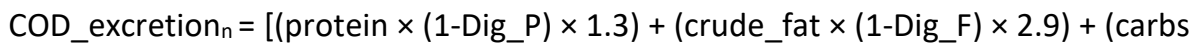
$\times(1$-Dig_C $) \times 1.07)] \times \mathrm{DFI}_{\mathrm{n}}$

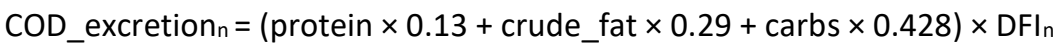

Equation 17:

COD_susp $n=\left(C O D \_\right.$excretion $n+C O D \_w_{n}$ aste $) \times(1-$ sol_susp $)$

COD_susp $n=($ protein $\times 0.12155+$ crude_fat $\times 0.27155+$ carbs $\times 0.372895) \times \mathrm{DFI}_{\mathrm{n}}$

COD_sludge $=$ COD_susp $\mathrm{n} \times(1-$ retention_susp $)$

COD_sludge $_{n}=($ protein $\times 0.012155+$ crude_fat $\times 0.027155+$ carbs $\times 0.0372895) \times$ $\mathrm{DFI}_{\mathrm{n}}$

COD_eff $=$ COD_susp $n-C O D \_s l u d g e_{n}$

COD_eff $f_{n}=($ protein $\times 0.109395+$ crude_fat $\times 0.244395+$ carbs $\times 0.3356055) \times D F I_{n}$ 



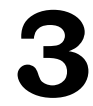

\title{
Environmental impacts of genetic improvement of growth rate and feed conversion ratio in fish farming under rearing density and nitrogen output limitations
}

\author{
M. Besson ${ }^{1,2,3}$, J. Aubin ${ }^{4}$, H. Komen ${ }^{1}$, M. Poelman ${ }^{5}$, E. Quillet ${ }^{3}$, M. Vandeputte ${ }^{3,7}$, \\ J.A.M. van Arendonk ${ }^{1}$, I.J.M. de Boer ${ }^{6}$
}

\footnotetext{
${ }^{1}$ Animal Breeding and Genomics Centre, Wageningen University, PO Box 338, $6700 \mathrm{AH}$ Wageningen, the Netherlands

${ }^{2}$ AgroParisTech, UMR1313 Génétique animale et biologie intégrative, 16 rue Claude Bernard, 75231 Paris 05, France

3 INRA, UMR1313 Génétique animale et biologie intégrative, Allée de Vilvert, 78350 Jouy-en-Josas, France

${ }^{4}$ INRA, Agrocampus Ouest Rennes, UMR1069 Sol Agronomie Spatialisation, 65 rue de Saint Brieuc, 35042 Rennes, France

${ }^{5}$ IMARES, Wageningen UR, Korringaweg 5, 4401 NT Yerseke, the Netherlands

${ }^{6}$ Animal Production Systems group, Wageningen University, P.O. Box 338, 6700 AH Wageningen, the Netherlands

${ }^{7}$ IFREMER, Chemin de Maguelone, 34250 Palavas-les-Flots, France
}

Journal of Cleaner Production (2016) 116: 100-109 



\section{Abstract}

Today, fish farming faces an increasing demand in fish products, but also various environmental challenges. Genetic improvement in growth rate and feed conversion ratio is known to be an efficient way to increase production and increase efficiency in fish farming. The environmental consequences of genetic improvement in growth rate and feed conversion ratio, however, are unknown. In this study, we investigated the environmental consequences of genetic improvement in growth rate and feed conversion ratio in an African catfish farm, using Recirculating Aquaculture System (RAS). In RAS, total fish production of the farm is limited by rearing density or by the capacity to treat dissolved nitrogen. To evaluate the environmental consequences of genetic improvement in growth rate and feed conversion ratio, we combined life cycle assessment and bioeconomic modeling of genetic response to selection. We explored different impact categories, such as climate change, eutrophication, acidification and energy use, and we expressed impacts per ton of fish produced. Results show that the environmental impact of genetic improvement in growth rate and feed conversion ratio varies among impact categories and depends on the factor limiting production at farm level (i.e. rearing density or nitrogen treatment capacity). Genetic improvement of feed conversion ratio reduces environmental impacts in each scenario tested, while improving growth rate reduces environmental impacts only when rearing density limits farm production. Environmental responses to genetic selection were generally positive and show similar trends as previously determined economic responses to genetic improvement in growth rate and feed conversion ratio in RAS. These results suggest that genetic improvement of growth rate and feed conversion ratio for species kept in RAS will benefit both the environmental impacts and the economics of the production system.

Keywords: life cycle assessment, African catfish, feed efficiency, recirculating aquaculture system, selection, thermal growth coefficient. 


\subsection{Introduction}

Fish farming is the fastest growing animal food-producing sector in the world, due to the joint effect of an increase in demand of fish products and a stagnation of fisheries captures (FAO, 2012). Fish farming, however, also faces some environmental challenges, such as eutrophication resulting from emission of pollutants during fish rearing and the use of natural resources for feed (Folke et al., 1994; Naylor et al., 2000; Read and Fernandes, 2003). Previous life cycle assessments (LCA) showed that production of feed and fish farming are chain stages that contribute most to environmental impacts of fish farming (Aubin et al., 2006; Pelletier et al., 2009). Several studies have investigated the potential of alternative feed compositions (Boissy et al., 2011; Papatryphon et al., 2004; Pelletier and Tyedmers, 2007) or alternative rearing systems (Aubin et al., 2009; Ayer and Tyedmers, 2009; d'Orbcastel et al., 2009) to reduce the environmental impact. These studies found trade-offs between different environmental impacts, such as climate change and eutrophication, when changing feed composition or rearing conditions.

Genetic improvement has potential to reduce various environmental impacts simultaneously but this aspect of selective breeding has not been explored so far in fish production. In many fish species, genetic response to selective breeding is high due to high heritability of commercial important traits, high intensity of selection and high genetic variation (Gjedrem et al., 2012). Genetic improvement, obtained through selective breeding programs, is a powerful tool to generate cumulative change in animal population. A genetic change in fish performances is expected to improve not only economic benefit of farms (Besson et al., 2014; Ponzoni et al., 2007), but to reduce also environmental impacts, as shown in livestock (Bell et al., 2011; Buddle et al., 2011). Wall et al. (2010) suggested to evaluate these environmental impacts of genetic improvement by calculating environmental values (ENV), based on the principle of economic values (EV) from Hazel (1943). These environmental values express the difference in environmental impacts between a base situation and a situation with genetic improvement in one trait while keeping the other traits constant (Groen, 1988). From the whole farm perspective, genetic improvement in a trait can alter feeding strategy, management practices and also purchase of inputs like feeds (van Middelaar et al., 2014). Moreover, the impact of genetic improvement on farm management changes according to the factor limiting production at farm level (Gibson, 1989; Groen, 1989). Evaluating the environmental impact of genetic improvement requires, therefore, (1) to model the whole farm, using, for example, a bio- 
economic model and (2) to evaluate the environmental impact of changes at farm level, which can be performed using LCA.

Van Middelaar et al. (2014) combined bioeconomic farm modelling with an LCA to calculate EV and ENV in dairy production. They found that genetic improvement of milk yield and longevity increased economic benefit at farm level and decreased greenhouse gas (GHG) emissions along the production chain of one ton of fat-andprotein-corrected milk (FPCM). In fish farming, we developed a bioeconomic model for a farm producing African catfish (Clarias gariepinus) in recirculating aquaculture system (RAS) and investigated the EV of growth rate and feed conversion ratio (Besson et al., 2014). Growth rate and feed conversion ratio are considered key production parameters by fish farmers. In Besson et al. (2014), we showed that genetic improvement of both traits could increase farm income by improving the production of the farm and/or by improving production efficiency (fish produced per unit of feed consumed). Modelling the whole farm showed that the impact of genetic improvement on farm income depends on the trait and on the factor limiting the production of the farm: the capacity of the bio-filter to treat nitrogen or the maximum rearing density in the system studied.

Changes in production and production efficiency are expected to decrease environmental impacts also, by diluting fixed environmental impacts over more fish produced and by reducing the use of feed per ton of fish produced (Wall et al., 2010). In fish farming, however, the impact of genetic improvement on the direction and on the magnitude of a change in environmental impacts is not known. Moreover, possible synergies or trade-offs between EV and ENV are unknown. In this study, therefore, environmental values of growth rate and feed conversion ratio of African catfish reared in a RAS were calculated by combining the bioeconomic model developed in Besson et al. (2014) with an LCA of fish production.

\subsection{Method}

\subsubsection{Bioeconomic model}

The bioeconomic model used in this study was developed in Besson et al. (2014) using R ( $R$ Development Core Team, 2008). This model describes a RAS producing 500 tons of African catfish per year. Tanks are restocked after fishing all along the year and during a one year period, the model assumes that all stocked fish have a common genetic value. The model was based on information provided by private companies. The RAS was composed of four main compartments: (1) a series of 20 
rearing tanks ( 6 tanks of $6 \mathrm{~m}^{3}$ for fish from 13 to $80 \mathrm{~g}$ and 14 tanks of $50 \mathrm{~m}^{3}$ for fish from 80 to $1300 \mathrm{~g}$ ), (2) a mechanical filter, which remove solid waste, (3) a bio-filter where nitrifying bacteria brake down the ammoniacal nitrogen $\left(\mathrm{NH}_{3}-\mathrm{N}\right)$ excreted by the fish into nitrites and nitrates and (4) a denitrification reactor where denitrifying bacteria processes nitrates into nitrogen gas $\left(\mathrm{N}_{2}\right)$. Clean-up water was re-used in rearing tanks and only $30 \mathrm{~m}^{3} /$ day of effluent water was directed to a municipal waste water treatment plant. The bioeconomic model was divided in 3 parts: (1) fish model, estimating individual fish growth using thermal growth coefficient (Dumas et al., 2007) and estimating individual emission of pollutants using massbalance (Cho and Kaushik, 1990; Cowey and Cho, 1991); (2) batch model, estimating the maximum stocking density of a batch according to the two limiting factors, the density at harvest $\left(230 \mathrm{~kg} / \mathrm{m}^{3}\right)$ and the maximum treatment capacity of the bio-filter (40 kg of dissolved $\mathrm{NH}_{3}-\mathrm{N}$ per day); (3) farm model, estimating annual fish production, pollutants emission, feed consumption and finally annual profit by combining technical and economic parameters. Further details about the bioeconomic model are given in appendix 3.1. The outputs of the bioeconomic model were used to generate inventory data for the LCA.

\subsubsection{Life cycle assessment}

\section{Goal and scope}

LCA is a standardized method to calculate the environmental impact of a production chain, from raw material extraction up to the product's end-of life (Guinée et al., 2002). In this study, we applied LCA according to the main specifications of ILCD standards (Joint Research Center, 2010). The system was defined from cradle-to-farm-gate and included five distinct sub-systems (Figure 3.1): (1) production of purchased feed, including cultivation of ingredients, processing, and transportation; (2) production of energy expended at farm level (electricity and gas); (3) production of farming facilities and equipment used; (4) fish farming, including nutrients emission from biological transformation of feed after onsite treatment of wastewater; (5) offsite treatment of effluent at a municipal wastewater treatment plant. The functional unit in which environmental impacts were expressed was ton of fish produced at farm level on a basis of one year of routine production.

\section{Life cycle inventory}

(1) Production of purchased feed - Crop-derived ingredients used in fish feed originated from Brazil and France (e.g. soybean meal from Brazil and wheat bran 
from France), whereas fish-derived ingredients originated from the Peruvian and the Norwegian fish milling industry (e.g. fish meal from Peru and fish meal from fish trimming from Norway). The exact diet composition is given in appendix 3.2. Economic allocation was used to calculate the environmental impacts of processes yielding multiple products. We chose economic allocation because it has the advantage of stimulating the use of by-products from crops in feed ingredients for livestock compare to mass allocation, which put high environmental impacts to byproducts with high mass value. Economic allocation is, therefore, the most used method to deal with process yielding multiple outputs in livestock production systems (de Vries and de Boer, 2010). The transport of feed ingredients to feed manufacture in France was by transoceanic ship and by lorry $(>32 t)$, whereas the transport of feed from France to the fish farm in Eindhoven was by lorry ( $>32 t)$. Transport distances and other data required to compute the environmental impact of feed ingredients were based on the literature (Boissy et al., 2011; Pelletier et al., 2009), and presented in detail in appendices 3.2 and 3.3.

Figure 3.1: Diagram of the system studied including emission of nitrogen ( $N$ ), phosphorus $(\mathrm{P})$ and dissolved organic matter (DOM) from biological transformation of the feed by the fish.

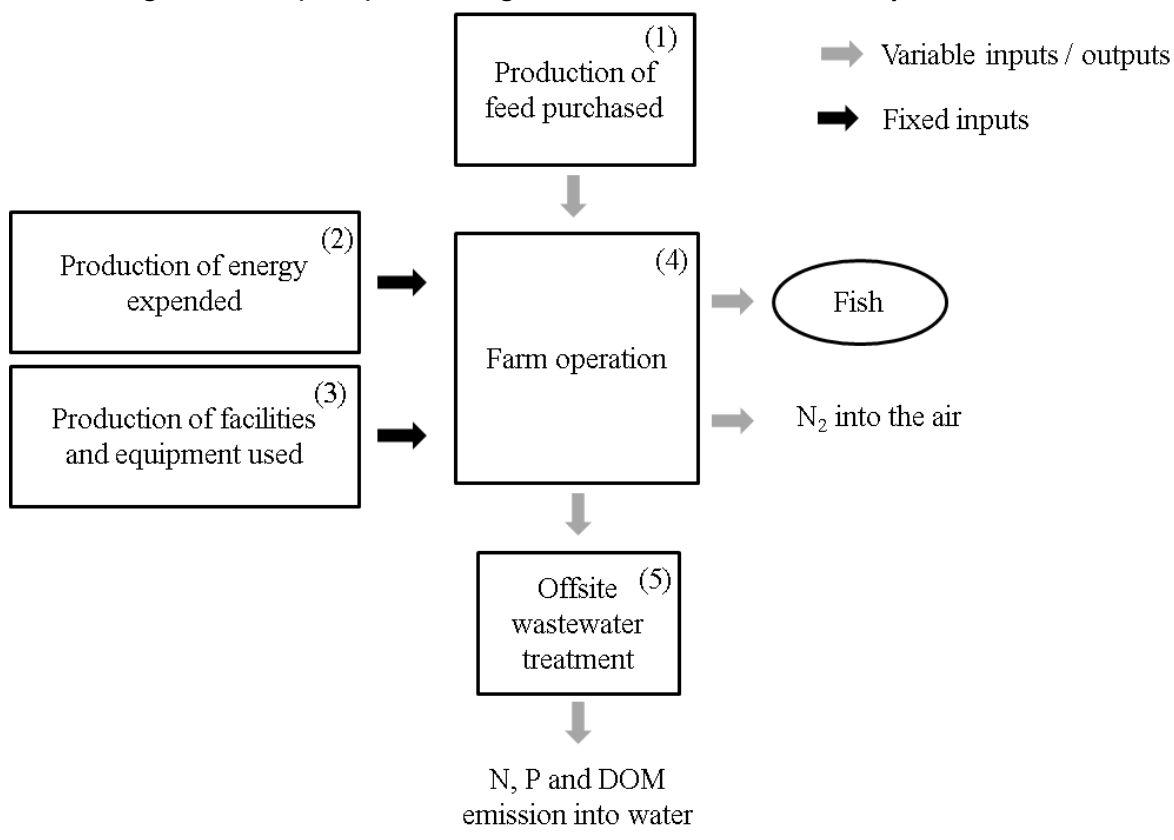

(2) Production of energy expended on farm - The energy consumed by the farm was considered fixed at $600 \mathrm{MWh}$ per year of electricity and $600 \mathrm{MWh}$ per year of 
natural gas. The electricity used by the farm was coming from the Dutch energy mix proposed by Ecoinvent v2.2 database (Swiss Centre for Life Cycle Inventories, 2010). Contribution analysis is available in appendix 3.4.

(3) Production of farming facilities and equipment used - We consider the construction of a building of $5200 \mathrm{~m}^{2}$ with a life span of 30 years. The production of equipment used (i.e. pump, tanks) was calculated using data from INRA and corresponded to $11477 \mathrm{~kg}$ of material used for a building of $5200 \mathrm{~m}^{2}$ per year. The use of building and equipment was considering fixed per year at farm level. Contribution analysis is available in appendix 3.5 .

(4) Fish farming - The farm operation sub-system includes the use of energy, facilities and equipment as well as the emission of pollutants from biological transformation of the feed distributed to the fish. The amount of nitrogen $(\mathrm{N})$, phosphorus $(\mathrm{P})$ and chemical oxygen demand (COD) of the dissolved organic matter excreted by the fish in effluent water were calculated through the bioeconomic model based on the onsite treatment capacity of the bio-filter. The effluent water was further treated in an offsite wastewater treatment plant. The sludge produced by the farm was used for agricultural purposes and was not included in the analysis.

(5) Offsite treatment of waste water - Effluent water, highly concentrated in nutrients, coming from the fish farm was disposed in a plant treating wastewater. We considered a typical treatment plant running in Europe, including three treatment stages: mechanical treatment, biological treatment, chemical treatment. It also included sludge digestion via fermentation. Life cycle inventory data of water treatment were extracted from Ecoinvent v2.2 database (Swiss Centre for Life Cycle Inventories, 2010). The final amount of nutrients emitted to the environment was calculated based on the capacity of the offsite plant to treat wastewater. Thus, $28 \%$ of the COD, $75 \%$ of the nitrogen and $52 \%$ of the phosphorus coming from the fish farm were assumed to be released into water (Swiss Centre for Life Cycle Inventories, 2010). Contribution analysis is available in appendix 3.6.

\section{Life cycle impact assessment}

Each flow observed in the system was assigned to different impact categories relatively to its potential environmental effects. The four environmental categories investigated were: eutrophication, acidification, climate change (CML2 Baseline 2000 version 2.04) (Guinée et al., 2002) and cumulative energy demand (Frischknecht et al., 2007). These four impact categories were chosen because they 
represent the main environmental impacts that aquaculture contributes to (Aubin, 2013; Henriksson et al., 2012; Pelletier et al., 2007). Eutrophication is mainly the consequence of the emissions of nitrogen $(N)$ and phosphorus $(P)$ to the air, water and soil and is expressed in $\mathrm{kg} \mathrm{PO}_{4}{ }^{3-}$ equivalents. Acidification refers to negative effects of acidifying pollutants, such as $\mathrm{SO}_{2}, \mathrm{NO}_{x}, \mathrm{HCL}$ and $\mathrm{NH}_{3}$, on the environment and is expressed in $\mathrm{kg} \mathrm{SO}_{2}$-equivalents. Climate change is the potential impact of gaseous emissions, such as $\mathrm{CO}_{2}$ and $\mathrm{CH}_{4}$ on the heat radiation absorption in the atmosphere. Climate change was calculated according to the GWP100 factors (potential effect at a 100-year time horizon) and expressed in $\mathrm{kg} \mathrm{CO}_{2}$-equivalents. Cumulative energy demand expresses the depletion of energy resources, expressed in MJ. The characterisation factors from CML2 Baseline 2000 version 2.04 were used for eutrophication, acidification and climate change. The impact categories were calculated using Simapro ${ }^{\circledR} 7.0$ software.

\subsubsection{Environmental values}

Similarly to the economic values proposed by Hazel (1943), environmental values (ENV) express the change in each environmental impact category as a result of one generation of selection for a given trait while keeping the other trait constant. We calculated ENV for two important traits representing rearing performances of a farm, the thermal growth coefficient (TGC) and the feed conversion ratio (FCR). Rearing performances in the reference scenario were 8.33 for TGC and 0.81 for FCR. Changes in environmental impacts were calculated as environmental impacts per ton of fish produced before genetic improvement minus environmental impacts per ton of fish produced after genetic improvement. Genetic parameters for TGC and FCR are not yet available for African catfish, therefore, as in Besson et al. (2014), we used genetic parameters of rainbow trout (Onchorhynchus mykiss) to estimate genetic improvement $\left(\Delta_{\mathrm{t}}\right)$ in both trait (Sae-Lim et al., 2012): $\Delta_{\mathrm{TGC}}=$

$\mu_{\mathrm{TGC}} \times 6.8 \%$ and $\Delta_{\mathrm{FCR}}=\mu_{\mathrm{FCR}} \times 7.6 \%$. We used genetic parameters of rainbow trout as a proxy because there are not yet genetic parameters for African catfish. This proxy is in the range of what has been observed or estimated in many fish species (Gjedrem et al., 2012; Gjedrem and Thodesen, 2005). The different FCR values were obtained by varying only the weight exponent of the $F C R_{w n}$ formula (Appendix 3.1). The model assumes genetic improvement of the traits over time. We calculated values at several hypothetical time points within that "transition" period. ENV each trait, which resulted in nine scenarios and nine ENV $V_{T G C}$ and ENV $F$ FR (Table 3.1). The endpoint of selection and thus transition period, is not defined. 
Table 3.1: Thermal growth coefficient (TGC) and feed conversion ratio (FCR) of the nine scenarios tested according to two generations of selection (G1 and G2) from the reference scenario (RS).

\begin{tabular}{ccccc} 
& & \multicolumn{3}{c}{ Feed conversion ratio, FCR (in kg/kg) } \\
\cline { 3 - 5 } & & RS $=0.81$ & G1 $=0.75$ & G2 $=0.69$ \\
\hline $\begin{array}{c}\text { Thermal } \\
\text { growth }\end{array}$ & $\mathrm{RS}=8.33$ & $\times$ & $\times$ & $\times$ \\
$\begin{array}{c}\text { coefficient, } \\
\text { TGC }\end{array}$ & $\mathrm{G} 1=8.9$ & $\times$ & $\times$ & $\times$ \\
\hline
\end{tabular}

\subsection{Results}

\subsubsection{Environmental impacts in the reference scenario}

In the reference scenario $(T G C=8.33$ and $F C R=0.81$ ), fish production is limited to 518 tons per year because emission of dissolved $\mathrm{NH}_{3}-\mathrm{N}$ by the fish at maximum standing stock reaches the maximum treatment capacity of the bio-filter, 40 $\mathrm{kg} /$ day. Table 3.2 shows the contribution of each different sub-systems to the four environmental impact categories in this scenario. Production of purchased feed is by far the main contributor for acidification, climate change and cumulative energy demand (respectively 57.2\%, 72.3\%, 68.5\%). The second major contributors to these impact categories are the fixed sub-systems at farm level, i.e. production of facilities and equipment used contributes to $37.6 \%$ to acidification, production of energy expended contributes to $21.5 \%$ to climate change and to $23.8 \%$ to cumulative energy demand. Conversely, the two main contributors to eutrophication are farm operation (68.5\%) and production of feed purchased (38.9\%).

\subsubsection{Effects of genetic improvement in TGC and FCR}

In our previous study (Besson et al., 2014), we showed that the economic response to genetic improvement in TGC and FCR is different depending on whether the limiting factor is dissolved $\mathrm{NH}_{3}-\mathrm{N}$ or rearing density. Depending on the limiting factor, genetic improvement will impact production (i.e. annual fish production) and production efficiency (i.e. ton of fish produced per ton of feed consumed) differently (Table 3.3). 
Table 3.2: Percentage of contribution of the different sub-systems to the four impact categories in the reference scenario where TGC $=\mathbf{8 . 3 3}$ and $\mathrm{FCR}=\mathbf{0 . 8 1}$.

\begin{tabular}{lcccc}
\hline & $\begin{array}{c}\text { Acidification, } \\
\mathrm{kg} \mathrm{SO} \text {-eq }\end{array}$ & $\begin{array}{c}\text { Eutrophication, } \\
\mathrm{kg} \mathrm{PO}_{4} \text {-eq }\end{array}$ & $\begin{array}{c}\text { Climate } \\
\text { change, } \mathrm{kg} \\
\mathrm{CO}_{2} \text {-eq }\end{array}$ & $\begin{array}{c}\text { Cumulative } \\
\text { energy } \\
\text { demand, } \mathrm{MJ}\end{array}$ \\
\hline $\begin{array}{l}\text { Production of feed } \\
\text { purchased }\end{array}$ & $57.3 \%$ & $38.9 \%$ & $72.3 \%$ & $68.5 \%$ \\
$\begin{array}{l}\text { Production of energy } \\
\text { expended on farm }\end{array}$ & $4.7 \%$ & $3.6 \%$ & $21.5 \%$ & $23.8 \%$ \\
$\begin{array}{l}\text { Production of facilities } \\
\text { and equipment used }\end{array}$ & $37.7 \%$ & $0.5 \%$ & $5.4 \%$ & $7 \%$ \\
$\begin{array}{l}\text { Farm operation } \\
\begin{array}{l}\text { Offsite waste water } \\
\text { treatment }\end{array}\end{array}$ & $0.3 \%$ & $56.8 \%$ & $0 \%$ & $0 \%$ \\
\hline $\begin{array}{l}\text { Total \% } \\
\text { Total quantity }\end{array}$ & $100 \%$ & $0.2 \%$ & $0.8 \%$ & $0.7 \%$ \\
\hline
\end{tabular}

Table 3.3: Summary of the impact of genetic improvement in TGC and FCR on technical performance of a recirculating aquaculture system (Besson et al., 2014).

\begin{tabular}{lcc}
\hline Limiting factor & Improved TGC & Improved FCR \\
\hline Dissolved $\mathrm{NH}_{3}-\mathrm{N}$ & No effect & $\begin{array}{c}\text { Higher production } \\
\text { Higher production efficiency }\end{array}$ \\
$\begin{array}{l}\text { Density at } \\
\text { harvest }\end{array}$ & Higher production & Higher production efficiency \\
\hline
\end{tabular}

Increasing production, while keeping the same production efficiency, dilutes environmental impacts that are fixed at farm level, such as production of facilities and equipment used, over more fish produced. Increasing production efficiency, while keeping the same production, decreases the amount of feed required to produce one ton of fish and decreases the amount of nutrients emitted per ton of fish, which decreases environmental impacts. Consequently, the environmental response to genetic improvement in FCR and TGC after 2 generations of selection is different depending on whether the limiting factor is dissolved $\mathrm{NH}_{3}-\mathrm{N}$ or rearing density (Figure 3.2). 
Figure 3.2: Environmental impacts calculated per ton of fish for four impact categories as a function of improving FCR at a given value for TGC. In graph (a), the arrows illustrate the point where the limiting factor switches from dissolved $\mathrm{NH}_{3}-\mathrm{N}(\mathrm{N})$ to rearing density (D).
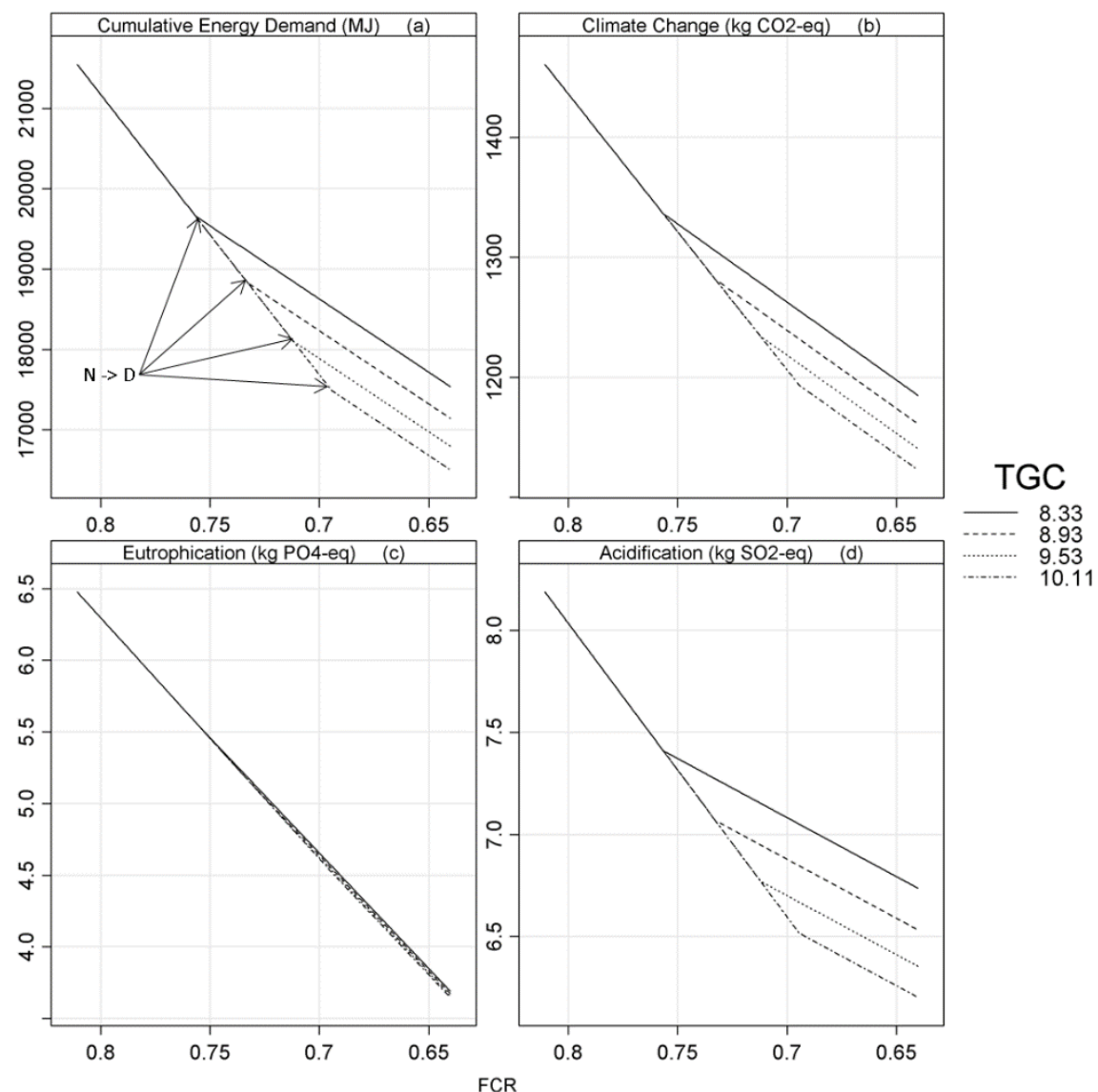

3.3.3. Dissolved $\mathrm{NH}_{3}-\mathrm{N}$ as limiting factor

Faster growing fish have higher daily feed intake (at constant FCR), which increases dissolved $\mathrm{NH}_{3}-\mathrm{N}$ excreted per fish per day. When dissolved $\mathrm{NH}_{3}-\mathrm{N}$ is the limiting factor, fewer fish should be stocked per batch to respect the limitations on dissolved $\mathrm{NH}_{3}-\mathrm{N}$ defined by the treatment capacity of the bio-filter. This decreasing number of fish is offset by the possibility to rear more batches. Consequently, improving TGC (without changing FCR) when dissolved $\mathrm{NH}_{3}-\mathrm{N}$ is the limiting factor does not improve production nor production efficiency (Table 3.3) and environmental impacts remain constant (superimposed lines on Figure. 3.2). 
On the other hand, improving FCR (at constant TGC) results not only in lower total feed distributed per fish but also in lower dissolved $\mathrm{NH}_{3}-\mathrm{N}$ excreted per day. With lower excretion, the number of fish stocked per batch can be increased until the limitation on dissolved $\mathrm{NH}_{3}-\mathrm{N}$ is reach again. Consequently, improving $\mathrm{FCR}$ when dissolved $\mathrm{NH}_{3}-\mathrm{N}$ is the limiting factor improves production efficiency and production (Table 3.3), which decreases environmental impacts per ton of fish produced (Figure 3.2).

\subsubsection{Rearing density as limiting factor}

When rearing density is the limiting factor and the dissolved $\mathrm{NH}_{3}-\mathrm{N}$ excretion is below the limit set by the bio-filter, the number of fish harvested per batch is constant. Improving FCR (at constant TGC) decreases the total amount of feed distributed per fish. With fixed densities, improving FCR increases production efficiency (Table 3.3), which decreases environmental impacts per ton of fish produced (Figure 3.2).

Improving TGC (at constant FCR) increases the number of batches reared during a year. Consequently, improving TGC when rearing density is the limiting factor improves production (Table 3.3), which decreases environmental impacts per ton of fish produced (Figure 3.2). The environmental response to genetic improvement in TGC, however, differs among impact categories. Improving TGC in this situation decreases acidification, climate change, cumulative energy demand quite significantly and eutrophication only to a very limited extent. The difference can be explained by the main sub-systems contributing to the impact categories.

Eutrophication is dependent on the production of feed purchased and on farm operation due to the emission of $\mathrm{NH}_{3}-\mathrm{N}$ directly into the water (Table 3.2). When rearing density is the limiting factor, increasing TGC increases production, which increases not only the annual consumption of feed but also the emission of $\mathrm{NH}_{3}-\mathrm{N}$. Consequently, improving TGC has little impact on eutrophication because the dilution of fixed environmental impacts over more fish produced is almost compensated by the increase in the annual emission of nitrogen and the increase in annual purchased of feed.

In most livestock system, $\mathrm{NH}_{3}-\mathrm{N}$ is released into the air and contributes to acidification. In fish farming, however, $\mathrm{NH}_{3}-\mathrm{N}$ is released into the water and does not participate to acidification. Consequently, the sub-systems contributing to acidification are the production of feed purchased and the production of facilities and equipment used (Table 3.2). Thus, when rearing density is the limiting factor, 
improving TGC increases production, which dilutes fixed environmental effects of the production of facilities and equipment used, over more fish produced.

Climate change and cumulative energy demand are both influenced by the production of feed purchased and by the production of energy expended (Table 3.2). When rearing density is the limiting factor, improving TGC increases production, which dilutes fixed environmental impacts of the production of energy expended over more fish produced.

\subsubsection{Environmental values (ENV)}

\section{Effects of changes in TGC (Table 3.4)}

When dissolved $\mathrm{NH}_{3}-\mathrm{N}$ is the limiting factor, $\mathrm{ENV}_{\mathrm{TGC}}$ are null as TGC does not alter environmental impacts. When rearing density is the limiting factor, ENV $T$ TGC are positive because increasing TGC increases production, which in turn dilutes fixed costs and environmental impacts at farm level. ENV $\mathrm{EGC}_{\mathrm{T}}$ for eutrophication is, however, close to zero because, as mentioned earlier, improvement in TGC increases not only production but also feed consumption and nutrients emission.

\section{Effects of changes in FCR (Table 3.5)}

When dissolved $\mathrm{NH}_{3}-\mathrm{N}$ is the limiting factor, $\mathrm{ENV}_{\mathrm{FCR}}$ are positive because improving FCR increases both production and production efficiency. When rearing density is the limiting factor, ENV FCR of acidification, climate change and cumulative energy demand are also positive but to a lower extent because improved FCR increases production efficiency only. 


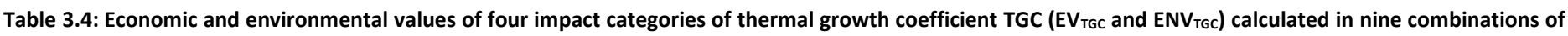
TGC and feed conversion ratio FCR. For each case, the limiting factor before genetic improvement and after genetic improvement is specified, $\mathrm{D}=$ rearing density and $\mathrm{N}=\mathrm{NH}_{3}-\mathrm{N}$.

\begin{tabular}{|c|c|c|c|c|c|c|c|}
\hline \multirow[b]{2}{*}{ TGC } & \multirow[b]{2}{*}{ FCR } & \multirow{2}{*}{$\begin{array}{l}\text { Limiting } \\
\text { factors }\end{array}$} & \multicolumn{4}{|c|}{$\mathrm{ENV}_{\mathrm{TGC}}(\% / \mathrm{t}$ of fish) } & \multirow[b]{2}{*}{$\begin{array}{c}E V_{\mathrm{TGC}} \\
(€ / \mathrm{kg} \text { of fish) }\end{array}$} \\
\hline & & & $\begin{array}{l}\text { Acidification } \\
\left.\text { (kg SO}{ }_{2}-\mathrm{eq}\right)\end{array}$ & $\begin{array}{c}\text { Eutrophication } \\
\text { (kg } \mathrm{PO}_{4} \text {-eq) }\end{array}$ & $\begin{array}{c}\text { Climate change } \\
\left(\mathrm{kg} \mathrm{CO} \mathrm{CO}_{2}-\mathrm{eq}\right)\end{array}$ & $\begin{array}{c}\text { Cumulative energy } \\
\text { demand (MJ) }\end{array}$ & \\
\hline 8.33 & 0.81 & $\mathrm{~N} \rightarrow \mathrm{N}$ & 0 & 0 & 0 & 0 & 0 \\
\hline 8.33 & 0.75 & $\mathrm{D} \rightarrow \mathrm{N}$ & 0.8 & 0.1 & 0.5 & 0.6 & 0.01 \\
\hline 8.33 & 0.69 & $D \rightarrow D$ & 2.9 & 0.4 & 1.9 & 2.0 & 0.03 \\
\hline 8.9 & 0.81 & $\mathrm{~N} \rightarrow \mathrm{N}$ & 0 & 0 & 0 & 0 & 0 \\
\hline 8.9 & 0.75 & $\mathrm{~N} \rightarrow \mathrm{N}$ & 0 & 0 & 0 & 0 & 0 \\
\hline 8.9 & 0.69 & $D \rightarrow D$ & 2.6 & 0.3 & 1.7 & 1.8 & 0.03 \\
\hline 9.5 & 0.81 & $\mathrm{~N} \rightarrow \mathrm{N}$ & 0 & 0 & 0 & 0 & 0 \\
\hline 9.5 & 0.75 & $\mathrm{~N} \rightarrow \mathrm{N}$ & 0 & 0 & 0 & 0 & 0 \\
\hline 9.5 & 0.69 & $D->D$ & 2.3 & 0.3 & 1.5 & 1.6 & 0.03 \\
\hline
\end{tabular}


Table 3.5: Economic and environmental values of four impact categories of feed conversion ratio FCR (EV FCR $_{\text {and }}$ ENV $_{\mathrm{FCR}}$ ) calculated in nine combinations of thermal growth coefficient TGC and FCR. For each case, the limiting factor before genetic improvement and after genetic improvement is specified, $D=$ rearing density and $\mathrm{N}=\mathrm{NH}_{3}-\mathrm{N}$.

\begin{tabular}{|c|c|c|c|c|c|c|c|}
\hline \multirow[b]{2}{*}{ TGC } & \multirow[b]{2}{*}{ FCR } & \multirow{2}{*}{$\begin{array}{l}\text { Limiting } \\
\text { factors }\end{array}$} & \multicolumn{4}{|c|}{$\mathrm{ENV}_{\mathrm{FCR}}(\% / \mathrm{t}$ of fish) } & \multirow{2}{*}{$\begin{array}{c}\mathrm{EV}_{\mathrm{FCR}} \\
(€ / \mathrm{kg} \text { of fish) }\end{array}$} \\
\hline & & & $\begin{array}{c}\text { Acidification } \\
\left(\mathrm{kg} \mathrm{SO}_{2}-\mathrm{eq}\right)\end{array}$ & $\begin{array}{c}\text { Eutrophication } \\
\left(\mathrm{kg} \mathrm{PO}_{4}-\mathrm{eq}\right)\end{array}$ & $\begin{array}{c}\text { Climate change } \\
\left(\mathrm{kg} \mathrm{CO} \mathrm{CO}_{2}-\mathrm{eq}\right)\end{array}$ & $\begin{array}{c}\text { Cumulative energy } \\
\text { demand (MJ) }\end{array}$ & \\
\hline 8.33 & 0.81 & $\mathrm{~N} \rightarrow \mathrm{D}$ & 10 & 15.9 & 9.2 & 9.3 & 0.13 \\
\hline 8.33 & 0.75 & $D-D$ & 4.5 & 16.8 & 5.6 & 5.4 & 0.06 \\
\hline 8.33 & 0.69 & $D \rightarrow D$ & 4.3 & 18.6 & 5.4 & 5.3 & 0.06 \\
\hline 8.9 & 0.81 & $\mathrm{~N} \rightarrow \mathrm{N}$ & 10.8 & 15.9 & 9.7 & 9.8 & 0.14 \\
\hline 8.9 & 0.75 & $\mathrm{~N} \rightarrow \mathrm{D}$ & 6.4 & 17.0 & 6.9 & 6.8 & 0.08 \\
\hline 8.9 & 0.69 & $D \rightarrow D$ & 4.4 & 18.7 & 5.5 & 5.4 & 0.06 \\
\hline 9.5 & 0.81 & $\mathrm{~N} \rightarrow \mathrm{N}$ & 10.8 & 15.9 & 9.7 & 9.8 & 0.14 \\
\hline 9.5 & 0.75 & $N \rightarrow D$ & 8.9 & 17.3 & 8.4 & 8.5 & 0.12 \\
\hline 9.5 & 0.69 & $D \rightarrow D$ & 4.6 & 18.8 & 5.6 & 5.5 & 0.06 \\
\hline
\end{tabular}




\subsection{Discussion}

We combined bioeconomic modelling and life cycle assessment to assess the environmental consequences of genetic improvement in thermal growth coefficient (TGC) and in feed conversion ratio (FCR), in a recirculating aquaculture system (RAS). This combined approach allows to calculate environmental values (ENV) of selected traits, which express the changes in environmental impacts due to genetic improvement of a trait. A cradle-to-farm-gate LCA was carried to avoid over estimation of ENV of traits decreasing environmental impacts at farm level, but increasing environmental impacts at chain level (van Middelaar et al., 2014). The results showed that the ENV of FCR and TGC depend on the limiting factor, density or dissolved $\mathrm{NH}_{3}-\mathrm{N}$.

In case dissolved $\mathrm{NH}_{3}-\mathrm{N}$ was the limiting factor, improving TGC did not increase production or production efficiency. In case density was the limiting factor, however, improving TGC increased production, which diluted fixed environmental impacts over more fish produced. Consequently, the environmental impacts per ton of fish produced decreased. The magnitude of the environmental value of TGC is, therefore, dependent on the relative importance of fixed environmental impacts. An energy mix with a greater contribution of fossil energy, for example, would increase the relative importance of fixed environmental impacts of the farm, which would lower the reduction of environmental impacts per ton of fish produced observed when production increases. The direction of the change, however, would stay the same, and increasing production would always decrease the environmental impacts per ton of fish produced. The dilution of fixed environmental impacts per unit of fish produced reflects how efficient capital goods, such as energy input, are used. The relevance of the capital goods inclusion, therefore, is closely correlated to the target question of the study and to the type of system. In RAS, the weight of capital good is high relatively to total plant production capacity. In RAS, therefore, the environmental costs of capital goods are not sufficiently diluted by the production level to be neglected.

The results obtained could be analysed also through a geographic perspective, by splitting global and local environmental impacts. For instance, the emission of greenhouse gases contributing to climate change is a global issue. In RAS, climate change is mainly caused by capital goods thus, climate change can be diluted with higher production. Conversely, the emission of nutrients participating to eutrophication has an impact at local scale on the neighbourhood of the emission source. The emission of nutrients from the biological transformation of the feed is variable and increases with higher production. Therefore, when density is the 
limiting factor, improving TGC increases production and dilutes climate change at global scale but it does not affect eutrophication at local scale. The environmental values can be used also to assess the impact of genetic change at global or local scale.

FCR, however, always decreased environmental impacts, because improving FCR improved production efficiency, in case density was the limiting factor, and production efficiency plus production, in case dissolved $\mathrm{NH}_{3}-\mathrm{N}$ was the limiting factor. Compared to TGC, therefore, an improvement of FCR does not only dilute fixed environmental impacts, but also reduces the use variable inputs such as feed per unit of fish produced. Consequently, improving FCR would also have a positive effect on environmental impacts. d'Orbcastel et al. (2009) investigated the impact of a RAS producing rainbow trout with different value of FCR, 1.1 and 0.8 . This range would correspond to $27.3 \%$ of improvement, or 3.6 generations of selection in case percentage of improvement in FCR is $7.6 \%$ per generation, as in this study. Scaling their results to our genetic response shows that decreasing FCR by $7.6 \%$ decreased acidification by $5.8 \%$, eutrophication by $4.3 \%$, climate change by $6 \%$ and cumulative energy demand by $2.4 \%$. The environmental values calculated from d'Orbcastel et al. (2009), therefore, are similar to the ENV $V_{F C R}$ calculated in our study for acidification, climate change and cumulative energy demand, in case rearing density is the limiting factor, These similar results are the consequence of better production efficiency observed in d'Orbcastel et al. (2009) study and in our study, in case rearing density is the limiting factor. The response in eutrophication, however, is higher (18.6\%) in our study than in d'Orbcastel et al. (2009), because our bioeconomic model includes a mass-balance approach to evaluate nitrogen emission of the fish. In case density at harvest is the limiting factor, improving FCR not only decreases feed consumption but also decreases nitrogen emission, which plays an important role in eutrophication.

Using dynamic modelling of the relationship between genetic improvement and farm management (i.e. number of fish stocked per batch), the results shows that improving FCR can lead to switch limiting factors. Then, when dissolved $\mathrm{NH}_{3}-\mathrm{N}$ becomes the new limiting factor improving FCR increases also production. In our study, changes in ENV represent not only the direct change in environmental impacts, due to a change in a trait, but also the indirect change due to changes in number of fish and changes in farm management (van Middelaar et al., 2014). It is, therefore, difficult to fully use the results from d'Orbcastel et al. (2009) as a comparison basis for our results, because we considered all changes that could occur in farm management when genetic improvement occurs. 
Genetic improvement is also a tool used for economic development in fish farming. In Besson et al. (2014), we calculated economic values FCR and TGC using the bioeconomic model. It is, therefore, possible to compare those economic values and environmental values from our simulations (Tables 3.4 and 3.5). The comparison underlines interesting synergies between economic and environmental values. Both values depend on the nature of the limiting factor, whether rearing density or dissolved $\mathrm{NH}_{3}-\mathrm{N}$. When $\mathrm{NH}_{3}-\mathrm{N}$ is the limiting factor, only genetic improvement in FCR increases profit $\left(\mathrm{EV}_{\mathrm{FCR}}=0.13 € / \mathrm{kg}\right.$ of fish and $\mathrm{EV}_{\mathrm{TGC}}=0 € / \mathrm{kg}$ of fish) and decreases environmental impacts because it increases both production and production efficiency. On the contrary, when rearing density is the limiting factor both genetic improvement in TGC and FCR increase profit $\left(\mathrm{EV}_{\mathrm{FCR}}=0.06 € / \mathrm{kg}\right.$ of fish and $E_{\mathrm{TGC}}=0.03 € / \mathrm{kg}$ of fish) and decrease environmental impacts because improving FCR increases production efficiency and improving TGC increases production. Such synergies between economic and environmental values have been observed also in dairy cow by van Middelaar et al. (2014), who found that a genetic improvement of milk yield and longevity increased economic return and decreased greenhouse gases emissions per unit of fat-and-protein-corrected milk. It is established that the quality and quantity of protein in the feed can have an impact on FCR of fish (Albrektsen et al., 2006). In the present study we assumed, therefore, a fixed diet and we assumed that improvement in FCR was exclusively due to genetic improvement. Our results confirm that FCR would be the major trait to include in the breeding goals for increasing economic profit and decreasing environmental impacts in RAS. This can be explained by the importance of the feed in farm costs but also in environmental impacts. As a result, any improvement in FCR will at the same time increase farm incomes and decrease environmental impacts.

In fish breeding FCR is a difficult trait to improve as it is difficult to measure individual feed intake. FCR is expected to be correlated to TGC, however, studies diverge on this subject. In rainbow trout, Kause et al. (2006) predicted that selection only for daily gain, increases daily gain by $17.6 \%$ per generation and simultaneously increases feed efficiency (1/FCR) by $8.4 \%$. In parallel, some other studies in salmonids did not observe any correlation between growth rate and feed efficiency and showed that genetic gain in growth is due to higher feed intake, while feed efficiency remains unchanged (Mambrini et al., 2004; Sanchez et al., 2001).

As a result, fish breeders developed breeding programs aiming mainly to improve growth rate, easier to measure, assuming a positive correlation with feed conversion ratio. Our results (Besson et al. 2014) and the present study show, 
however, that improvement in TGC may result in an increase in economic profit and a decrease in environmental impacts only in specific conditions (when rearing density is the limiting factor). It means that without genetic correlation between growth rate and feed conversion ratio, such breeding programs aiming only at increasing growth rate when $\mathrm{NH}_{3}-\mathrm{N}$ is the limiting factor would not be economically and environmentally beneficial.

These findings can be extended to other livestock systems where animal manure is responsible for high environmental impacts. In the UK, farmers located in Nitrate Vulnerable Zones (NVZs), are restricted in the amount of nitrogen from livestock manure they can apply on their farm (Department for Environment Food \& Rural Affairs, 2013). With such limitation, faster growing animals (with the same feed efficiency) will have a similar impact as faster growing fish in RAS when dissolved $\mathrm{NH}_{3}-\mathrm{N}$ is the limiting factor. Faster growing animals would increase production rate but farmers would have to keep fewer animals, which will keep the environmental impacts constant.

The results of the study confirm the importance of precisely defining the rearing system and its production limiting factors to be able to design effective breeding programs in terms of environmental or economic consideration. Environmentally effective breeding program could be developed by using environmental values, which would put more emphasis on the most relevant traits in a specific limiting factor situation. Furthermore, the synergy between economic and environmental values is a conductive factor for the development of economically and environmentally efficient breeding program.

\subsection{Conclusion}

The framework applied in this study is a first step towards the future development of selective breeding programs in fish farming considering environmental objectives. We showed that there are opportunities of developing breeding objectives aiming at reducing environmental impacts while at the same time maintaining economic objectives. In other words, economic profit and environmental impacts are not antagonists. In recirculating aquaculture system, thermal growth coefficient (TGC) and feed conversion ratio (FCR) were identified as two production traits that can contribute to improve both economic and environmental performances. In particular, improvement in FCR always improves environmental impacts and increases economic incomes in the range of scenarios tested. On the other hand, selecting for increased TGC is only relevant in specific situations. This result emphasizes the need for further studies aiming at better 
characterising the genetic bases of feed efficiency, especially any possible genetic correlation with growth trait, to implement efficient selective breeding program for improving feed efficiency. The results obtained in this study are, however, characteristic to a RAS and this framework needs to be tested on other systems where economic and environmental responses to selection might be different. For instance, in sea cages system, waste water is directly released into the environment and fish production relies on environmental conditions such as water temperature and oxygen availability. Such differences could lead to different economic and environmental values of growth rate and feed conversion ratio in different systems.

\section{Acknowledgement}

M. Besson benefited from a joint grant from the European Commission and IMARES, within the framework of the Erasmus-Mundus joint doctorate "EGS-ABG". 


\section{Appendices}

Appendix 3.1: Calculations and parameters involved in the bioeconomic model (Besson et al., 2014).

Parameters Formulas

Fish model

Thermal growth coefficient (TGC)

$1-b=$ weight exponent $=0.475$

$T$ (temperature) $=27^{\circ} \mathrm{C}$

$W_{H}$ (harvest weight) $=13 \mathrm{~g}$

$W_{1}($ initial weight $)=1300 \mathrm{~g}$

$\mathrm{TGC}=\frac{\mathrm{W}_{\mathrm{H}}^{1-\mathrm{b}}-\mathrm{W}_{\mathrm{I}}^{1-\mathrm{b}}}{\sum_{\mathrm{i}=1}^{\mathrm{n}} \mathrm{T}}$

$n$ is the length of growing period until

harvest weight

Fish weight $\left(W_{n}\right)$ in $k g$

$$
\mathrm{W}_{n}=\left[\mathrm{W}_{\mathrm{I}}^{0.475}+\left(\mathrm{TGC} \times \sum_{\mathrm{i}=1}^{\mathrm{n}} \mathrm{T}\right)\right]^{1 / 0.475}
$$

Daily weight gain $\left(D W G_{n}\right)$ in $\mathrm{g}$

$$
\mathrm{DWG}_{\mathrm{n}}=\mathrm{W}_{\mathrm{n}}-\mathrm{W}_{\mathrm{n}-1}
$$

Feed conversion ratio $\left(\mathrm{FCR}_{\mathrm{Wn}_{\mathrm{n}}}\right)$ in $\mathrm{g} / \mathrm{g}$

$\mathrm{FCR}_{W n}=0.37 \times \mathrm{W}_{\mathrm{n}}^{0.112}$

Daily feed intake $\left(\mathrm{DFI}_{\mathrm{n}}\right)$ in $\mathrm{g}$

$\mathrm{DFI}_{\mathrm{n}}=\mathrm{DWG}_{\mathrm{n}} \times \mathrm{FCR}_{\mathrm{Wn}}$

\section{Fish waste emission}

Daily dissolved N (N_dissolved ) $_{\mathbf{n}}$ in $\mathrm{g}$

$\mathrm{N}_{\text {_dissolved }}=\mathrm{DWG}_{\mathrm{n}}\left(\left(65.988 \times \mathrm{FCR}_{\mathrm{Wn}}\right)\right.$ $-25)$

Daily emission of $\mathbf{N}$ in effluent water $\mathrm{N}_{-}$eff ${ }_{\mathrm{n}}=0.6732 \times \mathrm{FCR}_{\mathrm{Wn}} \times \mathrm{DWG}_{\mathrm{n}}$

(N_eff $\mathbf{n}$ ) in $\mathrm{g}$

Daily COD of effluent water

COD_eff $\mathrm{n}_{\mathrm{n}}=$ (protein $\times 0.11$

(COD_eff $)$

+ crude_fat $\times 0.24$

protein $=\%$ of protein in the feed

+ carbs $\times 0.33) \times \mathrm{DFI}_{\mathrm{n}}$

crude fat $=\%$ crude fat in the feed

carbs $=\%$ of carbohydrates in the feed

Daily emission of $\mathbf{P}$ in effluent water (P_eff ${ }_{n}$ )

Batch model

Number of fish of $13 \mathrm{~g}$ stocked per batch (Nb_fish 13 $_{13}$ )

Maximum $\mathrm{NH}_{3}-\mathrm{N}$ load $=40 \mathrm{~kg} / \mathrm{day}$

$\mathrm{Nb} f i s h_{13} \frac{\text { maximum NH3_N load }}{\sum_{\mathrm{i}=1}^{\mathrm{j}}\left(\mathrm{N}_{\text {dissolved }_{\text {MSS }(\mathrm{j})}}\right) \times\left(1-\mathrm{M}_{\mathrm{Wn}(\mathrm{j})}\right)}$

$j=1$ to 14 (number of batch reared

simultaneously)

Cumulative mortality $\left(\mathbf{M}_{\mathrm{Wn}_{n}}\right)$ in \%

$\mathrm{M}_{\mathrm{Wn}}=0.001 \times \mathrm{W}_{\mathrm{n}}+0113$

Farm model

Growth period in days

P_eff $_{\mathrm{n}}=00876 \mathrm{DFI}_{\mathrm{n}}-004 \mathrm{DWG}_{\mathrm{n}}$

Number of batch per year

$$
\mathrm{Nb}_{\text {days }}=\frac{\left(W_{H}^{0.475}-W_{I}^{0.475}\right) \times \mathrm{T}}{\mathrm{TGC}}=\frac{597.30}{\mathrm{TGC}}
$$

Nb_batch $=\frac{365 \times 14}{\text { Nb_days }}=\frac{5510}{\text { Nb_days }}$

$$
=9.22 \times \mathrm{TGC}
$$

Economic FCR

FCR $=\frac{\text { feed distributed per year }}{\text { fish production per year }}$ 
Appendix 3.2: Chemical composition and components of the feed of the catfish feed (Besson et al., 2014).

\begin{tabular}{ll}
\hline Chemical composition & $\%$ \\
\hline Protein & 45 \\
Crude fat & 12.5 \\
Crude ash & 9 \\
Other Carbohydrates & 22.5 \\
Phosphorus & 1.1 \\
\hline Components & $\%$ \\
\hline Fish meal, Peru & 43 \\
Fish oil, Peru & 3.4 \\
Fish meal from fish trimmings, Norway & 10.7 \\
Fish oil from fish trimmings, Norway & 0.8 \\
Soybean meal, Brazil & 9 \\
Wheat starch, France & 23.4 \\
Wheat bran, France & 8.8 \\
\hline
\end{tabular}


Appendix 3.3: Contribution analysis of $1 \mathrm{t}$ of standard African catfish feed.

\begin{tabular}{|c|c|c|c|c|}
\hline Ingredients & $\begin{array}{l}\text { Acidification, } \\
\text { kg SO}{ }_{2}-\mathrm{eq}\end{array}$ & $\begin{array}{l}\text { Eutrophication, } \\
\qquad \mathrm{kg} \mathrm{PO}_{4} \text {-eq }\end{array}$ & $\begin{array}{l}\text { Climate } \\
\text { change, } \\
\text { kg CO} 2-e q\end{array}$ & $\begin{array}{c}\text { Cumulative } \\
\text { energy } \\
\text { demand, MJ }\end{array}$ \\
\hline Fish meal & $32.6 \%$ & $24.1 \%$ & $44.2 \%$ & $41 \%$ \\
\hline Fish oil & $2 \%$ & $1.5 \%$ & $2.7 \%$ & $2.5 \%$ \\
\hline $\begin{array}{l}\text { Fish meal from } \\
\text { fish trimmings }\end{array}$ & $4.9 \%$ & $5.9 \%$ & $9.8 \%$ & $11.7 \%$ \\
\hline $\begin{array}{l}\text { Fish oil from fish } \\
\text { trimmings }\end{array}$ & $0.3 \%$ & $0.3 \%$ & $0.6 \%$ & $0.7 \%$ \\
\hline Soybean meal & $5.6 \%$ & $16.4 \%$ & $9 \%$ & $3.9 \%$ \\
\hline Wheat starch & $20.7 \%$ & $38 \%$ & $17 \%$ & $18.9 \%$ \\
\hline Wheat bran & $0.8 \%$ & $5.7 \%$ & $1.2 \%$ & $0.9 \%$ \\
\hline \multicolumn{5}{|l|}{ Other } \\
\hline $\begin{array}{l}\text { Feed processing, } \\
\text { packaging and } \\
\text { transportation }\end{array}$ & $33 \%$ & $8 \%$ & $15.5 \%$ & $20.4 \%$ \\
\hline Total \% & $100 \%$ & $100 \%$ & $100 \%$ & $100 \%$ \\
\hline Total quantity & 5.8 & 3.1 & 1300.2 & 18205.7 \\
\hline
\end{tabular}

Appendix 3.4: Contribution analysis of energy carriers to acidification, eutrophication, climate change and cumulative energy demand, calculated for $1000 \mathrm{kWh}$ of energy expended.

\begin{tabular}{lcccc}
\hline & $\begin{array}{c}\text { Acidification, } \\
\mathrm{kg} \mathrm{SO} \text {-eq }\end{array}$ & $\begin{array}{c}\text { Eutrophication, } \\
\mathrm{kg} \mathrm{PO}_{4} \text {-eq }\end{array}$ & $\begin{array}{c}\text { Climate } \\
\text { change, } \\
\mathrm{kg} \mathrm{CO} \text {-eq }\end{array}$ & $\begin{array}{c}\text { Cumulative } \\
\text { energy } \\
\text { demand, MJ }\end{array}$ \\
\hline $\begin{array}{l}\text { Electricity mix } \\
\text { production }\end{array}$ & $79.8 \%$ & $93 \%$ & $71.4 \%$ & $70.2 \%$ \\
$\begin{array}{l}\text { Natural gas } \\
\text { production }\end{array}$ & $20.2 \%$ & $7 \%$ & $28.6 \%$ & $29.8 \%$ \\
\hline $\begin{array}{l}\text { Total \% } \\
\text { Total quantity }\end{array}$ & $100 \%$ & $100 \%$ & $100 \%$ & $100 \%$ \\
\hline
\end{tabular}


Appendix 3.5: Environmental impacts of the construction of $1000 \mathrm{~m} 2 \mathrm{y}$ of facilities, of the production 1 $t$ of material, and of the treatment of $1 \mathrm{~m} 3$ of waste water at wastewater treatment plant.

\begin{tabular}{lcccc}
\hline & $\begin{array}{c}\text { Acidification, } \\
\mathrm{kg} \mathrm{SO}_{2} \text {-eq }\end{array}$ & $\begin{array}{c}\text { Eutrophication, } \\
\mathrm{kg} \mathrm{PO}_{4} \text {-eq }\end{array}$ & $\begin{array}{c}\text { Climate } \\
\text { change, } \\
\mathrm{kg} \mathrm{CO}_{2} \text {-eq }\end{array}$ & $\begin{array}{c}\text { Cumulative } \\
\text { energy } \\
\text { demand, } \mathrm{MJ}\end{array}$ \\
\hline $\begin{array}{l}\text { Construction of } \\
1000 \mathrm{~m}^{2} \mathrm{y} \text { of } \\
\text { facilities }\end{array}$ & 83.4 & 1.0 & 2197.8 & 43500.7 \\
$\begin{array}{l}\text { Production of } 1 \\
\text { ton of } \\
\text { equipment }\end{array}$ & 101.5 & 1.2 & 2605.1 & 48237.4 \\
$\begin{array}{l}\text { Treatment of } 1 \\
\mathrm{~m}^{3} \text { of waste }\end{array}$ & & & & \\
water & 1.1 & & & \\
\hline
\end{tabular}

Appendix 3.6: Environmental impacts of the emission to water of one ton of nitrogen (N), phosphorus (P) and chemical oxygen demand (COD).

\begin{tabular}{lcccc}
\hline & $\begin{array}{c}\text { Acidification, } \\
\text { kg SO2-eq }\end{array}$ & $\begin{array}{c}\text { Eutrophication, } \\
\text { kg PO4-eq }\end{array}$ & $\begin{array}{c}\text { Climate } \\
\text { change, } \\
\text { kg CO2-eq }\end{array}$ & $\begin{array}{c}\text { Cumulative } \\
\text { energy } \\
\text { demand, MJ }\end{array}$ \\
\hline 1 ton of N & 0 & 0.42 & 0 & 0 \\
1 ton of $P$ & 0 & 3.06 & 0 & 0 \\
1 ton of COD & 0 & 02 & 0 & 0 \\
\hline
\end{tabular}





\title{
4
}

\section{Influence of water temperature on the economic value of growth rate in fish farming: the case of sea bass (Dicentrarchus labrax) cage farming in the Mediterranean}

\author{
M. Besson ${ }^{1,2}$, M. Vandeputte ${ }^{2,3}$, J.A.M. van Arendonk ${ }^{1}$, J. Aubin ${ }^{4}$, \\ I.J.M. de Boer ${ }^{5}$,E. Quillet ${ }^{2}$, H. Komen ${ }^{1}$
}

\begin{abstract}
${ }^{1}$ Animal Breeding and Genomics Centre, Wageningen University, PO Box 338, 6700 AH Wageningen, the Netherlands

${ }^{2}$ Génétique animale et biologie intégrative, INRA, AgroParisTech, Université Paris-Saclay, 78350 Jouyen-Josas, France

${ }^{3}$ IFREMER, Chemin de Maguelone, 34250 Palavas-les-Flots, France

${ }^{4}$ INRA, Agrocampus Ouest Rennes, UMR1069 Sol Agronomie Spatialisation, 65 rue de Saint Brieuc, 35042 Rennes, France
\end{abstract}

${ }^{5}$ Animal Production Systems group, Wageningen University, P.O. Box 338, $6700 \mathrm{AH}$, the Netherlands

Aquaculture (2016) 462: 47-55 



\section{Abstract}

In sea cage farming, fish are exposed to seasonal variations of water temperature, and these variations can differ from one location to another. A small increase in water temperature does not only stimulate growth of the fish (until an optimal level) but also lowers dissolved oxygen concentration in water. Dissolved oxygen may then become a rearing constraint during the production cycle if the oxygen requirement of fish is higher than the supply. The impact of this constraint on production parameters (stocking density of cages and/or batch rotation) and thus on economic profit of a farm will depend on both local thermal regime and growth potential of the fish. Increased growth is one of the most important traits in a breeding objective to increase production capacity and profitability. We used a bioeconomic model of seabass reared in cages to calculate the economic value (EV) of increasing thermal growth coefficient (TGC) by selection in different conditions of average temperature ( $\mathrm{Tm}$ ) and amplitude of temperature variation (Ta). Tm and Ta values were taken from different locations in the eastern and western Mediterranean. Results show that increasing TGC has two consequences: (i) fast growing fish reach harvest weight earlier, which increases the number of batches that can be produced per year, and (ii) fast growing fish have higher daily feed intake and, consequently, higher daily oxygen consumption. To balance the oxygen demand and availability in a cage, a farmer might have to reduce the average stocking density, resulting in fewer fish produced per batch. Consequently, EV of TGC is positive when $\mathrm{Tm}$ is $19.5^{\circ} \mathrm{C}$ or $21{ }^{\circ} \mathrm{C}$, when an increase in number of batches produced compensates for the decrease in stocking density. EV of TGC is negative or null in areas where $\mathrm{Tm}$ is closer to $18{ }^{\circ} \mathrm{C}$ because the increase in number of batches produced cannot compensate for the decrease in stocking density. Our results show, for the first time, the importance of variation in ambient temperatures for breeding programs in fish.

Keywords: economic values, bioeconomic model, fish farming, genetic improvement, temperature, thermal growth coefficient 


\subsection{Introduction}

Genetic improvement aims at modifying the performances of animals and, in case of production limitations, can affect the management strategy of a farm. In dairy farming, for instance, increasing milk yield in a situation with milk quota decreases the number of milking cows on farms (Groen, 1989). Such changes in the production system need to be accounted for when building breeding objectives, guaranteeing that expected gains will be met (Groen, 1989; Amer et al., 1994). According to this principle, Rose et al. (2015) calculated the economic values of several traits, including live weight at different live stages, for sheep farms across different environments that varied in the amount and distribution of annual pasture growth. Pasture growth is a key parameter because it determines how much feed is available for sheep farms. The economic values of live weights were higher in regions with high and low variation, compared to regions with medium variation in pasture growth. This result was explained by changes in energy requirements when live weight was increased, which required different management adaptations according to the region. The conclusion was that breeding objectives for live weights could be similar for regions with either high or low variation of pasture growth but should be different for regions with medium variation of pasture growth. Such results demonstrate that breeding objectives should be finely tuned to the local conditions of production, according to constraints on input availability, namely, pasture growth and feed availability.

In fish farming, the potential economic impact of selective breeding for growth has been studied by Besson et al. (2014) in a recirculating aquaculture system where production of African catfish (Clarias gariepinus) is alternatively constrained by two limiting factors, either the nitrogen treatment capacity of the bio-filter, or the density of fish. However, such recirculating system differs from most fish culture systems by the fact that the environment (temperature and water quality) are highly controlled and stable. In most open production systems, such as sea cages, fish are exposed to seasonal variation in water temperature, and these variations can differ from one location to another. Temperature has a major impact on farm management and productivity for two main reasons. Firstly, fish are poikilothermic animals, implying that their metabolic activity and growth depend on ambient water temperature. Secondly, changes in water temperature generate variation in oxygen supply because warmer water can hold less dissolved oxygen which is vital for fish growth (Thetmeyer et al., 1999; Pichavant et al., 2001).

Therefore, we decided to investigate a sea cage system producing sea bass (Dicentrarchus labrax) in the Mediterranean where temperature conditions differ 
across regions. For instance, the average temperature in south Turkey is about 21 ${ }^{\circ} \mathrm{C}$, with a difference of $10.6{ }^{\circ} \mathrm{C}$ between winter and summer. In northwestern Italy, the average temperature is $18{ }^{\circ} \mathrm{C}$ and the difference is $9.5^{\circ} \mathrm{C}$ (Llorente and Luna, 2013). For sea bass, growth is optimal around $24{ }^{\circ} \mathrm{C}$ (Person-Le Ruyet et al., 2004). Consequently, the time required to reach harvest weight, and therefore, costs associated with fish farming vary across regions (Gasca-Leyva et al., 2002). Llorente and Luna (2013) showed that the difference in water temperature between areas in the Mediterranean Sea is a major source of competitive advantages for fish farms. A higher annual average temperature generates faster growth and enables farmers to either produce more batches, or alternatively, bigger fish in a given production system. A lower seasonal difference is associated with less extreme summer and winter temperatures, closer to the optimum, resulting in better feed conversion ratio (Llorente and Luna, 2013). Moreover, the oxygen supply is potentially lower in south eastern Turkey than in eastern Spain (for the same level of water renewal). For sea bass, an oxygen concentration under $3.5 \mathrm{mg} / \mathrm{L}$ affects growth and causes mortality (Coves et al., 1991; Thetmeyer et al., 1999; Breitburg, 2002). Dissolved oxygen, therefore, may become a rearing constraint during the production cycle when the oxygen requirement of fish is higher than oxygen supply.

In fish farming, rearing constraints were shown to affect the economic impact of selective breeding for growth because the management strategy must be adapted to fit the change in fish performances (Besson et al., 2014). In case of sea cage farming, increasing growth will change the oxygen requirement at both individual and cage level which would imply changes in stocking management. Similarly to pasture growth in sheep farming, temperature conditions might affect the economic value of traits differently according to the location, with potential implications on the definition of breeding objectives. To our knowledge, the impact of temperature profiles on the economic impact of genetic improvement in cage farming has never been studied.

We investigated the economic impact of selection for growth rate in sea bass cages exposed to variations of water temperature inducing limitation on oxygen supply, using a bioeconomic modelling approach. Growth rate is considered the most important trait by fish farmers (Sae-Lim et al., 2012) and is consistently part of the breeding objectives. The bioeconomic model developed for recirculating aquaculture systems by Besson et al. (2014) was adapted to a sea cage system. By modelling the whole farm, we enable quantification of economic impacts from changes in management, such as stocking density, due to genetic improvement. 


\subsection{Materials and methods}

\subsubsection{Bioeconomic model in the reference scenario}

The bioeconomic model developed in R ( $R$ Development Core Team, 2008) is based on the model presented by Besson et al. (2014) to calculate economic values of growth rate and feed conversion ratio in a recirculating aquaculture system. The reference scenario of the model describes a hypothetical sea cage farm producing 1,000 tonnes of sea bass in southern France. The farm was composed of 34 circular cages of $600 \mathrm{~m}^{3}$ for pre-growing and 34 circular cages of 1,800 $\mathrm{m}^{3}$ for on-growing. Fish were stocked in pre-growing cages at $10 \mathrm{~g}$ and the fish were sold at a fixed harvest weight of $400 \mathrm{~g}$. Stocking took place all year round. The hypothetical farm and the bioeconomic model were based on information provided by Gloria Maris and Kefalonia Fisheries. The symbols used for different parameters of the bioeconomic model are summarized in Table 4.4.

\subsubsection{Physical parameters of sea water}

The daily temperature $T_{n}$ is modeled using a sinusoidal function with a period of 365 days (Figure 4.1). As suggested by Seginer and Halachmi (2008), $T_{n}$ is given by:

$$
\mathrm{T}_{\mathrm{n}}=\mathrm{Tm}-\mathrm{Ta} \times \sin \left(2 \pi \frac{\mathrm{n}+\phi_{\mathrm{T}}}{365}\right)
$$

$\mathrm{n}=$ day (1 to 365$)$

$\mathrm{Tm}=$ mean water temperature $=18^{\circ} \mathrm{C}$ in the reference scenario

$\mathrm{Ta}=$ amplitude of the variation $=5.77^{\circ} \mathrm{C}$ in the reference scenario (corresponding to a difference of $2 \times 5.77=11.54{ }^{\circ} \mathrm{C}$ between the maximum and minimum daily value across the whole year)

$\varphi T=$ phase shift (time-delay) $=27.36$ days

In total, we tested 15 different scenarios of temperature profile according to three values of $\mathrm{Tm}$ and five values of Ta (Table 4.1). Several combinations of $\mathrm{Tm}$ and $\mathrm{Ta}$ are similar to real conditions in different regions of the Mediterranean Sea presented by Llorente and Luna (2013). The highest amplitude is displayed in eastern Spain where the difference between maximum and minimum temperature is $12.2^{\circ} \mathrm{C}$. The lowest amplitude is observed in northwestern Italy and southern Greece where the difference between maximum and minimum temperature is 9.5 ${ }^{\circ} \mathrm{C}$. 
Table 4.1: Summary of the different average temperature $(\mathrm{Tm})$ and variation $(\mathrm{Ta})$ tested.

\begin{tabular}{|c|c|c|c|c|}
\hline & & \multicolumn{3}{|c|}{$\operatorname{Tm}\left(\right.$ in $\left.{ }^{\circ} \mathrm{C}\right)$} \\
\hline & & 18 & 19.5 & 21 \\
\hline \multirow{5}{*}{$\mathrm{Ta}\left(\right.$ in $\left.{ }^{\circ} \mathrm{C}\right)$} & 6.09 & $\mathrm{ES}^{2}$ & & \multirow{5}{*}{$\mathrm{ST}^{2}$} \\
\hline & 5.77 & $\mathrm{SF}^{1}$ & & \\
\hline & 5.3 & & & \\
\hline & 4.9 & \multirow{2}{*}{\multicolumn{2}{|c|}{$\begin{array}{l}W^{2}{ }^{2} \\
S G^{2}\end{array}$}} & \\
\hline & 4.75 & & & \\
\hline \multicolumn{5}{|c|}{$\begin{array}{l}\text { The letters indicates the region of the Mediterranean sea corresponding to these } \\
\text { temperature parameters, } 1=\text { personal data, } 2=\text { Llorente and Luna }(2013) . \mathrm{SF}= \\
\text { southern France }(\mathrm{Tm}=18, \mathrm{Ta}=5.77), \mathrm{ES}=\text { eastern Spain }(\mathrm{Tm}=18, \mathrm{Ta}=6.09), \mathrm{WG} \\
=\text { western Greece }(\mathrm{Tm}=19.25, \mathrm{Ta}=5.0), \mathrm{SG}=\text { south } \mathrm{Greece}(\mathrm{Tm}=19.34, \mathrm{Ta}= \\
4.75), \mathrm{NWI}=\text { northwestern Italy }(\mathrm{Tm}=18, \mathrm{Ta}=4.72) \text { and } \mathrm{ST}=\text { southern Turkey ( } \mathrm{Tm} \\
=20.84, \mathrm{Ta}=5.3) .\end{array}$} \\
\hline
\end{tabular}

Dissolved oxygen concentration at day $\mathrm{n}$ in surface water $\left(\left[\mathrm{O}_{2}\right]_{\mathrm{n}}\right.$ in $\left.\mathrm{mg} / \mathrm{L}\right)$ is calculated from Weiss equation (Weiss, 1970) as a function of salinity (S, set to 39 $\%$ ) and water temperature $\left(T_{n}\right.$ in ${ }^{\circ}$ kelvin $=T_{n}$ in $\left.{ }^{\circ} \mathrm{C}+272.15\right)$ :

$$
\begin{aligned}
& {\left[\mathrm{O}_{2}\right]_{\mathrm{n}}=} \\
& \quad \begin{array}{l}
1.4722 \times \exp \left[-173.492+\frac{24963.39}{\mathrm{~T}_{\mathrm{n}}}+143.3483\right. \\
\quad \times \ln \left(\frac{\mathrm{T}_{\mathrm{n}}}{100}\right)-0.218492 \mathrm{~T}_{\mathrm{n}}+\mathrm{S}
\end{array} \\
& \left.\quad \times\left(-0.033096+0.00014259 \mathrm{~T}_{\mathrm{n}}-0.00000017 \mathrm{~T}_{\mathrm{n}}^{2}\right)\right]
\end{aligned}
$$

The Weiss equation indicates that with higher the temperature there is lower oxygen concentration, as shown in Figure 4.1. 


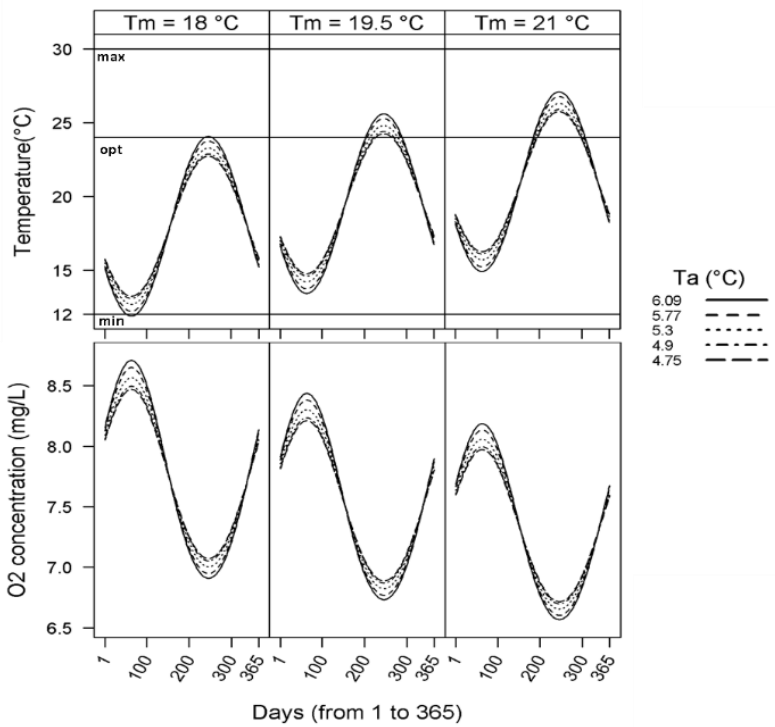

Figure 4.1: Graphical presentation of the temperature conditions tested and the resulting oxygen concentration in sea water. $\mathrm{Tm}$ is the average temperature and $\mathrm{Ta}$ is the amplitude of the temperature. max, opt and $\min$ are respectively the maximum, optimum and minimum temperature for sea bass rearing.

\subsubsection{Fish model}

The fish model describes the daily weight and the daily weight gain of fish based on thermal growth coefficient (TGC). The two main model assumptions are: (i) growth rate is allometrically related to body weight ( $W$ in $g$ ) and (ii) growth rate is an allometric constant related to mean daily water temperature averaged over the rearing period. However, the relationship between growth rate and water temperature is non-linear (see e.g. Person-Le Ruyet et al. (2004)). Therefore, the TGC formula needs to be corrected for the concave relationship between growth rate and temperature, which can be done by using a corrected temperature $\mathrm{K}$ as proposed by Mallet et al. (1999):

$$
\mathrm{TGC}=\frac{\mathrm{W}_{\mathrm{H}}^{1-\mathrm{b}}-\mathrm{W}_{\mathrm{I}}^{1-\mathrm{b}}}{\sum_{\mathrm{i}=1}^{\mathrm{n}} \mathrm{K}_{\mathrm{i}}} \times 1000
$$

$\mathrm{W}_{\mathrm{H}}=$ harvest weight $=400 \mathrm{~g}$

$\mathrm{W}_{\mathrm{I}}=$ initial weight $=10 \mathrm{~g}$

$1-b=0.51$ 
TGC $=2.25$, so that harvest weight is achieved in 573 days on average in the reference scenario. TGC and 1-b were obtained through optimization to fit the calculated growth curve to the growth curve observed from farm data (personal communication).

$\mathrm{K}_{\mathrm{n}}=$ corrected temperature index

$$
\mathrm{K}_{\mathrm{n}}=\frac{\mathrm{T}_{\mathrm{opt}}\left(\mathrm{T}_{\mathrm{n}}-\mathrm{T}_{\min }\right)\left(\mathrm{T}_{\mathrm{n}}-\mathrm{T}_{\text {max }}\right)}{\left(\mathrm{T}_{\mathrm{n}}-\mathrm{T}_{\min }\right)\left(\mathrm{T}_{\mathrm{n}}-\mathrm{T}_{\max }\right)-\left(\mathrm{T}_{\mathrm{n}}-\mathrm{T}_{\mathrm{opt}}\right)^{2}}
$$

when $T_{\min } \leq K_{n} \leq T_{\max }$ and $K_{n}=0$ for other values.

$\mathrm{T}_{\min }=$ minimal temperature below which there is no growth

$T_{\text {opt }}=$ optimal temperature for which growth is maximal

$\mathrm{T}_{\max }=$ maximal temperature above which there is no growth

For sea bass, $\mathrm{T}_{\min }, \mathrm{T}_{\mathrm{opt}}$ and $\mathrm{T}_{\max }$ are respectively $12^{\circ} \mathrm{C}(\mathrm{K}=0), 24^{\circ} \mathrm{C}(\mathrm{K}=24)$ and $30^{\circ} \mathrm{C}$ $(\mathrm{K}=0$ ) extrapolating from Person-Le Ruyet et al. (2004) and unpublished data. Therefore, $\mathrm{T}_{n}$ must be between $12^{\circ} \mathrm{C}$ and $30^{\circ} \mathrm{C}$ to have a positive $\mathrm{K}_{n}$ and hence a positive growth rate (Figure 4.2).

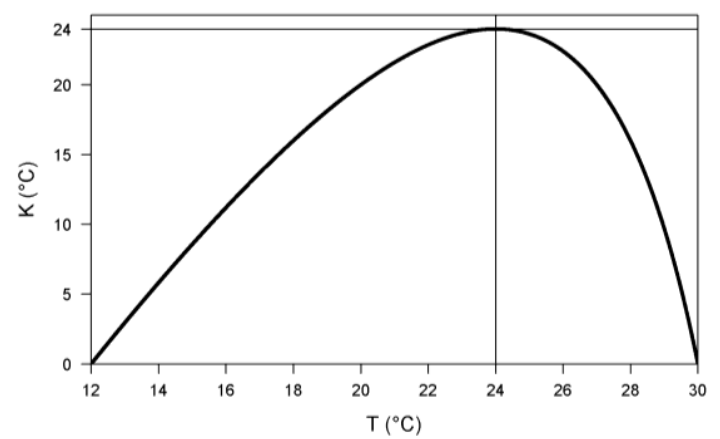

Figure 4.2: Temperature $\mathrm{K}$ as a function of temperature $\mathrm{T}$. $\mathrm{K}$ reaches a maximum at $24^{\circ} \mathrm{C}$ when temperature $\mathrm{T}$ is $24^{\circ} \mathrm{C}$.

The daily weight $(\mathrm{Wn})$ and the daily weight gain (DWGn) were calculated as:

$$
\begin{gathered}
\mathrm{W}_{\mathrm{n}}=\left[\mathrm{W}_{\mathrm{I}}^{0.51}+\left(\frac{\mathrm{TGC}}{1000} \times \sum_{\mathrm{i}=1}^{\mathrm{n}} \mathrm{K}_{\mathrm{i}}\right)\right]^{1 / 0.51} \\
\mathrm{DWG}_{\mathrm{n}}=\mathrm{W}_{\mathrm{n}}-\mathrm{W}_{\mathrm{n}-1}
\end{gathered}
$$


Feed conversion ratio (FCR) was modelled by combining a third order polynomial model from Person-Le Ruyet et al. (2004) that models feed efficiency as a function of temperature at a fixed body weight with an exponential model from Lanari et al. (2002) that models the variation of FCR with fish body weight. The resulting model was the following:

$$
\begin{aligned}
& \mathrm{FCR}_{\mathrm{Wn}}= \\
& \alpha \times \frac{\mathrm{W}_{\mathrm{n}}^{0.14} / 1000}{1.318-\left(0.103 \times \mathrm{T}_{\mathrm{n}}\right)+\left(0.007174 \times \mathrm{T}_{\mathrm{n}}^{2}\right)-\left(0.0001395 \times \mathrm{T}_{\mathrm{n}}^{3}\right)}
\end{aligned}
$$

$\alpha$ is a scaling factor which was set to 2.6 to obtain a realized FCR of 2.0 in the reference scenario. Daily feed intake $\left(D F I_{n}\right)$ is calculated back from $F C R_{n}$ and $D W G_{n}$ by:

$$
\mathrm{DFI}_{\mathrm{n}}=\mathrm{DWG}_{\mathrm{n}} \times \mathrm{FCR}_{\mathrm{Wn}}
$$

Oxygen consumption was estimated via indirect calorimetry principles. Oxygen consumption per fish was calculated from the nutrient catabolized (nutrient digested minus nutrient retained corrected for branchial and urinary losses), using the oxy-caloric coefficient (Qox) of nutrient.

$$
\begin{aligned}
& \mathrm{O}_{2_{\operatorname{cons}_{\text {fish }}}}=\left[\left(\mathrm{DFI}_{\mathrm{n}} \times \mathrm{P}_{\text {feed }} \times \mathrm{D}_{\mathrm{P}}\right)-\left(\mathrm{DWG}_{\mathrm{n}} \times \mathrm{P}_{\text {fish }}\right)\right] \times \frac{\mathrm{E}_{\mathrm{P}}}{\mathrm{Q}_{\mathrm{ox}_{\mathrm{P}}}} \\
& +\left[\left(D_{\mathrm{n}} \times \mathrm{F}_{\text {feed }} \times \mathrm{D}_{\mathrm{P}}\right)-\left(\mathrm{DWG}_{\mathrm{n}} \times \mathrm{F}_{\text {fish }}\right)\right] \times \frac{\mathrm{E}_{\mathrm{F}}}{\mathrm{Q}_{\mathrm{ox}_{\mathrm{F}}}} \\
& +\left[\left(\mathrm{DFI}_{\mathrm{n}} \times \mathrm{C}_{\text {feed }} \times \mathrm{D}_{\mathrm{C}}\right)\right] \times \frac{\mathrm{E}_{\mathrm{C}}}{\mathrm{Q}_{\mathrm{ox}_{\mathrm{C}}}}
\end{aligned}
$$

$P_{\text {feed }}, F_{\text {feed }}, C_{\text {feed }}=$ Protein, fat and carbohydrates content of the feed

$P_{\text {fish }}, F_{\text {fish }}=$ Protein and fat content of the fish

$D_{P}, D_{F}, D_{c}=$ Digestibility of protein, fat and carbohydrates

Qoxp, Q QxF, Q

$E_{P}, E_{F}, E_{C}=$ Energy content of protein, fat and carbohydrates

All values of parameters in Eq. [4.9] are given in Table 4.2. The assumption in this equation is that fat deposition cannot be higher than the fat content of the feed. The value given by Eq. [4.9] are in line with values estimated by the Fishit-3 program $\left(r^{2}=0.993\right.$ ) (Kaushik, pers. comm, based on Cho, 1992; Cho and Kaushik, 1990; Kaushik, 1998). 
Table 4.2: Data used in equation of oxygen consumption.

\begin{tabular}{lccc}
\hline & protein & fat & carbohydrate \\
\hline Feed content $(\mathrm{g} / \mathrm{g})$ & $0.46^{1}$ & $0.14^{1}$ & $0.21^{1}$ \\
Fish content $(\mathrm{g} / \mathrm{g})$ & $0.16^{2}$ & $0.19^{2}$ & - \\
Digestibility $(\mathrm{g} / \mathrm{g})$ & $0.94^{2}$ & $0.9^{2}$ & $0.7^{2}$ \\
Oxy-caloric coefficient $\left(\mathrm{kJ} / \mathrm{g} \mathrm{O}_{2}\right)$ & $14.8^{3}$ & $13.7^{4}$ & $13.4^{3}$ \\
Energy content $(\mathrm{kJ} / \mathrm{g})$ & $17.2^{5}$ & $39.5^{5}$ & $23.6^{5}$ \\
\hline
\end{tabular}

${ }^{1}$ Biomar EFICO YM 868

${ }^{2}$ (Kaushik et al., 2004)

${ }^{3}$ (Brafield and Solomon, 1972)

4 (Elliott and Davison, 1975)

${ }^{5}$ (Brafield and Llewellyn, 1982)

The overall mortality is fixed at $10 \%$ from stocking to harvest. Thus, the cumulative mortality at a given day is expressed by a linear equation:

$$
\mathrm{M}_{\mathrm{Wn}}=0.00025 \times \mathrm{W}_{\mathrm{n}}-0.0025
$$

\subsubsection{Batch model}

A batch represents all the fish of the same cohort stocked in the same cage. $A$ batch is first stocked at $10 \mathrm{~g}$ in a cage of $600 \mathrm{~m}^{3}$ (period 1), then the fish are transferred to a cage of $1,800 \mathrm{~m}^{3}$ (period 2). The transfer takes place when the rearing density reached $10 \mathrm{~kg} / \mathrm{m}^{3}$ in the $600 \mathrm{~m}^{3}$ cage. The number of $10 \mathrm{~g}$ fish stocked per batch was constrained by the daily oxygen supply in cages during the whole rearing period. Daily oxygen supply $\left(\mathrm{O}_{2}\right.$ supply_cage $\left.\mathrm{e}_{n}\right)$ depends on: 1$)$ The concentration of dissolved oxygen in the cage which was constrained to a minimum $3.5 \mathrm{mg} / \mathrm{L}$. 2) The water flow going through the cage and carrying the oxygen. 3) The concentration of dissolved oxygen in water entering the cage. Daily oxygen supply at the cage level is expressed, therefore, as:

$$
\mathrm{O}_{2 \_} \text {supply_cage }_{\mathrm{n}}=\mathrm{WF}_{\min } \times \mathrm{V}_{\text {cage }} \times\left(\left[\mathrm{O}_{2}\right]_{\mathrm{n}}-3.5\right)
$$

$W F_{\min }=$ minimum water flow per $\mathrm{m}^{3}$. It was estimated to be $54 \mathrm{~m}^{3} / \mathrm{m}^{3} /$ day using data from the reference farms and constrained by oxygen supply.

$\left[\mathrm{O}_{2}\right]_{\mathrm{n}}=$ concentration of dissolved oxygen in water at day $\mathrm{n}$ from Eq. [4.4.2] 
O2_supply_cage is variable according to water temperature at day $\mathrm{n}$ but $\mathrm{WF}_{\min }$ was kept constant. Water current depends, however, on coastal geography or weather conditions but we considered that all farms in all environments were undergoing the same water flow in order to allow fair comparison.

Combining Eq. [4.4.11] and Eq. [4.4.9], we estimated the maximum number of fish that could be sustained in the cage at day $n\left(N_{-}\right.$fish_max $n$ ):

$$
\mathrm{Nb} f i s h \_m a x_{n}=\frac{\mathrm{O}_{2 \_} \text {supply_cage }_{\mathrm{n}}}{\mathrm{O}_{2 \_} \text {cons_fish }_{\mathrm{n}}}
$$

The number of fish stocked to reach $\mathrm{Nb}_{-}$fish_max $\mathrm{n}$ at day $\mathrm{n}$ includes the cumulated mortality from day 0 to day $n$ :

$$
\mathrm{Nb} f i s h \_s t o c k e d_{\mathrm{n}}=\mathrm{Nb}_{-} \text {fish_max } \mathrm{m} /\left(1-\mathrm{M}_{\mathrm{Wn}}\right)
$$

However, the number of fish stocked in a batch must be capped to avoid the oxygen demand to exceed the supply at any day $n$ of the growth period. Then, the number of fish stocked is determined by the minimum value of $\mathrm{Nb}_{-}$fish_stocked $\mathrm{n}$ over the whole growth period of the batch.

Consequently, the number of fish stocked or in other words the stocking density depends on the combination of oxygen supply and its consumption. During the production cycle, the oxygen consumption of the batch will always be lower than the supply except at one day, Dlimit, where oxygen consumption equals oxygen supply (Figure 4.3). When the oxygen supply is low (in summer), a batch of smaller fish with a lower consumption of oxygen per fish, can contain more fish than a batch with bigger fish having higher oxygen requirements per fish. Therefore, the number of fish stocked depends on the date when the batch was stocked.

Finally, the production of fish per batch is given by:

$$
\text { Prod_fish } \text { batch }_{-}=\mathrm{Nb}_{-} \text {fish }_{0} \times \mathrm{W}_{\mathrm{H}}
$$

$\mathrm{W}_{\mathrm{H}}=$ harvest weight 


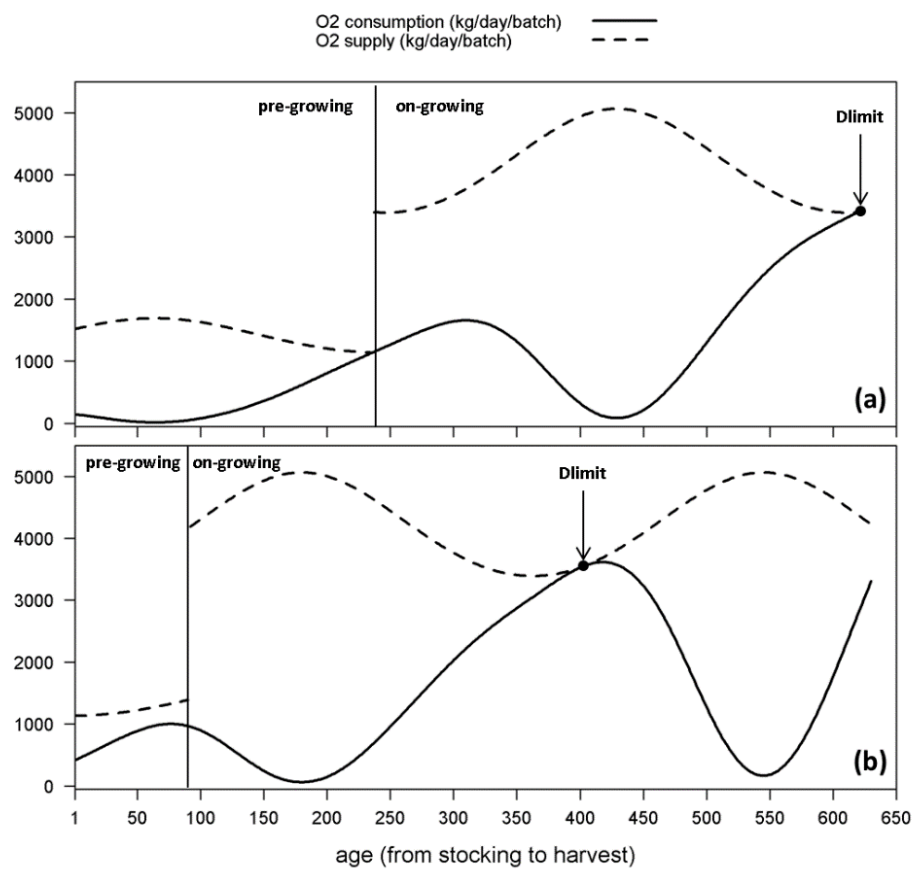

Figure 4.3: Total daily oxygen consumption (full line) of a batch stocked on the 1st of January (a) and on the 7th of September (b) from harvest to stocking compared to the total daily oxygen supply of this batch (dash line) during pre-growing (600 m3 cages) and on-growing (1800 $\mathrm{m} 3$ cages). The point represents the day when the oxygen consumption of the batch is equal to the oxygen supply (Dlimit). When the batch is stocked on the 1st of January, Dlimit is reached at harvest and the number of fish stocked is $\mathbf{8 2 , 5 1 2}$. When the batch is stocked on the 7th of September, Dlimit is reached during on-growing period and the number of fish socked is 117,557.

\subsubsection{Farm model}

Fish production and feed consumption per batch are multiplied by the number of batches produced during a year to estimate the yearly fish production and feed consumption of the farm. In this study, we investigated a production system where fish are stocked all year round. To do so, we first calculated the production and feed consumption of a batch stocked at any day $n$ of the year, i.e. Prod_fishbatchn. Then, the average of batch production and feed consumption is multiplied by the number of batches produced per year ( $\mathrm{Nb}$ _batchyear) to obtain the average estimated farm production, independent on any specific stocking date, Prod_fishfarm. 


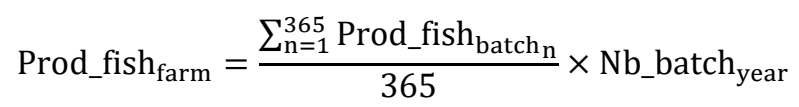

The number of batches that can be produced per year ( $\mathrm{Nb}$ _batch ${ }_{\text {year }}$ ) depends on the length of the production period and on the number of cages. In our study, the number of batches is constrained by the on-growing period because the length of this period ( $\left.L_{22}\right)$ is always longer than the pre-growing period. Note that the length of pre-growing and on-growing period depends on the stocking date of the fish (Figure 4.3). The number of cages for on-growing, Nb_cagep2, is 34 . Nb_batch expressed as:

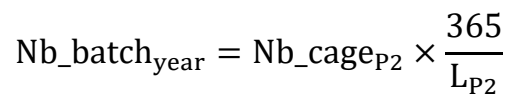

Calculating the average production per cage across all possible stocking dates is a way to estimate potential production of a farm per year considering an indeterminate period of time. In the bioeconomic model, Nb_fish_stockedn was different across stocking dates in order to maximize cage production and to comply with lower oxygen supply in summer. For instance, when $\mathrm{Tm}=18{ }^{\circ} \mathrm{C}, \mathrm{Ta}=5.77^{\circ} \mathrm{C}$ and $\mathrm{TGC}=2.25$, the average calculated stocking density was 91,022 fish per cage with a maximum of 121,908 (16th of September) and a minimum of 82,280 on the (13th of December).

In this study, every time a batch is harvested, a new one is stocked. When TGC increases, more batches can be stocked because $L_{p n}$ decreases. Finally farm profit is given by:

$$
\begin{aligned}
& \text { Profit }_{\text {farm }}=\left(\text { Pfish } \times \text { Prod }_{\text {fish }_{\text {farm }}}\right) \\
& -\left(\text { Cjuv } \times \text { Juv }_{\text {stocked }_{\text {farm }}}\right) \\
& -\left(\text { Cfeed } \times \text { Feed }_{\text {consumption }} \text { farm }_{\text {ffixed }}\right) \\
& - \text { Cfixe }
\end{aligned}
$$

Pfish $=$ selling price of $1 \mathrm{~kg}$ of sea bass

Cjuv $=$ cost of juveniles

Cfeed $=$ cost of feed

Cfixed $=$ fixed cost

Juv_stocked $d_{\text {farm }}=$ number of juveniles stocked per year per farm

Feed_consumption $\mathrm{farm}_{\mathrm{f}} \mathrm{kg}$ of feed distributed per year per farm 
All economic parameters are given in Table 4.3. Fixed costs are not detailed because the economic values represent the relative change in profit after genetic improvement. Therefore, the economic value depends on the costs that vary with genetic improvement. If the fixed costs are the same after genetic improvement, which is our case, they can be ignored in the calculation of economic values.

Table 4.3: Revenue and costs (variable and fixed) of a sea bass farm in the reference scenario.

\begin{tabular}{lccc}
\hline Item & abbreviation & value & unit \\
\hline Price of fish & Pfish & 5.57 & $€ / \mathrm{kg}$ \\
Cost of feed & Cfeed & 1.3 & $€ / \mathrm{kg}$ \\
Cost of juveniles & Cjuv & 0.25 & $€ / \mathrm{pc}$ \\
\hline Fixed costs & Cfixed & $2,245,000$ & $€ / \mathrm{farm}$ \\
\hline
\end{tabular}

\subsubsection{Genetic change and economic value of growth rate}

The economic value of growth rate was calculated for 15 different temperature profile scenarios using the bioeconomic model in three steps:

1) The model was run for the current population mean for TGC ( $\mu=2.25)$ to obtain the initial reference annual profit per farm, which was divided by annual fish production to obtain profit per kg of fish (Profit_fish ${ }_{\mu}$ ).

2) The model was run a second time when TGC mean value was increased by one genetic standard deviation $(\mu+\sigma g)$ to calculate the annual profit per farm after selection. From Vandeputte et al. (2014), og was estimated to be 0.13 . The annual profit per farm was divided by the reference annual fish production (i.e. before genetic improvement for TGC) according to Groen (1989) to obtain profit per kg of fish: Profit_fish $\mu+\sigma g$.

3) Finally, the economic value per genetic standard deviation was calculated for TGC as:

$$
\mathrm{EV}_{\mathrm{TGC}}=\text { profit_fish }_{\mu+\sigma \mathrm{g}}-\text { profit_fish }_{\mu}
$$


Table 4.4: Summary of some important parameters of the bioeconomic model with their abbreviation and unit.

\begin{tabular}{|c|c|c|}
\hline Parameters & Abbreviations & Units \\
\hline Daily temperature & $T_{n}$ & ${ }^{\circ} \mathrm{C}$ \\
\hline Daily corrected temperature & $K_{n}$ & ${ }^{\circ} \mathrm{C}$ \\
\hline Daily oxygen concentration & {$[02]_{n}$} & $\mathrm{mg} / \mathrm{L}$ \\
\hline Thermal growth coefficient & TGC & - \\
\hline Daily weight & $W_{n}$ & $\mathrm{~g}$ \\
\hline Daily weight gain & $\mathrm{DWG}_{\mathrm{n}}$ & g/day \\
\hline Feed conversion ratio & $\mathrm{FCR}_{W n}$ & $\mathrm{~g} / \mathrm{g}$ \\
\hline Daily feed intake & $\mathrm{DFI} I_{\mathrm{n}}$ & g/day \\
\hline Daily oxygen consumption of fish & O2_cons_fish $n$ & mg/fish/day \\
\hline Cumulative mortality & $M_{w n}$ & $\%$ \\
\hline Daily oxygen cage supply & O2_supply_cagen & $\mathrm{mg} /$ cage/day \\
\hline Number of fish stock per cage & $\mathrm{Nb}$ _fish_stocked $\mathrm{n}$ & \#/cage \\
\hline Fish production of batch & Prod_fish batch & g/cage \\
\hline Fish production of farm & Prod_fish farm & $\mathrm{g} /$ farm \\
\hline Number of batch produced per year & $\mathrm{Nb \_ batch}$ year & \#/year/farm \\
\hline Farm profit & Profitfarm & $€ /$ year/farm \\
\hline
\end{tabular}




\subsection{Results}

\subsubsection{Effect of temperature profile on farm profit}

\section{Effect of average temperature $\mathrm{Tm}$}

Increasing $\mathrm{Tm}$ from 18 to $21^{\circ} \mathrm{C}$ decreased the time to reach harvest weight because the optimal temperature for sea bass growth is $24^{\circ} \mathrm{C}$. The first consequence of this was that more batches could be stocked per year (Table 4.5). Furthermore, the longer the time to reach harvest weight, the higher the probability for the fish to undergo two summer periods. In summer, high temperature generates high growth hence high oxygen consumption, together with limited oxygen supply. Therefore, these periods are the most constraining regarding stocking density. When a batch went through two summers, the day when oxygen consumption of the batch equaled oxygen supply (Dlimit) occurred during the second summer when the fish reached harvest weight. Therefore, individual oxygen consumption was high at Dlimit, which in turn, strongly constrained the initial stocking density (Figure 4.3a). Conversely, when a batch went through only one summer, Dlimit could occur earlier in the life of the fish, with smaller fish having lower oxygen needs, and then a potential to stock more fish (Figure 4.3b). When Tm increased, growth rate was higher and more batches were in the second situation, with just one summer during the on-growing period. However, when Tm is higher, oxygen supply is lower. We observed that at Dlimit, the reduction in individual oxygen consumption results in a total oxygen demand that equals the lower oxygen supply. This results in similar stocking densities across a range of Tm values. In summary, increasing Tm only increased the number of batches produced (but not the number of fish per batch), which resulted in higher farm profit (Table 4.6).

\section{Effect of the amplitude of temperature Ta}

Profit increased when Ta decreased (lower amplitude) for two reasons:

1) A lower amplitude reduces the periods where fish are exposed to extreme (higher or lower than $24{ }^{\circ} \mathrm{C}$ ) temperature conditions at which growth is reduced. With low Ta harvest weight was reached faster and more batches could be stocked in a year (Table 4.5). 2) Oxygen supply varies across the year. When the temperature was high (in summer) the oxygen supply was low (Figure 4.1). Therefore, the stocking density of a batch is dependent on the period of low oxygen availability during summer. With low Ta the maximum temperature reached in summer was lower and the oxygen supply was, therefore, higher and thus more fish could be stocked per batch (Table 4.5). 
Table 4.5: Effect of different values of thermal growth coefficient (TGC) on fish production parameters according to the average ( $\mathrm{Tm})$ and the amplitude $(\mathrm{Ta})$ of temperature.

\begin{tabular}{|c|c|c|c|c|c|c|c|}
\hline $\begin{array}{c}\mathrm{Tm} \\
\left({ }^{\circ} \mathrm{C}\right)\end{array}$ & $\begin{array}{c}\mathrm{Ta} \\
\left({ }^{\circ} \mathrm{C}\right)\end{array}$ & TGC & $\begin{array}{c}\text { Time } \\
\text { to } \\
\text { harvest } \\
\text { (days) } \\
\end{array}$ & $\begin{array}{l}\text { Number of } \\
\text { fish stocked } \\
\text { per batch }\end{array}$ & $\begin{array}{c}\text { Number } \\
\text { of batch } \\
\text { produced } \\
\text { per year }\end{array}$ & $\begin{array}{l}\text { Production } \\
\text { at farm } \\
\text { level } \\
\text { (tonnes) } \\
\end{array}$ & $\begin{array}{c}\text { Feed } \\
\text { consumption } \\
\text { at farm } \\
\text { (tonnes) } \\
\end{array}$ \\
\hline 18 & 6.09 & 2.25 & 580 & 89,598 & 30.27 & 976 & 1,975 \\
\hline 18 & 6.09 & 2.38 & 554 & 84,475 & 31.85 & 969 & 1,962 \\
\hline 18 & 5.77 & 2.25 & 573 & 91,023 & 30.54 & 1,001 & 2,032 \\
\hline 18 & 5.77 & 2.38 & 547 & 86,047 & 32.15 & 996 & 2,026 \\
\hline 18 & 5.3 & 2.25 & 564 & 93,596 & 30.89 & 1,041 & 2,125 \\
\hline 18 & 5.3 & 2.38 & 537 & 88,865 & 32.57 & 1,042 & 2,131 \\
\hline 18 & 4.9 & 2.25 & 556 & 96,203 & 31.11 & 1,078 & 2,210 \\
\hline 18 & 4.9 & 2.38 & 530 & 91,648 & 32.85 & 1,084 & 2,227 \\
\hline 18 & 4.75 & 2.25 & 554 & 97,275 & 31.18 & 1,092 & 2,243 \\
\hline 18 & 4.75 & 2.38 & 527 & 92,791 & 32.94 & 1,100 & 2,265 \\
\hline 19.5 & 6.09 & 2.25 & 504 & 88,754 & 34.82 & 1,113 & 2,261 \\
\hline 19.5 & 6.09 & 2.38 & 479 & 85,653 & 36.96 & 1,140 & 2,320 \\
\hline 19.5 & 5.77 & 2.25 & 496 & 90,250 & 35.30 & 1,147 & 2,334 \\
\hline 19.5 & 5.77 & 2.38 & 471 & 87,585 & 37.46 & 1,181 & 2,407 \\
\hline 19.5 & 5.3 & 2.25 & 485 & 92,929 & 35.91 & 1,201 & 2,448 \\
\hline 19.5 & 5.3 & 2.38 & 460 & 90,642 & 38.13 & 1,244 & 2,539 \\
\hline 19.5 & 4.9 & 2.25 & 476 & 95,483 & 36.34 & 1,249 & 2,548 \\
\hline 19.5 & 4.9 & 2.38 & 452 & 93,305 & 38.65 & 1,298 & 2,652 \\
\hline 19.5 & 4.75 & 2.25 & 474 & 96,456 & 36.49 & 1,267 & 2,586 \\
\hline 19.5 & 4.75 & 2.38 & 449 & 94,267 & 38.83 & 1,318 & 2,693 \\
\hline 21 & 6.09 & 2.25 & 460 & 91,102 & 38.19 & 1,252 & 2,547 \\
\hline 21 & 6.09 & 2.38 & 436 & 88,681 & 40.54 & 1,294 & 2,635 \\
\hline 21 & 5.77 & 2.25 & 450 & 92,306 & 38.90 & 1,293 & 2,626 \\
\hline 21 & 5.77 & 2.38 & 426 & 89,835 & 41.39 & 1,339 & 2,722 \\
\hline 21 & 5.3 & 2.25 & 437 & 94,084 & 39.92 & 1,352 & 2,740 \\
\hline 21 & 5.3 & 2.38 & 413 & 91,149 & 42.65 & 1,399 & 2,837 \\
\hline 21 & 4.9 & 2.25 & 427 & 95,420 & 40.74 & 1,400 & 2,830 \\
\hline 21 & 4.9 & 2.38 & 403 & 91,952 & 43.62 & 1,444 & 2,919 \\
\hline 21 & 4.75 & 2.25 & 424 & 95,863 & 41.03 & 1,416 & 2,861 \\
\hline 21 & 4.75 & 2.38 & 400 & 92,220 & 43.95 & 1,459 & 2,948 \\
\hline
\end{tabular}


Table 4.6: Effect of different values of thermal growth coefficient (TGC) on economic parameters according to the average $(\mathrm{Tm})$ and the amplitude $(\mathrm{Ta})$ of temperature.

\begin{tabular}{|c|c|c|c|c|c|c|c|}
\hline $\begin{array}{l}\mathrm{Tm} \\
\left({ }^{\circ} \mathrm{C}\right)\end{array}$ & $\begin{array}{c}\mathrm{Ta} \\
\left({ }^{\circ} \mathrm{C}\right)\end{array}$ & TGC & $\begin{array}{c}\text { Income } \\
(€ \times \\
1000)\end{array}$ & $\begin{array}{c}\text { Feed } \\
\text { cost } \\
(€ \times \\
1000)\end{array}$ & $\begin{array}{l}\text { Juveniles } \\
\text { cost } \\
(€ \times 1000)\end{array}$ & $\begin{array}{c}\text { Cost } \\
\text { per kg } \\
\text { of fish } \\
(€ / \mathrm{kg})\end{array}$ & $\begin{array}{l}\text { Profit } \\
(€ / \text { farm })\end{array}$ \\
\hline 18 & 6.09 & 2.25 & 5,446 & 2,568 & 678 & 5.62 & $-45,214$ \\
\hline 18 & 6.09 & 2.38 & 5,402 & 2,551 & 673 & 5.65 & $-66,784$ \\
\hline 18 & 5.77 & 2.25 & 5,582 & 2,642 & 695 & 5.58 & 0 \\
\hline 18 & 5.77 & 2.38 & 5,555 & 2,633 & 692 & 5.59 & $-15,449$ \\
\hline 18 & 5.3 & 2.25 & 5,805 & 2,762 & 723 & 5.51 & 74,554 \\
\hline 18 & 5.3 & 2.38 & 5,811 & 2,770 & 723 & 5.51 & 72,147 \\
\hline 18 & 4.9 & 2.25 & 6,010 & 2,873 & 748 & 5.44 & 143,775 \\
\hline 18 & 4.9 & 2.38 & 6,045 & 2,895 & 753 & 5.44 & 152,557 \\
\hline 18 & 4.75 & 2.25 & 6,089 & 2,915 & 758 & 5.42 & 170,527 \\
\hline 18 & 4.75 & 2.38 & 6,138 & 2,944 & 764 & 5.41 & 184,506 \\
\hline 19.5 & 6.09 & 2.25 & 6,205 & 2,940 & 773 & 5.35 & 247,682 \\
\hline 19.5 & 6.09 & 2.38 & 6,356 & 3,016 & 791 & 5.31 & 303,736 \\
\hline 19.5 & 5.77 & 2.25 & 6,396 & 3,034 & 796 & 5.30 & 320,726 \\
\hline 19.5 & 5.77 & 2.38 & 6,587 & 3,129 & 820 & 5.24 & 392,728 \\
\hline 19.5 & 5.3 & 2.25 & 6,700 & 3,182 & 834 & 5.21 & 438,219 \\
\hline 19.5 & 5.3 & 2.38 & 6,940 & 3,301 & 864 & 5.15 & 529,892 \\
\hline 19.5 & 4.9 & 2.25 & 6,968 & 3,313 & 868 & 5.14 & 542,143 \\
\hline 19.5 & 4.9 & 2.38 & 7,241 & 3,447 & 902 & 5.08 & 646,883 \\
\hline 19.5 & 4.75 & 2.25 & 7,067 & 3,362 & 880 & 5.12 & 580,097 \\
\hline 19.5 & 4.75 & 2.38 & 7,350 & 3,500 & 915 & 5.05 & 689,614 \\
\hline 21 & 6.09 & 2.25 & 6,985 & 3,312 & 870 & 5.13 & 558,925 \\
\hline 21 & 6.09 & 2.38 & 7,217 & 3,426 & 899 & 5.08 & 648,228 \\
\hline 21 & 5.77 & 2.25 & 7,209 & 3,414 & 898 & 5.07 & 653,052 \\
\hline 21 & 5.77 & 2.38 & 7,466 & 3,538 & 930 & 5.01 & 753,179 \\
\hline 21 & 5.3 & 2.25 & 7,541 & 3,562 & 939 & 4.99 & 795,111 \\
\hline 21 & 5.3 & 2.38 & 7,805 & 3,688 & 972 & 4.93 & 900,171 \\
\hline 21 & 4.9 & 2.25 & 7,806 & 3,679 & 972 & 4.93 & 909,191 \\
\hline 21 & 4.9 & 2.38 & 8,053 & 3,795 & 1,003 & 4.88 & $1,010,105$ \\
\hline 21 & 4.75 & 2.25 & 7,897 & 3719 & 983 & 4.91 & 949,081 \\
\hline 21 & 4.75 & 2.38 & 8,138 & 3,832 & 1,013 & 4.86 & $1,047,939$ \\
\hline
\end{tabular}




\subsubsection{Economic value of thermal growth coefficient (TGC)}

Improving growth rate allowed reaching harvest weight in a shorter period of time and had two major impacts: 1) improving growth rate increased the daily feed intake and consequently, the daily consumption of oxygen as well (Eq. [4.4.9]). When oxygen consumption increases, the farmers must stock less fish in a batch to avoid oxygen consumption to exceed the supply; 2 ) more batches can be produced. Improving growth rate decreased production per batch but increased the number of batches per year.

Table 4.7: Economic values (in $€ / \mathrm{kg}$ ) of thermal growth coefficient (TGC) according to the average $(\mathrm{Tm})$ and the amplitude $(\mathrm{Ta})$ of temperature. When $\sigma \mathrm{g}=\mathbf{0 . 1 3}$.

\begin{tabular}{cccc}
\hline & & \multicolumn{2}{c}{$\operatorname{Tm}\left({ }^{\circ} \mathrm{C}\right)$} \\
\cline { 3 - 4 } & & 18 & 19.5 \\
\hline \multirow{3}{*}{$\operatorname{Ta}\left({ }^{\circ} \mathrm{C}\right)$} & 6.09 & -0.02 & 0.05 \\
& 5.77 & -0.02 & 0.06 \\
& 5.3 & 0 & 0.08 \\
& 4.9 & 0.01 & 0.08 \\
& 4.75 & 0.01 & 0.09 \\
\hline
\end{tabular}
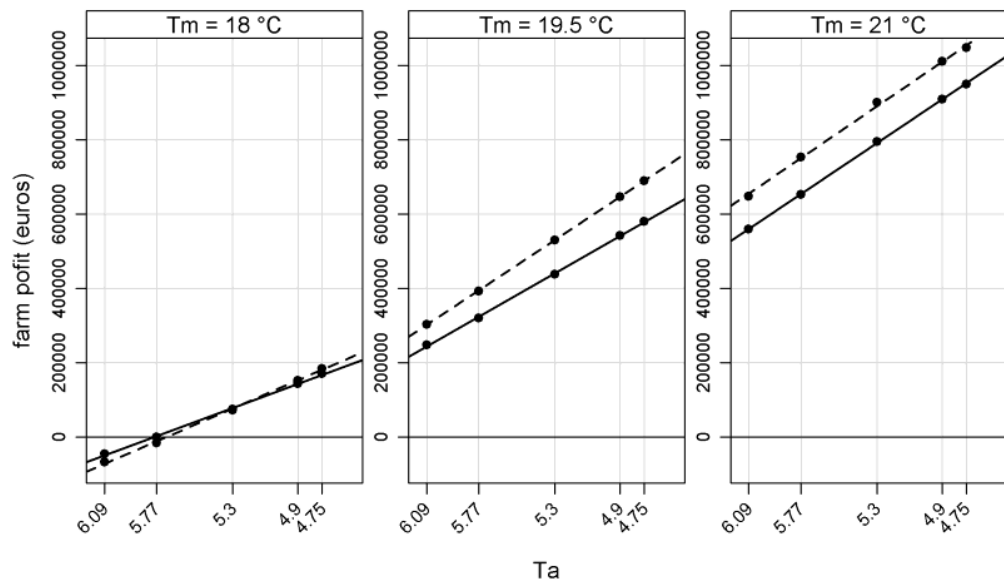

TGC

$2.25---$

Figure 4.4: Annual profit per farm for different thermal growth coefficient (TGC) and as a function of the average ( $\mathrm{Tm}$ ) and the amplitude (Ta) of temperature. 
Variation of $E V_{T G C}$ as a function of $T a$ - When $\mathrm{Tm}$ was low $\left(18^{\circ} \mathrm{C}\right)$ and $\mathrm{Ta}$ was high $\left(\geq 5.3{ }^{\circ} \mathrm{C}\right)$, the reduction in production per batch was not compensated by the higher number of batches, and improving growth rate thus decreased profit (Figure 4.4). Consequently, the economic value of TGC (EVTGC) was negative, $-0.01 € / \mathrm{kg}$ (Table 4.7). However, when Ta decreased (less fluctuation), the profit from improving TGC became null or even slightly positive, $\mathrm{EV}_{\mathrm{TGC}}=0.01$ when $\mathrm{Ta}$ is 4.75

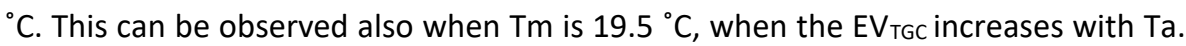
When $\mathrm{Tm}$ was $21^{\circ} \mathrm{C}$, however, the $\mathrm{EV}_{\mathrm{TGC}}$ started to decrease when Ta was lower than $5.3{ }^{\circ} \mathrm{C}$ because the oxygen available at Dlimit started to decrease, constraining the number of fish stocked per batch.

Variation of $E V_{T G C}$ as a function of $\mathrm{Tm}$ - When $\mathrm{Tm}$ was higher $\left(19.5^{\circ} \mathrm{C}\right.$ or $\left.21^{\circ} \mathrm{C}\right)$, the decrease in time to reach harvest weight due to improvement of TGC was higher than at $18{ }^{\circ} \mathrm{C}$. As an example, for $\mathrm{Ta}=6.09{ }^{\circ} \mathrm{C}$, this decrease was $2.87 \%$ at $\mathrm{Tm}=21$ ${ }^{\circ} \mathrm{C}$ compared to $2.54 \%$ at $\mathrm{Tm}=18{ }^{\circ} \mathrm{C}$. We already saw in section 3.1.1 that a reduction in the time to reach harvest weight decreased the average oxygen consumption at Dlimit. Therefore, the decrease in number of fish stocked due to higher daily oxygen requirements was lower at $\mathrm{Tm}=21{ }^{\circ} \mathrm{C}$ than at $\mathrm{Tm}=18{ }^{\circ} \mathrm{C}$, and this reduction was compensated by the higher batch number at $21{ }^{\circ} \mathrm{C}$, while that was not the case at $18{ }^{\circ} \mathrm{C}$. Improving growth rate when $\mathrm{Tm}$ was $19.5^{\circ} \mathrm{C}$ or $21^{\circ} \mathrm{C}$ increased profit (Figure 4.4) and hence the economic value of TGC (Table 4.7).

\subsection{Discussion}

The bioeconomic model developed by Besson et al. (2014) was adapted to investigate the economic impact of genetic improvement of sea bass produced in a sea cage farming system. In sea cages, fish are exposed to variations in water temperature, which has two consequences: variation in metabolic rate and feed intake (see Eq. [4.4.5]) and variation in oxygen supply across the year (see Eq. [4.4.2] and Eq. [4.4.11]). An increase in water temperature, increases the oxygen demand, because of an increase in feed intake, but decreases the oxygen supply. As a result, dissolved oxygen may become a rearing constraint during the production cycle when the oxygen requirement of the fish is higher than the supply. The aim of the study, therefore, was to estimate the economic impact of improving TGC of sea bass produced in sea cages in different scenarios of temperature profiles typically observed in the Mediterranean Sea. The differences in temperature profiles led to differences in oxygen supply profiles likely to modify the economic benefit expected from selective breeding for growth. This economic 
impact was expressed via economic values (EV) calculated as extra profit obtained per kg of fish produced when increasing TGC by one genetic standard deviation. The definition of the EV of a trait is the economic gain/loss due to change in a trait while keeping the other traits constant. Therefore, when calculating EV TGC $_{\text {we }}$ should not change other traits to avoid interactions effects that could bias our economic values. This is why we kept the total FCR constant while changing TGC level.

Improving TGC leads to faster growing fish with higher daily energy requirement and therefore, higher daily oxygen consumption. Faster growth of fish has two consequences for farm management: 1 ) it forces farmers to reduce the average stocking density in order to avoid oxygen shortage, and 2) it accelerates the time period required to reach the targeted harvest weight, enabling farmers to produce more batches in a given time. We found that the economic value of TGC varied across tested scenarios differing in temperature profiles. In the range of averages and amplitudes tested, the economic value of TGC was influenced mostly by the average temperature. Accordingly, the Mediterranean can be divided in two regions: (i) the western part of the Mediterranean with an average temperature of $18{ }^{\circ} \mathrm{C}$, broadly encompassing the eastern coast of Spain, southern France and northwestern Italy. In this region, the economic value of TGC was close to zero or even negative (when $\mathrm{Ta}>4.9^{\circ} \mathrm{C}$ ) because the higher batch rotation due to faster growth did not compensate for the reduction in stocking density, and (ii) the eastern part of the Mediterranean where the average temperature is $19{ }^{\circ} \mathrm{C}-21^{\circ} \mathrm{C}$, encompassing western Greece, southern Greece and southern Turkey. Under these latter conditions, the economic value of TGC was positive. The difference with western Mediterranean is due to the fact that increasing average temperature limited the reduction of stocking density due to faster growing fish. Therefore, improving TGC increased profit because the increase in batch number compensated for the lower stocking density, resulting in a positive economic value. Our results provide a first insight into the economic impact of genetic improvement of TGC of sea bass produced in sea cages under different temperature conditions. Our findings are supported by our previous study focused on recirculating aquaculture system (RAS) where we showed that the economic value of TGC was null when the limiting factor is the treatment capacity of the bio filter because increasing TGC increases daily feed intake and daily nitrogen emission (Besson et al., 2014). As a result, genetic improvement of TGC forces farmers to stock less fish to comply with the nitrogen treatment capacity of the bio-filter but this loss is compensated for by higher number of batches grown. Similarly, in a sea cage system limited with an average temperature of $18{ }^{\circ} \mathrm{C}$, the gain of productivity due 
to faster growing fish is offset by a lower stocking density due to higher oxygen requirements. The results of the present study and the results of Besson et al. (2014) show that it is essential to calculate the economic value of TGC in the right context with the right limiting factor to evaluate the economic impact of genetic improvement and to make decisions regarding breeding objectives.

In the present study, we considered that economic and technical parameters were fixed across the different temperature profiles. In reality, farms differ in their fixed and variable cost structure, which would impact the economic value of TGC. Those costs are, indeed, fixed until a certain limit. We could easily imagine that if the production doubles, farmers would need to hire technicians. However, we assume that the changes in fish production due to genetic improvement of TGC by one genetic standard deviation, in our case, will not impact fixed costs. Moreover, each farm has a different stocking strategy, depending on temperature profile. Some farms avoid stocking juveniles in winter when temperature is close to the minimal for sea bass $\left(12{ }^{\circ} \mathrm{C}\right)$, because growth and feed efficiency are low. Water flow can also affect the profitability of the farm. The effects of water flow and average water temperature are similar with respect to oxygen supply. With a lower water flow, a lower amount of oxygen is supplied to the cage similarly as when average temperature Tm increases. Consequently, when water flow is lower, the number of fish stocked decreases and annual profit decreases as well. Water flow therefore acts as a scaling factor for profit. Keeping economic and technical parameters fixed enabled us to fairly compare the economic impact of genetic improvement for growth across temperature profiles considering an average farm producing sea bass in the Mediterranean. However, our model does not represent all the situations, and conclusions should be refined according to specific situations.

From a theoretical point of view, the calculation of economic values is only relevant in a system with optimized management (Dekkers, 1991; Amer et al., 1994). This study used a management strategy where farmers optimized the number of fish stocked per batch across the year depending on the predicted temperature to prevent any drop of oxygen below the limit during production cycle. This study used a management strategy where farmers optimized the number of fish stocked per batch across the year depending on the predicted temperature to prevent any drop of oxygen below the limit during the production cycle. The relevance of this strategy is supported by studies from Seginer and Halachmi (2008) and Villanueva et al. (2013) who showed, using modelling, that stocking density varies from batch to batch according to environmental variation, i.e. rearing temperature. However, some farmers might decide to stock at the same safe density across the year to avoid a drop of oxygen below the safe limit. Such a management decision leads to 
an underutilisation of the system's capacities. It would be more efficient, therefore, to first stock batches optimally before using genetically improved fish to increase farm profit. We verified the outcome of this hypothesis of suboptimal constant stocking - i.e. stocking fish in all batches at a level such that the most critical batch would not reach the oxygen limitation at any time - using our bioeconomic model (data not shown). This resulted in lower gains due to lower overall stocking rate, but a similar pattern with EVs of TGC at low temperatures being zero or negative and higher at high temperatures. Furthermore, Hernández et al. (2007) as well as Seginer and Ben-Asher (2011) showed that optimal harvest weight also changes according to temperature. However, in our study we considered fixed harvest weight as a market requirement; the effect of genetic improvement of TGC on optimal harvest weight would require further investigation.

Another main assumption of the model is the independence of feed conversion ratio (FCR) relative to TGC. Ponzoni et al. (2007) showed that the economic return of implementing genetic improvement of harvest weight would increase the benefit/cost ratio of a farm producing tilapia in Malaysia if the genetic correlation of harvest weight with feed intake was 0.85 , which implies a correlated response in FCR to selection on harvest weight. When including a correlated response between TGC and FCR, the EV of TGC would be partly influenced by the better efficiency of the fish. However, there is not yet consensus on the genetic correlation between TGC and FCR because FCR is a trait difficult to measure on individual fish (Thodesen et al., 1999; Sanchez et al., 2001; Mambrini et al., 2004; Silverstein et al., 2005; Kause et al., 2006). Moreover, we wanted to focus this paper on studying the effect of growth per se (and not an hypothetical correlated increase in feed efficiency) in an environment with limited supply of oxygen. For these reasons, we chose to implement an empirical equation of FCR dependent on fish weight (Lanari et al., 2002) and temperature (Person-Le Ruyet et al., 2004) rather than a bioenergetics model. A bioenergetics model such as presented by Cho and Bureau (1998) would generate an intrinsic correlation between TGC and FCR whereas with Eq. [4.4.7], daily FCR depends only on body weight and temperature. Whatever the TGC value, the individual FCR integrated over the growing period remained constant to 2.0 using Eq. [4.7].

Considering these main assumptions, our results show that implementing genetic selection to improve only TGC would not be economically profitable for all fish farms across the Mediterranean. Given the climatic conditions, the western and eastern part of the Mediterranean could require a separate breeding program. This is comparable to the conclusion of Rose et al. (2015) who demonstrated that sheep breeding programs in Australia should be region specific, depending on 
pasture growth. For sea bass in Europe, most breeding programs include several traits in the breeding objective (Chavanne et al., 2016; Janssen et al., In Press). Therefore, to confirm the hypothesis that different breeding programs between eastern and western Mediterranean are needed, the economic values of all the traits in the breeding objectives and the correlation between breeding objectives from both regions should be estimated (Rose et al., 2015).

When multiple traits are included in a breeding objective the response to selection is the response in the aggregate genotype. The aggregate genotype is calculated by the sum of the products of the economic value of all traits and the responses per trait. The responses per trait depend on the additive genetic variance of each trait, but also on genetic correlations between traits in the aggregate genotype. TGC is a trait with high heritability and easy to measure. Despite the fact that it has a negative economic value in certain regions it could still be interesting to select fish with faster growth because of positive genetic correlations with other economically interesting traits. For instance, fillet yield is an economic important trait in fish farming and Rutten et al. (2005) showed that the genetic correlation between body weight and fillet yield in Nile tilapia (Oreochromis niloticus) was 0.74 . Therefore, improvement of fillet yield could be obtained through selection for increased body weight. FCR is another important trait that could simultaneously increase economic return and decrease environmental impacts (Besson et al., 2014). However, further research is needed to quantify the genetic correlation of feed conversion ratio with growth traits.

Finally, our results raise the idea of evaluating the potential for selecting traits related to oxygen consumption and to estimate the genetic correlation of these traits with TGC. Previous studies already suggested a high heritability about 0.5 for tolerance to hypoxia in common carp (Nagy et al., 1980). Our bioeconomic model could be extended in future work to compute the economic interest of changing the tolerance to hypoxia for sea bass. Positive economic values would makes tolerance to hypoxia a potential interesting trait to breed for, provided that the trait shows sufficient additive genetic variance. 


\subsection{Conclusion}

Our study is the first investigating the economic impact of genetic improvement of growth rate (TGC) in sea bass reared in sea cages with different temperature profiles. Oxygen supply was considered the limiting factor constraining stocking density in the cages. We show through the calculation of economic values that the economic impact is dependent on temperature conditions. When the average temperature was $18{ }^{\circ} \mathrm{C}$, which corresponds to the average temperature encountered in the western Mediterranean, improving TGC did not impact farm profit. However, when the average temperature was $19.5^{\circ} \mathrm{C}$ or $21{ }^{\circ} \mathrm{C}$ like in eastern Mediterranean, improving TGC had a positive impact on farm profit. These results emphasize the need of calculating economic values of all the traits included in breeding programs of sea bass to investigate the potential need of developing different breeding objectives according to the geographic location.

\section{Acknowledgement}

M. Besson benefited from a joint grant from the European Commission and IMARES, within the framework of the Erasmus-Mundus joint doctorate "EGS-ABG". The authors thank Kefalonia Fisheries and Gloria Maris for their collaboration. M. Besson is grateful to K. Janssen for his help in developing the bioeconomic model. 


\section{5 \\ Effect of production quotas on economic and environmental values of growth rate and feed efficiency in sea cage fish farming}

M. Besson ${ }^{1,2}$, I.J.M. de Boer ${ }^{3}$, M. Vandeputte ${ }^{2,4}$, J.A.M. van Arendonk ${ }^{1}$, E. Quillet ${ }^{2}$, H. Komen ${ }^{1}$, J. Aubin ${ }^{5}$

\footnotetext{
${ }^{1}$ Animal Breeding and Genomics Centre, Wageningen University, PO Box 338, 6700 AH Wageningen, the Netherlands

${ }^{2}$ Génétique animale et biologie intégrative, INRA, AgroParisTech, Université Paris-Saclay, 78350 Jouyen-Josas, France

${ }^{3}$ Animal Production Systems group, Wageningen University, P.O. Box 338, $6700 \mathrm{AH}$

${ }^{4}$ IFREMER, Chemin de Maguelone, 34250 Palavas-les-Flots, France

5 INRA, Agrocampus Ouest, UMR1069 Sol Agronomie Spatialisation, 65 rue de Saint Brieuc, 35042 Rennes, France
}

Submitted 



\section{Abstract}

In sea cage fish farming, production quotas aim to constrain the impact of fish farming on the surrounding ecosystem. It is unknown how these quotas affect economic profitability and environmental impact of genetic improvement. We combined bioeconomic modelling with life cycle assessment (LCA) to calculate the economic (EV) and environmental (ENV) values of thermal growth coefficient (TGC) and feed conversion ratio (FCR) of sea bass reared in sea cages, given four types of quota commonly used in Europe: annual production (Qprod), annual feed distributed (Qannual_feed), standing stock (Qstock), and daily feed distributed (Qdaily_feed). ENV were calculated for LCA impact categories climate change, eutrophication and acidification. ENV were expressed per ton of fish produced per year (ENV(fish)) and per farm per year (ENV(farm)). Results show that irrespective of quota used, EV of FCR as well as ENV(fish) and ENV(farm) were always positive, meaning that improving FCR increased profit and decreased environmental impacts. However, the EV and the ENV(fish) of TGC were positive only when quota was Qstock or Qdaily_feed. Moreover, the ENV(farm) of TGC was negative in Qstock and Qdaily_feed quotas, meaning that improving TGC increased the environmental impact of the farm. We conclude that Qstock quota and Qdaily_feed quota are economically favorable to a genetic improvement of TGC, a major trait for farmers. However, improving TGC increases the environmental impact of the farm. Improving FCR represents a good opportunity to balance out this increase but more information on its genetic background is needed to develop breeding programs improving FCR.

Keywords: bioeconomic model, economic weights, environmental values, fish farming, life cycle assessment, quota 


\subsection{Introduction}

The production of fish in sea cages releases, without being filtered, nutrients to the surrounding environment. The accumulation of organic matter stemming from the cages on the benthos may cause eutrophication, which affects the natural ecosystem (Folke et al., 1994; Mente et al., 2006). In all European countries, therefore, producing fish in sea cages has to comply with regulatory measures. These measures require an environmental impact study of biotic and abiotic changes due to the farming process (Read and Fernandes, 2003; Holmer et al., 2008). The aim of this environment impact study is to explore how much fish can be produced based on the carrying capacity of the natural ecosystem. The estimations can be supported by modeling tools. In Norway, for example, the Modelling - On growing fish farms - Monitoring (MOM) (Ervik et al., 1997; Hansen et al., 2001; Stigebrandt et al., 2004) is legally required by the Directorate of Fisheries for site selection (Lundebye, 2013). The environmental impact study determines the delivery of the farming authorization accompanied by prescriptions that set a specific quota to the farm. The nature of the quota varies across European countries. In France, Greece or Spain, quotas constrain the annual production of fish or the annual feed distributed per farm (FAO, 2014a,b), whereas in Denmark, the quota is based on annual emission of nitrogen (Holmer et al., 2008). In Ireland, the production is constrained by the density of fish (Holmer et al., 2008). In Norway, the production of salmon is limited by the standing biomass at a given site (Asche et al., 2011). The main goal of these quotas is to limit the environmental impact of the farm to an acceptable level.

Nevertheless, fish farming is growing due to an increasing demand for fish products; the challenge, therefore, is to reach the demand while constraining or reducing environmental impacts. This context makes genetic improvement particularly important as it acts at the source of emission by generating cumulative changes in animal performances (Wall et al., 2010; van Middelaar et al., 2014). The economic (EV) and environmental value (ENV) of genetic improvement of traits included in the breeding goal can be estimated using bio-economic models. These values represent the economic or environmental impacts of a change in one trait keeping the other traits constant (Hazel, 1943). Environmental values were first calculated in dairy systems using the principles of life cycle assessment (LCA) (Bell et al., 2010; Bell et al., 2011; van Middelaar et al., 2014). In fish farming, we combined a bioeconomic model with an LCA to estimate the economic and environmental values of thermal growth coefficient (TGC) and feed conversion ratio (FCR) of African catfish (Clarias gariepinus) produced in a recirculating 
aquaculture system, RAS (Besson et al., 2016a). The results showed that in dairy as well as in fish farming, genetic change of a trait can simultaneously reduce environmental impacts per unit of products and increase economic farm profit by improving production efficiency or production level. An improved production efficiency decreases the amount of resources needed per unit of product. A higher production level dilutes fixed environmental impacts over more production. However, as we showed in Besson et al. (2014); Besson et al., (2016a), the economic and environmental values depended on the factors limiting production, which in the case of RAS are fish rearing density and nitrogen treatment capacity. In sea cages, the limiting factor is, most of the time, the production quota. The variety of quotas applied in sea cage farming suggests that genetic improvement might lead to a variety of economic and environmental responses, depending on which quota is being applied.

This study aims to investigate how different types of quota affect the economic and environmental impacts of genetic improvement in sea cage system. Using our bioeconomic / LCA model, we calculate the economic and environmental values of TGC and FCR in a sea cage system producing sea bass. First, we express ENV as a change of environmental impacts per ton of fish produced. This functional unit emphases the change in environmental efficiency of producing fish after genetic improvement. However, in the context of quotas such a functional unit cannot describe the dynamics of environmental impacts at farm level. Therefore, we also calculate ENV at farm level.

\subsection{Material and methods}

\subsubsection{Bioeconomic model}

The bioeconomic model developed in R ( $R$ Development Core Team, 2008) was based on the model described in Besson et al., (2014) and Besson et al., (2016b). In the present study the model was adapted to estimate the production of sea bass (Dicentrarchus labrax) in a hypothetical sea cage farm (based on a real farms data from Gloria Maris) constrained by quota. The farm was composed of 34 circular cages of $600 \mathrm{~m}^{3}$ for pre-growing and 34 circular cages of 1,800 $\mathrm{m}^{3}$ for on-growing. Fish were stocked at $10 \mathrm{~g}$ and sold at a fixed harvest weight of $400 \mathrm{~g}$. Stocking occurred all year round. The bioeconomic model was divided in 4 model parts.

(1) The fish model estimates individual fish growth using the thermal growth coefficient (TGC) corrected for the concave relationship between growth rate and temperature (Mallet et al., 1999). The time to reach harvest weight, therefore, 
varied according to the daily temperature encountered by the fish and thus according to the stocking date. Feed conversion ratio (FCR) was modelled by combining a specific seabass model from Person-Le Ruyet et al. (2004) with a model from Lanari et al. (2002). The fish model also estimates the individual emission of nutrient based pollutants using mass-balance (Cho et al., 1990; Cowey et al., 1991). Further details about the fish model are given in appendix 5.1.

(2) The batch model estimates the average stocking density of a batch depending on individual fish performances (from fish model) and mortality. A batch is defined as the group of fish stocked at the same time in the same pre-growing cage.

(3) The farm model estimates the number of batches produced to calculate annual fish production, emission of pollutants, and annual feed consumption. At farm level, a quota is applied which constrain farm production. In the reference scenario the production of the farm was set to 1,000 tons per year and four different quotas were tested:

- Production quota (Qprod). The production of the farm was limited to 1,000 tons per year.

- Feed quota (Qannual_feed). The total amount of feed distributed per year per farm was limited to 2,050 tons.

- Standing stock (Qstock). The instant biomass present on site at any day of the year was constrained to 435 tons.

- Daily feed distribution (Qdaily_feed). The amount of feed distributed per day per farm was limited to 4 tons.

The values of each quota was set to allow the farm to produce 1,000 tons in the reference scenario. In this study, we considered that $\mathrm{O}_{2}$ availability was never limiting. In every quota scenario, the density of stocking was considered fixed along the year. The outputs of the bioeconomic model were used to generate inventory data for the LCA.

(4) Finally, in the economic model, annual profit is calculated by combining results of the farm model with economic parameters.

\subsubsection{Life cycle assessment}

\section{Goal and scope}

LCA is a standardized method conceived to calculate the environmental impact of a production chain, from raw material extraction up to the product's end-of life (Guinée et al., 2002). In this study, we applied LCA according to the main specifications of ILCD standards. 
The system was defined from cradle-to-farm-gate and included five distinct subsystems: (1) production of purchased feed, including production of ingredients, processing, and transportation; (2) production of energy expended at farm level (electricity, gas and petrol); (3) production of farming facilities and equipment; (4) Chemical used, including the production and the use of anti-fouling for nets; (5) farming operation, including nutrient based pollutants emission from biological transformation of feed.

The functional units in which environmental impacts were expressed was (a) per ton of fish produced on a basis of one year of routine production (impact_fish) and (b) per farm on a basis of one year of routine production (impact_farm). impact_fish and impact_farm were used to calculate environmental values.

\section{Life cycle inventory}

(1) Production of purchased feed - Crop-derived ingredients originated from Brazil and France (e.g. soybean meal from Brazil and wheat from France), whereas fishderived ingredients originated from the Peruvian fish milling industry (Biomar, personnal communication, 2014). The chemical composition of the diet and the origin of the ingredients are given in appendix 5.2. The exact composition is not given to respect confidentiality. Economic allocation was used to calculate the environmental impacts of processes yielding multiple products in the feed production industry (de Vries et al., 2010). Ingredients were transported to the feed manufacture in France (Aquitaine) by transoceanic ship and by lorry (>32t), whereas the transport of feed from feed mill to the fish farm in southern France was by lorry (>32t). Transport distances and other data required to compute the environmental impact of feed ingredients were based on Pelletier et al. (2009); Boissy et al. (2011), and presented in detail in appendices 5.2 and 5.3.

(2) Production of energy expended on farm - The energy consumed by the farm was considered fixed. The energy consumption was set at 25,000 I of diesel per year, 55,000 I of petrol per year and $110,000 \mathrm{kWh}$ of electricity per year. The electricity used by the farm was coming from the French energy mix proposed by Ecolnvent v3 database. Contribution analysis is available in appendix 5.4.

(3) Production of farming facilities and equipment used - We considered the construction of a building of $650 \mathrm{~m}^{2}$ with a life span of 30 years. The equipment includes cages ( 64 in total), vehicles ( 2 boats and 6 barges, 2 trucks, 1 car), two ice making machines and other small equipment (i.e. plastic buckets). The use of building and equipment was considering fixed per year at farm level. The 
background processes stem from Ecolnvent v3. Contribution analysis is available in appendix 5.5 .

(4) Chemical used - This sub-system includes the emission from the production and the use of anti-fouling for nets. We considered that the nets were treated every nine months with water-based anti-fouling with copper dioxide at $24 \%$.

(5) Farm operation - The farm operation sub-system includes the emission of pollutants from biological transformation of the feed distributed to the fish. The amount of nitrogen $(N)$, phosphorus $(P)$ and chemical oxygen demand (COD) of the dissolved organic matter excreted by the fish directly into the sea were calculated through the bioeconomic model. Contribution analysis is available in appendix 5.6.

\section{Life cycle impact assessment}

Each flow observed in the system was assigned to different impact categories relatively to its potential environmental effects. We chose to investigate eutrophication, acidification and climate change (Guinée et al, 2002), because fish farming contributes most to these environmental impact categories (Pelletier et al., 2007; Aubin, 2013). The characterisation factors from CML2 Baseline 2000 version 2.04 were used for eutrophication and climate change. The impact categories were calculated using Simapro ${ }^{\circledR} 7.0$ software.

\subsubsection{Economic and environmental values}

Economic (EV) and environmental values (ENV) represent the change in profit and environmental impacts due to genetic improvement in a trait, while keeping other traits in the breeding goal constant. We calculated EV and ENV for two important traits representing production performance of a farm: TGC and the FCR. EV and ENV were calculated for each quota scenario. The genetic improvement implemented was one genetic standard deviation $\left(\sigma_{\mathrm{g}}\right)$ from the mean $(\mu)$. $\mu_{\mathrm{TGC}}=$ $2.25, \sigma_{\mathrm{g}-\mathrm{TGC}}=0.23$ (Vandeputte et al., 2014) and $\mu_{\mathrm{FCR}}=2.0, \sigma_{\mathrm{g}-\mathrm{FCR}}=0.38$. The genetic standard deviation of FCR was calculated according to Sutherland (1965) using data from Kause et al., (2006). EVs were calculated as the difference between profit after genetic change minus profit before genetic change, divided by annual production before genetic change (Groen, 1989). The EV was expressed in euro per ton of fish produced. 


$$
\mathrm{EV}=\frac{\text { Profit }_{\mu+\sigma_{\mathrm{g}}}-\text { Profit }_{\mu}}{\text { Production }_{\mu}}
$$

Environmental values were first calculated per ton of fish produced; ENV(fish). ENV(fish) were calculated as environmental impacts (category level) per ton of fish produced before genetic improvement minus environmental impacts per ton of fish produced after genetic improvement:

$$
\operatorname{ENV}(\text { fish })=\text { Impact_fish }_{\mu+\sigma_{\mathrm{A}}}-\text { Impact_fish }_{\mu}
$$

ENV(fish) express, therefore, the capacity of a trait to improve environmental efficiency of fish production. However, the aim of the quota is mainly to limit the impact of the farming process on the local environment. Hence, we also calculated environmental values at farm level; ENV(farm). ENV(farm) estimate the capacity of a trait to affect environmental impacts of a specific farming site. They were calculated similarly as economic values i.e. difference between the impacts at farm level after genetic change minus the impacts at farm level before genetic change divided by annual production before genetic change. It means that the ENV(farm) were rescaled to impacts per farm per ton of fish to be able to compare with ENV(fish).

$$
\operatorname{ENV}(\text { farm })=\frac{\text { Impact_farm }_{\mu+\sigma_{\mathrm{A}}}-\text { Impact_farm }_{\mu}}{\text { Production }_{\mu}}
$$

Each trait has an ENV(fish) and an ENV(farm) for each of the three impact categories investigated. ENV(fish) and ENV(farm) were also expressed in percentage of change.

$$
\begin{aligned}
\operatorname{ENV}(\text { fish\%) } & =\frac{\text { ENV(fish }) \times 100}{\text { Impact_fish }_{\mu}} \\
E N V(\text { farm\% }) & =\frac{\text { ENV(farm }) \times 100}{\text { Impact_farm }_{\mu}}
\end{aligned}
$$




\subsection{Results}

Genetic improvement can affect the production level (i.e. tonnes of fish produced per year) and/or the production efficiency of the farm (i.e. quantity of input used per unit of fish produced) (Table 5.1). These changes affect the economic and environmental values of thermal growth coefficient (TGC) and feed conversion ratio (FCR).

\subsubsection{Economic values, EV (Table 5.1 and 5.2)}

\section{EV of TGC}

Improving TGC decreased the time to reach harvest size and increased daily feed intake. In consequence, production should increase as more batches can be produced (increasing batch rotation). When the quota was on annual production (Qprod), higher batch rotation was balanced by lower stocking density to comply with the quota. This situation was similar with a quota on annual feed distributed (Qannual_feed). Thus, the economic value economic value of TGC was null in Qprod and Qannual_feed. Conversely, when the quota was on daily standing stock (Qstock) or daily feed distributed (Qdaily_feed), increasing TGC led to more batches, but without a proportional decrease in stocking density. The resulting annual production was higher. Therefore, the economic value of TGC was positive: $0.12 € / \mathrm{kg}$ of fish for Qstock and $0.08 € / \mathrm{kg}$ of fish for Qdaily_feed.

\section{EV of FCR}

Improving FCR decreased the amount of feed required per unit of fish produced. When the quota was on feed distributed (Qannual_feed or Qdaily_feed) better FCR increased, therefore, production efficiency but production could also be increased until the feed quota was reached. Consequently, the economic value of FCR was $1.14 € / \mathrm{kg}$ for Qannual_feed and $0.95 € / \mathrm{kg}$ for Qdaily_feed. When Qprod or Qstock were the quotas, improving FCR improved only production efficiency. Thus, less feed was consumed at farm level and the economic value of FCR was $0.50 € / \mathrm{kg}$. 
Table 5.1: Summary of the consequences of genetic improvement in TGC (thermal growth coefficient) and FCR (feed conversion ratio) on technical performances of a sea cage farm constrained by different quota. Qprod is the quota on annual production, Qannual_feed is on annual feed distributed, Qstock is on the daily biomass present on site and Qdaily_feed is on daily feed distributed.

\begin{tabular}{lcc}
\hline \multicolumn{1}{c}{ Quota type } & Improving TGC & Improving FCR \\
\hline Qprod & none & Production efficiency \\
Qannual_feed & none & Production + Production efficiency \\
Qstock & Production & Production efficiency \\
Qdaily_feed & Production & Production + production efficiency \\
\hline
\end{tabular}

\subsubsection{Environmental value at fish level, ENV(fish)}

More details about the results of the life cycle assessment are given in appendices 5.7, 5.8 and 5.9 .

\section{ENV(fish) of TGC (Table 5.3 and 5.4)}

ENV(fish) of TGC were null for all impact categories when the quota was Qprod or Qannual_feed because in this situation TGC did not increase production or production efficiency. However, when the quota was Qstock or Qdaily_feed, improving TGC increased production. When production increased, the fixed environmental impacts are diluted over more fish produced. The fixed environmental impacts are the production of energy, the use of chemical and the production of equipment and infrastructure. These impacts represent $16.4 \%$ of acidification and $6.7 \%$ of climate change. Consequently, the environmental impact per ton of fish produced decreased and the ENV(fish) of TGC were positive for acidification and climate change categories. However, fixed environmental impacts represent less than $1 \%$ of eutrophication. The $99 \%$ remaining are caused by feed production and fish excretion which increased with higher production in Qstock and Qdaily_feed. Therefore, ENV(fish) of TGC for eutrophication is close to zero in Qstock and Qdaily_feed.

\section{ENV(fish) of FCR (Table 5.3 and 5.5)}

The ENV(fish) of FCR in all quotas is positive, i.e. improving FCR decreases environmental impacts, because improving FCR decreased the amount of inputs 
need to produce one tonne of fish. The decrease was higher for eutrophication because eutrophication also includes the reduction in pollutants emission from the fish.

\subsubsection{Environmental values at farm level, ENV(farn)}

\section{ENV(fish) of TGC (Table 5.3 and 5.4)}

ENV(farm) of TGC was null or close to null for all impact categories when quota was Qprod or Qannual_feed because TGC did not increase production or production efficiency. When the quota was Qstock or Qdaily_feed, production increased as well as feed consumption and emission of pollutants, which are the main contributors to environmental impacts. Consequently, the ENV(farm) of TGC was negative for all impact categories, meaning that increasing TGC increased environmental impacts at farm level. The increase of environmental impacts was higher in Qstock quota than in Qdaily_feed.

\section{ENV(fish) of FCR (Table 5.3 and 5.5)}

When the quota was Qprod or Qstock, improving FCR improved production efficiency. Therefore, less feed was consumed at farm level and the ENV(farm) of FCR were positive for all impacts categories, meaning that environmental impacts decreased. When the quota was Qannual_feed, improving FCR increased production efficiency and production, which kept annual consumption of feed constant. Consequently the ENV(farm) of FCR for climate change and acidification was null. However, with better FCR, less nutrient based pollutants were emitted. It resulted in a decrease in eutrophication by $6.66 \%$ because the nutrients-based pollutants emitted to water were considered to remain in water and thus they were contributing to eutrophication only. Thus, for Qannual_feed, the ENV(farm) of FCR for eutrophication was positive. When the quota was Qdaily_feed, improving FCR increased at the same time production efficiency and production but less feed was consumed at farm level. It resulted in a positive ENV(farm) for FCR. The $\mathrm{ENV}$ (fam) of FCR was also higher for eutrophication than other impact categories because improving FCR reduces the amount of pollutants emitted. 
Table 5.2: Effect of different values of thermal growth coefficient (TGC) and feed conversion ratio (FCR) on fish production parameters in different quota scenarios. Qprod is the quota on annual production, Qannual_feed is on annual feed distributed, Qstock is on the daily biomass present on site and Qdaily_feed is on daily feed distributed.

\begin{tabular}{|c|c|c|c|c|c|c|c|c|c|c|c|c|c|c|}
\hline Quota & TGC & FCR & $\begin{array}{l}\text { Days to } \\
\text { reach } \\
\text { harvest } \\
\text { weight } \\
\text { (d) }\end{array}$ & $\begin{array}{c}\text { Number } \\
\text { of batch } \\
\text { produced } \\
\text { (\#) }\end{array}$ & $\begin{array}{l}\text { Production } \\
\text { per batch } \\
\text { (t) }\end{array}$ & $\begin{array}{l}\text { Production } \\
\text { at farm (t) }\end{array}$ & $\begin{array}{c}\text { Feed } \\
\text { consumption } \\
\text { per farm (t) }\end{array}$ & $\begin{array}{l}\text { Incomes } \\
(€ \times \\
1000)\end{array}$ & $\begin{array}{c}\text { Feed } \\
\text { cost } \\
(€ \times \\
1000)\end{array}$ & $\begin{array}{c}\text { Juveniles } \\
\text { cost }(€ \times \\
1000)\end{array}$ & $\begin{array}{l}\text { Fixed } \\
\text { cost } \\
(€ \times \\
1000)\end{array}$ & $\begin{array}{l}\text { Profit } \\
(€)\end{array}$ & $\begin{array}{c}E V \\
T G C \\
(€ / \mathrm{kg})\end{array}$ & $\begin{array}{c}E V \\
F C R \\
(€ / \mathrm{kg})\end{array}$ \\
\hline \multirow{3}{*}{ Qprod } & 2.25 & 2.02 & 573 & 30.87 & 32.4 & 1000 & 2047 & 5598 & 2662 & 692 & 2245 & -0.03 & \multirow{3}{*}{0} & \multirow{3}{*}{0.5} \\
\hline & 2.48 & 2.02 & 528 & 35.64 & 28.1 & 1000 & 2047 & 5598 & 2662 & 692 & 2245 & -521.88 & & \\
\hline & 2.25 & 1.64 & 573 & 30.87 & 32.4 & 1000 & 1660 & 5598 & 2159 & 692 & 2245 & 503048.8 & & \\
\hline \multirow{3}{*}{ Qannual_feed } & 2.25 & 2.02 & 573 & 31.22 & 32.0 & 1000 & 2047 & 5597 & 2661 & 692 & 2245 & 0.56 & \multirow{3}{*}{0} & \multirow{3}{*}{1.14} \\
\hline & 2.48 & 2.02 & 528 & 36.43 & 27.4 & 1000 & 2047 & 5597 & 2661 & 692 & 2245 & -521.19 & & \\
\hline & 2.25 & 1.64 & 573 & 28.97 & 42.5 & 1232 & 2047 & 6900 & 2661 & 853 & 2245 & 1141326 & & \\
\hline \multirow{3}{*}{ Qstock } & 2.25 & 2.02 & 573 & 32.02 & 31.2 & 1000 & 2046 & 5596 & 2659 & 692 & 2245 & 0.46 & \multirow{3}{*}{0.12} & \multirow{3}{*}{0.5} \\
\hline & 2.48 & 2.02 & 528 & 34.49 & 30.6 & 1055 & 2160 & 5904 & 2809 & 730 & 2245 & 120354.6 & & \\
\hline & 2.25 & 1.64 & 573 & 32.02 & 31.2 & 1000 & 1657 & 5596 & 2155 & 692 & 2245 & 504751.8 & & \\
\hline \multirow{3}{*}{ Qdaily_feed } & 2.25 & 2.02 & 573 & 31.12 & 32.1 & 1000 & 2046 & 5597 & 2660 & 692 & 2245 & 0.59 & \multirow{3}{*}{0.08} & \multirow{3}{*}{0.95} \\
\hline & 2.48 & 2.02 & 528 & 35.06 & 29.5 & 1035 & 2118 & 5792 & 2753 & 716 & 2245 & 77713.2 & & \\
\hline & 2.25 & 1.64 & 573 & 29.34 & 39.6 & 1162 & 1929 & 6506 & 2508 & 804 & 2245 & 949212.7 & & \\
\hline
\end{tabular}


Table 5.3: Effect of different values of thermal growth coefficient (TGC) and feed conversion ratio (FCR) on annual emission of pollutants and environmental impacts in different quota scenarios. Qprod is the quota on annual production, Qannual_feed is on annual feed distributed, Qstock is on the daily biomass present on site and Qdaily_feed is on daily feed distributed.

\begin{tabular}{|c|c|c|c|c|c|c|c|c|c|}
\hline Quota & TGC & FCR & $\begin{array}{l}\text { Production } \\
\text { per farm } \\
\text { (t) }\end{array}$ & $\begin{array}{c}\text { Nitrogen } \\
\text { emission }(t)\end{array}$ & $\begin{array}{c}\text { COD } \\
\text { emission }(t)\end{array}$ & $\begin{array}{l}\text { Phosphorus } \\
\text { emission (t) }\end{array}$ & $\begin{array}{l}\text { Climate change } \\
\text { (kg CO} 2 \text {-eq / } \\
\text { ton of fish) }\end{array}$ & $\begin{array}{c}\text { Eutrophication } \\
\text { (kg } \mathrm{PO}_{4}-\mathrm{eq} / \text { ton } \\
\text { of fish) }\end{array}$ & $\begin{array}{c}\text { Acidification } \\
\text { (kg SO} \mathrm{S}_{2} \text {-eq / ton } \\
\text { of fish) }\end{array}$ \\
\hline & 2.25 & 2.02 & 1000 & 114.92 & 2614.15 & 16.44 & 3636.53 & 168.62 & 21.77 \\
\hline \multirow[t]{3}{*}{ Qprod } & 2.48 & 2.02 & 1000 & 114.98 & 2616.06 & 16.45 & 3636.53 & 168.73 & 21.77 \\
\hline & 2.25 & 1.64 & 1000 & 88.29 & 1959.10 & 12.18 & 2995.38 & 127.90 & 18.33 \\
\hline & 2.25 & 2.02 & 1000 & 114.87 & 2613.11 & 16.43 & 3636.02 & 168.59 & 21.76 \\
\hline \multirow[t]{3}{*}{ Qannual_feed } & 2.48 & 2.02 & 1000 & 114.93 & 2615.01 & 16.45 & 3636.02 & 168.69 & 21.76 \\
\hline & 2.25 & 1.64 & 1232 & 108.84 & 2414.94 & 15.02 & 2949.75 & 127.66 & 17.66 \\
\hline & 2.25 & 2.02 & 1000 & 114.79 & 2611.13 & 16.42 & 3635.28 & 168.51 & 21.76 \\
\hline \multirow[t]{3}{*}{ Qstock } & 2.48 & 2.02 & 1055 & 121.20 & 2757.49 & 17.34 & 3622.52 & 168.57 & 21.57 \\
\hline & 2.25 & 1.64 & 1000 & 88.11 & 1954.71 & 12.16 & 2991.65 & 127.68 & 18.31 \\
\hline & 2.25 & 2.02 & 1000 & 114.86 & 2612.80 & 16.43 & 3635.76 & 168.58 & 21.76 \\
\hline \multirow[t]{2}{*}{ Qdaily_feed } & 2.48 & 2.02 & 1035 & 118.94 & 2706.36 & 17.02 & 3627.54 & 168.67 & 21.64 \\
\hline & 2.25 & 1.64 & 1162 & 102.59 & 2276.24 & 14.16 & 2960.63 & 127.67 & 17.83 \\
\hline
\end{tabular}


Table 5.4: Environmental value (ENV) of TGC (thermal growth coefficient) at fish and farm level in different quota. Qprod is the quota on annual production, Qannual_feed is on annual feed distributed, Qstock is on the daily biomass present on site and Qdaily_feed is on daily feed distributed. Between brackets is the percentage a change in environmental impacts. A negative sign means that the environmental impact considered increased after genetic change.

\begin{tabular}{|c|c|c|c|c|c|c|c|c|}
\hline \multirow[b]{2}{*}{ Quota } & \multirow[b]{2}{*}{ TGC } & \multirow[b]{2}{*}{ FCR } & \multicolumn{3}{|c|}{ ENV at farm level } & \multicolumn{3}{|c|}{ ENV at fish level } \\
\hline & & & $\begin{array}{c}\text { Climate } \\
\text { change } \\
\text { (kg CO}{ }_{2} \text {-eq) }\end{array}$ & $\begin{array}{c}\text { Eutrophication } \\
\text { ( kg PO} 4-e q)\end{array}$ & $\begin{array}{l}\text { Acidification } \\
\text { (kg SO} 2-e q)\end{array}$ & $\begin{array}{c}\text { GWP } \\
\text { (kg CO} 2-e q)\end{array}$ & $\begin{array}{l}\text { Eutrophication } \\
\text { ( kg PO} 4-e q)\end{array}$ & $\begin{array}{l}\text { Acidification } \\
\text { (kg SO} 2-e q)\end{array}$ \\
\hline \multirow{2}{*}{ Qprod } & 2.25 & 2.02 & 0 & -0.11 & 0 & 0 & -0.11 & 0 \\
\hline & 2.48 & 2.03 & (0\%) & $(-0.06 \%)$ & $(0 \%)$ & $(0 \%)$ & $(-0.06 \%)$ & $(0 \%)$ \\
\hline \multirow{2}{*}{ Qannual_feed } & 2.25 & 2.02 & 0 & -0.11 & 0 & 0 & -0.11 & 0 \\
\hline & 2.48 & 2.03 & $(0 \%)$ & $(-0.06 \%)$ & $(0 \%)$ & $(0 \%)$ & $(-0.06 \%)$ & $(0 \%)$ \\
\hline \multirow{2}{*}{ Qstock } & 2.25 & 2.02 & -186.84 & -9.35 & -1.00 & 12.76 & -0.06 & 0.19 \\
\hline & 2.48 & 2.03 & $(-5.14 \%)$ & $(-5.55 \%)$ & $(-4.61 \%)$ & $(0.35 \%)$ & $(-0.04 \%)$ & $(0.86 \%)$ \\
\hline \multirow{2}{*}{ Qdaily_feed } & 2.25 & 2.02 & -3.25 & -5.97 & -0.63 & 8.23 & -0.09 & 0.12 \\
\hline & 2.48 & 2.03 & $(-3.25 \%)$ & $(-3.54 \%)$ & $(-2.91 \%)$ & $(0.23 \%)$ & $(-0.05 \%)$ & $(0.55 \%)$ \\
\hline
\end{tabular}


Table 5.5: Environmental value (ENV) of FCR (feed conversion ratio) at fish and farm level in different quota. Qprod is the quota on annual production, Qannual_feed is on annual feed distributed, Qstock is on the daily biomass present on site and Qdaily_feed is on daily feed distributed. Between brackets is the percentage a change in environmental impacts. A positive value means that the environmental impact considered decreased after genetic change.

\begin{tabular}{|c|c|c|c|c|c|c|c|c|}
\hline \multirow[b]{2}{*}{ Quota } & \multirow[b]{2}{*}{ TGC } & \multirow[b]{2}{*}{ FCR } & \multicolumn{3}{|c|}{ ENV per farm } & \multicolumn{3}{|c|}{ ENV per ton of fish } \\
\hline & & & $\begin{array}{c}\text { Climate } \\
\text { change } \\
\text { (kg CO} 2-e q)\end{array}$ & $\begin{array}{c}\text { Eutrophication } \\
\text { ( kg PO} \\
\text {-eq) }\end{array}$ & $\begin{array}{l}\text { Acidification } \\
\text { (kg SO} 2 \text {-eq) }\end{array}$ & $\begin{array}{c}\text { GWP } \\
\text { (kg CO} 2-e q)\end{array}$ & $\begin{array}{l}\text { Eutrophication } \\
\text { ( kg PO} 4-e q)\end{array}$ & $\begin{array}{c}\text { Acidification } \\
\text { (kg SO} \mathrm{SO}_{2} \text {-eq) }\end{array}$ \\
\hline \multirow{2}{*}{ Qprod } & 2.25 & 2.02 & 641.15 & 40.72 & 3.44 & 641.15 & 40.72 & 3.44 \\
\hline & 2.25 & 1.64 & (17.63\%) & (24.15\%) & $(15.80 \%)$ & (17.63\%) & $(24.15 \%)$ & $(15.80 \%)$ \\
\hline \multirow{2}{*}{ Qannual_feed } & 2.25 & 2.02 & 0 & 11.23 & 0 & 686.27 & 40.93 & 4.11 \\
\hline & 2.25 & 1.64 & $(0 \%)$ & (6.66 \%) & $(0 \%)$ & (18.87 \%) & $(24.28 \%)$ & (18.87 \%) \\
\hline \multirow{2}{*}{ Qstock } & 2.25 & 2.02 & 643.63 & 40.83 & 3.45 & 643.63 & 40.83 & 3.45 \\
\hline & 2.25 & 1.64 & (17.71 \%) & (24.23 \%) & (15.86 \%) & (17.71 \%) & (24.23\%) & (15.86 \%) \\
\hline \multirow{2}{*}{ Qdaily_feed } & 2.25 & 2.02 & 194.12 & 20.16 & 1.04 & 675.13 & 40.91 & 3.94 \\
\hline & 2.25 & 1.64 & $(5.34 \%)$ & (11.96 \%) & $(4.79 \%)$ & (18.57 \%) & $(24.27 \%)$ & (18.09\%) \\
\hline
\end{tabular}




\subsection{Discussion}

In sea cage farming, quotas are implemented to limit the environmental impacts of farm operations, such as the deposition of organic matter under the cages and the emission of dissolved nutrients in water, leading to eutrophication. In the present study, we investigated the effect of these quotas on economic and environmental responses to genetic improvement of sea bass. This is the first time the effect of quotas on genetic improvement of fish is tested.

Economic values are used to maximize the economic response in the breeding goal. These values weigh the traits of a breeding goal according to their impacts on farm profit. They are specific to production systems according to the quota applied (Gibson, 1989) or the environmental conditions (Rose et al., 2015). When EVs differ from one production system to another, a single breeding program may not be enough to maximize economic response in all production systems (Rose et al., 2015).

In sea cage farming system, EVs of TGC and FCR varied across quota scenarios. When the quota was standing stock (Qstock) or daily feed distributed (Qdaily_feed), both TGC and FCR had a positive EV, but when the quota was annual production (Qprod) and annual feed (Qannual_feed), only FCR had a positive EV. Thus, in Qprod and Qannual_feed, economic gain would be achieved only if FCR could be improved, either by direct selection or by a genetically correlated response to improvement of TGC, meaning that increasing TGC would decrease FCR. However, there are no practical ways to directly select for FCR in fish as it is difficult to measure this trait in individual fish. Moreover, the existence and the magnitude of the genetic correlation between FCR and TGC is still debated (Sanchez et al., 2001; Thodesen et al., 2001; Mambrini et al., 2004; Kause et al., 2006). Conversely, Qstock and Qdaily_feed had positive values for EV of TGC. Consequently these are the quotas that will generate farm profit from selective breeding on TGC, which is easily achieved in fish breeding programs (Janssen et al., 2016). Additionally, Qstock and Qdaily_feed have a large positive EV for FCR, which could promote the inclusion of this trait in future breeding programs if efficient selection methods for this trait are developed. The different EVs observed across quotas imply, however, that different breeding programs would be needed to optimize economic response in each quota system.

The concerns about environmental impacts of aquaculture are increasing and, in the future, the objective of breeding programs might also shift towards decreasing environmental impacts instead of maximizing economic profit. To do so, environmental values could be used in breeding programs to orient them towards 
the reduction of environmental impacts. In this study, the environmental values were calculated per ton of fish produced (ENV(fish)) and per farm (ENV(farm)).

At fish level, the ENV expresses the capacity of the trait to affect the environmental efficiency of fish production. This type of production-related functional unit has been used for evaluating the environmental impacts of genetic improvement in dairy farming (Bell et al., 2011; van Middelaar et al., 2014) as well as in fish farming in RAS (Besson et al., 2016a). In this latter study, we found a positive ENV(fish) of TGC for climate change and eutrophication because faster growing fish could increase production, which diluted fixed environmental impacts (i.e. energy use). In RAS, fixed environmental impacts represent a high proportion of the total impacts, i.e. $42.4 \%$ of acidification and $26.9 \%$ of climate change in the above-mentioned study. This is because RAS is a highly technological production system requiring a lot of energy and equipment (Aubin et al., 2009). In a sea cage system, we also observed the same trend when Qstock and Qdaily_feed were the quotas. Nevertheless, ENV(fish) of TGC for acidification and climate change were small and even null for eutrophication because in sea cage system, there are less fixed environmental impacts to dilute with higher production. Fixed environmental impacts represented only $6.7 \%$ of climate change, $16.4 \%$ of acidification and $0.8 \%$ of eutrophication. Hence, the ENV(fish) are very sensitive to the type of system and to the proportion of fixed environmental impacts. Regarding FCR, the ENV(fish) were always positive for all impact categories meaning that environmental impacts decreases per ton of fish produced. According to these results, genetic improvement of TGC or FCR affects environmental impacts per ton of fish produced similarly in all quotas. Therefore, a single breeding program using ENV(fish) of TGC and FCR would minimize environmental impacts per ton of fish produced in all quota scenarios.

In sea cage systems, the aim of the quota is mainly to limit the impact of the farming process on the local environment. Calculating the ENV(farm) allows, therefore, to estimate the capacity of a trait to affect environmental impacts of a specific farming site in compliance with the aim of quota system. At farm level, mitigation does not exist anymore and an increase in production increases feed distribution and hence nitrogen emission. Therefore, the ENV(farm) of TGC are negative in Qstock and Qdaily_feed. It means that, in Qstock and Qdaily_feed, the environmental response to selection on TGC can be interpreted differently whether we look at farm level or at fish level. This has been shown in dairy where genetic improvement in milk yield would increase emission of $\mathrm{CO}_{2}$-eq. at herd level but reduce emission per kilogram of milk produced (Bell et al., 2011). 
Regarding FCR, genetic improvement would always decrease environmental impacts at farm level in every quota scenario. However, the ENV(farm) of FCR in Qannual_feed and Qdaily_feed are lower than in Qprod and Qstock because improving FCR in Qannual_feed and Qdaily_feed increases production level together with production efficiency. The variation of ENV(farm) of TGC and FCR suggests that a single breeding program including ENV(farm) would not minimize environmental response in all quotas. It also suggests that breeding objectives using ENV(farm) and ENV(fish) would not lead to the same response. Therefore, the choice between ENV(farm) and ENV(fish) depends on the objectives of the breeding program.

In our model, the only limiting factor was one of the four production quota, which implied a constant stocking density through the time. This stocking density was calculated to reach the quota limitation without overtaking it. In the reference scenario (without genetic improvement) we considered that the oxygen availability was not limiting the number of fish stocked. However, in the scenario with genetic improvement, increasing TGC increases individual oxygen consumption due to higher feed intake and increasing FCR decreases individual oxygen consumption due to lower feed intake. Therefore, if you considered oxygen limitation, changing TGC and FCR could impact the number of fish stocked in cages to avoid hypoxia. In Besson et al., (2016b), we showed that the economic value of TGC, when oxygen was the limiting factor, was null when the average temperature was $18{ }^{\circ} \mathrm{C}$ and increased with higher average temperatures. These results suggest that the ENV(fish) of TGC would also increase with higher temperature when oxygen is the limiting factor. However, ENV(farm) would decrease with higher temperature. Regarding FCR, both the EV and ENV(fish) would be positive because better FCR decreases feed intake and oxygen consumption which would increase production and increase production efficiency. However, ENV(farm) would also be positive be only due to better production efficiency.

In the future, breeding companies could be forced to develop breeding programs that consider both economic and environmental sustainability. However, it is not possible to combine EV and ENV in a common breeding objective as they are not expressed with the same unit. EV is in euros while ENV is, for instance, in $\mathrm{CO}_{2}$-eq. Consequently, the economic breeding objective may have adverse effects on the environment. In that case, environmental values could be calculated differently. van Middelaar et al., (2014) suggested to estimate the ENV of a trait using linear programming to minimize environmental response while keeping profit constant after genetic change. 


\subsection{Conclusion}

This is the first study investigating the influence of different quotas on the economic and environmental value of production traits in a selective breeding program. The results show that the economic and environmental responses change across quota scenarios, which suggest that each quota might need a specific breeding program in order to maximize profit or to minimize environmental impacts. It also suggests that policy makers could choose the quota depending on the objectives to achieve. For instance, standing stock quota and daily feed quota are economically favorable to a genetic improvement of growth rate, a major trait for farmers. However, in these quotas, improving growth increases the environmental impact of the farm. Improving FCR represents a good opportunity to balance out this increase in environmental impacts but we need more information on its genetic background to develop breeding programs including FCR. FCR is the most important trait to increase economic profit and to decrease environmental impacts in all scenarios.

\section{Acknowledgement}

M. Besson benefited from a joint grant from the European Commission and IMARES, within the framework of the Erasmus-Mundus joint doctorate "EGS-ABG". The authors thank Gloria Maris and Biomar for their collaboration. 


\section{Appendices}

Appendix 5.1: Calculations and parameters involved in the fish model.

Parameters of fish model

Formulas

Thermal growth coefficient (TGC) :

$1-b=$ weight exponent $=0.51$

$K_{i}=$ daily corrected temperature

$W_{H}$ (harvest weight) $=13 \mathrm{~g}$

$W_{1}($ initial weight $)=1300 \mathrm{~g}$

$\mathrm{TGC}=\frac{\mathrm{W}_{\mathrm{H}}^{1-\mathrm{b}}-\mathrm{W}_{\mathrm{I}}^{1-\mathrm{b}}}{\sum_{\mathrm{i}=1}^{\mathrm{n}} \mathrm{K}_{\mathrm{i}}}$

$n$ is the length of growing period until

harvest weight

Fish weight $\left(W_{n}\right)$ in $\mathbf{k g}$ :

$$
\mathrm{W}_{n}=\left[\mathrm{W}_{\mathrm{I}}^{0.51}+\left(\mathrm{TGC} \times \sum_{\mathrm{i}=1}^{\mathrm{n}} \mathrm{K}_{\mathrm{i}}\right)\right]^{1 / 0.51}
$$

Daily weight gain (DWGn) in $\mathbf{g}$ :

$$
\mathrm{DWG}_{\mathrm{n}}=\mathrm{W}_{\mathrm{n}}-\mathrm{W}_{\mathrm{n}-1}
$$

Feed conversion ratio ( $\left.F C R_{w_{n}}\right)$ in $\mathrm{g} / \mathrm{g}$ :

$$
\text { FCR }_{W n}=\alpha \times \frac{W_{n}^{0.14}}{1.318-\left(0.103 \times T_{i}\right)+\left(0.007174 \times T_{i}^{2}\right)-\left(0.0001395 \times T_{i}^{3}\right)}
$$

Daily feed intake (DFI $)$ in $\mathrm{g}$ :

$\mathrm{DFI}_{\mathrm{n}}=\mathrm{DWG}_{\mathrm{n}} \times \mathrm{FCR}_{\mathrm{Wn}}$ 
Appendix 5.2: Chemical composition of the feed of sea bass (Biomar, EFICO).

\begin{tabular}{lc}
\hline Chemical composition & $\%$ \\
\hline Protein & 43 \\
Crude fat & 21 \\
Crude ash & 7 \\
Other Carbohydrates & 20 \\
Phosphorus & 1.1 \\
\hline Components & Origin \\
\hline Fish meal & Peru \\
Fish oil & Peru \\
Corn gluten & France \\
Rape meal & France \\
Rape oil & France \\
Soybean meal & Brazil \\
Wheat gluten & France \\
Wheat & France \\
Sunflower meal & France \\
Additive premix & France \\
\hline
\end{tabular}

Appendix 5.3: Contribution analysis of $1 \mathrm{t}$ of standard sea bass feed (Biomar, EFICO).

\begin{tabular}{lccc}
\hline & $\begin{array}{c}\text { Climate change, } \\
\mathrm{kg} \mathrm{CO} \text {-eq }\end{array}$ & $\begin{array}{c}\text { Eutrophication, kg } \\
\mathrm{PO}_{4} \text {-eq }\end{array}$ & $\begin{array}{c}\text { Acidification, } \\
\mathrm{kg} \mathrm{SO}_{2} \text {-eq }\end{array}$ \\
\hline Fish meal and oil & $22.02 \%$ & $9.30 \%$ & $19.70 \%$ \\
Crops & $41.65 \%$ & $82.26 \%$ & $51.29 \%$ \\
Other & $0.17 \%$ & $0.35 \%$ & $0.13 \%$ \\
\hline Feed processing, & & & \\
packaging and & $36.16 \%$ & $8.09 \%$ & $28.87 \%$ \\
transportation & & & \\
\hline Total \% & $100 \%$ & $100 \%$ & 8.88 \\
Total quantity & 1656.89 & 5.42 & \\
\hline
\end{tabular}


Appendix 5.4: Contribution analysis of energy carriers to acidification, eutrophication, and climate change.

\begin{tabular}{lccc}
\hline & $\begin{array}{c}\text { Climate change } \\
\left(\mathrm{kg} \mathrm{CO}_{2}-\mathrm{eq}\right)\end{array}$ & $\begin{array}{c}\text { Eutrophication } \\
\left(\mathrm{kg} \mathrm{PO}_{4}-\mathrm{eq}\right)\end{array}$ & $\begin{array}{c}\text { Acidification } \\
\left(\mathrm{kg} \mathrm{SO}_{2} \text {-eq }\right)\end{array}$ \\
\hline $\begin{array}{l}\text { Electricity mix production } \\
(1000 \mathrm{kWh})\end{array}$ & 94.35 & 0.18 & 0.53 \\
Diesel production (1000 I) & 532.71 & 0.80 & 5.11 \\
Fuel production (1000 I) & 518.02 & 0.75 & 5.16 \\
\hline
\end{tabular}

Appendix 5.5: Environmental impacts of the construction of $1 \mathrm{~m}^{2} \mathrm{y}$ of buildings and of the production of all equipment needed at farm level.

\begin{tabular}{lccc}
\hline & $\begin{array}{c}\text { Climate } \\
\text { change } \\
(\mathrm{kg} \mathrm{CO} \text {-eq })\end{array}$ & $\begin{array}{c}\text { Eutrophication } \\
\left(\mathrm{kg} \mathrm{PO}_{4} \text {-eq }\right)\end{array}$ & $\begin{array}{c}\text { Acidification } \\
\left(\mathrm{kg} \mathrm{SO}_{2} \text {-eq }\right)\end{array}$ \\
\hline $\begin{array}{l}\text { Construction of } \\
1000 \mathrm{~m}^{2} \mathrm{y} \text { of } \\
\text { facilities }\end{array}$ & $9,586.57$ & 13.79 & 37.29 \\
$\begin{array}{l}\text { Production of total } \\
\text { equipment used }\end{array}$ & 27300.7 & 59.57 & 146.95 \\
\hline
\end{tabular}

Appendix 5.6: Environmental impacts of the emission to water of one ton of nitrogen ( $N$ ), phosphorus (P) and chemical oxygen demand (COD).

\begin{tabular}{lccc}
\hline & $\begin{array}{c}\text { Climate change } \\
(\mathrm{kg} \mathrm{CO}-\mathrm{eq})\end{array}$ & $\begin{array}{c}\text { Eutrophication } \\
\left(\mathrm{kg} \mathrm{PO}_{4}-\mathrm{eq}\right)\end{array}$ & $\begin{array}{c}\text { Acidification } \\
\left(\mathrm{kg} \mathrm{SO}_{2}-\mathrm{eq}\right)\end{array}$ \\
\hline 1 ton of $\mathrm{N}$ & 0 & 0.42 & 0 \\
1 ton of $\mathrm{P}$ & 0 & 3.06 & 0 \\
1 ton of $\mathrm{COD}$ & 0 & 02 & 0 \\
\hline
\end{tabular}


Appendix 5.7: Climate change per ton of fish produced for the five sub-systems as a function of thermal growth coefficient (TGC) and feed conversion ratio (FCR). Qprod is the quota on annual production, Qannual_feed is on annual feed distributed, Qstock is on the daily biomass present on site and Qdaily_feed is on daily feed distributed.

\begin{tabular}{|c|c|c|c|c|c|c|c|}
\hline \multirow[b]{2}{*}{ Quota } & \multirow[b]{2}{*}{ TGC } & \multirow[b]{2}{*}{ FCR } & \multicolumn{5}{|c|}{ Climate change ( $\mathrm{kg} \mathrm{CO}_{2}$-eq) / ton of fish) } \\
\hline & & & $\begin{array}{c}\text { Feed } \\
\text { production }\end{array}$ & $\begin{array}{l}\text { Energy } \\
\text { use }\end{array}$ & $\begin{array}{l}\text { Equipment and } \\
\text { facilities }\end{array}$ & $\begin{array}{c}\text { Chemical } \\
\text { used }\end{array}$ & $\begin{array}{c}\text { Farm } \\
\text { operation }\end{array}$ \\
\hline & 2.25 & 2.02 & 3392.34 & 52.14 & 110.76 & 81.29 & 0 \\
\hline \multirow[t]{3}{*}{ Qprod } & 2.33 & 2.02 & 3392.34 & 52.14 & 110.76 & 81.29 & 0 \\
\hline & 2.25 & 1.64 & 2751.19 & 52.14 & 110.76 & 81.29 & 0 \\
\hline & 2.33 & 2.02 & 3391.79 & 52.15 & 110.78 & 81.31 & 0 \\
\hline \multirow[t]{3}{*}{ Qannual_feed } & 2.25 & 2.02 & 3391.79 & 52.15 & 110.78 & 81.31 & 0 \\
\hline & 2.33 & 1.64 & 2751.61 & 42.31 & 89.87 & 65.96 & 0 \\
\hline & 2.25 & 2.02 & 3390.97 & 52.17 & 110.81 & 81.33 & 0 \\
\hline \multirow[t]{3}{*}{ Qstock } & 2.33 & 2.02 & 3390.97 & 49.44 & 105.02 & 77.08 & 0 \\
\hline & 2.25 & 1.64 & 2747.34 & 52.17 & 110.81 & 81.33 & 0 \\
\hline & 2.25 & 2.02 & 3391.50 & 52.16 & 110.79 & 81.31 & 0 \\
\hline \multirow[t]{2}{*}{ Qdaily_feed } & 2.33 & 2.02 & 3391.50 & 50.40 & 107.06 & 78.58 & 0 \\
\hline & 2.25 & 1.64 & 2750.51 & 44.87 & 95.30 & 69.95 & 0 \\
\hline
\end{tabular}


Appendix 5.8: Eutrophication per ton of fish produced for the five sub-systems as a function of thermal growth coefficient (TGC) and feed conversion ratio (FCR). Qprod is the quota on annual production, Qannual_feed is on annual feed distributed, Qstock is on the daily biomass present on site and Qdaily_feed is on daily feed distributed.

\begin{tabular}{|c|c|c|c|c|c|c|c|}
\hline \multirow[b]{2}{*}{ Quota } & \multirow[b]{2}{*}{ TGC } & \multirow[b]{2}{*}{ FCR } & \multicolumn{5}{|c|}{ Eutrophication (kg $\left.\mathrm{PO}_{4}-\mathrm{eq}\right) /$ ton of fish) } \\
\hline & & & $\begin{array}{c}\text { Feed } \\
\text { production }\end{array}$ & $\begin{array}{c}\text { Energy } \\
\text { use }\end{array}$ & $\begin{array}{c}\text { Equipment and } \\
\text { facilities }\end{array}$ & $\begin{array}{c}\text { Chemical } \\
\text { used }\end{array}$ & $\begin{array}{c}\text { Farm } \\
\text { operation }\end{array}$ \\
\hline \multirow{3}{*}{ Qprod } & 2.25 & 2.02 & 11.13 & 0.08 & 0.16 & 1.16 & 156.09 \\
\hline & 2.33 & 2.02 & 11.13 & 0.08 & 0.16 & 1.16 & 156.19 \\
\hline & 2.25 & 1.64 & 9.03 & 0.08 & 0.16 & 1.16 & 117.47 \\
\hline \multirow{3}{*}{ Qannual_feed } & 2.33 & 2.02 & 11.13 & 0.08 & 0.16 & 1.16 & 156.05 \\
\hline & 2.25 & 2.02 & 11.13 & 0.08 & 0.16 & 1.16 & 156.16 \\
\hline & 2.33 & 1.64 & 9.03 & 0.07 & 0.13 & 0.94 & 117.49 \\
\hline \multirow{3}{*}{ Qstock } & 2.25 & 2.02 & 11.13 & 0.08 & 0.16 & 1.16 & 155.98 \\
\hline & 2.33 & 2.02 & 11.13 & 0.08 & 0.15 & 1.10 & 156.12 \\
\hline & 2.25 & 1.64 & 9.02 & 0.08 & 0.16 & 1.16 & 117.26 \\
\hline \multirow{3}{*}{ Qdaily_feed } & 2.25 & 2.02 & 11.13 & 0.08 & 0.16 & 1.16 & 156.05 \\
\hline & 2.33 & 2.02 & 11.13 & 0.08 & 0.16 & 1.12 & 156.19 \\
\hline & 2.25 & 1.64 & 9.03 & 0.07 & 0.14 & 1.00 & 117.44 \\
\hline
\end{tabular}


Appendix 5.9: Acidification per ton of fish produced for the five sub-systems as a function of thermal growth coefficient (TGC) and feed conversion ratio (FCR). Qprod is the quota on annual production, Qannual_feed is on annual feed distributed, Qstock is on the daily biomass present on site and Qdaily_feed is on daily feed distributed.

\begin{tabular}{|c|c|c|c|c|c|c|c|}
\hline \multirow[b]{2}{*}{ Quota } & \multirow[b]{2}{*}{ TGC } & \multirow[b]{2}{*}{ FCR } & \multicolumn{5}{|c|}{ Acidification (kg SO $\mathrm{S}_{2}-\mathrm{eq}$ ) / ton of fish) } \\
\hline & & & $\begin{array}{c}\text { Feed } \\
\text { production }\end{array}$ & $\begin{array}{c}\text { Energy } \\
\text { use }\end{array}$ & $\begin{array}{l}\text { Equipment and } \\
\text { facilities }\end{array}$ & $\begin{array}{c}\text { Chemical } \\
\text { used }\end{array}$ & $\begin{array}{c}\text { Farm } \\
\text { operation }\end{array}$ \\
\hline \multirow{3}{*}{ Qprod } & 2.25 & 2.02 & 18.19 & 0.62 & 0.44 & 2.52 & 0 \\
\hline & 2.33 & 2.02 & 18.19 & 0.62 & 0.44 & 2.52 & 0 \\
\hline & 2.25 & 1.64 & 14.76 & 0.62 & 0.44 & 2.52 & 0 \\
\hline \multirow{3}{*}{ Qannual_feed } & 2.33 & 2.02 & 18.19 & 0.62 & 0.44 & 2.52 & 0 \\
\hline & 2.25 & 2.02 & 18.19 & 0.62 & 0.44 & 2.52 & 0 \\
\hline & 2.33 & 1.64 & 14.76 & 0.50 & 0.36 & 2.04 & 0 \\
\hline \multirow{3}{*}{ Qstock } & 2.25 & 2.02 & 18.19 & 0.62 & 0.44 & 2.52 & 0 \\
\hline & 2.33 & 2.02 & 18.19 & 0.58 & 0.42 & 2.39 & 0 \\
\hline & 2.25 & 1.64 & 14.74 & 0.62 & 0.44 & 2.52 & 0 \\
\hline \multirow{3}{*}{ Qdaily_feed } & 2.25 & 2.02 & 18.19 & 0.62 & 0.44 & 2.52 & 0 \\
\hline & 2.33 & 2.02 & 18.19 & 0.59 & 0.42 & 2.43 & 0 \\
\hline & 2.25 & 1.64 & 14.75 & 0.53 & 0.38 & 2.17 & 0 \\
\hline
\end{tabular}




\title{
6
}

\section{Comparing economic and environmental responses of breeding goals for sea bass designed for different production quota}

\author{
M. Besson ${ }^{1,2}$, H. Komen ${ }^{1}$, G. Rose ${ }^{3}$, E. Quillet ${ }^{2}$, J.A.M. van Arendonk ${ }^{1}$, I.J.M. de Boer ${ }^{4}$, \\ J. Aubin ${ }^{5}$, M. Vandeputte ${ }^{2,6}$
}

\footnotetext{
${ }^{1}$ Animal Breeding and Genomics Centre, Wageningen University, PO Box 338, $6700 \mathrm{AH}$ Wageningen, the Netherlands

${ }^{2}$ Génétique animale et biologie intégrative, INRA, AgroParisTech, Université Paris-Saclay, 78350 Jouyen-Josas, France

${ }^{3}$ Aristotle University, Animal Husbandry, Veterinary Faculty, 54124 Thessaloniki, Greece

${ }^{4}$ Animal Production Systems group, Wageningen University, P.O. Box 338, $6700 \mathrm{AH}$, the Netherlands

5 INRA, Agrocampus Ouest, UMR1069 Sol Agronomie Spatialisation, 65 rue de Saint Brieuc, 35042 Rennes, France

${ }^{6}$ IFREMER, Chemin de Maguelone, 34250 Palavas-les-Flots, France
} 


\begin{abstract}
In sea cage farming systems, fish production can be constrained by four quotas: annual production; annual feed fed; standing stock; and daily feed fed. Economic values (EV) and environmental values (ENV) of genetic improvement of thermal growth coefficient (TGC) and feed conversion ratio (FCR) were previously shown to differ across these quotas. We do not know, however, how genetic gain in a breeding program with both TGC and FCR in the breeding goal would differ when using different sets of quota-specific EVs or ENVs, as responses will also depend on the genetic and phenotypic correlations between these two traits. We therefore used pseudo-BLUP index calculations to simulate a breeding program for sea bass with TGC and FCR in the breeding goal. Traits in the index were TGC and percentage of visceral fat, the latter as an indirect measure for FCR. Because phenotypic and genetic correlations between TGC and FCR are still uncertain, we simulated the breeding program for five values of correlations ( $r g=r p):-0.2,-0.1$, $0,0.1,0.2$. First, we calculated the genetic gain in the aggregate genotype of four breeding goals, represented by EVs of TGC and FCR under each of the four quota systems. The objective was to investigate which quota system would give the highest economic gain and how this economic gain would depend on the genetic and phenotypic correlations between TGC and FCR. Next, we calculated, for each quota, the genetic gain for eutrophication in the aggregate genotype when using a breeding goal with either EVs or ENVs of TGC and FCR. Eutrophication is mainly the consequence of the emissions of nitrogen $(N)$ and phosphorus $(P)$ to the air, water and soil and is considered as a major environmental impact of sea cage culture. The second objective was, thus, to investigate if EV alone could be used to decrease environmental impacts or whether ENV should be used. Results suggest that breeding programs should be finely tuned according to the limiting factor of the production system to maximize economic return of farmers. Economic optimisation will decrease environmental impacts of fish production for all quota systems when the phenotypic and genetic correlations between TGC and FCR were negative.
\end{abstract}

Keywords: breeding goals, economic values, environmental values, fish farming, quota, response to selection 


\subsection{Introduction}

In selective breeding, the direction and the magnitude of genetic change in the aggregate genotype is usually determined by the economic values of the traits that are included in the breeding goal. Economic values represent the change in profitability due to a change in one trait of the breeding goal, while keeping other traits constant. Using these values in a selection index optimizes the economic return of genetic improvement. Economic values represent the benefits of selective breeding only. Therefore, the management of the farm such as herd size and feed ration must be optimised within the farm's production constraints (Groen, 1989). These constraints can be technical or regulatory, such as production quota.

In fish farming, production quotas aim at constraining the local environmental impacts caused by the production of fish. These local impacts include eutrophication from sedimentation of organic matter from uneaten feed and excretion of ammonia by the fish. In Europe, four main types of production quotas exist in sea cage systems: annual production (Qprod); annual feed fed (Qannual_feed); standing stock (Qstock); and daily feed fed (Qdaily_feed). Farms under each quota have a different optimal management. For sea bass, we (Besson et al., submitted) showed that the economic values of thermal growth coefficient (TGC) and feed conversion ratio (FCR) vary across quotas. Consequently, genetic gain in each of these quotas is expected to differ if fish were to be produced from a single breeding program. In sheep, Rose et al. (2015) found that genetic gain from a single breeding program varied across different climatic regions in Australia, due to differences in relative economic values of traits. They also demonstrated that different breeding goals were needed to maximize economic response in each climatic region. In fish farming, however, we do not know if differences in EVs of TGC and FCR between quotas are large enough to warrant separate breeding programs. The response in the aggregate genotype depends on the economic values and the phenotypic and genetic correlations between traits in the breeding goal and the selection index. In fish, there is still uncertainty concerning the phenotypic and the genetic correlations between TGC and FCR. Therefore, the first objective was to compare the total economic gain generated by the breeding goals from the four quotas according to the correlations between TGC and FCR.

The livestock and fish farming sectors aim to reduce their impact on the environment. Selective breeding for more efficient animals can contribute to this reduction (Wall et al., 2010; van Middelaar et al., 2014, 2015). In previous studies, we calculated the environmental values of fish traits by combining bioeconomic modelling and life cycle assessment (LCA) (Besson et al., 2014; Besson et al., 
2016a). LCA is a standardized method to calculate the environmental impact of a production chain, from raw material extraction to the product's end-of life (Guinée et al., 2002). Parallel to economic values, environmental values express the change in different environmental impact categories (e.g. climate change or eutrophication) after changing the genetic value of one trait, keeping the other traits of the breeding goal constant.

In Besson et al. (submitted), we estimated environmental values of TGC and FCR for sea bass produced in sea cages, under the four previously described production quotas. We investigated three different categories of environmental impacts, i.e. climate change, eutrophication and acidification. We calculated environmental values per ton of fish produced (ENV(fish)) representing how selective breeding affects the global environmental efficiency of production. We also calculated environmental values per farm (ENV(farm)) to show how selective breeding affects the environmental impacts of a specific farming site. Results showed that, as with EVs, ENVs vary according to quotas. ENVs have been calculated in livestock and in fish farming before (Bell et al., 2010; van Middelaar et al., 2014, 2015; Besson et al., 2016a), but have never been implemented in a breeding program until now. It means that we do not know if choosing an environmental breeding goal rather than an economic breeding goal would generate different or similar genetic gains in traits. Thus, the second objective was to investigate, within quota, if EV alone could be used to decrease environmental impacts or whether ENVs should be used.

\subsection{Material and methods}

\subsubsection{Economic and environmental values}

In Besson et al. (submitted), we calculated EV and ENV for a trait change of one genetic standard deviation, using a bioeconomic model and an LCA for sea bass reared in sea cages. The EV and ENV were calculated for four different quotas: annual production (Qprod), where the production of the farm was limited to 1,000 tons per year; annual feed (Qannual_feed), where the total amount of feed distributed on the farm was limited to 2,050 tons per year; standing stock (Qstock), where the instant biomass present on site at any day of the year was constrained to 435 tons; and daily feed distribution (Qdaily_feed), where the amount of feed distributed on the farm was limited to 4 tons per day. In the reference scenario before genetic improvement, all these quotas generated the same amount of annual production of fish (Besson et al., submitted). EVs were expressed as monetary gain per trait unit of change (e.g. euro/kg) and are thus numerically 
different from the ones previously estimated in Besson et al. (submitted). Recalculation was done as follows. First, the bioeconomic model was used to estimate fish growth and feed intake, depending on TGC and FCR values. Then, the optimal number of fish per batch and the optimal number of batches produced per year were estimated in order to comply with the constraints of the quota. Then, the annual production of fish and the annual consumption of feed were used to estimate the annual profit of the farm. Finally, the EVs of traits were calculated as the difference between profit after changing each trait and profit before change, divided by the production of fish before genetic change. We changed each trait by one trait unit (from 2.25 to 3.25 for TGC and from 2.03 to 1.03 for FCR). Resulting values are given in table 6.1 .

Table 6.1: Economic values of TGC and FCR in the four different quota tested.

\begin{tabular}{ccc}
\hline & \multicolumn{2}{c}{ EV in $€ / \mathrm{kg} /$ trait unit } \\
\cline { 2 - 3 } Quota & TGC & FCR \\
\hline Qprod & 0 & 1.32 \\
Qannual_feed & 0 & 4.8 \\
Qstock & 0.65 & 1.32 \\
Qdaily_feed & 0.3 & 3.75 \\
\hline
\end{tabular}

ENVs were calculated by using LCA to estimate the eutrophication potential caused by the production of fish. We assessed eutrophication potential from craddle-tofarm-gate and included five sub-systems in our analysis: production of purchased feed, including production of ingredients, processing, and transportation; production of energy used on the farm (electricity, gas and petrol); production of farming facilities and equipment; production of chemicals used, including production and use of anti-fouling for nets; and farming operation, including nutrient-based pollutants emission from biological transformation of feed. Each flow in the system was assigned to its eutrophication potential. We chose to investigate only eutrophication because quotas are essentially designed to limit eutrophication caused by fish farming. We used characterisation factors from CML2 Baseline 2000 version 2.04. The environmental values for eutrophication were expressed per ton of fish produced per year of routine production (impact_fish). Then, impact_fish was used to calculate environmental values for eutrophication at fish level (ENV(fish)) of TGC and FCR, as the difference between impact_fish after genetic change and the impact_fish before genetic change. Resulting values are given in table 6.2. 
When the ENV is positive it means that an improvement of the trait decreases environmental impacts of the farm. For FCR, a positive EV and ENV implies that FCR should decrease (i.e. improve) to increase farm profit and decrease eutrophication, whereas for TGC, a positive EV or ENV implies that TGC should increase to increase farm profit and decrease eutrophication.

Table 6.2: Environmental values (in kg PO4-eq / $\mathrm{t} / \mathrm{trait}$ unit) of TGC and FCR in the four different quotas tested.

\begin{tabular}{ccccc}
\hline & \multicolumn{2}{c}{ ENV(fish) } & \multicolumn{2}{c}{ ENV(farm) } \\
\cline { 2 - 5 } Quota & TGC & FCR & TGC & FCR \\
\hline Qprod & -0.36 & 106.54 & -0.36 & 106.54 \\
Qannual_feed & -0.36 & 107.27 & -0.36 & 47.24 \\
Qstock & 0.04 & 106.67 & -48.83 & 106.67 \\
Qdaily_feed & 0.17 & 107.2 & -23.63 & 65.27 \\
\hline
\end{tabular}

\subsubsection{Simulated breeding program}

For each quota, we calculated the expected genetic change in TGC and FCR for two situations: the economic breeding objective using EV and the environmental breeding objectives using ENV(fish) and ENV(farm). We simulated a simple breeding program for sea bass using SelAction (Rutten et al., 2005). In this breeding program, 100 females were mated to 100 males to create 100 full-sib families. 40 fish (20 females and 20 males) were kept per family (4,000 fish in total) as selection candidates. From these candidates 200 (5\%) were selected as parents for the next generation, corresponding to a standardised intensity of selection of 2.06. The breeding objective included two traits, TGC and FCR. The aggregate genotype can be written as:

$$
\mathrm{H}=\mathrm{W}_{\mathrm{TGC}} \times \mathrm{A}_{\mathrm{TGC}}+\mathrm{W}_{\mathrm{FCR}} \times \mathrm{A}_{\mathrm{FCR}}
$$

Where, $\mathrm{W}$ is the weighting value of traits and $\mathrm{A}$ is the additive genetic value. $\mathrm{W}$ was either the economic value (EV) or one of the environmental values: (ENV(fish) or $\mathrm{ENV}(\mathrm{farm})$ ). Feed intake is difficult to measure in fish. FCR therefore is not used in selection indices. Instead, we used percentage of visceral fat (\%fat) as an indirect measure to select for FCR. Percentage of visceral fat can be measured without killing the fish, using echography measurements of the depth of the belly cavity (Vandeputte, pers. com.) and is expected to be correlated with FCR (Quinton et al., 
2007). Selection response was predicted with a pseudo-BLUP selection index based on own performance and information from 39 full sibs for TGC and \%fat. The genetic gain per generation obtained from SelAction was converted per year considering an average generation interval of 2.5 years ( 3 years for female and 2 years for male).

\subsubsection{Genetic parameters of traits}

Genetic parameters of the three traits (i.e. TGC, FCR and \%fat) are given in table 6.3 and 6.4. Because estimates of FCR in sea bass are lacking, we used values for rainbow trout (Oncorhynchus mykiss), whereas correlations between FCR and \%fat were based on values for European whitefish (Coregonus lavaretus). Genetic $\left(r_{\mathrm{g}}\right)$ and phenotypic $\left(r_{p}\right)$ correlations between TGC and FCR are unknown. We tested, therefore, five different options, assuming similar genetic and phenotypic correlations: $-0.2,-0.1,0,0.1$ and 0.2 .

Table 6.3: Values of genetic parameters of thermal growth coefficient (TGC), feed conversion ratio (FCR) and percentage of visceral fat (\% fat) used to simulate response to selection

\begin{tabular}{cccc}
\hline Trait & Heritability & $\begin{array}{c}\text { Genetic standard } \\
\text { deviation }\end{array}$ & References \\
\hline TGC & 0.43 & 0.23 & (Vandeputte et al., 2014) \\
FCR & 0.17 & 0.38 & (Kause et al., 2006) \\
$\%$ fat & 0.48 & 1.59 & (Saillant et al., 2009) \\
\hline
\end{tabular}

Table 6.4: Genetic (above diagonal) and phenotypic (below diagonal) correlations between thermal growth coefficient (TGC), feed conversion ratio (FCR) and percentage of visceral fat (\% fat).

\begin{tabular}{c|ccc}
\hline & TGC & FCR & $\%$ fat \\
\hline \multirow{2}{*}{ TGC } & & $-0.2 /-0.1 / 0 / 0.1 /$ & $0.75^{(1)}$ \\
FCR & $-0.2 /-0.1 / 0 / 0.1 /$ & 0.2 & \\
\% fat & 0.2 & & $-0.03^{(2)}$ \\
\hline
\end{tabular}

Saillant et al. (2009)

Quinton et al. (2007) 


\subsection{Results}

When the EV and ENV of FCR were positive, the expected response in FCR was a decrease. Conversely, when the EV and ENV of TGC were positive, the expected response in TGC was an increase.

\subsubsection{Genetic gain using EV (Figure 6.1)}

Genetic gain achieved in TGC and FCR with the different breeding goals depended on assumed correlations between TGC and FCR. Genetic gain achieved using EV from Qprod and Qannual_feed was exactly the same ( $\Delta$ and 0 in Figure 6.1), regardless of correlation assumed. However, the genetic gain in Qstock and Qdaily_feed was different from the gain in Qprod and Qannual_feed.

For each quota, genetic gain in TGC was the highest when correlations between TGC and FCR were -0.1. Genetic gain in TGC decreased when correlations increased. When the correlations were positive, the genetic gain in TGC was positive only in Qstock.

For every quota, the genetic gain in FCR was negative, which was the expected direction of change as lower FCR means lower feed cost. In Qprod, Qannual_feed and Qdaily_feed, the gain in FCR was similar. Gains were close to zero when there was no correlation between TGC and FCR. In Qstock, however, the gain in FCR was lower across correlations, especially when the correlations were zero or positive.

Although the differences between quotas were higher when the correlations were positive, quotas are ranked in the same order across correlations suggesting that the correlations between TGC and FCR had more influence than the quotas.

\subsubsection{Economic gain using EV (Figure 6.2)}

Economic gain resulting from different breeding goals (representing different quota systems) also varied across quota and correlations between TGC and FCR. Economic gain from Qprod was the lowest, except for correlations of 0.2 , where it was similar to economic gain from Qstock. Qstock quota gave the highest economic gain when correlations were close to zero. When correlations were either positive or negative, Qannual_feed and Qdaily_feed gave the highest economic gains. For correlations equal to -0.1 , they were only marginally superior or even equal to Qstock. 


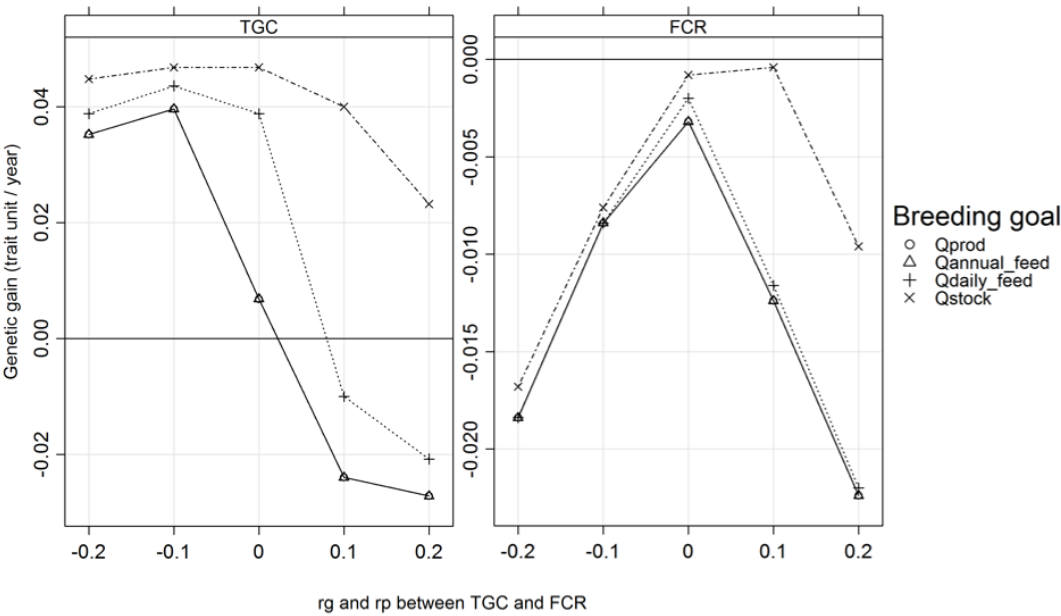

Figure 6.1: Simulated genetic gain in feed conversion ratio (FCR) and thermal growth coefficient (TGC), in trait unit per year, for different breeding goals using economic values calculated in four quota systems. The quota systems are: annual production (Qprod), annual feed (Qannual_feed), standing stock (Qstock) and daily feed (Qdaily_feed). Genetic gains are presented for five different values of genetic $(\mathrm{rg})$ and phenotypic $(\mathrm{rp})$ correlation between TGC and FCR.

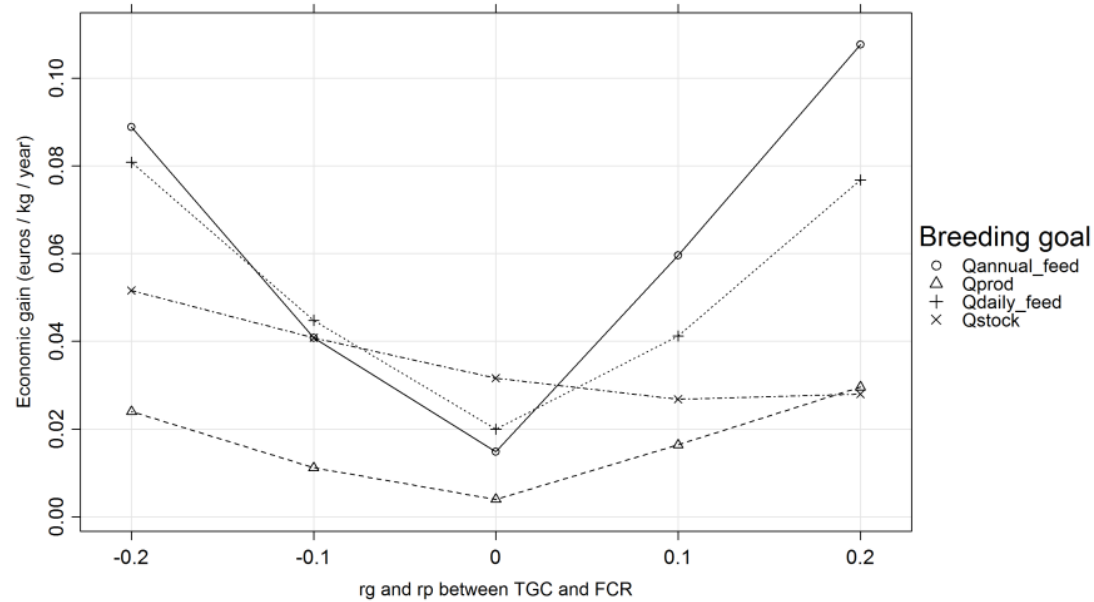

Figure 6.2: Simulated economic gain, in euros per $\mathrm{kg}$ of fish produced, for different breeding goal using economic values calculated in four quota systems. The quota systems are; annual production (Qprod), annual feed (Qannual_feed), standing stock (Qstock) and daily feed (Qdaily_feed). These economic gain are presented for five different values of genetic ( $\mathrm{rg}$ ) and phenotypic (rp) correlation between TGC and FCR. 


\subsubsection{Genetic gain using EV and ENV (Figure 6.3)}

Genetic gain in TGC and FCR using ENV(fish) or ENV(farm) were almost the same when using Qprod or Qannual_feed. For Qstock and Qdaily_feed, genetic gain in TGC and FCR depended on assumed correlations between TGC and FCR. When correlations were positive, genetic gains in TGC and FCR were both negative when using ENV(fish) or ENV(farm) although the absolute values were different. When the correlations were zero or negative, genetic gains in TGC and FCR when using ENV(fish) or ENV(farm) started to diverge. Interestingly, using ENV(farm) or ENV(fish) results in opposite values of genetic gain in TGC. For FCR, the genetic gain was positive when using ENV(fish) while it was negative when using ENV(farm) when the correlations were -0.1. Moreover, there was little difference in gain in FCR between EV and ENV(fish), except for Qstock when the correlations between TGC and FCR were positive.

\subsubsection{Economic and environmental response (Figure 6.4)}

The change in profit and environmental impacts when applying EV, ENV(fish) and ENV(farm) from the four quota situations is shown in figure 6.4. There was more economic gain when using EV, there was less eutrophication at fish level using ENV(fish) and there was less eutrophication at farm level was larger using ENV(farm). Economic and environmental responses were the same for Qprod and Qannual_feed irrespective of using EV, ENV(fish) or ENV(farm). For these quotas the economic and environmental gains were close to zero when TGC and FCR were not correlated. When the correlation between TGC and FCR increased and decreased, the economic gain increased and the environmental gains decreased. In Qdaily_feed and in Qstock, we could see differences in economic and environmental responses when using EV, ENV(fish) or ENV(farm). In Qstock, when the correlations between TGC and FCR were negative, the economic and eutrophication responses were similar when using EV or ENV(fish), but different when using ENV(farm). For example, using ENV(farm) generated economic loss while using EV generated an increase in eutrophication at farm level across all correlations. Moreover, using ENV(fish) also increased eutrophication at farm level when the correlations were 0 and -0.1 . Using ENV(farm) increased eutrophication at fish level only when the correlations were -0.1. In Qdaily_feed, the economic and the eutrophication responses were very similar using EV and ENV(fish) across all correlations. Alternatively, the economic and eutrophication responses diverged when using ENV(farm), especially when the correlations were negative. 

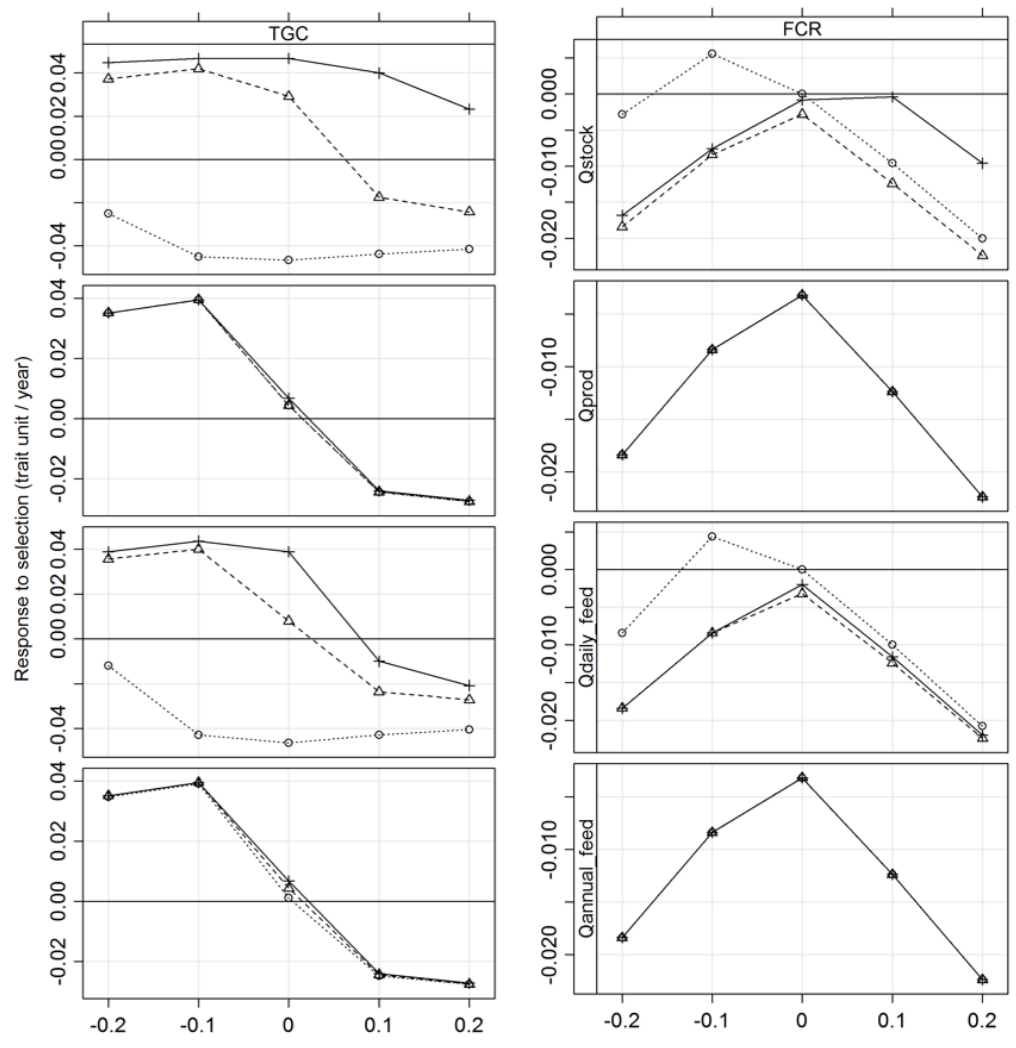

$\begin{array}{ll} & \text { ENV(farm) } \\ \triangle & \text { ENV(fish) }\end{array}$
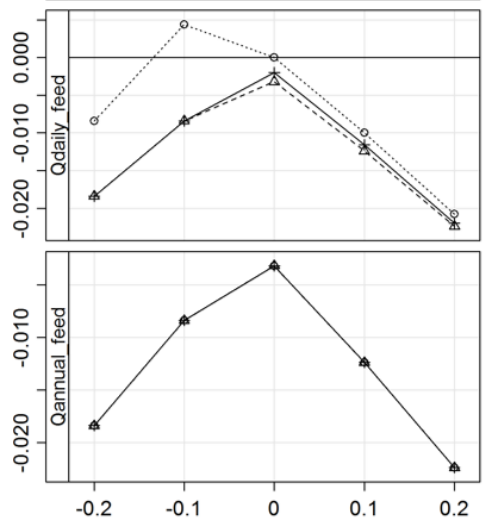

$\mathrm{rg}$ and $\mathrm{rp}$ between TGC and FCR

Figure 6.3: Simulated genetic gain for feed conversion ratio (FCR) and thermal growth coefficient (TGC), in trait unit per year, for different breeding goals using three types of weighting factors calculated in four quota systems. The weighting factors are economic value (EV), environmental value at fish level (ENV(fish)) or environmental value at farm level (ENV(farm)). The quota systems are: annual production (Qprod), annual feed (Qannual_feed), standing stock (Qstock) and daily feed (Qdaily_feed). The genetic gain was estimated for five different values of genetic (ra) and phenotypic ( $r p)$ correlations between TGC and FCR. 


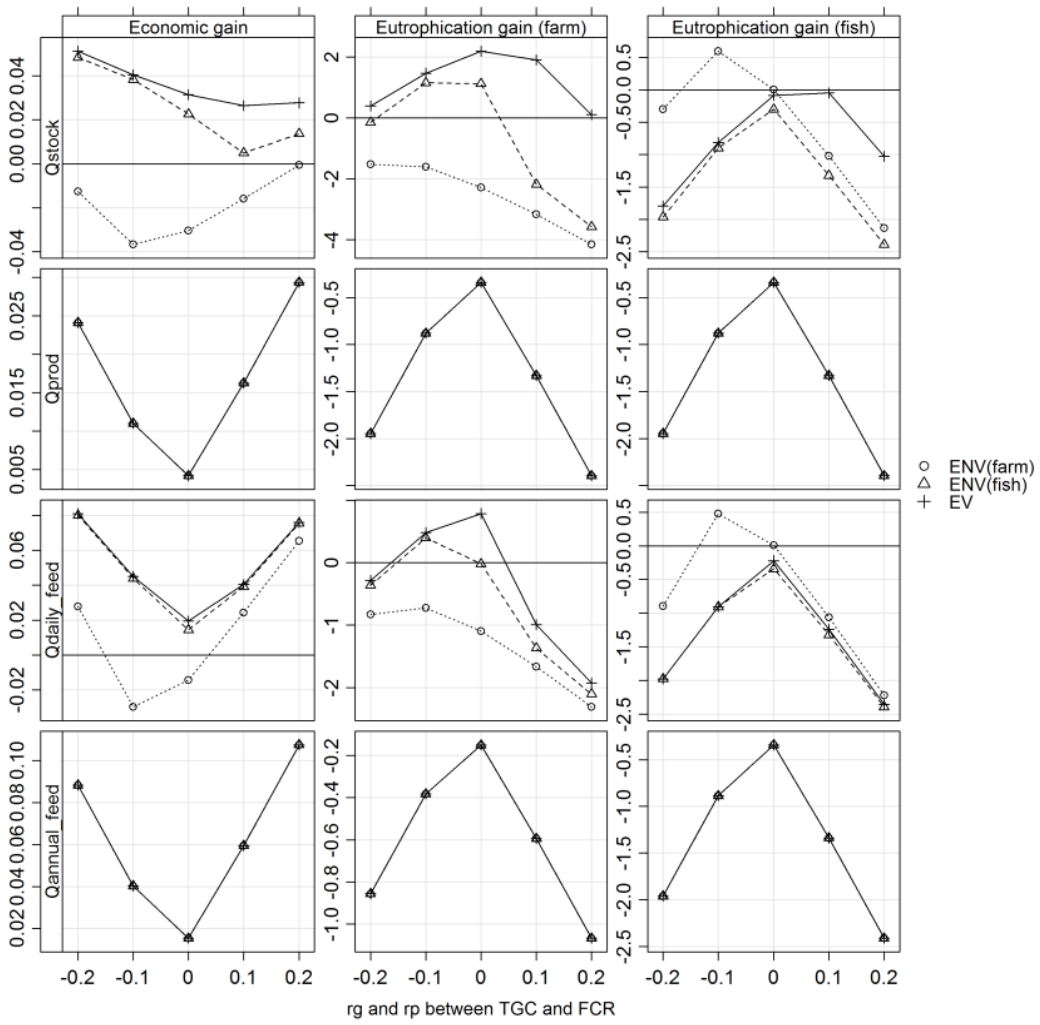

Figure 6.4: Change in economic return in euros per $\mathrm{kg}$ of fish produced per year, in eutrophication in $\mathrm{kg}$ per ton of fish produced at farm level per year (Eutrophication (farm)) and in eutrophication in $\mathrm{kg}$ per ton of fish produced at fish level per year (Eutrophication (fish)) when using either EV, ENV(fish) of ENV(farm) as weighting factors in four breeding goals corresponding to four quotas: annual production (Qprod), annual feed (Qannual_feed), standing stock (Qstock) and daily feed (Qdaily_feed). 


\subsection{Discussion}

In sea cage fish farming, each quota has a unique set of economic (EV) and environmental values (ENV). These values represent the economic or environmental importance of improving each trait by selection. They do not, however, predict the genetic gain from a selective breeding program, which depends on the additive genetic variance and heritability of each trait, and on genetic and phenotypic correlations between the traits in the breeding goal and the traits in the index. Therefore, evaluating the expected genetic gain provides more information on the effect that quota can have on the economic returns of selective breeding. In the present study, we used EVs of TGC and FCR to compare the economic gain between four breeding goals, corresponding to the four investigated quotas. We focussed on TGC and FCR because these two traits are expected to impact profit and environmental impact in fish farming.

Genetic and phenotypic correlations between traits are important because they define the scope for selecting on both traits simultaneously. The magnitude and sign of the correlation between TGC and FCR in fish is still a matter of debate. We therefore investigated a range of correlation values (from -0.2, to 0.2 ). FCR is the ratio of feed intake over weight gain. Increasing growth, is likely to decrease feed conversion ratio, when feed intake, which is highly related to growth, is also increasing but at a lower rate. In poultry, Emmerson (1997) argued that the improvement obtained in FCR was generated indirectly by selection on growth rate. Other studies in pig and poultry found a negative correlation between growth rate and FCR (Crawford, 1990; Clutter and Brascamp, 1998). Cai et al. (2008) found a genetic correlation of -0.46 and a phenotypic correlation of -0.30 between average daily weight gain and FCR, in swine. The correlation between FCR and TGC in fish is still unknown because individual feed intake is difficult to measure. It is hard to measure because fish are kept in groups in water tanks. Nevertheless, Thodesen et al., (1999) found a reduction in FCR of $4 \%$ per generation as a correlated response to selection for growth in Atlantic salmon. In rainbow trout, Kause et al. (2006) predicted that an increase of $17.6 \%$ of daily weight gain per generation would simultaneously decrease FCR by $8.4 \%$. This suggests a negative correlation between FCR and growth rate. Thodesen et al. (2001), found a phenotypic correlation of -0.79 between FCR and growth rate, while Silverstein et al. (2005) found a moderate correlation of -0.38 between residual feed intake (a substitute of FCR) and growth rate. Other studies in different fish species found no correlation between growth rate and FCR (Sanchez et al., 2001; Mambrini et al., 2004). In these studies, genetic gain in growth was due to higher feed intake, while 
FCR remained unchanged. Therefore, even though results are not consistent across studies in fish, the evidence reported in fish and in livestock suggests that the most likely phenotypic and genetic correlations between TGC and FCR are negative or null rather than positive.

Results of our study confirm that complying with different types of quotas had an impact on the genetic gain achieved for TGC and FCR in each situation. Differences in genetic gain of TGC and FCR across quota depended on the assumed correlations between TGC and FCR. Differences in genetic gain were more pronounced when the correlations between TGC and FCR were positive. In Qstock, TGC increased because the ratio between the EV of TGC and FCR was low, meaning that improving TGC has more importance than in other quota situations (i.e. Qprod, Qdaily_feed and Qannual_feed) where TGC decreased when FCR had more emphasis. In the most likely case of negative correlations between TGC and FCR, genetic gain followed similar trends in all quotas because the EV of FCR was positive in all quotas. Therefore, it was valuable to decrease FCR whilst increasing TGC, which is easy to achieve when there are negative correlations between the two traits. The differences observed in genetic gain based on different EV have been shown to exist in terrestrial production systems Spelman and Garrick (1997) or Rose et al. (2015).

As expected, Differences in genetic gain across quota also generated differences in economic gains, suggesting that each quota would need a specific breeding program to maximize economic return for farmers and that using only one breeding goal with one set of EVs for all quotas would not be profitable for all farmers. To demonstrate this, we calculated the economic shortfall of a farm constrained by a specific quota, when rearing fish selected for another quota. We first calculated the extra annual profit for a farm rearing fish selected for its own specific quota (in bold in Table 6.5). Then we calculated how much money the farm will lose (relative to this extra gain) if fish selected for another quota were produced. We did that for phenotypic and genetic correlations between TGC and FCR of $0,-0.1$ and -0.2 . Table 6.5 shows that rearing fish in a certain quota system while they were selected for another quota would decrease the maximum expected economic return. The genetic gain achieved using the EV from Qprod, Qannual_feed and Qdaily_feed generated a net economic loss (shortfall being superior to expected gain) when fish were reared in Qstock. For instance, considering the correlations between TGC and FCR to be -0.1 , a farm operating in Qstock would lose -94,650 euros per year from the expected extra profit of 40,800 if the farm used fish selected for Qannual_feed. This means that the farm will lose $40,800-94,650=-53,850$ euros per year. Such results demonstrate that rearing 
fish which are selected on the wrong breeding goal could be costly. On the other hand, a breeding goal using EV from Qstock will generate less economic shortfall across all quotas than any other breeding goal when correlations are 0 or $-0,1$. Conversely, Qprod is the quota system where rearing fish from different breeding goal will generate the least economic shortfall.

Table 6.5: Economic shortfall (in euros) when rearing fish selected for another quota system. This economic shortfall is expressed as a deviation from the maximum expected extra profit when rearing fish selected for the same quota system. This maximum expected extra profits are in bold on the diagonals. The economic shortfalls were calculated for three genetic and phenotypic correlations between TGC and FCR: $0,-0.1$ and $\mathbf{- 0 . 2}$.

\begin{tabular}{|c|c|c|c|c|c|c|}
\hline \multirow{2}{*}{$\begin{array}{c}r_{\mathrm{g}} \\
\text { and } \\
r_{\mathrm{p}}\end{array}$} & \multirow{2}{*}{ Breeding goal } & \multicolumn{4}{|c|}{ Fish produced in: } & \multirow{2}{*}{$\begin{array}{l}\text { Sum of } \\
\text { shortfall }\end{array}$} \\
\hline & & Qprod & Qannual_feed & Qstock & Qdaily_feed & \\
\hline \multirow{4}{*}{0} & Qprod & 4,000 & 0 & $-36,880$ & $-5,890$ & $-42,770$ \\
\hline & Qannual_feed & 0 & 14,800 & $-51,130$ & $-5,890$ & $-57,020$ \\
\hline & Qstock & $-2,950$ & $-10,960$ & 31,600 & $-2,490$ & $-16,400$ \\
\hline & Qdaily_feed & $-1,380$ & $-5,200$ & $-34,360$ & 20,000 & $-40,940$ \\
\hline \multirow{4}{*}{$-0,1$} & Qprod & 11,200 & -480 & $-55,580$ & $-1,020$ & $-57,080$ \\
\hline & Qannual_feed & 0 & 40,800 & $-94,650$ & $-1,020$ & $-95,670$ \\
\hline & Qstock & $-1,244$ & $-4,320$ & 40,800 & $-1,790$ & $-7,350$ \\
\hline & Qdaily_feed & 0 & -480 & $-73,140$ & 44,800 & $-73,620$ \\
\hline \multirow{4}{*}{$-0,2$} & Qprod & 24,000 & -480 & $-4,430$ & -890 & $-5,800$ \\
\hline & Qannual_feed & 0 & 88,800 & $-168,810$ & -890 & $-169,700$ \\
\hline & Qstock & $-1,990$ & $-8,160$ & 51,600 & $-3,910$ & $-14,060$ \\
\hline & Qdaily_feed & 0 & -480 & $-134,610$ & 80,800 & $-135,090$ \\
\hline
\end{tabular}

Table 6.5 shows that rearing fish in a certain quota system while they were selected for another quota would decrease the maximum expected economic return. The genetic gain achieved using the EV from Qprod, Qannual_feed and Qdaily_feed generated a net economic loss (shortfall being superior to expected gain) when fish were reared in Qstock. For instance, considering the correlations between TGC and FCR to be -0.1, a farm operating in Qstock would lose $-94,650$ euros per year from the expected extra profit of 40,800 if the farm used fish selected for Qannual_feed. This means that the farm will lose $40,800-94,650=-53,850$ euros per year. Such results demonstrate that rearing fish which are selected on the wrong breeding goal could be costly. On the other hand, a breeding goal using EV from Qstock will 
generate less economic shortfall across all quotas than any other breeding goal when correlations are 0 or $-0,1$. Conversely, Qprod is the quota system where rearing fish from different breeding goal will generate the least economic shortfall. These results suggest that breeding programs should be finely tuned according to the limiting factor of the production system to maximize economic return of farmers. Ideally, a breeding company should develop enough breeding programs to produce fish for every quota. However, generating different breeding programs is expensive. The choice of the set of EVs to use in the breeding goal could depend, therefore, on the quota satisfying most of the customers of the breeding company. Moreover, from Table 5, some quotas are more economically resilient to economic shortfall, such as Qdaily_feed. This suggests that farms constrained by Qdaily_feed gain almost as much money when using fish selected for another quota than when using fish selected for them. Breeding companies must, therefore, carefully estimate the EVs of traits in different production systems to find the best strategy to fit the needs of their customers.

While profitability remains the main challenge for fish farmers, reducing the environmental impacts of fish farming has gained more attention. In this study, we compared, within each quota, the genetic gain achieved when using EVs or ENVs. The ENVs represent the effect of changing one trait on environmental impacts, i.e. eutrophication. ENVs were calculated per kg of fish (ENV(fish)) or ENVs calculated per farm (ENV(farm)) (Besson et al., submitted). The principle of environmental values has been developed in dairy cattle (Bell et al., 2011; van Middelaar et al., 2014, 2015) and in fish (Besson et al., 2016a). To our knowledge, the present study is the first to investigate the consequences of the implementation of ENV in a simulated breeding program and to compare the genetic gain achieved using EV or ENV. Results show that, within certain quotas, genetic gains differ when using ENV estimated for the farm or fish or using EV. The genetic gain in TGC and FCR using ENV(fish) were the same for all quotas, because the ENV(fish) were the same for each quota. These were all the same because eutrophication is caused mainly by the production of feed and by the excretion of manure by fish. Only $1 \%$ of eutrophication is fixed with the rest dependent on feed production. For farms, before genetic change and after increasing TGC (FCR being kept constant), fish still need to eat $2.05 \mathrm{~kg}$ of feed per $\mathrm{kg}$ of fish produced. Therefore, regardless of the total production on the farm or quota used, fish will produce the same amount of manure per kg of fish, if FCR is not changed. The only way to lower environmental impacts per $\mathrm{kg}$ of product is then by improving FCR. In the most likely case of negative correlations between TGC and FCR, improving FCR can be reached by improving TGC. When correlations between TGC and FCR were negative, the 
genetic gain for TGC and FCR between a breeding goal using EV and a breeding goal using ENV(fish) became similar. It means that using ENV(fish) would at the same time decrease eutrophication per $\mathrm{kg}$ of fish and increase farm profit. There would be, therefore, a direct financial incentive for farmers to reduce the eutrophication per $\mathrm{kg}$ of fish produced even though the maximum economic gain expected from the breeding program would not be reached if ENV(fish) was used.

On the contrary, the same eutrophication per kg of fish produced means that the quotas with the lowest eutrophication per farm also result into the lowest production level in $\mathrm{kg}$ of fish. Therefore, when genetic improvement of TGC increases production at the farm level, the ENV(farm) of TGC is positive (meaning that increasing TGC increases eutrophication at the farm level) while its EV is positive. This generates an antagonism between profitability and environmental impact at farm level. This antagonism can be observed when comparing the genetic gain in TGC based on EV or ENV(farm) in Qstock when the correlation between TGC and FCR is negative. In this quota, the breeding goal generates a positive gain in TGC when using EV because TGC has a positive EV and because selecting for higher TGC enhances the response in FCR. When using ENV(farm), however, the breeding goal generates a negative response in TGC because the $E N V(f a r m)$ of TGC is negative. Consequently, there is no financial incentive for the farmer to reduce eutrophication of their farm. Therefore, in this case, selective breeding is not the solution to decrease eutrophication per farm.

Quotas are set after carrying an environmental impact study that determines the production quota of the farm. Therefore, the quota is a consequence of spatial planning that aims to constrain the environmental impacts of a single farm on the local environment. Hence, ENV(farm) is interesting as it shows that reducing global environmental impacts is not necessarily reducing local environmental impacts. Whether ENV(fish) or ENV(farm) should be used in a breeding program then depends on which impacts are to be minimized. In practice, however, local environmental impacts can be managed by revising the quota systems or managing the number of farms in a certain location, while global impacts can only be managed by improving efficiency. Thus it would be logical to favor ENV(fish) rather than ENV(farm) in breeding programs. Still, in order to be able to revise the quota system, it is important to know if the effects of using ENV(farm) are similar or different to the effects of using ENV(fish) or EV 


\subsection{Conclusion}

Our study is the first to compare the response to selection between economic and environmental breeding objectives in different quota systems of fish farming. It is also the first study implementing ENV of the target traits in a breeding goal to compare the genetic gains to those resulting from a breeding program based on EV of the same traits. We show that breeding goals designed to comply with different quotas induce a different evolution of broodstock performance and genetic value over time. Moreover, we showed that within quotas the genetic gain for the different traits is not the same when using ENV estimated for the farm or fish or when using EV. In all cases, the genetic gain depends on the phenotypic and genetic correlations between the selected traits, here TGC and FCR. Such differences in response suggest that different breeding goals are needed to achieve the maximum economic return or the maximum decrease of eutrophication per $\mathrm{kg}$ of fish or per farm. These results emphasize the need of calculating EVs and ENVs of all traits included in breeding programs, for all different production system as well as the resulting genetic gain and economic profit. These data can then be used to compare responses to selection based on EV or ENV and designing production quotas that increase profit while decreasing environmental impacts.

\section{Acknowledgement}

M. Besson benefited from a joint grant from the European Commission and IMARES, within the framework of the Erasmus-Mundus joint doctorate "EGS-ABG" 



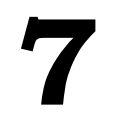

General Discussion 



\subsection{Introduction}

As an economic sector of increasing importance, fish farming is subject to many concerns, among which those of economic viability and environmental sustainability are repeatedly raised (Folke et al., 1994; Oglend, 2013). Several studies already showed that selective breeding could contribute to sustainable development of livestock (Wall et al., 2010; Bell et al., 2011; van Middelaar et al., 2014). In fish farming, however, the economic and environmental impacts of selective breeding are unknown.

Our aim was to study how breeding programs could contribute, at the same time, to economic viability and environmental sustainability of fish production. The first objective in this thesis was to develop a method to estimate the economic and environmental impacts of changing traits by selective breeding in fish farming. By combining bioeconomic modeling with life cycle assessment (LCA), we managed to simultaneously estimate the economic profit and environmental impacts of a farm, depending on the value of the traits in the breeding goal. From this combined model, it was possible to calculate economic (EV) and environmental values (ENV) of two major traits for farmers, i.e. growth rate, expressed as thermal growth coefficient (TGC), and feed conversion ratio (FCR), expressed as total feed intake divided by total weight gain per fish. This method was developed and illustrated first in a recirculating aquaculture system (RAS, chapter 2 and $\mathbf{3}$ ). We chose to study RAS because this is a closed containment system, where water temperature is kept constant. In our RAS, fish production was limited by fish density or the treatment capacity of the bio-filter. The second objective was to adapt the combined bioeconomic-LCA model to another system to investigate the impact of other limiting factors. A sea cage system was chosen as a major system for fish farming that differs from RAS, because it is open and, therefore, affected by seasonal variation in temperature and oxygen availability in water. In chapter 4 , we explored the complex interactions between temperature, oxygen availability and growth to investigate the EV of TGC in sea cages. In addition to variations in environmental conditions, farmers must comply with quotas that constrain the production of their farm. Thus, in chapter 5, we further investigated EV and ENV of TGC and FCR, assuming application of different production quotas sea cage farming. We studied four quotas: annual production (Qprod), annual feed distributed (Qannual_feed), standing stock (Qstock) and daily feed (Qdaily_feed). Finally, the third objective was to investigate how economic and environmental 
values can be used to develop breeding programs that improve profit and decrease environmental impacts in fish farming and this was studied in chapter 6 .

In the discussion of this thesis, I will explore, first, the relevance and challenges of combining a bioeconomic model with an LCA to estimate EV and ENV of traits. Then, I will discuss how fish breeding program could enhance economic and environmental performance of fish farms.

\subsection{Relevance and challenges of the method used to derive EV and ENV}

\section{Choice of traits}

In theory, all traits of economic importance should be included in the breeding goal, and the economic value of all these traits should be calculated to optimize the economic return of the breeding program. Thermal growth rate (TGC), daily feed intake (DFI) and feed conversion ratio (FCR), are all expected to affect economic returns of a farm. Those three traits, however, are strongly related to each other: FCR represents the ratio of feed intake over weight gain; phenotypic and genetic correlations between weight gain and feed intake are strongly positive (Kause et al., 2006). TGC (or more generally growth rate) is considered by farmers as the most important trait to increase production (Sae-Lim et al., 2012). To address production efficiency, either DFI or FCR could be considered as a second trait to include in breeding goals.

The aim of this work was to estimate the increase in profit and the decrease in environmental impacts that could be generated when genetic improvement is implemented. Therefore, we calculated EV of TGC and FCR rather than EV of TGC and DFI. Firstly because, unlike DFI which needs to be associated with TGC to be an indicator of production efficiency, FCR is a direct indicator of production efficiency. Thus, it is a parameter that farmers know well and that they consider a major one to improve (Sae-Lim et al., 2012), because lower FCR results in a lower cost of production. Secondly, in the literature, the positive genetic and phenotypic correlations between TGC and DFI have clearly been demonstrated, while the genetic and phenotypic correlations between TGC and FCR seem to be weak or null (Sanchez et al., 2001; Thodesen et al., 2001; Mambrini et al., 2004; Kause et al., 2006). As EVs and ENVs of one trait are calculated, while keeping the other traits constant, calculating the EV of TGC while keeping FCR constant is more intuitive and closer to reality than calculating the EV of TGC while keeping DFI constant. 
Indeed, increasing TGC while keeping DFI constant decreases the time to reach harvest weight, and subsequently reduces the total amount of feed intake and FCR. Calculating EV of TGC and DFI could be interesting when developing breeding programs in practice that aim to optimize genetic gain in FCR. This is a more practical approach, because it was demonstrated that selecting directly on FCR is possible but less efficient than selecting for TGC and against feed intake, combined in a linear index (Gunsett, 1984; Lin and Aggrey, 2013). While this is true for the detailed optimization of such breeding programs, choosing TGC and FCR or TGC and DFI is not expected to result in different trends in genetic gain.

\section{Bioeconomic model versus profit equation}

In fish farming, there is a large variety of production systems and environmental conditions, even for a given species. Furthermore, production methods are still evolving. Consequently, current fish farming systems are continuously changing, which could explain the fact that economic values of production traits are not yet available. To our knowledge, only Ponzoni et al. (2007) and Ponzoni et al. (2008) investigated economic values of traits in fish farming. They derived EV using a profit equation. A profit equation is a single equation that describes the change in profit as a function of biological and economic parameters. It defines the system in a simple way and, most often, neglects changes in management as a consequence of changes in fish performance (Nielsen et al., 2013). Ponzoni et al. (2007), for instance, developed a profit equation to calculate EV of harvest weight, feed intake and survival rate for Nile tilapia in ponds. They found a positive EV for survival rate, because they assumed that increasing survival rate would increase production. They, however, did not include in their profit equation factors that limit the production volume of a farm. For instance, one can easily imagine that the total production of fish could be constrained by the density of fish in a pond (Diana et al., 2004). In that case, improving survival rate could lead to a decrease in the number of juveniles stocked to meet the limitation instead of increasing the number of fish harvested, and this would result in a different EV of survival rate. Such changes in optimal management strategy of the farm need to be accounted for to calculate how genetic changes affect profitability of the farm and to calculate relevant EV (Groen, 1989; Amer et al., 1994).

Simple profit equations can be made more sophisticated to take into account interactions between herd structures, limiting factors of the production system and environmental constraints (e.g. Henryon et al., (1999)). When profit equations increase in complexity, however, they might become too complex to derive. 
Bioeconomic modeling is a way to handle this complexity. When developing a bioeconomic model, relevant biological and economic aspects of the production system are described as a system of equations to estimate profit. Bioeconomic models are commonly divided in sub-models, like in our case a fish growth model, a batch-model and a farm model. This division in sub-models helps the model developer to focus on a smaller fraction of the problem at one time and lowers the chance of mistakes when taking into account interactions between parameters. In fish farming, for example, the growth of fish depends on environmental conditions such as temperature, dissolved oxygen or water quality. Then, the number of fish stocked in a batch depends on the performance of the fish from the fish-model and can be constrained by an optimal density or a maximum oxygen availability. In the farm model, the number of batches produced depends on farming infrastructures and might be constrained by different quotas, such as the maximum production of fish per year. Finally, farm profit depends on the number of batches stocked and price variation. Bioeconomic modeling has been widely used in fish farming to optimize stocking rate, feeding ration or harvest weight (Cacho, 1997).

To our knowledge, however, bioeconomic modeling has never been used in fish farming to optimize management of production system after changing animal performances by selective breeding. Any changes in the performance of a fish in the fish-model will generate a reaction chain that might affect the optimal management strategy at batch and/or farm level according to the potential limiting factors. Bioeconomic modeling has, therefore, the advantage of accounting for such interactions. Throughout the thesis, we confirmed that the optimization of management after genetic improvement was affected by the type of limiting factor, which in return affected the economic value of traits.

\section{ENV(fish) versus ENV(farm)}

Mass-based functional units are the most dominant functional units in LCAs of livestock products, because an LCA by definition relates the environmental impact of a production system (e.g. meat production) to its main output (de Vries and de Boer, 2010). We, therefore, calculated the ENV per ton of fish produced, in short ENV(fish), in RAS (chapter 3) and in sea cages (chapter 5). Results show that $E N V$ (fish) of traits depended, as EV, on the effect of genetic change on the annual production of the farm and on the production efficiency of the farm. When annual production increases, fixed environmental impacts are diluted over more fish produced. Therefore, environmental impacts per ton of fish decreased and ENV(fish) for TGC and FCR were positive. When improving production efficiency, 
the use of inputs per ton of fish produced decreases and ENV(fish) were positive. Improving TGC can only increase the production of the farm, not production efficiency. Therefore, the ENV(fish) of TGC was positive only in situations where the limiting factors did not constrain the production of the farm. In RAS this was the case when the density of fish limited production, whereas in sea cages this was the case when the oxygen availability limited production (for average water temperature above $18{ }^{\circ} \mathrm{C}$ ), or when a quota was defined on standing stock (Qstock) or daily feed distributed (Qdaily_feed). Conversely, improving FCR always improved the production efficiency of the farm and, in some production systems, FCR also improved the production of the farm. Therefore, the ENV(fish) of FCR was always positive.

A mass-based functional unit, such as ton of fish produced used to calculate ENV(fish), however, ignores the increase in absolute amount of resources used and pollutants emitted due to higher production volumes (Salou et al., 2016). In chapter 5, therefore, we also calculated the ENV at farm level (ENV(farm)) in a sea cage system with different production quotas. ENV(farm) determines the absolute environmental impact of a farm. This unit is particularly interesting for production systems where quotas are applied because these quotas are implemented to limit the absolute impact of a farming site on the local environment. The use of this functional unit revealed that in the situations where genetic improvement increased production, ENV(farm) were negative, meaning that the absolute environmental impacts of a farm increased. When calculating at farm level, genetic improvement decreased environmental impacts only when production efficiency was improved. When improving TGC increased production, the ENV(farm) of TGC were negative. In chapter 6, we calculated the response to selection using ENV(fish) or ENV(farm) in different quota systems. The result showed that the genetic gain when using ENV(fish) could lead to an increase in environmental impacts at farm level.

Whether ENV(fish) or ENV(farm) should be used in a breeding program then depends on which impacts are to be minimized. In practice, however, the local environmental impact (i.e. benthos degradation, dissolved nutrient emissions, ecosystem changes) of fish farming is also determined by farm density and can be managed by quota systems, while global impacts can only be managed by improving efficiency. Hence, it would be logical to favor ENV(fish) rather than ENV(farm) in breeding programs. Still, in order to be able to revise the quota system, it is important to know if $\operatorname{ENV(farm)~is~changing~in~the~same~way~than~}$ 
ENF(fish) or EV - so it is important to calculate ENV(farm), even if it is not the value that is used to optimize the breeding goal, but just a value used to evaluate the consequences of the chosen breeding goal.

\section{Sensitivity and Uncertainty in LCA}

To calculate environmental values we need accurate data about environmental impacts of every input and output of the farm. The estimation of environmental impacts using LCA, however, is subject to variability due to seasonal, geographic or socio-economic variations. The combination of bioeconomic modeling and LCA can be used to assess the importance of this variability on foreground processes. In chapter 4, for instance, we investigated the effect of water temperature on the economic impact of improving TGC, whereas in chapter 5 we assessed the environmental impacts of improving TCG and FCR when farmers are constrained by different quotas. The flexibility of the bioeconomic model, therefore, enables assessing the impacts of variable parameters on environmental impacts. This can be considered as sensitivity analysis and used to identify the most influential parameters in an LCA. However, when calculating EV and ENV we do not take into account the correlated response that genetic changes can generate in other parameters. Groen (2016) showed that ignoring these correlations between parameters when carrying out a sensitivity analysis could lead to under or over estimation of the sensibility of these parameters. Wolf et al. (2016) applied sensitivity analysis including correlated responses to assess which parameters affected greenhouse gas emissions of milk production the most. They found, that the $\mathrm{CH}_{4}$ emission factor of enteric fermentation was among the most important parameters affecting the carbon footprint of milk. Thus, they concluded that future research should focus on improving data quality for this parameter. Such approach could be implemented in the bioeconomic model to assess the most important parameters affecting LCA results of fish farming.

In addition, the data used to assess the environmental impacts can be uncertain due to measurement errors and observational errors. This is known as epistemic uncertainty, which can affect the data about the system, the choice of models used to calculate emissions, and the choice of scenarios to define system boundaries (Röös and Nylinder, 2013). For instance, in this thesis, we used a mass-balance approach to estimate the excretion of nitrogen and phosphorus by the fish. We implied a fixed digestibly of nutrients. However, there is some uncertainty in the digestibility of nutrients that has not been taken into account and which could affect the results of the LCA. Uncertainty also exists for economic parameters, such 
as feed and gas prices, which can affect the optimal management of the farm and therefore the environmental impacts of genetic change. The potential effect of these uncertainties can be assessed using, for example, Monte Carlo Sampling (Chen and Corson, 2014; Groen et al., 2014). This method consists of drawing random numbers in the distribution function of each input parameter to obtain a distribution of the output parameters and a confidence interval for the environmental impacts. Monte Carlo is not so easy to perform because one must include dependency between parameters in the analysis otherwise the variability will be over or under expressed. Uncertainty analysis is generally recommended but not so often presented in LCA studies. It has not been conducted during the thesis but it would be interesting to do it in order to confirm the robustness of the conclusions.

\subsection{Matching breeding goals and farming systems}

\section{EV and farming systems}

Developing a bioeconomic model to calculate the EV of traits gave us the opportunity to investigate which traits are economically more important across production systems and across limiting factors within a given production system. We tested the influence of different limiting factors on the EV of TGC and FCR in two systems, RAS and sea cages.

In chapter 2, 4 and 5, we were able to show that EV of TGC and FCR varied across farming systems and were affected by limiting factors (summary of the results in Table 7.1). The EV of TGC is positive only if an improvement of TGC can increase the production level of the farm. Therefore, EV was zero when an increase of production level was constrained by, e.g., the treatment capacity of the biofilter in RAS, the oxygen availability (at $18^{\circ} \mathrm{C}$ average temperature of sea water) in sea cages, or by a quota limiting the total production level (i.e. quota on annual production or annual feed distributed). Conversely, improving FCR always improved production efficiency and, in some systems, also increased the production level of the farm. Consequently, the EV of FCR was always positive. These results show that understanding production system and associated limiting factors is extremely important when calculating EV of traits. 
Table 7.1: Summary of the economic value of thermal growth coefficient (TCG) and feed conversion ratio (FCR) in a recirculating aquaculture system (RAS) and a sea cage system.

\begin{tabular}{|c|c|c|c|c|}
\hline System & Limiting factor & $\mathrm{EV}_{\mathrm{TGC}}$ & $\mathrm{EV}_{\mathrm{FCR}}$ & Source \\
\hline \multirow[b]{2}{*}{ RAS } & Density & + & + & \multirow[b]{2}{*}{ Chapter 2} \\
\hline & $\begin{array}{c}\text { Nitrogen treatment } \\
\text { capacity }\end{array}$ & 0 & + & \\
\hline \multirow{5}{*}{ Sea cage } & Oxygen availability & $0->+$ & + & Chapter 4 \\
\hline & Qprod & 0 & + & \multirow{4}{*}{ Chapter 5} \\
\hline & Qannual_feed & 0 & + & \\
\hline & Qstock & + & + & \\
\hline & Qdaily_feed & + & + & \\
\hline \multirow[t]{2}{*}{ Pond } & Oxygen availability & + & + & $\begin{array}{l}\text { Omasaki et al. } \\
\text { (submitted) }\end{array}$ \\
\hline & Density & + & + & Predicted \\
\hline $\begin{array}{l}\text { Flow- } \\
\text { through }\end{array}$ & Nitrogen output & 0 & + & Predicted \\
\hline
\end{tabular}

Given these results, we could elaborate on EV of TGC and FCR in other systems, such as pond and flow-through systems depending on system-specific limiting factors. First, FCR would have a positive EV in all systems and for all limiting factors. Conversely, the EV of TGC will depend on the limiting factor constraining the system. In a pond, oxygen availability and density commonly limit the production of fish. When oxygen availability is the limiting factor, the EV of TGC will depend on the temperature. If the average water temperature is close to the optimal of the species reared in the system, the EV of TGC will most certainly be positive. If oxygen is not a problem but density is, the EV of TGC will be positive because fish will reach harvest weight earlier and more batches will be produced. In a flowthrough system, the production of the farm can be constrained by nitrogen emission from the farm (Nielsen, 2012). In that case, the EV of TGC would be null, because faster growing fish will excrete more nitrogen, which will constrain farmers to stock less fish.

Another situation arises when fish are transferred from one system to the other during their life. Let's consider the situation where pre-growing phase of fish takes place in RAS, whereas the final on-growing phase takes place in a sea cage system. The pre-growing phase, therefore, would be constrained by the treatment capacity of the bio filter, whereas the on-growing phase would be limited by the standing 
stock. The economic value of TGC would be null for the pre-growing life phase and positive for the on-growing life phase. Selecting for faster growing fish, therefore, will only benefit to on-growing farmers and not pre-growing farmers. This particular situation has been investigated by Jiang et al. (1998) for broiler chicken. They calculated the EV of many traits in a non-integrated and integrated production system of broiler. In the case of an integrated system, the calculation of EV should be done by including the different phases of production in the same bioeconomic model, while taking into account the influence that changing a trait in pre-growers can have on on-growers. In a non-integrated system, they showed that the traits of interest depend on the group of producers, either multipliers, hatchers, commercial growers or processors. They argue that the hatchery may not necessarily benefit from an improvement in finishing weight of broilers because it could reduce the number of chicks bought by the commercial grower to reach its production level. They suggested, therefore, that a probable compensation for the hatchery would be have to be paid according to the genetic quality of the chicks.

In fish farming, breeders and on-growers can be integrated in the same company or not. In an integrated company, the aim of the breeders is to select fish that will maximize the profit of the company. Thus, breeders have direct interest in estimating the economic value of traits. When a breeding company is not integrated, the aim of breeders is to comply with the needs of farmers in order to extend their market share. Consequently, fish breeding companies often sell juveniles to a variety of production systems. So, in order to select fish for this variety of production systems, fish breeders often use desired gains to weight the traits of the breeding goal. This approach is an empirical way to choose the traits that appear interesting for all stakeholders across different systems (Sae-Lim et al., 2012; Omasaki et al., 2016). However, unlike economic values, the desired gain approach is not meant for maximizing farm profit. In this system, breeders and pregrowers could also be paid according to the genetic quality of the fish.

\section{Genetic gain and farming systems}

Even if EV are informative about the economic importance of a particular trait, they do not fully predict the response to selection because the genetic gain per trait also depends on the additive genetic variance of each trait and on the phenotypic and genetic correlations between traits of the breeding goal and the index. TGC is an easy to measure trait with high heritability. Despite the fact that its EV is null in certain production systems it could still be interesting to select fish with faster growth because of genetic correlations with other economically interesting traits, 
e.g. filet yield (Rutten et al., 2005) or survival (Vandeputte et al., 2002). In chapter 6, therefore, we used the EV of TGC and FCR to compare the genetic gain between four breeding goals corresponding to the four quotas in sea cage, Qprod, Qannual_feed, Qstock and Qdaily_feed where EV varied. We saw that TGC could still be improved when the correlation between FCR and TGC was negative, even though its EV was null, because improving TGC generated a correlated response in FCR, which had a high EV. This shows the importance to implement EV in breeding programs to really see the impacts of different EV on the choice of fish that will actually be selected.

The results of this study show that different quotas imply different breeding goals and thus different genetic gains. It means that the types of fish that would bring the highest economic return to farmers differ across quota. We also showed that using only one breeding goal for all quota would lead to economic shortfall for farmers or even economic loss in some cases. In order to maximize economic return, therefore, a breeding company should develop different breeding programs. However, breeding companies often sell juveniles to a wide range of farms having a different environment and limiting factors. It suggests, therefore, that a breeding company should develop enough breeding programs to produce fish for each production system. However, generating different breeding programs is costly and a breeding company cannot easily afford developing multiple breeding programs. The choice of the set of EV to use in the breeding goal could depend, therefore, on the quota constraining most of the customers of the breeding company. However, such method will not maximize profit of all farms. Another approach could be to unify the quota system in large areas, such as the Mediterranean. Nowadays, sea bass production is constrained by annual production quotas or by annual feed distributed in France, Spain and Greece, which are all members of the European Union (FAO, 2014a,b). A unified quota policy across MED countries in the European Union, for example, would enable a single breeding program to maximize economic profit of all farms across the Mediterranean. Then, the choice of the best quota would depend on the objective: maximize profit or minimize environmental impact.

\section{Relationship between EV and ENV(fish) according to farming system}

In chapter 3, we showed, in a RAS, that the EV and ENV(fish) of TGC and FCR displayed synergy. When the EV of TGC and FCR were positive, the ENV was too. When $\mathrm{NH}_{3}-\mathrm{N}$ was the limiting factor, only genetic improvement in FCR increased profit and decreased environmental impacts because it increased both production 
and production efficiency. When density was the limiting factor, genetic improvement in TGC and FCR increased profit and decreased environmental impacts because improving TGC increases production and improving FCR increases production efficiency. This relationship between EV and ENV calculated from massbased functional unit was also observed in dairy farming (Bell et al., 2011; van Middelaar et al., 2014). In chapter 5, however, when investigating the EV and ENV(fish) of TGC and FCR in sea cage system, we found that the synergy between the two values was weaker than in RAS. This was because, in sea cages, the fixed environmental impacts represented a lower proportion of the total impacts which decreased the dilution of environmental impacts over higher production. In chapter 6, we compared the genetic gain when using EV or ENV(fish). We found differences especially when the quota was on Qstock and on Qdaily_feed. These differences in genetic gain in TGC and in FCR lead to a lower economic response when using ENV(fish) and a lower decrease of eutrophication when using EV. There are differences in the response because the ENV(fish) of TGC was rather small due to the fact that fixed environmental impacts represented a small proportion of the total impacts. Therefore, we can imagine that in a system where fixed environmental impacts are larger, such as RAS, the ENV(fish) becomes also larger, which would generate the same trends in genetic gain of TGC and FCR when using EV or ENV(fish). These results suggest that it would be easier to develop breeding programs increasing profit and decreasing environmental impacts per unit of fish in farming systems with higher proportion of fixed environmental impacts, such as RAS. Additionally, in systems with more variable environmental impacts, such as sea cages, improving traits affecting production efficiency should be emphasised.

\subsection{Enhancing sustainability in fish farming}

\section{Improving production efficiency}

Improving production efficiency always increased profit and reduced environmental impacts, because improving the production efficiency reduces the amount of inputs (e.g. feed) used to produce one kg of fish, which reduces both the economic and environmental costs of production. In addition, improving production efficiency is also of interest for reducing the feed-food competition. The feed-food competition refers to the use of human edible ingredients for feeding animals. The improvement of production efficiency, while keeping production level and the diet constant, allows for reducing the use of human edible ingredients for feeding animals as it decreases the total use of feed per $\mathrm{kg}$ of animal produced. Consequently, selective breeding should focus on traits that contribute to better 
production efficiency rather than higher production. This is especially true when it is not possible to develop different breeding programs for different production systems because any type of system would benefit economically and environmentally benefit from an improvement of production efficiency.

Production efficiency can be expressed at different levels. In this thesis, we looked at a change of production efficiency at the fish level, because the change in FCR reduced the amount of feed required by the fish to reach harvest weight. Nonetheless, selective breeding for FCR in fish farming is currently challenged by the ability to estimate individual variation in feed intake. This trait is, difficult to measure because fish are kept in groups in tanks. Consequently, genetic parameters for feed intake and FCR are lacking and selection for more efficient fish is still difficult. Different methods to estimate feed intake have been developed. One method is based on using body weight variations during feeding deprivation and re-feeding periods as predictors of residual feed intake, a proxy of feed efficiency. Using this method, Grima et al. (2008) showed, in rainbow trout, that combining weight loss during feed deprivation and compensatory growth during refeeding period could explain about $60 \%$ of the variation of residual feed intake. Daulé et al. (2014) performed one generation of divergent selection in sea bass based on weight loss during feed deprivation but they did not find any significant response in feed efficiency. However, the authors argued that a second generation of selection could reveal differences in feed efficiency, as in the base population, sea bass with a lower weight loss during fasting also had a lower residual feed intake. Another way to improve FCR could be by selecting on lipid deposition, which in pigs, was shown to be correlated with feed efficiency (Hermesch et al., 2000; Gilbert et al., 2007). However, there are inconsistencies in the results of experiments with. In rainbow trout, Quillet et al. (2007) showed no significant correlation between muscle fat content and feed efficiency after two generations of selection for high or low muscle fat content. Though they found a significant difference after 7 generations of selection (Quillet, pers. comm.). However, they estimated feed intake and feed efficiency in groups of fish, which cannot provide individual performances. Conversely, Quinton et al. (2007) showed for European whitefish that whole body lipid percentage displayed positive phenotypic and genetic correlations with growth rate and feed intake. This finding suggested that direct selection on growth rate together with an indirect selection against lipid content could be a way to improve feed efficiency. In this study they used Xradiography to detect feed pellets marked with dense marker in the gastro- 
intestinal tract and to estimate feed intake. This method showed, however, low repeatability.

Being able to estimate feed intake is essential for developing a breeding program that would enhance the sustainable development of fish farming. This because, in chapter 6, we showed that the correlation between TGC and FCR has more influence on genetic gains achieved than the choice of quota. For instance, when using EV from Qdaily_feed, economic gain of the breeding program was $0.09 € / \mathrm{kg}$ when the correlations were -0.2 , whereas economic gain was $0.02 € / \mathrm{kg}$ when the correlations were zero. Additionally, this breeding goal could decrease eutrophication per $\mathrm{kg}$ of fish when the correlations were -0.2 but not when they were -0.1 .

Production efficiency, however, is not limited at fish level. At farm level, production efficiency represents how much inputs are required to a farm to produce a certain amount of fish. The production efficiency of the farm depends, therefore, on mortality due to diseases because dead fish were fed for a certain period of time but not harvested. Many fish breeding programs already include disease resistance as a major trait to improve (Chavanne et al., 2016). Mclnerney et al. (1992) proposed a method to estimate the cost of disease outbreak in livestock. The economic cost of a disease outbreak is a combination of costs due to loss of production (dead fish and reduced growth) and costs of expenditure for treating the disease or to prevent it. Using the bioeconomic model it would, therefore, be possible to estimate the EV of better disease resistance. However, this approach would require deriving economic values for each disease separately.

At the supply chain level, production efficiency includes all the processes taking place before or after the production of the fish, as for instance, filleting. When including filleting, other traits might become interesting for the improvement of production efficiency such as filet yield. When fillet yield is low, only a small proportion of the fish can be sold to consumers. Conversely, a high fillet yield means that most of the feed distributed to the fish was converted to fillet and that less waste was produced. Therefore, high filet yield is associated to better production efficiency at the supply chain level. Filet yield has already been included in most breeding programs (Janssen et al., 2016) because this trait displays moderate heritability and positive phenotypic and genetic correlations with body weight (Rutten et al., 2005; Saillant et al., 2009). The bioeconomic model 
developed in this thesis could be extended to include filet processing, which would allow for estimating the EV and ENV of filet yield.

\section{Using limiting factors to enhance sustainability of fish production}

Until recently, genetic improvement was mainly oriented towards production traits. Nowadays, welfare and health issues have become more important in selective breeding (Olesen et al., 2011). The genetic variability is, therefore, a tool to adapt animals to new challenges that fish farming is facing. Throughout the thesis, we showed that fish breeding must now also adapt breeding objectives to production systems and their limiting factors, which had not been considered in the design of fish breeding programs yet. Limiting factors clearly influence the capacity of genetic change to increase farm profit or to reduce environmental impacts per ton of fish or per farm. In chapter 5, we calculated the economic and environmental values of TGC and FCR in different scenarios of production quota. Then, we estimated the economic and environmental response of using EV and ENV in a simple breeding program in chapter 6 . The results show that quota on daily feed and on annual feed distributed seem to be the best quotas. They were the best because they increase economic profit and decrease eutrophication at the same time regardless of the type of weighting factor used (EV or ENV(fish)). Thus, such study could be a tool for the definition of public policies regarding production quotas. According to our results, the implementation of Qannual_feed and Qdaily_feed should be stimulated.

Qdaily_feed and Qannual_feed performed well because most of the genetic gain was achieved in FCR, the trait with the highest EV and ENV(fish). This result, however, is based on the assumptions that it is possible to improve FCR (even indirectly), which is not the case yet. Nowadays, growth is still the major trait of interest, consequently, quotas that make TGC non profitable might discourage farmers to buy and invest on faster growing juveniles from selective breeding programs. A solution could be to give more importance first on quotas that make selection on TGC profitable for farmers. Then, the money earned by breeding companies should be re-invested into research to develop efficient technology of improving FCR and other traits involved in production efficiency such as disease resistance.

\section{Cost of environmental impacts}

The environmental values calculated in the present study or in van Middelaar et al. (2014) cannot be associated with economic values in aggregate genotype because 
they are not expressed in the same unit. Economic values are expressed in euros / $\mathrm{kg}$, while environmental values are expressed in, for example, $\mathrm{kg} \mathrm{CO}_{2 \text {-eq }} / \mathrm{t}$ when looking at climate change.

The social cost of carbon is an indicator of the marginal cost of $\mathrm{CO}_{2}$ defined as the damage done by emitting an additional ton of $\mathrm{CO}_{2}$. In 2007, the social cost of carbon was estimated to be $\$ 21$ per ton of $\mathrm{CO}_{2}$ (Interagency Working Group, 2010). However, there is a lot of debate around this value because the estimation of the social cost of carbon depends on multiple assumptions and is rather difficult. Some studies suggested that the social cost of carbon could reach $\$ 900$ per ton of $\mathrm{CO}_{2}$ in 2010 and $\$ 1,500$ in 2050 (Ackerman and Stanton, 2012). The social cost of carbon could be used to convert the ENV for climate change of traits into economic values of climate change. The economic value of climate change (EVcc) could then be added to the classic economic values in breeding programs. This method could be used more particularly when there is antagonism between EV and ENV. This because combining EV and ENV in the same breeding goal would balance out the genetic gain.

To test this hypothesis, we combined in the same breeding goal EV and ENV(farm) for TGC and FCR. We chose ENV(farm) rather than ENV(fish) to test this hypothesis because ENV(farm) are antagonist to EV but not ENV(fish). We used the values from Qstock where the EV of TGC is positive ( 0.65 euros / $\mathrm{kg}$ of fish) and ENV(farm) is negative (-983.5 $\mathrm{kg} \mathrm{CO}$-eq / $\mathrm{t}$ of fish). We calculated the response to selection using a breeding goal combining EV and ENV(farm) for TGC and FCR as follows:

$$
H=\left(E V_{T G C}+E V_{C C T G C}\right) \times A_{F C R}+\left(E V_{F C R}+E V_{C C F C R}\right) \times A_{F C R}
$$

For a social cost of carbon of $800 € / t$, this breeding goal becomes:

$$
H=(0.65-0.78) \times A_{T G C}+(1.32+1.34) \times A_{F C R}
$$

The index was the same as in chapter 6 and was composed of TGC and visceral fat percentage. The genetic parameters for each trait as well as the phenotypic and genetic correlations between the traits were the same as chapter 6. Figure 7.1 shows the economic gain and climate change impact when using EV, ENV(farm) or a combination of EV and EVcc in a breeding goal. We also tested two hypotheses with a social cost of carbon of $800 € / t$ (EVcc-800) or 1,350 €/t (EVcc-1,350). We estimated the economic gain and the climate change impact when the correlation between TGC and FCR was $-0.2,-0.1$ or 0 . 


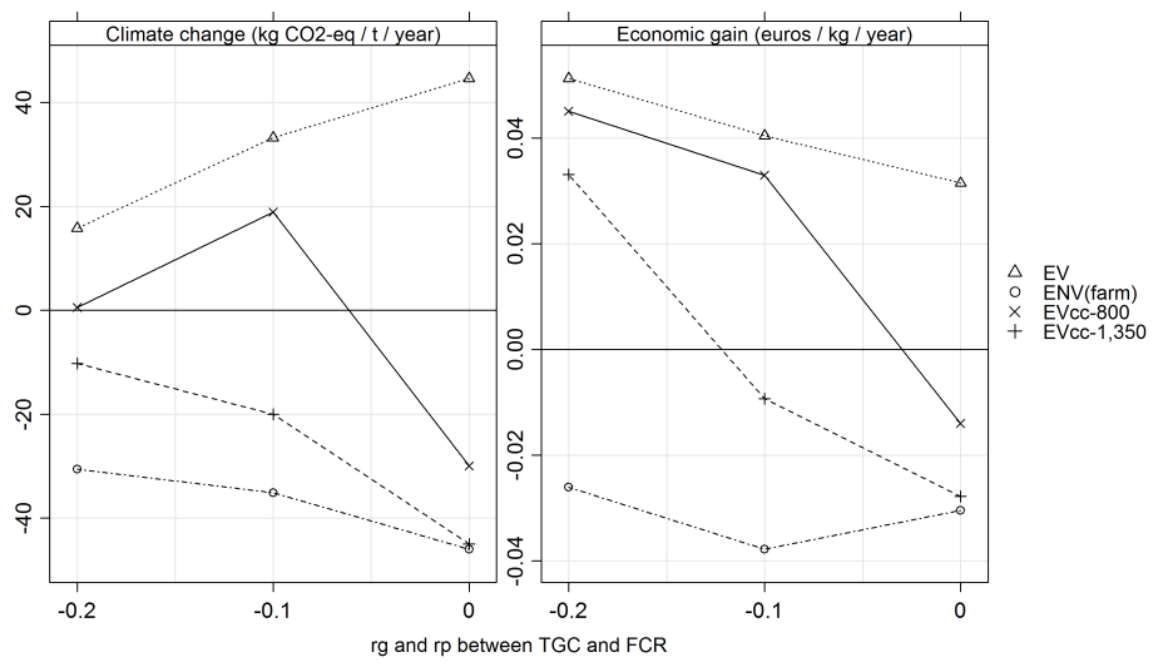

Figure 7.1: Economic gain and climate change impact when using EV, ENV(farm) or a combination of EV and EVcc in a breeding goal for different phenotypic and genetic correlation between TGC and FCR.

Results show that the breeding goals combining EV and EVcc have intermediate economic gain and impact on climate change in between breeding goals using only EV and ENV(farm) (Figure 7.1). When the social cost of carbon was $1,350 € / t$, the economic gain decreased but the response in climate change became negative, meaning that climate change per ton of fish at farm level decreased. These results are encouraging because it shows that combining EV and EVcc in a breeding goal can generate economic profit and decrease climate change of farms. Such an approach could stimulate the development of breeding goals including environmental objectives while maintaining economic objectives when there is antagonism between EV and ENV. This approach could also be used for other environmental impacts than climate change, such as eutrophication. Ultimately, all potential economic costs of environmental impacts could be combine in a single breeding goal.

\section{Effect of global warming on breeding objectives}

It has been proven that we are in a period of global warming and this global warming affects the temperature of the ocean. Since 1971, the surface temperature of the ocean increased on average by $0.11{ }^{\circ} \mathrm{C}$ per decade (Rhein et al. 2013). In chapter 5, we tested the effect of different average temperatures and different amplitude of temperature on the EV of TGC. The results showed that the 
EV of TGC was null in conditions where the average annual temperature (Tm) was $18{ }^{\circ} \mathrm{C}$ and positive when $\mathrm{Tm}$ was 19.5 or $21^{\circ} \mathrm{C}$. This result was due to the fact that production level of the farm could be increased by improving TGC when Tm was 19.5 or $21^{\circ} \mathrm{C}$ whereas it was not possible to improve production level at $\mathrm{Tm} 18^{\circ} \mathrm{C}$. It shows, therefore, that breeding objectives could change when the water temperature changes. Our bioeconomic model can be used as a tool to evaluate the impact of global warming on farm management and on the breeding objectives.

\subsection{Conclusions}

In this thesis we showed that breeding goals can be designed that increase profitability and reduce environmental impacts. However, there are still some challenges ahead.

First, breeders must select fish for the right production system with the right limiting factors. To do so, it is essential to calculate the economic and environmental values of traits of interest. This should be done for every production system because we showed that the EV and ENV of traits vary according to the limiting factor constraining the production of fish. Second, we found that improving FCR has positive effect on profit and on environmental impacts irrespective of the limiting factor. Improving production efficiency, unlike production level, would always benefit profit and environmental impacts because it allows for using less inputs for the same amount of product output. In fish farming, feed is the major economic and environmental cost. Therefore, reducing the use of feed per $\mathrm{kg}$ of fish increases profit and reduce environmental impacts. However FCR is still difficult to improve because feed intake is difficult to measure on fish. Hence, efficient methods to estimate feed intake in fish must be developed. In addition, other traits that we did not consider in this thesis could be used to improve production efficiency, such mortality and disease resistance or filet yield.

This work could help fish breeders in developing breeding programs that enhance the economic viability and the environmental sustainability of fish production by selecting for traits that will maximize profit and decrease the environmental impacts according to production system and its limitations. These results could also help policy makers to define the best quota to minimize the environmental impact of fish farming. 

References 

Ackerman, F., and E. Stanton. 2012. Climate risks and carbon prices: Revising the social cost of carbon. Economics: The Open-Access, Open-Assessment EJournal 6: 10.

Albrektsen, S., H. Mundheim, and A. Aksnes. 2006. Growth, feed efficiency, digestibility and nutrient distribution in Atlantic cod (Gadus morhua) fed two different fish meal qualities at three dietary levels of vegetable protein sources. Aquaculture 261: 626-640.

Amer, P. R., G. C. Fox, and C. Smith. 1994. Economic weights from profit equations: appraising their accuracy in the long run. Anim. Sci. 58:11-18.

Asche, F., and T. Bjorndal. 2011. The economics of salmon aquaculture. John Wiley \& Sons.

Asche, F., H. Hansen, R. Tveteras, and S. Tveterås. 2009. The salmon disease crisis in Chile. Mar. Resour. Econ. 24: 405-411.

Ashley, P. J. 2007. Fish welfare: Current issues in aquaculture. Appl. Anim. Behav. Sci. 104: 199-235.

Aubin, J. 2013. Life Cycle Analysis as applied to environmental choices regarding farmed or wildcaught fish. CAB Reviews: Perspectives in Agriculture, Veterinary Science, Nutrition and Natural Resources 8.

Aubin, J., E. Papatryphon, H.M.G. van der Werf, and S. Chatzifotis. 2009. Assessment of the environmental impact of carnivorous finfish production systems using life cycle assessment. J. Clean. Prod. 17: 354-361.

Aubin, J., E. Papatryphon, H.M.G. van der Werf, J. Petit, and Y.M. Morvan. 2006. Characterisation of the environmental impact of a turbot (Scophthalmus maximus) re-circulating production system using Life Cycle Assessment. Aquaculture 261: 1259-1268.

Ayer, N.W., and P.H. Tyedmers. 2009. Assessing alternative aquaculture technologies: life cycle assessment of salmonid culture systems in Canada. J. Clean. Prod. 17: 362-373.

Bell, M. J., R. J. Eckard, M. Haile-Mariam, and J. E. Pryce. 2013. The effect of changing cow production and fitness traits on net income and greenhouse gas emissions from Australian dairy systems. J. Dairy. Sci. 96: 7918-7931.

Bell, M.J., E. Wall, G. Russell, G. Simm, and A.W. Stott. 2011. The effect of improving cow productivity, fertility, and longevity on the global warming potential of dairy systems. J. Dairy. Sci. 94: 3662-3678.

Bell, M.J., E. Wall, G. Russell, C. Morgan, and G. Simm. 2010. Effect of breeding for milk yield, diet and management on enteric methane emissions from dairy cows. Anim. Prod. Sci. 50: 817-826.

Besson, M., J. Aubin, K. Komen, M. Poelman, E. Quillet, M. Vandeputte, J.M.A. van Arendonk, and I.J.M. de Boer. 2016a. Environmental impacts of genetic improvement of growth rate and feed conversion ratio in fish farming under rearing density and nitrogen output limitations. J. Clean. Prod. 116: 100-109. 
Besson, M., I.J.M. de Boer, M. Vandeputte, J.A.M. van Arendonk, E. Quillet, H. Komen, J. Aubin. Submitted. Effect of production quotas on economic and environmental values of growth rate and feed efficiency in sea cage fish farming.

Besson, M., H. Komen, J. Aubin, I.J.M. de Boer, M. Poelman, E. Quillet, C. Vancoilie, M. Vandeputte, and J.A.M. van Arendonk. 2014. Economic values of growth and feed efficiency for fish farming in recirculating aquaculture system with density and nitrogen output limitations: a case study with African catfish (Clarias gariepinus). J. Anim. Sci. 92: 5394-5405.

Besson, M., M. Vandeputte, J.M.A. van Arendonk, J. Aubin, I.J.M. de Boer, E. Quillet, H. Komen. 2016b. Influence of water temperature on the economic value of growth rate in fish farming: The case of sea bass (Dicentrarchus labrax) cage farming in the Mediterranean. Aquaculture 462: 47-55.

Boissy, J., J. Aubin, A. Drissi, H.M.G. van der Werf, G.J. Bell, and S.J. Kaushik. 2011. Environmental impacts of plant-based salmonid diets at feed and farm scales. Aquaculture 321: 61-70.

Brafield, A. E., and M.J. Llewellyn. 1982. Animal energetics. Blackie Glasgow, UK.

Brafield, A. E., D.J. Solomon. 1972. Oxy-calorific coefficients for animals respiring nitrogenous substrates. Comparative Biochemistry and Physiology Part A: Physiology. 43: 837-841.

Breitburg, D. 2002. Effects of hypoxia, and the balance between hypoxia and enrichment, on coastal fishes and fisheries. Estuaries 25: 767-781.

Buddle, B.M., M. Dennis, G.T. Attwood, E. Altermann, P.H. Janssen, R.S. Ronimus, C.S. Pinares-Patiño, S. Muetzel, and D. Neil Wedlock. 2011. Strategies to reduce methane emissions from farmed ruminants grazing on pasture. Vet. J. 188: 11-17.

Cacho, O. J. 1997. Systems modelling and bioeconomic modelling in aquaculture. Aquacult. Econ. Manage. 1: 45-64.

Cai, W., D. S. Casey, and J. C. M. Dekkers. 2008. Selection response and genetic parameters for residual feed intake in Yorkshire swine. J. Anim. Sci. 86: 287-298.

Chavanne, H., K. Janssen, J. Hofherr, F. Contini, P. Haffray, H. Komen, E.E. Nielsen, L. Bargelloni. 2016. A comprehensive survey on selective breeding programs and seed market in the European aquaculture fish industry. Aquat. Int. 121.

Chen, X., and M. S. Corson. 2014. Influence of emission-factor uncertainty and farm-characteristic variability in LCA estimates of environmental impacts of French dairy farms. J. Clean. Prod. 81: 150-157.

Cho, C. Y. 1990. Feeding systems for rainbow trout and other salmonids with reference to current estimates of energy and protein requirements. Aquaculture 100: 107-123. 
Cho, C. Y., and D.P. Bureau. 1998. Development of bioenergetic models and the Fish-PrFEQ software to estimate production, feeding ration and waste output in aquaculture. Aquat. Living. Resour. 11: 199-210.

Cho, C. Y., and S. J. Kaushik. 1990. Nutritional energetics in fish: energy and protein utilization in rainbow trout (Salmo gairdneri). World. Rev. Nutr. Dietetics. 1: 132-172.

Clutter, A. C., and E. W. Brascamp. 1998. Genetics of performance traits. Pages $427-$ 455 in The genetics of the pig. M. F. Rotschild and A. Ruvinsky, Ed. CAB Int., Wallingford, UK.

CNA, Conseil National de l'Alimentation. 2011. Quelle place pour les protéines animales transformées (PAT) dans l'alimentation des porcs, des volailles et des poissons?

Conover, D. O., J.J. Brown, A. Ehtisham. 1997. Counter gradient variation in growth of young striped bass (Morone saxatilis) from different latitudes 1. Can. J. Fish. Aquat. Sci. 54: 2401-2409.

Coves, D., G. Dewavrin, G. Breuil, and N. Devauchelle. 1991. Culture of sea bass (Dicentrarchus labrax L.).

Cowey, C. B., and C. Y. Cho. 1991. Nutritional strategies and aquaculture waste. Proc. 1st Int. Symp. Nutritional strategies in management of aquaculture waste. Univ. Guelph, Guelph, Ontario.

Crawford, R. D. 1990. Poultry breeding and genetics. Elsevier, Oxford.

Daulé, S., M. Vandeputte, A. Vergnet, B. Guinand, L. Grima, and B. Chatain. 2014. Effect of selection for fasting tolerance on feed intake, growth and feed efficiency in the European sea bass Dicentrarchus labrax. Aquaculture 420: S42-S49.

De Boer, I.J.M. 2012. Innovation born of integration. Moving towards sustainable production of animal-source food. Inaugural Lecture, Wageningen University, Wageningen.

Dekkers, J. C. M. 1991. Estimation of economic values for dairy cattle breeding goals: Bias due to sub-optimal management policies. Livest. Prod. Sci. 29: 131-149.

Department for Environment Food \& Rural Affairs. 2013. Guidance on complying with the rules for Nitrate Vulnerable Zones in England for 2013 to 2016.

De Vries, M., and I.J.M. De Boer. 2010. Comparing environmental impacts for livestock products: A review of life cycle assessments. Livest. Sci. 128: 111.

Diana, J. S., Y. Yi, and C. K. Lin. 2004. Stocking densities and fertilization regimes for Nile tilapia (Oreochromis niloticus) production in ponds with supplemental feeding. In: Proceedings of the sixth international symposium on tilapia in aquaculture, R. Bolivar, G. Mair and K. Fitzsimmons, Eds. Manila, Philippines, BFAR, Philippines. p 487-499.178 
d'Orbcastel, E.R., J.-P. Blancheton, and J. Aubin. 2009. Towards environmentally sustainable aquaculture: Comparison between two trout farming systems using Life Cycle Assessment. Aquacult. Eng. 40: 113-119.

Dumas, A., J. France, and D. P. Bureau. 2007. Evidence of three growth stanzas in rainbow trout (Oncorhynchus mykiss) across life stages and adaptation of the thermal-unit growth coefficient. Aquaculture 267: 139-146.

Dupont-Nivet, M., B. Karahan-Nomm, A. Vergent, O. Merdy, P. Haffray, H. Chavanne, B. Chatain, and M. Vandeputte. 2010. Genotype by environment interactions for growth in European seabass (Dicentrarchus labrax) are large when growth rate rather than weight is considered. Aquaculture 306:365-368.

Ecoinvent, 2010. Online: http://www.ecoinvent.ch/.

Elliott, J., and W. Davison. 1975. Energy equivalents of oxygen consumption in animal energetics. Oecologia 19: 195-201.

Emmerson, D. 1997. Commercial approaches to genetic selection for growth and feed conversion in domestic poultry. Poultry Sci. 76: 1121-1125.

Ervik A., P.K. Hansen, J. Aure, A. Stigebrandt, P. Johannessen, and T. Jahnsen. 1997. Regulating the local environmental impact of intensive marine fish farming I. The concept of the MOM system (Modelling-Ongrowing fish farmsMonitoring). Aquaculture 158: 85-94.

FAO. 2016. FAO yearbook. Fishery and aquaculture statistics, 2014.

FAO. 2014a. Vue générale du secteur aquacole national. http://www.fao.org/fishery/countrysector/naso_france/fr

FAO. 2014b. National Aquaculture Legislation Overview. http://www.fao.org/fishery/legalframework/nalo_greece/en\#tcNB008E

FAO.2012. FAO yearbook. Fishery and aquaculture statistics, 2010..

Folke, C., N. Kautsky, and M. Troell. 1994. The Costs of Eutrophication from Salmon Farming: Implications for Policy. J. Environ. Manage. 40: 173-182.

Frischknecht, R., N. Jungbluth, H.J. Althaus, G. Doka, T. Heck, S. Hellweg, R. Hischier, T. Nemecek, G. Rebitzer, M. Spielmann, and G. Wenet. 2007. Overview and Methodology. Swiss Centre for Life Cycle Inventories, Dübendorf, Switzerland.

Gasca-Leyva, E., C.J. León, M. Hernández, and J.M. Vergara. 2002. Bioeconomic analysis of production location of sea bream (Sparus aurata) cultivation. Aquaculture 213: 219-232.

Gibson, J., and B. Kennedy. 1990. The use of constrained selection indexes in breeding for economic merit. Theor. Appl. Genet. 80: 801-805.

Gibson, J. P. 1989. Selection on the major components of milk: alternative methods of deriving economic weights. J. Dairy Sci. 72: 3176-3189.

Gibson, J.P. 1989. Economic weights and index selection of milk production traits when multiple production quotas apply. Anim. Sci. 49: 171-181.

Gilbert, H. et al. 2007. Genetic parameters for residual feed intake in growing pigs, with emphasis on genetic relationships with carcass and meat quality traits. J. Anim. Sci. 85: 3182-3188. 
Gjerde, B., and B. Olsen. 1990. Economic value of breeding program ( $\varnothing$ konomisk Verdi av avlsarbeidet). Husdyrfors $\varnothing$ ksm $\varnothing$ tet 1990 . Akvakultur. Aktuelt fra Statens Fagtjeneste for landbruket, No 5, pp. 61-65.

Gjedrem, T., and M. Rye. 2016. Selection response in fish and shellfish: a review. Rev Aquacult. : 0: 1-12.

Gjedrem, T., N. Robinson, and M. Rye. 2012. The importance of selective breeding in aquaculture to meet future demands for animal protein: A review. Aquaculture. 350-353: 117-129.

Gjedrem, T. 2010. The first family-based breeding program in aquaculture. Rev. Aquacult. 2: 2-15.

Gjedrem, T., and J. Thodesen. 2005. Selection. In: Gjedrem, T. (Ed.), Selection and Breeding Programs in Aquaculture. Springer, p. 364.

Goddard, M. E. 1983. Selection Indexes for Non-Linear Profit-Functions. Theor. Appl. Genet. 64: 339-344.

Grima, L. et al. 2008. Genetic variability in residual feed intake in rainbow trout clones and testing of indirect selection criteria. Genet. Select. Evol. 40: 1.

Groen, A. F. 1989. Economic values in cattle breeding. II. Influences of production circumstances in situations with output limitations. Livest. Prod. Sci. 22: 17-30.

Groen, A. F. 1988. Derivation of economic values in cattle breeding: A model at farm level. Agr. Syst. 27: 195-213.

Groen, E. A. 2016. An uncertain climate : the value of uncertainty and sensitivity analysis in environmental impact assessment of food, Wageningen University, Wageningen.

Groen, E., R. Heijungs, E. Bokkers, and I.J.M. de Boer. 2014. Methods for uncertainty propagation in life cycle assessment. Environ. Model. Softw. 62: 316-325.

Guinée, J.B., M. Gorrée, R. Heijungs, G. Huppes, R. Kleijn, A. de Koning, L. van Oers, A. Wegener Sleeswijk, S. Suh, H.A.U. de Haes, H. de Bruijn, R. van Duin, M.A.J. Huijbregts, E. Lindeijer, A.A.H. Roorda, B.L. van der Ven, and P.P. Weidema. 2002. Handbook on Life Cycle Assessment, Operational Guide to the ISO Standards. Kluwer Academic Publishers, Dordrecht, The Netherlands.

Gunsett, F. 1984. Linear index selection to improve traits defined as ratios. J. Anim. Sci. 59: 1185-1193.

Hansen, P.K., A. Ervik, M. Schaanning, P. Johannessen, J. Aure, T. Jahnsen, and A. Stigebrandt. 2001. Regulating the local environmental impact of intensive, marine fish farming: II. The monitoring programme of the MOM system (Modelling-Ongrowing fish farms-Monitoring). Aquaculture. 194: 75-92.

Havenstein, G., P. Ferket, S. Scheideler, and B. Larson. 1994. Growth, livability, and feed conversion of 1957 vs 1991 broilers when fed "typical" 1957 and 1991 broiler diets. Poultry Sci. 73: 1785-1794.

Hazel, L. N. 1943. The genetic basis for constructing selection indexes. Genetics. 28: 476-490. 
Henriksson, P.G., J. Guinée, R. Kleijn, and G. Snoo. 2012. Life cycle assessment of aquaculture systems - a review of methodologies. Int. J. Life. Cycle. Assess. 17: 304-313.

Henryon, M., I. W. Purvis, and P. Berg. 1999. Definition of a breeding objective for commercial production of the freshwater crayfish, marron (Cherax tenuimanus). Aquaculture 173: 179-195.

Hermesch, S., B. G. Luxford, and H. U. Graser. 2000. Genetic parameters for lean meat yield, meat quality, reproduction and feed efficiency traits for Australian pigs: 2 . Genetic relationships between production, carcase and meat quality traits. Livest. Prod. Sci. 65: 249-259.

Hernández, J. M., M. León-Santana, and C.J. León. 2007. The role of the water temperature in the optimal management of marine aquaculture. Eur. J. Oper. Res. 181: 872-886.

Holmer, M., P.K. Hansen, I. Karakassis, J.A. Borg, and P.J. Schembri. 2008. Monitoring of environmental impacts of marine aquaculture. Springer.

Imsland, A., and T. Jonassen. 2001. Regulation of growth in turbot (Scophthalmus maximus Rafinesque) and Atlantic halibut (Hippoglossus hippoglossus L.): aspects of environment $\times$ genotype interactions. Rev. Fish. Biol. Fisher. 11: 71-90.

International Energy Agency (2010). Energy Technology Perspectives 2010: Scenarios \& Strategies to 2050, Paris. http://www.iea.org/techno/etp/index.asp.

James, J. 1982. Economic aspects of developing breeding objectives: general considerations. Pages 107-118 in Future developments in the genetic improvement of animals. J. S. F. Barker, K. Hammond, and A. E. McClintock, Ed. Academic press, Australia.

Janssen, K., H. Chavanne, P. Berentsen, H. Komen. 2016. Impact of selective breeding on European aquaculture. Aquaculture doi:10.1016/j.aquaculture.2016.03.012

Jiang, X., A. Groen, and E. Brascamp. 1998. Economic values in broiler breeding. Poultry Sci. 77: 934-943.

Kause, A., D. Todin, D. F. Houlihan, S. A. M. Martins, E. A. Mäntysaari, O.Ritola, and K. Ruohonen. 2006. Feed efficiency of rainbow trout can be improved through selection: Different genetic potential on alternative diets. J. Anim. Sci. 84: 807-817.

Kaushik, S, J. 1998. Nutritional bioenergetics and estimation of waste production in non-salmonids. Aquat. Living. Resour. 11(4): 211-217.

Kaushik, S. J., D. Covès, G. Dutto, and D. Blanc. 2004. Almost total replacement of fish meal by plant protein sources in the diet of a marine teleost, the European seabass, Dicentrarchus labrax. Aquaculture 230: 391-404.

Lanari, D., E. D'Agaro, and R. Ballestrazzi. 2002. Growth parameters in European sea bass (Dicentrarchus labrax L.): effects of live weight and water temperature. Ital. J. Anim. Sci. 1: 181-186. 
Lin, C. Y., and S. E. Aggrey. 2013. Incorporation of economic values into the component traits of a ratio: Feed efficiency. Poultry Sci. 92: 916-922.

Llorente, I., and L. Luna. 2013. The competitive advantages arising from different environmental conditions in seabream, Sparus aurata, production in the Mediterranean Sea. J. World. Aquacult. Soc. 44: 611-627.

Lundebye, A.K. 2013. Aquaculture site selection and carrying capacity for inland and coastal aquaculture in Northern Europe. In Ross LG, Telfer TC, Falconer L, Soto D, Aguilar-Manjarrez J, eds. Site selection and carrying capacities for inland and coastal aquaculture, pp. 171-181. FAO/Institute of Aquaculture, University of Stirling, Expert Workshop, 6-8 December 2010. Stirling, the United Kingdom of Great Britain and Northern Ireland. FAO Fisheries and Aquaculture Proceedings No. 21. Rome, FAO. 282 pp.

Mallet, J. P., S. Charles, H. Persat, and P. Auger. 1999. Growth modelling in accordance with daily water temperature in European grayling (Thymallus thymallus L.). Can. J. Fish. Aquat. Sci. 56: 994-1000.

Mambrini, M., F. Médale, M. P. Sanchez, B. Recalde, B. Chevassus, L. Labbé, E. Quillet, and T. Boujard. 2004. Selection for growth in brown trout increases feed intake capacity without affecting maintenance and growth requirements. J. Anim. Sci. 82: 2865-2875.

Martins, C. I. M., E. H. Eding, M. C. J. Verdegem, L. T. N. Heinsbroek, O. Schneider, J. P. Blancheton, E. Roque d'Orbcastel, and J. A. J. Verreth. 2010. New developments in recirculating aquaculture systems in Europe: $A$ perspective on environmental sustainability. Aquacult. Eng. 43: 83-93.

Mclnerney, J. P., K. S. Howe, and J. A. Schepers. 1992. A framework for the economic analysis of disease in farm livestock. Prev. Vet. Med. 13: 137154.

Mente, E., G.J. Pierce, M.B. Santos, and C. Neofitou. 2006. Effect of feed and feeding in the culture of salmonids on the marine aquatic environment: a synthesis for European aquaculture. Aquacult. Int. 14: 499-522.

Nagy, A., V. Csanyi, J. Bakos, and L. Horvath. 1980. Development of a short-term laboratory system for the evaluation of carp growth in ponds. Bamidgeh 32: 6-15.

Naylor, R. L., R.J. Goldburg, H. Mooney, M. Beveridge, J. Clay, C. Folke, N. Kautsky, J. Lubchenco, J. Primavera, and M. Williams. 1998. Nature's subsidies to shrimp and salmon farming. Science 282: 883-884.

Naylor, R.L., R.J. Goldburg, H.J. Primavera, N. Kautsky, M.C.M. Beveridge, J. Clay, C. Folke, J. Lubchenco, H. Mooney, and M. Troell. 2000. Effect of aquaculture on world fish supplies. Nature. 405: 1017-1024.

Naylor, R. L., R.W. Hardy, D.P. Bureau, A. Chiu, M. Elliott, A.P. Farrell, I. Foster, D.M. Gatlin, R.J.Goldburg, K. Hua, and P.D. Nichols. 2009. Feeding aquaculture in an era of finite resources. P. Natl. Acad. Sci. 106: 15103-15110.

Nielsen, R. 2012. Introducing individual transferable quotas on nitrogen in Danish fresh water aquaculture: Production and profitability gains. Ecol. Econ. 75: 83-90. 
Nielsen, H. M., P. R. Amer, and T. J. Byrne. 2013. Approaches to formulating practical breeding objectives for animal production systems. Acta Agriculturae Scandinavica, Section A - Anim. Sci. 64: 2-12.

Nielsen, H. M., L. G. Christensen, and A. F. Groen. 2005. Derivation of Sustainable Breeding Goals for Dairy Cattle Using Selection Index Theory. J. Dairy. Sci. 88: 1882-1890.

Nielsen, H. M., L. G. Christensen, and J. Ødegård. 2006. A Method to Define Breeding Goals for Sustainable Dairy Cattle Production. J. Dairy. Sci. 89: 3615-3625.

Norsvin, 1996. Annual reports 1980-1996. Norwegian Pig Breeding Organisation. Hamar, Norway. NE, USA, pp. 107-112.

NRS, 1996. Annual statistics 1996. Royal Dutch Cattle Syndicate, Arnhem, The Netherlands.

Oglend, A. 2013. Recent trends in salmon price volatility. Aquacult. Econ. Manage. 17: 281-299.

Olesen, I., Alfnes, F., Røra, M. B., \& Kolstad, K. (2010). Eliciting consumers' willingness to pay for organic and welfare-labelled salmon in a nonhypothetical choice experiment. Livest. Sci. 127(2): 218-226.

Olesen, I., B. Gjerde, and A. Groen. 1999. Methodology for deriving non-market trait values in animal breeding goals for sustainable production systems. Interbull Bulletin (23), 13.

Olesen, I., A. F. Groen, and B. Gjerde. 2000. Definition of animal breeding goals for sustainable production systems. J. Anim. Sci. 78: 570-582.

Olesen, I., A. I. Myhr, and G. K. Rosendal. 2011. Sustainable aquaculture: are we getting there? Ethical perspectives on salmon farming. J. Agric. Environ. Ethics. 24: 381-408.

Omasaki, S., J. Arendonk, A. Kahi, and H. Komen. 2016. Defining a breeding objective for Nile tilapia that takes into account the diversity of smallholder production systems. J. Anim. Breed. Genet. 133: 404-413.

Omasaki, S.K., K. Janssen, M. Besson, H. Komen. Submitted. Economic values of growth rate, feed intake, feed conversion ratio, mortality and uniformity for Nile tilapia.

Papatryphon, E., J. Petit, S.J. Kaushik, and H.M.G. van der Werf. 2004. Environmental Impact Assessment of Salmonid Feeds Using Life Cycle Assessment (LCA). Ambio. 33: 316-323.

Pelletier, N., and P. Tyedmers. 2007. Feeding farmed salmon: Is organic better? Aquaculture 272: 399-416.

Pelletier, N.L., N.W. Ayer, P.H. Tyedmers, S.A. Kruse, A. Flysjo, G. Robillard, F. Ziegler, A.J. Scholz, and U. Sonesson. 2007. Impact categories for life cycle assessment research of seafood production systems: Review and prospectus. Int. J. Life Cycle Assess. 12: 414-421.

Pelletier, N., P. Tyedmers, U. Sonesson, A. Scholz, F. Ziegler, A. Flysjo, S. Kruse, B. Cancino, and H. Silverman. 2009. Not All Salmon Are Created Equal: Life 
Cycle Assessment (LCA) of Global Salmon Farming Systems. Environ. Sci. Technol. $43: 8730-8736$.

Person-Le Ruyet, J., K. Mahé, N. Le Bayon, and H. Le Delliou. 2004. Effects of temperature on growth and metabolism in a Mediterranean population of European sea bass, Dicentrarchus labrax. Aquaculture 237: 269-280.

Pichavant, K., J. Person-Le Ruyet, N. Le Bayon, A. Severe, A. Le Roux, and G. Bœuf. 2001. Comparative effects of long-term hypoxia on growth, feeding and oxygen consumption in juvenile turbot and European sea bass. J. Fish. Biol. 59: 875-883.

Ponzoni, R. W., N. H. Nguyen, and H. L. Khaw. 2007. Investment appraisal of genetic improvement programs in Nile tilapia (Oreochromis niloticus). Aquaculture 269: 187-199.

Ponzoni, R. W., N. H. Nguyen, H. L. Khaw, and N. H. Ninh. 2008. Accounting for genotype by environment interaction in economic appraisal of genetic improvement programs in common carp Cyprinus carpio. Aquaculture 285: 47-55.

Pré Consultants, 2010. SimaPro 7. Database Manual. Methods library. The Netherlands.

Quillet, E. et al. 2007. Response of a lean muscle and a fat muscle rainbow trout (Oncorhynchus mykiss) line on growth, nutrient utilization, body composition and carcass traits when fed two different diets. Aquaculture 269: 220-231.

Quinton, C., A. Kause, K. Ruohonen, and J. Koskela. 2007. Genetic relationships of body composition and feed utilization traits in European whitefish (L.) and implications for selective breeding in fishmeal-and soybean meal-based diet environments. J. Anim. Sci. 85: 3198-3208.

R Development Core Team. 2008. R: A language and environment for statistical computing. R Foundation for Statistical Computing, Vienna, Austria.

Rauw, W., E. Kanis, E. Noordhuizen-Stassen, and F. Grommers. 1998. Undesirable side effects of selection for high production efficiency in farm animals: a review. Livest. Prod. Sci. 56: 15-33.

Read, P., and T. Fernandes. 2003. Management of environmental impacts of marine aquaculture in Europe. Aquaculture 226: 139-163.

Robinson, E. H., and M. H. Li. 2010. Channel catfish, Ictalurus punctatus, size and feed conversion ratio. J. World Aquacult. Soc. 41: 829-833.

Röös, E., and J. Nylinder. 2013. Uncertainties and variations in the carbon footprint of livestock products. Department of Energy and Technology, Swedish University of Agricultural Sciences, Uppsala, Sweden.

Rose, G., H.A. Mulder, A.N. Thompson, J.H.J. van der Werf, J.A.M. van Arendonk. 2015. Breeding objectives for sheep should be customised depending on variation in pasture growth across years. Animal. 9-8: 1-10.

Rutten, M., P. Bijma, J. Woolliams, and J. Van Arendonk. 2002. SelAction: Software to predict selection response and rate of inbreeding in livestock breeding programs. J. Hered. 93: 456-458. 
Rutten, M. J. M., H. Bovenhuis, H. Komen. 2005. Genetic parameters for fillet traits and body measurements in Nile tilapia (Oreochromis niloticus L.). Aquaculture 246: 125-132.

Sae-Lim, P., H. Komen, A. Kause, J. A. M. van Arendonk, A. J. Barfoot, K. E. Martins, and E. Parsons. 2012. Defining desired genetic gains for rainbow trout breeding objective using analytic hierarchy process. J. Anim. Sci. 90: 17661776.

Saillant, E., M. Dupunt-Nivet, M. Sabourault, P. Haffray, S. Laureau, M.-O. Vidal, and B. Chatain. 2009. Genetic variation for carcass quality traits in cultured sea bass (Dicentrarchus labrax). Aquat. Living Resour. 22: 105-112.

Salhi, M., M. Bessonart, G. Chediak, M. Bellagamba, and D. Carnevia. 2004. Growth, feed utilization and body composition of black catfish, Rhamdia quelen, fry fed diets containing different protein and energy levels. Aquaculture 231: 435-444.

Salou, T., C. Le Mouël, and H. M. G. van der Werf. 2016. Environmental impacts of dairy system intensification: the functional unit matters! J. Clean. Prod. In Press.

Sanchez, M. P., B. Chevassus, L. Labbé, E. Quillet, and M. Mambrini. 2001. Selection for growth of brown trout (Salmo trutta) affects feed intake but not feed efficiency. Aquat. Living Resour. 14: 41-48.

Seginer, I., and R. Ben-Asher. 2011. Optimal harvest size in aquaculture, with RAS cultured sea bream (Sparus aurata) as an example. Aquacult. Eng. 44: 5564.

Seginer, I., and I. Halachmi. 2008. Optimal stocking in intensive aquaculture under sinusoidal temperature, price and marketing conditions. Aquacult. Eng. 39: 103-112.

Silverstein, J. T., M. Hostuttler, and K. P. Blemings. 2005. Strain differences in feed efficiency measured as residual feed intake in individually reared rainbow trout, Oncorhynchus mykiss (Walbaum). Aquac. Res. 36: 704-711.

Silverstein, J. T., R. L. Vallejo, Y. Palti, T. D. Leeds, C. E. Rexroad III, T. J. Welch, G. D. Wiens, and V. Ducrocq. 2009. Rainbow trout resistance to bacterial coldwater disease is moderately heritable and is not adversely correlated with growth. J. Anim. Sci. 87: 860-867.

Spelman, R., and D. Garrick. 1997. Effect of live weight and differing economic values on responses to selection for milk fat, protein, volume, and live weight. J. Dairy Sci. 80: 2557-2562.

Stigebrandt, A., J. Aure, A. Ervik, P.K. Hansen. 2004. Regulating the local environmental impact of intensive marine fish farming: III. A model for estimation of the holding capacity in the Modelling-Ongrowing fish farmMonitoring system. Aquaculture 234: 239-261.

Sutherland, T.M. 1965. The correlation between feed efficiency and rate of gain, a ratio and its denominator. Biometrics. 21(3): 739-749. 
Tacon, A. G., and M. Metian. 2008. Global overview on the use of fish meal and fish oil in industrially compounded aquafeeds: trends and future prospects. Aquaculture 285: 146-158.

Thetmeyer, H., U. Waller, K.D. Black, S. Inselmann, H. Rosenthal. 1999. Growth of European sea bass (Dicentrarchus labrax L.) under hypoxic and oscillating oxygen conditions. Aquaculture 174: 355-367.

Thodesen, J., B. Gjerde, B. Grisdale-Helland, and T. Storebakken. 2001. Genetic variation in feed intake, growth and feed utilization in Atlantic salmon (Salmo salar). Aquaculture 194: 273-281.

Thodesen, J., B. Grisdale-Helland, S. J. Helland, and B. Gjerde. 1999. Feed intake, growth and feed utilization of offspring from wild and selected Atlantic salmon (Salmo salar). Aquaculture 180: 237-246.

Vandeputte, M., R. Garouste, M. Dupont-Nivet, P. Haffay, A. Vergnet, H. Chavanne, S. Laureau, T.B. Ron, G. Pagelson, C. Mazorra, R. Ricoux, P. Marques, M. Gameiro, B. Chatain. 2014. Multi-site evaluation of the rearing performances of 5 wild populations of European sea bass (Dicentrarchus labrax). Aquaculture 424-425: 239-248.

Vandeputte, M. M. Dupont-Nivet, P. Haffray, H. Chavanne, S. Cenadelli, K. Parati, M.-O. Vidal, A. Vergnet, and B. Chatain. 2009. Response to domestication and selection for growth in the European sea bass (Dicentrarchus labrax) in separate and mixed tanks. Aquaculture 286: 20-27.

Van Middelaar, C. E., P. B. M. Berentsen, J. Dijkstra, J. A. M. Van Arendonk, and I. J. M. De Boer. 2015. Effect of feed-related farm characteristics on relative values of genetic traits in dairy cows to reduce greenhouse gas emissions along the chain. J. Dairy Sci. 98: 4889-4903.

Van Middelaar, C.E., P.B.M. Berentsen, J. Dijkstra, J.A.M. van Arendonk, and I.J.M. de Boer. 2014. Methods to determine the relative value of genetic traits in dairy cows to reduce greenhouse gas emissions along the chain. J. Dairy. Sci. 97: 5191-5205.

Van Rijn, J. 2013. Waste treatment in recirculating aquaculture systems. Aquacult. Eng. 53: 49-56.

Van Weerd, J. H., K. H. A. Khalaf, F. J. Aartsen, and P. A. T. Tijssen. 1999. Balance trials with African catfish Clarias gariepinus fed phytase-treated soybean meal-based diets. Aquacult. Nutr. 5: 135-142.

Villanueva, R. R., M.E. Araneda, M. Vela, and J.C. Seijo. 2013. Selecting stocking density in different climatic seasons: A decision theory approach to intensive aquaculture. Aquaculture 384-387: 25-34.

Wall, E., G. Simm, and D. Moran. 2010. Developing breeding schemes to assist mitigation of greenhouse gas emissions. Animal 4: 366-376.

Weiss, R. F. 1970. The solubility of nitrogen, oxygen and argon in water and seawater. Deep. Sea. Res. 17: 721-735.

Wolf, P., E.A. Groen, W. Berg, A. Prochnow, E.A.M. Bokkers, R. Heijungs, and I.J.M. De Boer. 2016. Assessing greenhouse gas emissions of milk production: 
which parameters are essential? Int. J. Life Cycle Assess. DOI: 10.1007/s11367-016-1165-y

Yáñez, J. M., L.N. Bassini, M. Flip, J.P. Lhorente, R.W. Ponzoni, and R. Neira. 2014. Inbreeding and effective population size in a coho salmon (Oncorhynchus kisutch) breeding nucleus in Chile. Aquaculture 420: S15-S19. 
Summary 

Fish farming is the fastest growing animal food-producing sector in the world, due to the joint effect of an increase in demand for fish products and of a stagnation of fisheries captures. The production of cultured fish grew from about 15 to 50 million tons from 1995 to 2014 (FAO, 2016). Fish farming, however, faces challenges regarding its economic viability and its environmental sustainability. One way to enhance the sustainability of fish farming systems is selective breeding. In terrestrial livestock breeding, a method combining bioeconomic modeling and life cycle assessment (LCA) has recently been developed to assess the economic (EV) and environmental values (ENV) of traits included in breeding goals. EV and ENV represent respectively the economic and environmental impacts of changing one trait while keeping the other traits in the breeding goal constant. In aquaculture, economic values or environmental values are lacking. Using EV in fish breeding program would be a step towards the development of breeding programs maximizing farm profitability. Furthermore, the potential of using LCA to define environmental breeding objectives in fish breeding has never been studied before. The aim of this thesis, therefore, was to investigate the opportunity to develop economically and environmentally sustainable breeding programs in fish farming.

The first objective was to develop a method that enables computing the economic and environmental values of two major traits in fish farming, thermal growth coefficient (TGC) and feed conversion ratio (FCR). In chapters $\mathbf{2}$ and $\mathbf{3}$, we combined a bioeconomic model and an LCA to calculate the EV and ENV of TGC and FCR in a recirculating aquaculture system (RAS) producing African catfish. In RAS, two factors could limit production, the nitrogen treatment capacity of the biofilter or the fish density in tanks, which we hypothesized could induce changes in EV of TGC and FCR. EV were calculated with the bioeconomic model, which was divided in 3 sub-model. The fish model enables the estimation of growth, feed intake and nutrient excretion of fish depending on environmental conditions and on traits levels. From this, the batch model estimates the number of fish that can be stocked per batch depending on fish performance and on the limiting factors. Finally, the farm model estimates the number of batches produced and the total feed consumed, in order to compute the annual profit of the farm. The outputs of the bioeconomic model were also used to generate inventory data for the LCA. With these inventory data, we calculated ENV for four environmental impact categories: eutrophication, climate change, acidification and energy use. Improving TGC or FCR affected the management strategy differently when the limiting factor was density or treatment capacity of the biofilter, and this affected both the EV and ENV of traits. EVs and ENVs were calculated as the difference in profit and in 
environmental impacts for each trait (TGC, FCR) between the current population mean for $(\mu \mathrm{t})$ and the next generation of selective breeding $(\mu \mathrm{t}+\Delta \mathrm{t})$. Results showed that when genetic change increased production level, EV and ENV were positive because higher production increases income and dilutes fixed environmental impacts over more fish produced. When genetic change improved the efficiency of production, EV and ENV were also positive because better production efficiency decreases the amount of feed input per kg of fish, which decreases both the cost of production and the environmental impacts associated with the production of feed required per $\mathrm{kg}$ of fish. When density was limiting, improving TGC increased the number of batches produced and increased production, thus the EV and ENV of TGC were positive, and the EV and ENV of FCR were also positive because better FCR meant better production efficiency. When the biofilter capacity-was the limiting factor, the EV and ENV of TGC were null because increasing growth rate increased the daily individual emission of nitrogen. Consequently, increasing TGC decreased the number of fish that could be stocked per batch but increased the number of batches that could be grown in the same proportion, which in the end kept production constant. The EV and ENV of FCR were positive and higher than when density was limiting because improving FCR decreased feed intake and emission of nitrogen, which allowed for simultaneously producing more fish and improving production efficiency. These results showed that EV and ENV of traits depend on the limiting factors acting on the production system.

The second objective of this thesis was to evaluate the economic and environmental values of TGC and FCR in another production system having different limiting factors. Hence, we adapted the bioeconomic-LCA model to a sea cage system because sea cages, unlike RAS, are undergoing variation of water temperature across the year. Consequently, the production of fish can be constrained by the availability of oxygen in the cage, which can be critical when temperature in high (low dissolved oxygen) and fish grow faster (higher metabolic rate). In chapter 4, we estimated the EV of TGC in different scenarios of average (Tm) and amplitude ( $\mathrm{Ta}$ ) of temperature. Tm and Ta values were taken from different locations in the eastern and western Mediterranean. We showed that the EV of TGC was positive when $\mathrm{Tm}$ was between $19.5^{\circ} \mathrm{C}$ and $21^{\circ} \mathrm{C}$, because higher TGC increased the number of batches produced, which compensated the decrease in stocking density due to higher daily oxygen consumption. The EV of TGC, however, was negative or null in areas where $\mathrm{Tm}$ was closer to $18{ }^{\circ} \mathrm{C}$ because the increase in number of batches produced could not compensate for the decrease in 
stocking density. This showed that the economic importance of TGC was different for different geographic locations in the Mediterranean. Furthermore, in sea cage farming, farmers must generally comply with quotas that constrain the production of the farm in order to control their environmental impact. Thus, we further investigated the EV and ENV of TGC and FCR when different production quotas were applied in sea cage farming in chapter $\mathbf{5}$. We studied four quotas: annual production (Qprod), annual feed distributed (Qannual_feed), standing stock (Qstock) and daily feed (Qdaily_feed). We expressed ENV per ton of fish produced per year (ENV(fish)) and per farm per year (ENV(farm)). Results show that irrespective of quota used, EV of FCR as well as ENV(fish) and ENV(farm) were always positive, meaning that improving FCR increased profit and decreased environmental impacts. However, the EV and the ENV(fish) of TGC were positive only when quota was Qstock and Qdaily_feed. Moreover, the ENV(farm) of TGC was negative in Qstock and Qdaily_feed, meaning that improving TGC increased the environmental impact of the farm. These results suggest that policy makers can choose the quota depending on the objectives to achieve, and that this may influence breeding objectives. Qstock and Qdaily_feed are economically favorable when genetic improvement is aimed at improving growth rate, a major trait for farmers. However, in these quotas, improving growth increases the environmental impact of the farm. Improving FCR represents a good opportunity to balance out this increase in environmental impacts.

Even if EV are informative about the economic importance of a trait, they do not fully predict the response to selection because the genetic gain per trait also depends on the additive genetic variance of each trait and the on genetic correlations between traits in the breeding goal and in the index. The last objective of the thesis was, therefore, to investigate how EV and ENV could be used to develop breeding programs that improve profit and decrease environmental impacts in fish farming in chapter 6 . We simulated a breeding program for fish with TGC and FCR in the breeding goal. The index was composed of TGC and percentage of visceral fat. We chose percentage of visceral fat as an indirect trait for FCR. We tested the breeding program for five values of phenotypic and genetic correlations between TGC and FCR. The first step was to compare the total economic gain generated by the breeding goals from the four quotas according to the correlations between TGC and FCR. The four quotas were again Qprod, Qannual_feed, Qstock and Qdaily_feed. In the second step, we investigated, within each quota, if EV alone could be used to decrease environmental impacts or whether ENV should be used. Results showed that the genetic gain and economic gain depended on 
correlations between TGC and FCR. The best breeding goal depended on the correlations between TGC and FCR showing that the knowledge of these parameters in fish is crucial. These results also suggest that each quota would need a specific breeding program to maximize economic return for farmers. When comparing genetic gain within quota for EV and ENV, we also observed that economic optimization could decrease eutrophication per $\mathrm{kg}$ of fish produced for all quota systems when the phenotypic and genetic correlations between TGC and FCR were negative. These results emphasize the need of calculating EV and ENV of all the traits included in breeding programs for all different production system as well as the resulting genetic gain. They also emphasize the need to develop an efficient method to measure feed intake of fish to estimate genetic parameters of FCR. These data can then be used to compare responses to selection based on EV or ENV and designing production quotas that increase profit while decreasing environmental impacts.

In the discussion, chapter 7, we address the relevance and challenges of using bioeconomic modeling and LCA to estimate EV and ENV of traits. Then, we discuss how fish breeding program could enhance economic and environmental performances of fish farms. We highlight the fact that breeding goals must be customized according to the production system and its limiting factors in order to optimize the response to selection, both for economic or environmental objectives. We emphasize the need of targeting, in breeding goals, traits improving production efficiency rather than production, in order to increase profit and decrease environmental impacts. Additionally, we used the social cost of carbon as a case study in an attempt to combine EV and ENV of traits in a single breeding goal.

This thesis is the first study estimating EV and ENV in fish farming by combining bioeconomic modeling and LCA. It is also the first time, in fish farming as well as in livestock, that genetic gains are compared between breeding goals using economic values and breeding goals using environmental values. We propose strategies to enhance the economic viability and the environmental sustainability of fish production using selective breeding. These strategies could help breeders to select for traits that will maximize profit and decrease the environmental impacts according to production system and its limitations. They could also help policy makers to find the best quota or limiting factors to optimize the effect of selective breeding and to orientate the type of traits to improve. 
Résumé 

La pisciculture est en pleine expansion du fait de l'effet conjoint de l'augmentation de la demande en poisson et de la stagnation des captures de pêche. La production de poisson d'élevage a ainsi augmenté de 15 à 50 million de tonnes de 1995 à 2014. Cependant, la pisciculture fait face à des défis concernant sa viabilité économique et sa durabilité environnementale. Une des solutions possible pour améliorer sa durabilité est la sélection génétique. Chez les animaux d'élevage terrestres, un outil combinant un modèle bio économique et une analyse de cycle de vie (ACV) a récemment été développé pour évaluer les valeurs économiques (EV) et environnementales (ENV) des caractères inclus dans les programmes de sélection génétique. Les EV et ENV représentent respectivement, les impacts économiques et environnementaux de l'amélioration d'un caractère en gardant les autres caractères constants. En pisciculture, il existe peu de données concernant les valeurs économiques des caractères, et leur utilisation pourrait permettre le développement de programmes de sélection maximisant la profitabilité des élevages. De plus, le potentiel de I'ACV pour définir des objectifs de sélection n'a jamais été étudié jusqu'à présent. Le but de cette thèse était donc d'étudier les possibilités de développer des programmes de sélection durable (sur les plans économiques et environnementaux) en pisciculture.

Le premier objectif était de développer un outil permettant le calcul des EV et ENV en pisciculture pour deux caractères: le taux de croissance (thermal growth coefficient, TGC) et l'efficacité alimentaire (feed conversion ratio, FCR). Dans les chapitres 2 et 3 , nous avons combiné un modèle bio économique et une ACV pour calculer les EV et ENV du TGC and du FCR dans un système de recirculation. Dans ce système, deux facteurs limitent la production, la capacité de traitement de l'azote du filtre biologique ou bien la densité d'élevage. Les EV ont été calculées à l'aide du modèle bio économique, lequel était divisé en trois sous-modèles. Le modèle «poisson» permet d'estimer la croissance, la consommation d'aliment et l'excrétion de nutriments des poissons en fonction des conditions environnementales et de la valeur des caractères TGC et FCR. A partir de ces données, le modèle "lot» permet d'estimer le nombre de poissons qui peut être stocké par lots en fonction des facteurs limitants. Finalement, le modèle «ferme» permet d'estimer le nombre de lots produits et la consommation totale d'aliment dans le but de calculer le profit annuel de la ferme. Les données générées par le modèle sont ensuite utilisées comme données d'inventaire pour l'ACV. Avec ces données d'inventaire, nous avons calculé les ENV pour quatre catégories d'impacts environnementaux: eutrophisation, changement climatique, acidification et utilisation d'énergie. Améliorer le TGC ou le FCR a des effets différents sur la 
gestion de la ferme selon que le facteur limitant est la densité ou la capacité de traitement du filtre biologique, ce qui entraine des différences dans les EV et les ENV. Les résultats montrent, en effet, que lorsqu'un gain génétique augmente le niveau de production, les EV et ENV sont positives, car une production plus élevée augmente les revenus financiers et dilue les impacts environnementaux fixes. Lorsque le gain génétique améliore l'efficacité de production, les EV et ENV sont aussi positives car une meilleure efficacité de production diminue l'utilisation d'aliment par kilo de poissons produit, ce qui diminue aussi bien les coûts de production que les impacts environnementaux associés à la production de l'aliment. Quand la densité est le facteur limitant, améliorer le TGC augmente le nombre de lots produits et augmente la production, et améliorer le FCR diminue la quantité d'aliment distribué. Donc, les EV et ENV du TGC et du FCR sont positives. Quand la capacité du filtre biologique est le facteur limitant, les EV et ENV du TGC sont nulles car augmenter la croissance augmente l'excrétion quotidienne d'azote. Par conséquence, augmenter le TGC augmente le nombre de lots produits mais diminue le nombre de poissons stockés par lot, ce qui au final n'affecte pas la production annuelle de l'élevage. Les EV et ENV de FCR sont positives car améliorer le FCR diminue l'ingéré des poissons mais aussi l'émission d'azote, ce qui permet de produire plus de poisson et d'améliorer l'efficacité de production. Ces résultats montrent que les EV et ENV dépendent des facteurs limitants.

Le deuxième objectif de la thèse était donc d'évaluer les EV et ENV du TGC et FCR dans un autre système de production possédant d'autres facteurs limitants. Nous avons adapté le modèle bioéconomique à un système de production en cage en mer, car ces cages sont soumises aux variations saisonnières de température. Par conséquent, la production de poisson peut être limitée par la disponibilité en oxygène dans les cages, particulièrement lorsque la température est élevée (faible concentration en oxygène) et que la croissance des poissons est stimulée. Dans le chapitre 4, nous avons estimé les EV du TGC en fonction de différents scénarios de température moyenne ( $\mathrm{Tm}$ ) et d'amplitude de température ( $\mathrm{Ta}$ ). Les valeurs de Tm et Ta utilisées représentent différentes conditions rencontrées en Méditerranée. Nous avons montré que l'EV du TGC est positive quand Tm était entre $19.5^{\circ} \mathrm{C}$ et 21 ${ }^{\circ} \mathrm{C}$, car augmenter le TGC augmente le nombre de lots produits, ce qui compense la diminution du nombre de poisson stockés due à l'augmentation de la consommation quotidienne d'oxygène. Cependant, I'EV du TGC est négative ou nulle lorsque $\mathrm{Tm}$ est proche de $18{ }^{\circ} \mathrm{C}$ car l'augmentation du nombre de lots ne pouvait alors compenser la diminution du nombre de poissons stockés. Ceci montre que l'importance économique du TGC peut être différente selon la région 
de Méditerranée ou se situe la ferme. De plus, dans les systèmes de cage en mer, les éleveurs sont soumis à des quotas de production qui permettent de contrôler I'impact environnemental des élevages. Dans le chapitre 5 , nous avons donc étudié les EV et ENV du TGC et du FCR lorsque différents quotas de production sont mis en place. Nous avons étudié quatre quotas: quota annuel de production (Qprod), quota annuel d'aliment distribué (Qannual_feed), quota sur la biomasse maximale de l'élevage (Qstock) et quota journalier d'aliment distribué (Qdaily_feed). Les ENV ont été calculées par tonne de poissons produits (ENV (fish)) et par ferme $(E N V(f a r m))$. Les résultats montrent que l'EV ainsi que l'ENV(fish) et l'ENV(farm) du FCR sont toujours positives, ce qui signifie que l'amélioration du FCR augmente le profit économique et diminue les impacts environnementaux par tonne de poisson produit et par ferme. En comparaison, l'EV et l'ENV(fish) du TGC étaient positives seulement lorsque le quota était Qstock ou Qdaily_feed. Avec les quotas Qstock et Qdaily_feed, I'ENV(farm) du TGC était cependant négative ce qui montre que l'amélioration du TGC peut augmenter l'impact environnemental d'un élevage. Les quotas Qstock and Qdaily_feed sont économiquement favorables à une augmentation du taux de croissance (important aux yeux des éleveurs) alors que ces quotas auraient tendance à augmenter l'impact environnemental des élevages. L'amélioration du FCR représenterait une possibilité de compenser l'augmentation de l'impact environnemental.

Même si les EV sont utiles pour connaitre l'importance économique d'un caractère, elles ne prédisent pas la réponse à la sélection car le gain génétique par caractère dépend aussi de la variance génétique additive et des corrélations génétiques entre les caractères de l'objectif de sélection et de l'index. Le dernier objectif de ma thèse (chapitre 6) était donc d'étudier comment les EV et ENV pouvaient être utilisées dans des programmes de sélection économiques et environnementaux. Nous avons simulé un programme de sélection avec TGC et FCR dans les objectifs de sélection. Nous avons choisi le pourcentage de gras viscéral comme caractère de sélection indirect pour le FCR. Nous avons testé ce programme de sélection pour cinq valeurs de corrélation phénotypique et génétique entre TGC et FCR. Dans un premier temps, nous avons évalué si le gain génétique était différent entre les quatre quotas (Qprod, Qannual_feed, Qstock and Qdaily_feed) qui avaient chacun leur EV pour TGC et FCR. Dans un deuxième temps, dans chaque quota, nous avons testé si l'utilisation des EV pouvait permettre de diminuer les impacts environnementaux, ou s'il fallait passer par les ENV dans ce but. Les résultats montrent que le gain génétique et économique dépend de la corrélation entre TCG et FCR. Ils suggèrent également que chaque quota devrait avoir un programme de 
sélection spécifique pour maximiser les profits économiques des éleveurs. Lorsqu'on compare les gains génétiques pour chaque quota en utilisant les EV ou les ENV, on observe que l'utilisation des EV pour maximiser les gains économiques pourrait diminuer l'eutrophisation par kilo de poisson produit quand la corrélation entre TGC et FCR est négative. Ces résultats mettent l'accent sur l'importance de calculer les EV et ENV de tous les caractères d'intérêt inclus dans les programmes de sélection. Le FCR étant particulièrement intéressant mais aujourd'hui difficile à sélectionner, II est également nécessaire de développer une méthode efficace de mesure de l'ingéré alimentaire pour pouvoir estimer ses paramètres génétiques ainsi que ses corrélations avec les autres caractères d'intérêt tel que la croissance. Ces données pourront être ensuite utilisées pour comparer les gains génétiques réalisés en utilisant EV ou ENV et ainsi de définir le meilleur quota de production pour améliorer le profit économique des éleveurs et diminuer l'impact environnemental des élevages.

Dans la discussion (chapitre 7), nous avons abordé la pertinence et les limites de I'utilisation d'un modèle bio économique pour l'estimation des EV et ENV. Puis nous nous sommes demandé comment les programmes de sélection en pisciculture pouvaient à la fois augmenter les profits économiques des éleveurs et diminuer les impacts environnementaux. Nous avons mis en avant le fait que les objectifs de sélection devaient être adaptés aux systèmes de production et à leurs facteurs limitants pour pouvoir optimiser la réponse économique et/ou environnementale. Nous avons mis l'accent sur l'intérêt d'améliorer par la sélection génétique des caractères améliorant l'efficacité de production plutôt que la productivité. Finalement, nous avons utilisé le coût social du carbone pour développer un exemple de combinaison d'EV et ENV au sein d'un même objectif de sélection.

Cette thèse est la première à calculer les EV et ENV en pisciculture en combinant un modèle bio économique et une ACV. C'est également la première fois, aussi bien en pisciculture que pour les animaux d'élevage terrestres, que l'on compare le gain génétique obtenu avec les ENV et les gains génétiques obtenus avec les EV. Nous proposons quelques pistes pour améliorer la viabilité économique des élevages ainsi que leur durabilité environnementale en utilisant la sélection génétique. Ces pistes pourraient aider les éleveurs à choisir de façon plus efficace les caractères à améliorer pour maximiser les gains économiques et diminuer les impacts en fonction des systèmes d'élevages. Ces pistes pourraient également être utiles aux responsables politiques pour trouver le meilleur quota de production pour 
optimiser les gains générés par la sélection génétique et pour orienter les choix dans les caractères à améliorer par sélection génétique. 

Acknowledgements 

The principle of sustainability is based on three pillars: economy, environment and society. I think the secret of happiness is also based on three pillars: family, friends and colleagues. These pillars are essential as a chair needs at least three feet to stand right. During my PhD, my family, my friends and my colleagues helped me to stand right and to carry on my PhD.

I would like to start by thanking my family. Thanks Mum and Dad for your total support in every condition. Je vous remercie d'avoir cru en moi et de m'avoir appris que, finalement, les seules limites qui existent sont celles que l'on se fixe. Je suis fier d'avoir des parents comme vous. Merci à mon frère et ma sœur de rendre notre famille si unique. Merci aussi à la famille Soissons de $\mathrm{m}$ 'avoir accueilli.

Then, I would like to thank my friends and colleagues for their help and support during my PhD.I am grateful to my supervisors Hans, Marc, Imke, Edwige, Johan and Joel. I know having six supervisors might look like a nightmare but I could not dream of a better team to supervise me. Even though everybody got his own idea on the way to pursue this PhD project, we always reached a common idea the end. I would more particularly like to thank Hans and Marc for according me so much of their time for questions and discussions. Thanks to Lisette for booking so many plane tickets, train tickets, hotel and Airbnb for me. Thanks to Alain and Béatrice at Ifremer for their support when finalizing the thesis. Thanks to Gilles Lemarchand for allowing me to use his photography for my thesis cover.

During these four years I met many friends and I will try to express my gratitude in a few lines. Gus, I guess our common interest for good beers (punk IPA and Flying dog) and good music (Alt-J, Foals etc.) was ideal to distract my mind after a hard day at work. Thank you so much for helping me with $\mathrm{R}$ and I am glad we could work together on chapter 6 of this thesis. Thanks to Réa for the delicious Greek food. I would like to thank André for all the evenings we spent eating pizza and playing FIFA. I just hope that one day I will beat you. Thank you and Viviane for inviting Laura and me to Brazil. Thanks Gabriel for listening to people and for your generosity. I am grateful to Maria for bringing her craziness into the office. You brought a wind of freshness into Wageningen. Many thanks to all the great people working at Wageningen, Mathijs, Yvonne (thanks for printing the thesis), Juanma, Pascal, Coralia, Kasper, Merina, Floor, Lucas (aka BBQ master) Claudia and Pierre. You all made my time in the Netherlands a time I will never forget.

In wageningen there is also a big French family and everybody knows that when you live away from home, it is always good to meet people with whom you share 
common habits. Pierre, thank you for your contagious enthusiasm. Thank you for all the kilometers we ran, biked and swam together during those 4 years. Every single time we discussed together was a fruitful experience. I just hope we will go to a PhD party together once more. As part of this French community I would like to thank Nicolas (my twin) and Gauthier. I hope we will make this trip to Bamberg. The last French guy I would like to thank is Marcos. Marcos might look Brazilian but trust me he is French. Everybody knows that the French galette-saucisse is Marco's favorite dish. Thank you Marcos for your kindness and your friendship. Thanks to Silvia for being our trip advisor in Vancouver and Brazil. I wish you two "bon vent" in Brazil.

During my PhD I had the chance to travel across Europe and across the world. These travels allowed me to meet people who participated in their own way to the accomplishment of my PhD. First, I moved to Rennes and I would like to thank all the people from the master's office. More particularly I am grateful to Thibault for all the good time in Rennes and in San Francisco. I would always remember the passionate debates we had on "hiking" and how you stepped on a venomous snake. In Finland, I met my dear Icelandic friend Ólafur. Thanks Ólafur for your kindness, for helping Laura and me discover your beautiful island and finally thanks for transmitting to me your passion for brewing beer.

Before starting my PhD I also met people who, one way or another, participated in my journey towards the PhD. Thanks to Jerome and Mathurin, because this journey started in high school with you. I will always be grateful to David Benhaim, who guided me towards research in marine biology and more particularly in aquaculture. Thanks to Blandine for the good time in Cherbourg and in La Rochelle and for hosting me in Sète. Then, I would like to thank people I met during my bachelor. Thanks to Joffrey, Clément, Camille, Justine and Tiphaine for inviting me to join your group of friends. I know we will continue to see each other often in the future because our friendship has no boundaries.

Finally, I want to end by thanking the most important person, Laura. Merci Laura pour tout ce que tu m'apportes au jour le jour. Merci pour tes innombrables relectures de manuscrits. Merci pour tes encouragements. Merci pour tous ces voyages et toutes ces belles aventures que tu me fais vivre. Pendant nos thèses, nous avons été là l'un pour l'autre dans les bons comme dans les mauvais moments et avec toi, je n'ai pas peur d'affronter le futur. 
Curriculum Vitae 



\section{About the author}

Mathieu Besson was born on the 6th of September 1989 in Tarare, France. In 2007, he graduated from high school with emphasis on scuba diving. In 2007, Mathieu started studying to become senior technician in marine biotechnology and aquaculture at Intechmer (France). In 2009, he graduated from Intechmer after a training period of five month at the research center of Holar University College (Iceland) where he studied the feeding behaviour of juvenile Arctic charr. His interest for scientific research led him to pursue his studies with a bachelor degree obtained with honour in 2010. Then, Mathieu was selected to join the European Master in Animal Breeding and Genetics program from which he graduated in 2012. For this program Mathieu studied one year in AgrioParisTech where he accomplished a training period at Inra on the detection of QTL for resistance to viral disease in rainbow trout. He spent the second year of his master in Norway at the Norwegian University of Life Sciences. He investigated the consequences of a long term utilization of QTL for a disease trait in fish breeding programs. In 2012, Mathieu started his PhD in the framework of the European Graduate School in Animal Breeding and Genetics at Wageningen University and at AgroParisTech. During his PhD Mathieu investigated the opportunities of developing breeding programs in fish farming that balance economic profitability and environmental impacts. 


\section{Peer reviewed publications}

Besson, M., I.J.M. de Boer, M. Vandeputte, J.A.M. van Arendonk, E. Quillet, H. Komen, J. Aubin. Submitted. Effect of production quotas on economic and environmental values of growth rate and feed efficiency in sea cage fish farming.

Besson, M., J. Aubin, K. Komen, M. Poelman, E. Quillet, M. Vandeputte, J.M.A. van Arendonk, and I.J.M. de Boer. 2016a. Environmental impacts of genetic improvement of growth rate and feed conversion ratio in fish farming under rearing density and nitrogen output limitations. J. Clean. Prod. 116: 100-109.

Besson, M., M. Vandeputte, J.M.A. van Arendonk, J. Aubin, I.J.M. de Boer, E. Quillet, H. Komen. 2016b. Influence of water temperature on the economic value of growth rate in fish farming: The case of sea bass (Dicentrarchus labrax) cage farming in the Mediterranean. Aquaculture 462: 47-55.

Besson, M., H. Komen, J. Aubin, I.J.M. de Boer, M. Poelman, E. Quillet, C. Vancoilie, M. Vandeputte, and J.A.M. van Arendonk. 2014. Economic values of growth and feed efficiency for fish farming in recirculating aquaculture system with density and nitrogen output limitations: a case study with African catfish (Clarias gariepinus). J. Anim. Sci. 92: 5394-5405.

Omasaki, S.K., K. Janssen, M. Besson, H. Komen. Submitted. Economic values of growth rate, feed intake, feed conversion ratio, mortality and uniformity for Nile tilapia.

Janssen, K., P. Berentsen, M. Besson, H. Komen. Submitted. Derivation of economic values for production traits in aquaculture species. 


\section{Individual and Training Supervision plan}

The Basic Package (5.5 credits)

Welcome to the EGS-ABG, Foulum (Denmark) 2012

Fall research school EGS-ABG, Addis Ababa (Ethiopia)

2013

Course on philosophy of science and/or ethics

2013

Dissemination of knowledge (17 credits)

\section{International conferences}

LCA food 2014, San Francisco (USA)

2014

World Congress on Genetics applied to Livestock Production

(WCGALP), Vancouver (Canada)

2014

International Symposium on Genetics in Aquaculture (ISGA),

Santiago de Compostella (Spain)

2015

Aquaculture Conference, Montpellier (France)

2015

European Aquaculture society (EAS), Rotterdam (Netherlands)

2015

\section{Seminars and workshops}

WIAS Science Day, Wageningen 2013

WIAS Science Day, Wageningen

2014

WIAS Science Day, Wageningen

2016

PhD seminar, INRA

2013

PhD seminar, INRA

2014

PhD seminar, INRA

2015

PhD seminar, INRA

2016

\section{Presentations}

Poster - PhD seminar, INRA

2013

Poster - WIAS Science Day

2016

Oral - WIAS Science Day

2014

Oral - PhD Seminar, INRA

2014

Oral - LCA food conference

2014

Oral - WCGALP conference

2014

Oral - ISGA conference 2015

Oral - Aquaculture conference

2015

Oral - EAS conference

2015 
Advanced Scientific Courses (17.8 credits)

Genetic improvement of livestock 2012

Getting started with ASReml 2013

Advanced quantitative genetics $\quad 2014$

Modeling agricultural systems $\quad 2014$

Environmental impact assessment of livestock systems 2015

Orientation on mathematical modeling in biology 2016

Statistics for the life sciences 2016

Professional Skills Support Courses (5.8 credits)

Techniques for writing and presenting a scientific papers 2013

Project and time management 2015

PhD Competence assessment $\quad 2015$

Entrepreneurship in and outside science 2015

Mobilising its scientific network 2015

EndNote litteracy 2016

Research Skills Training (4 credits)

External training period, INRA, Rennes 2013

External training period, IFREMER, Palavas-les-Flots 2014

Teaching and MSc supervision (3 credits)

Assistant for Genetic Improvement of Livestock (ABG-31306) 2014

MSc major Thesis 2014

Complied with the educational requirements set by the European Graduate School in Animal Breeding and Genetics, the Graduate School of Wageningen Institute of Animal Science and the Graduate School of Agriculture, Food, Biology, Environment and Health of the Agricultural, Veterinary and Forestry Institute of France. 


\section{Colophon}

The research described in this thesis was financially supported by a joint grant from the European Commission and IMARES, within the framework of the ErasmusMundus joint doctorate "EGS-ABG".

Cover photography by Gilles Lemarchand (

Printed by TARAPRINT, Tarare, France

ISBN 978-94-6343-006-7

DOI: http://dx.doi.org/10.18174/395219 